UNIVERSIDADE DE SÃO PAULO

INSTITUTO DE QUÍMICA DE SÃO CARLOS

\title{
BIOCOMPÓSITOS A PARTIR DE “POLIETILENO VERDE”, ÓLEOS VEGETAIS, MACRO E NANO FIBRAS DE CURAUÁ
}

\author{
Área de Concentração: Físico-Química
}

Daniele Oliveira de Castro

\begin{abstract}
Tese apresentada ao Instituto de Química de São Carlos, na Universidade de São Paulo para a obtenção do título de doutor em Ciências (Química)
\end{abstract}

Orientadora: Prof ${ }^{\mathrm{a} .}$ Dra. Elisabete Frollini

São Carlos 
Exemplar revisado

O exemplar original encontra-se em acervo reservado na Biblioteca do IQSC-USP 
A minha família, pelo constante incentivo, amor, por todos os exemplos de superação e, sobretudo, por sempre acreditarem em mim. 



\section{Agradecimentos}

Acima de tudo, agradeço a Deus pela minha vida e pela oportunidade de realizar este trabalho.

À minha orientadora Professora Dra. Elisabete Frollini, pela orientação, dedicação, paciência, por acreditar e confiar em mim e oportunidade de desenvolver este trabalho.

Ao Professor Dr. Adhemar Ruvolo-Filho pelos ensinamentos durante a iniciação científica e colaboração na realização deste trabalho.

Ao meu orientador no doutorado sanduíche, Professor Dr. Alain Dufresne, por me receber em seu grupo, e a todos os que estavam presentes durante o período em que trabalhei no laboratório LGP2 do Instituto Politécnico de Grenoble (INP), pela ótima convivência.

Aos meus pais e minhas irmãs, pelo carinho e incentivo em todos os momentos e por estarem sempre comigo, não importando a distância.

Aos meus amigos do Grupo de Materiais Macromoleculares e Fibras Lignocelulósicas, e do Grupo de Físico-química Orgânica: Fernando, Bruno, Rachel, Elaine, Érika, Cris, Bibi, Joice, Daiana, Juliana, Bruna, Roberta, Jorge, Tonimar, Anderson, Virgínia, Daniella, Lilian e Adriana.

Ao técnico Luiz, pela atenção, paciência e realização das análises térmicas. À técnica do grupo, Márcia Zambon.

Ao Departamento de Química (DQ- UFSCar) e Departamento de Engenharia de Materiais (DEMA- UFSCar) pela infraestrutura disponibilizada para a realização de 

grande parte deste trabalho; e ao Juliano, Fábio, Henrique, Carolina e Vanessa pela grande ajuda prestada.

A todos os meus amigos, em especial à Meire, Talita, Pathy, Qing, Vanessa e Jana, que independente da cidade ou país em que se encontram hoje, me acompanharam durante todo este percurso.

À Universidade de São Paulo e ao Instituto de Química de São Carlos, a todos os membros do Departamento de Físico-Química (DFQ) que, de alguma forma, contribuíram para a realização deste trabalho, e ao CNPq pelo apoio financeiro através da concessão das bolsas de doutorado e doutorado sanduíche. 

"Viver é não esperar a tempestade passar... É aprender como dançar na chuva." 



\section{RESUMO}

O polietileno de alta densidade utilizado neste trabalho foi obtido em escala industrial pela polimerização de eteno, gerado a partir do etanol de cana de açúcar. Este polímero é também chamado de biopolietileno (BPEAD), por ser preparado a partir de material oriundo de fonte natural. O BPEAD foi usado como matriz em compósitos reforçados por fibras de curauá em proporções em massa variando de 5 a 20\%, $1 \mathrm{~cm}$ de comprimento. Óleo de mamona (CO), óleo de canola (CA), óleo de linhaça epoxidado (OLE) e óleo de soja epoxidado (OSE) foram usados na preparação dos compósitos (5, 10, 15 e 20\%) visando atuação como agentes compatibilizantes, uma vez que o CO, CA, OLE e OSE têm cadeias hidrocarbônicas com afinidade pelo biopolietileno, e grupos hidroxilas com afinidades pelos grupos polares presentes nas fibras. Os compósitos foram caracterizados por microscopia eletrônica de varredura (MEV), Calorimetria Exploratória Diferencial (DSC), Termogravimetria (TG), Análise Dinâmico-Mecânica (DMA) e propriedades mecânicas (impacto e flexão). Os resultados de impacto, flexão e DMA apresentados pelos compósitos mostraram que a incorporação dos óleos nas diferentes composições, principalmente CO, no geral levou a melhores propriedades quando comparados aos compósitos BPEAD/Fibra, indicando uma possível ação dos óleos como compatibilizante na interface fibra/matriz. 0 compósito BPEAD/15\%CO/15\%Fibra apresentou uma maior resistência ao impacto $\left(280 \mathrm{~J} \mathrm{~m}^{-1}\right)$ se comparado ao BPEAD $\left(234 \mathrm{~J} \mathrm{~m}^{-1}\right)$, indicando o efeito compatibilizante do CO. As propriedades de compósitos (BPEAD/5\%CO, CA, OSE ou OLE/10\%Fibra) reforçados com curauá $(3 \mathrm{~mm})$, processados em misturador interno e termoprensados foram comparadas com aqueles processados por extrusão e moldados por injeção. A resistência ao impacto dos compósitos processados via extrusão BPEAD/CO $\left(287 \mathrm{~J} \mathrm{~m}^{-1}\right)$, CA $\left(240 \mathrm{~J} \mathrm{~m}^{-1}\right)$ ou OSE/Fibra $\left(222 \mathrm{~J} \mathrm{~m}^{-1}\right)$ foi maior quando comparada aos compósitos processados via misturador interno BPEAD/CO $\left(114 \mathrm{~J} \mathrm{~m}^{-1}\right), C A\left(123 \mathrm{~J} \mathrm{~m}^{-1}\right)$ ou OSE/Fibra $\left(110 \mathrm{~J} \mathrm{~m}^{-1}\right)$. A análise de DMA também mostrou que o compósito BPEAD/5\%CO/10\%Fibra preparado por extrusão/injeção apresentou maior módulo de armazenamento $\left(\mathrm{E}^{\prime}\right)$ a $30^{\circ} \mathrm{C}$ de $1660 \mathrm{MPa}$, enquanto que o compósito processado via misturador interno apresentou $E^{\prime}$ de $1219 \mathrm{MPa}$. Comparando as propriedades mecânicas dos compósitos processados por extrusão/injeção com a dos processados 
por misturador interno Haake/termoprensagem, conclui-se que extrusão/injeção é um processo mais eficiente para a preparação de compósitos de fibras curtas. O presente estudo também avaliou o potencial de aplicação de nanocristais de celulose (NCC) em filmes baseados em BPEAD. NCCs foram obtidos a partir da hidrólise ácida da fibra de curauá, e foram utilizados (3, 6 e 9 \%) na preparação de filmes de BPEAD, visando à obtenção de nanocompósitos. Os nanocompósitos reforçados com nanocristais de curauá foram processados por extrusão, também usando CO (3, 6 e 9\%), visando avaliar a ação do mesmo como agente de dispersão de NCC na matriz apolar de BPEAD. A partir dos resultados obtidos para estes filmes, a porcentagem de NCC foi fixada em $3 \%$, e $3 \%$ como porcentagem de óleo vegetal, por terem sido estas as condições que levaram ao melhor conjunto de resultados. Além de CO, OSE e OLE também foram usados e, além do processamento extrusão, extrusão/termoprensagem também foi considerado, a fim de comparar as propriedades obtidas nos dois processamentos. Os filmes foram caracterizados por calorimetria exploratória diferencial, termogravimetria, DMA, ensaio de tração, MEV e reologia. A análise de DMA mostrou que a presença de NCC leva a um material mais rígido, e o uso de óleos vegetais na preparação de filmes, levou a uma distribuição mais homogênea dos NCCs na matriz de BPEAD e a uma melhor adesão na interface, evidenciando o efeito compatibilizante dos óleos. As propriedades óticas dos nanocompósitos indicaram que a presença dos óleos levou a filmes menos opacos, para ambos os tipos de processamentos usados. Com relação aos diferentes processamentos usados na preparação dos filmes baseados em BPEAD, óleos e nanocristais, o melhor conjunto de resultados, com destaque para aqueles obtidos no ensaio de tração, foram resultantes do processamento via extrusão/termoprensagem, indicando que este processamento deve favorecer a dispersão de NCCs na matriz de BPEAD. Os resultados desse trabalho apontaram para boas perspectivas para o uso de nanocristais de celulose em filmes baseados em BPEAD (ou PEAD), utilizando óleos vegetais como compatibilizantes e também mostraram que é possível obter melhorias nas propriedades dos nanocompósitos através de processos mais adequados para a escala industrial, como a extrusão. No presente estudo, contribuiu-se para com o desenvolvimento de materiais que, dentre outras propriedades, na sua produção, utilização e substituição, ocorra menor emissão de $\mathrm{CO}_{2}$ para a atmosfera, comparativamente a outros materiais. 


\section{ABSTRACT}

The high-density polyethylene used in this work was obtained on an industrial scale by polymerization of ethylene derived from sugar cane ethanol. This polymer is also called biopolyethylene (HDBPE), as it is a material derived from a renewable resource. HDBPE was used as a polymer matrix in composites reinforced by curaua fibers containing 5 , 10, 15 and 20 wt\%, 1-cm long. Castor oil (CO), canola oil (CA), epoxidized linseed oil (ELO) and epoxidized soybean linseed oil (ESO) were used in the preparation of composites (5, 10, 15 e 20 wt\%) aiming to act as a coupling agent, since CO, CA, ESO and ELO have hydrocarbon chains with affinity for polyethylene and hydroxyl groups that can interact with polar groups on the fibers. The composites were characterized by scanning electron microscopy (SEM), differential scanning calorimetry (DSC), thermogravimetryc analysis (TG), dynamic mechanical analysis (DMA) and mechanical properties (flexural and impact strength). The results of impact, flexural strength and DMA presented by composites showed that the incorporation of oils in various compositions, particularly $\mathrm{CO}$, in general has led to improved properties when compared to the composite HDBPE/Fiber, thus indicating a possible action of the oil as a compatibilizer in the fiber/matrix interface. The composite HDBPE/15\%CO/15\%Fiber had a higher impact strength $\left(280 \mathrm{~J} \mathrm{~m}^{-1}\right)$ compared to HDBPE $\left(234 \mathrm{~J} \mathrm{~m}^{-1}\right)$, indicating the compatibilizer effect of CO. The properties of composites (HDBPE/5\%CO, CA, ESO or ELO/10\%Fiber) reinforced with curaua $(3 \mathrm{~mm})$ and prepared using an internal mixer (Haake) followed by thermopress molding were compared with those prepared by extrusion and was molded by injection. The properties of composites (HDBPE/5\%CO, CA, ESO or ELO/10\%Fiber) reinforced with curaua $(3 \mathrm{~mm})$, prepared using an internal mixer (Haake) followed by thermopress molding were compared with those prepared by extrusion and molded by injection. The impact strength of composites processed via extrusion HDBPE/CO $\left(287 \mathrm{~J} \mathrm{~m}^{-1}\right)$, CA $\left(240 \mathrm{~J} \mathrm{~m}^{-1}\right)$ or OSE / fiber $\left(222 \mathrm{~J} \mathrm{~m}^{-1}\right)$ was higher when compared to composites processed via internal mixer HDBPE/CO $\left(114 \mathrm{~J} \mathrm{~m}^{-1}\right), \mathrm{CA}$ $\left(123 \mathrm{~J} \mathrm{~m}^{-1}\right)$ or OSE/Fiber $\left(110 \mathrm{~J} \mathrm{~m}^{-1}\right)$. DMA analysis also showed that the composite HDBPE/5\%CO/10\%Fiber prepared by extrusion/injection showed higher storage modulus ( $\left.\mathrm{E}^{\prime}\right)$ at $30^{\circ} \mathrm{C}$ of $1660 \mathrm{MPa}$, while the composite processed by internal mixer presented an E' of $1219 \mathrm{MPa}$. Comparing the mechanical properties of the composites 
processed via extrusion with the composites prepared from internal mixing (Haake), it is observed that the extrusion is a more efficient process for the preparation of composites with short fibers. The present study also evaluated the application potential of cellulose nanocrystals (CNC) based on BPEAD films. CNCs were prepared from curaua, via acid hydrolysis, and used as a reinforcing phase $(3,6$ and 9 wt \%) in the preparation of HDBPE films, aiming to produce nanocomposites. Nanocomposites reinforced with curaua nanocrystals were processed by extrusion, also using $\mathrm{CO}$ (3, 6 and $9 \%$ ) to evaluate its action as CNC, a dispersing agent in the nonpolar HDBPE matrix. From the results obtained for these films, the percentage of CNC was set at $3 \%$, and $3 \%$ as the percentage of vegetable oil, as these were the conditions that led to the best set of results. In addition to CO, ELO and ESO were also used, and besides the processing extrusion, extrusion/thermopressing was also considered, in order to compare the properties obtained in the two processes. The films were characterized by differential scanning calorimetry (DSC), and thermogravimetryc analysis (TG), DMA, SEM, mechanical and rheological analyses. The presence of nanocrystals decreased some properties of HDBPE, such as tensile strength. The DMA analysis showed that the presence of CNC leads to a more rigid material, and the use of vegetable oils in the preparation of films led to a more homogenous distribution of the CNCs in the HDBPE matrix, as well as to a better adhesion at the interface, demonstrating the compatibilizing effect of the oils. The optical properties of the nanocomposites indicated that the presence of oil leads to less opaque films for both types of processing. With respect to different processes used in the preparation of films based on HDBPE, oils and nanocrystals, the best set of results, especially those obtained from tensile strength, were derived from processing by extrusion/thermopressing, thus indicating that this processing should favor CNCs dispersion in the HDBPE matrix. The results of this work pointed to good prospects for the use of cellulose nanocrystals films based on HDBPE (or HDPE), using vegetable oils as compatibilizers, and they also showed that it is possible to obtain improvements in the properties of the nanocomposites through more appropriate processes to industry scale such as extrusion. The aim of the present work was to contribute to the development of materials that release less $\mathrm{CO}_{2}$ into the atmosphere during their production, among other features. 


\section{LISTA DE FIGURAS}

Figura 1. Comparação entre a aplicação de compósitos reforçados com fibras naturais e os compósitos reforçados com fibras de vidro e de carbono usados, nos diferentes setores industriais em 2010. 29

Figura 2. Classificação dos reforços utilizados em compósitos. 33

Figura 3. Estrutura Química do Polietileno. 35

Figura 4. Polimerização do etileno utilizando os catalisadores de Ziegler-Natta. 36

Figura 5. Esquema indicativo do processo de obtenção do BPEAD a partir da cana de açúcar. I: cana-de-açúcar, II: Moagem, III: Preparação do caldo, IV: Fermentação, V: Destilação, VI: Etanol, VII: Eteno e VIII: Biopolietileno. 38

Figura 6. Estrutura da celobiose.

Figura 7. Esquema da parece celular de uma planta e a organização de uma microfibrila.

Figura 8. Unidades presentes na lignina: a) p- hidroxi-fenila, b) Guaiacila e c) Siringila.

Figura 9. Planta (a) e Fibras de Curauá (b). 43

Figura 10. Estrutura química da interface para o compósito PEBD/PALF tratado com silano. 45

Figura 11. Reação de epoxidação de alceno. 49

Figura 12. Fórmula estrutural do OSE. 50

Figura 13. Representação esquemática das interações entre os componentes dos compósitos (CO-Fibra) e (CO- BPEAD). 51

Figura 14. Representação esquemática das interações entre os componentes dos compósitos (OSE-Fibra) e (OSE- BPEAD). 52

Figura 15. Mecanismo de abertura do epóxido. 52

Figura 16. Misturador interno acoplado ao reômetro de torque Haake. 54

Figura 17. Representação esquemática do corte transversal do misturador interno... 55 Figura 18. Principais etapas envolvidas na preparação de nanocristais e de celulose microfibrilada.

Figura 19. Representação da inserção do grupo sulfato proveniente da hidrólise com ácido sulfúrico na cadeia de celulose. 
Figura 20. Lista de reagentes utilizados para a modificação de NCCs : (i) adsorção física, (ii) modificação da superfície da molécula e (iii) graftização do polímero. 64

Figura 21. Esquema geral das estratégias utilizadas para a preparação de nanocompósitos de nanocelulose por casting. 67

Figura 22. Foto do equipamento utilizado no ensaio de impacto Izod. 74

Figura 23. Foto do equipamento utilizado no ensaio de resistência à flexão. 76

Figura 24. Foto do reômetro Ares da Rheometric Scientific 81

Figura 25. Representação esquemática de uma termoprensa. 89

Figura 26. Perfil da extrusora. 90

Figura 27. Extrusora dupla-rosca DSM Micro 15 compounder. 91

Figura 28. Difratograma de raios $X$ das fibras de curauá. 98

Figura 29. (a) Curva DSC para a fibra de curauá e (b) Curvas TG e de primeira derivada da TG da fibra de curauá, atmosfera de $\mathrm{N}_{2}$, vazão de $20 \mathrm{~mL} \min ^{-1}$ e razão de aquecimento de $10^{\circ} \mathrm{C} \mathrm{min}^{-1}$. 99

Figura 30. (a) e (b) Micrografia dos feixes de fibra de curauá .100

Figura 31. Caracterização da Fibra de Curauá e da Polpa tratada com $\mathrm{NaOH}$. 101

Figura 32. Difratograma de Raios $X$ dos nanocristais de curauá 102

Figura 33. Curvas TG e de primeira derivada da TG dos nanocristais de curauá, atmosfera de $\mathrm{N}_{2}$, vazão de $20 \mathrm{~mL} \mathrm{~min}^{-1}$ e razão de aquecimento de $10^{\circ} \mathrm{C} \mathrm{min}^{-1}$. 102

Figura 34. Micrografia obtida por SEM-FEG para solução diluída de nanocristais de curauá. 103

Figura 35. Difratograma de Raios $X$ do BPEAD. 105

Figura 36. (a) Curva TG e de derivada primeira da TG do BPEAD e (b) Curva DSC do BPEAD, atmosfera de $\mathrm{N}_{2}$, fluxo de $20 \mathrm{~mL} \mathrm{~min}^{-1}$ e razão de aquecimento de $10^{\circ} \mathrm{C} \mathrm{min}$. 106

Figura 37. Curvas DMA do BPEAD: $E^{\prime} ; E^{\prime \prime}$ e $\tan \delta$ versus temperatura. 107 Figura 38. Curvas DSC para os óleos vegetais (a) CO, (b) CA, (c) OLE, e (d) OSE,

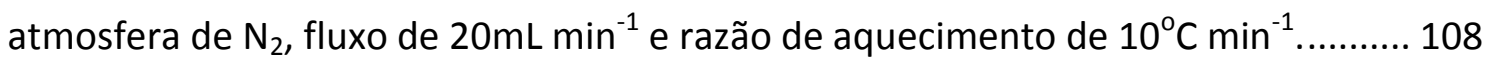
Figura 39. Curvas TG e dTG para os óleos vegetais (a) CO, (b) CA, (c) OLE, e (d) OSE, atmosfera de $\mathrm{N}_{2}$, fluxo de $20 \mathrm{~mL} \mathrm{~min}^{-1}$ e razão de aquecimento de $10^{\circ} \mathrm{C} \mathrm{min}^{-1}$. 110

Figura 40. Curvas de processamento dos compósitos no misturador interno Haake: (a) Torque em função do tempo (0-6 min), (b) (0-3 min). 
Figura 41. Valores de equilíbrio de torque após 4 min de mistura para compósitos preparados no misturador interno Haake....

Figura 42. Índice de fluidez para os compósitos BPEAD/CA/Fibra, BPEAD/CO/Fibra, BPEAD/OSE/Fibra, BPEAD/OLE/Fibra e BPEAD/Fibra (desvio padrão entre 5 e 10 \%). 114 Figura 43. $B P E A D$, fibra de curauá e compósitos $B P E A D / 5 \%$ CA,CO,OSE e OLE: (a) Curvas de TG e (b) Curvas de dTG, atmosfera de $\mathrm{N}_{2}$, fluxo de $20 \mathrm{~mL} \mathrm{~min}^{-1}$ e razão de aquecimento de $10{ }^{\circ} \mathrm{C} \mathrm{min}^{-1}$. 115

Figura 44. Curvas dTG: (a) Compósitos BPEAD/CO/Fibra; (b) Compósitos BPEAD/CA/Fibra; (c) Compósitos BPEAD/OSE/Fibra e (d) Compósitos BPEAD/OLE/Fibra,

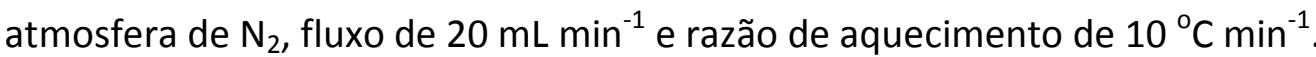
116

Figura 45. Curvas DSC para a fibra de curauá, BPEAD e compósitos processados no misturador interno e termoprensados, atmosfera de $\mathrm{N}_{2}$, fluxo de $20 \mathrm{~mL} \mathrm{~min}^{-1}$ e razão de aquecimento de $10{ }^{\circ} \mathrm{C} \mathrm{min}^{-1}$. 118

Figura 46. Curvas de módulo de armazenamento versus temperatura: (a) BPEAD/CO/Fibra; (b) BPEAD/CA/Fibra; (c) BPEAD/OSE/Fibra e (d) BPEAD/OLE/Fibra.120 Figura 47. Módulo de armazenamento $\left(\mathrm{a} 30^{\circ} \mathrm{C}\right.$ ) dos compósitos preparados por misturador interno (Haake)/termoprensagem.

Figura 48. Curvas tan $\delta$ versus temperatura: (a) e (b) BPEAD/CO/Fibra; (c) e (d) BPEAD/CA/Fibra; (e) e (f) BPEAD/OSE/Fibra e (g) e (h) BPEAD/OLE/Fibra.

Figura 49. Resistência ao impacto Izod dos compósitos (corpos de prova entalhados) processados por misturador interno. Desvio padrão entre 5-10\%. 125

Figura 50. Micrografias obtidas por MEV a partir da superfície de fratura dos compósitos entalhados: (a) BPEAD/5\%Fibra e (b) BPEAD/10\%Fibra.

Figura 51. Micrografias obtidas por MEV a partir da superfície de fratura dos compósitos entalhados: (a) BPEAD/15\%Fibra e (b) BPEAD/20\%Fibra. 127

Figura 52. Micrografias obtidas por MEV a partir da superfície de fratura dos compósitos entalhados: (a) BPEAD/5\%CO/5\%Fibra e (b) BPEAD/5\%OLE/5\%Fibra..... 128 Figura 53. Micrografias obtidas por MEV a partir da superfície de fratura dos compósitos entalhados: (a) BPEAD/10\%CO/10\%Fibra; (b) BPEAD/10\%CA/10\%Fibra; (c) BPEAD/10\%OSE/10\%Fibra e (d) BPEAD/10\%OLE/10\%Fibra. 128 
Figura 54. Micrografias obtidas por MEV a partir da superfície de fratura dos compósitos entalhados: (a) BPEAD/10\%CO/10\%Fibra; (b) BPEAD/15\%CO/15\%Fibra e (c) BPEAD/15\%OSE/15\%Fibra. 129

Figura 55. Curva de Tensão versus Deformação para o compósito de BPEAD/5\%CO/5\%Fibra. 130

Figura 56. Resistência à flexão dos compósitos, desvio padrão entre 4-10\%. 131

Figura 57. Módulo de flexão dos compósitos, desvio padrão entre 3-10\%. 132

Figura 58. Fibra de curauá, BPEAD e compósitos preparados por extrusão/injeção: (a) Curvas TG e (b) Curvas dTG, atmosfera de $\mathrm{N}_{2}$, fluxo de $20 \mathrm{~mL} \mathrm{~min}^{-1}$ e razão de aquecimento de $10^{\circ} \mathrm{C} \mathrm{min}^{-1}$. 134

Figura 59. Curvas DSC para a fibra de curauá, BPEAD e compósitos preparados por extrusão/injeção, atmosfera de $\mathrm{N}_{2}$, fluxo de $20 \mathrm{~mL} \mathrm{~min}^{-1}$ e razão de aquecimento de 10 ${ }^{\circ} \mathrm{C} \min ^{-1}$. 135

Figura 60. Curva de módulo de armazenamento versus temperatura para os compósitos BPEAD/5\%CO, CA e OSE/10\%Fibra e BPEAD/10\%Fibra, preparados por extrusão/injeção.

Figura 61. Módulo de armazenamento (a $30^{\circ} \mathrm{C}$ ) dos compósitos preparados por extrusão/injeção e por misturador interno (Haake)/termoprensagem. 137

Figura 62. Curvas de tan $\delta$ versus temperatura para os compósitos BPEAD/5\%CA, CO e OSE/10\%Fibra (3mm) extrudados e injetados: (a) -140 a $130^{\circ} \mathrm{C}$ e (b) -140 a $-90^{\circ} \mathrm{C}$... 138 Figura 63. Valores de $\tan \delta$ para os compósitos preparados por / misturador interno (Haake)/ termoprensagem e por extrusão/injeção. 140

Figura 64. Índice de Fluidez para os compósitos obtidos via extrusão/injeção e via misturador interno (Haake). (desvio entre 0,01 e 0,03 g10 $\mathrm{min}^{-1}$ ). 141

Figura 65. Resistência ao impacto Izod dos compósitos, corpos de prova entalhados, desvio padrão entre 5-10\%, Compósitos BPEAD/10\%Fibra, BPEAD/5\%CA, CO e OSE/10\%Fibra (3mm) preparados via misturador interno (Haake)/termoprensagem e por extrusão/injeção. 143

Figura 66. Micrografias obtidas por MEV a partir da superfície de fratura dos compósitos obtidos por extrusão/injeção e entalhados: (a), (b) BPEAD/5\%CA/10\%Fibra; (d), (e) BPEAD/5\%CO/10\%Fibra; (j) BPEAD/10\%Fibra (g), (h) BPEAD/5\%OSE/10\%Fibra e 
obtidos por misturador interno (Haake)/termoprensagem: (c) BPEAD/5\%CA/10\%Fibra; (f) BPEAD/5\%CO/10\%Fibra e (i) BPEAD/5\%OSE/10\%Fibra. 145

Figura 67. Resistência à flexão dos compósitos, desvio padrão entre 7-10\%. BPEAD/10\%Fibra, BPEAD/5\%CA, CO ou OSE/10\%Fibra $(3 \mathrm{~mm})$ processados por misturador interno (Haake)/termoprensados e extrusão/injeção.

Figura 68. Módulo de flexão dos compósitos, desvio padrão entre 6-10\%. Comparação entre o compósito BPEAD/5\%CA,CO ou OSE/10\%Fibra (3mm) processados no misturador interno (Haake) e extrudados 149

Figura 69. NCC liofilizado, BPEAD, BPEAD/3\%CO/3\%NCC, BPEAD/6\%CO/6\%NCC e BPEAD/9\%CO/9\%NCC extrudados: (a) curvas TG, (b) curvas dTG, atmosfera de $\mathrm{N}_{2}$, fluxo de $20 \mathrm{mLmin}^{-1}$ e razão de aquecimento de $10^{\circ} \mathrm{Cmin}^{-1}$. 151

Figura 70. Curvas DSC para o BPEAD e nanocompósitos reforçados com NCC extrudados, atmosfera de $\mathrm{N}_{2}$, fluxo de $20 \mathrm{~mL} \mathrm{~min}^{-1}$ e razão de aquecimento de $10^{\circ} \mathrm{C}$ $\min ^{-1}$.

Figura 71. Viscosidade versus Taxa de Cisalhamento para nanocompósitos de BPEAD reforçados com nanocristais de curauá extrudados. 154 Figura 72. G' (símbolo fechado) e G" (símbolo aberto) versus frequência angular a $175^{\circ} \mathrm{C}$ para nanocompósitos preparados por extrusão. 156

Figura 73. Ampliação na região de cruzamento entre $G^{\prime}-G^{\prime \prime}$. 156

Figura 74. Fotos de: BPEAD puro, BPEAD/3\%NCC, BPEAD/3\%CO/3\%NCC, BPEAD/6\%CO/6\%NCC e BPEAD/9\%CO/9\%NCC, filmes obtidos por extrusão. 157

Figura 75. Imagens de MEV da superfície fraturada dos nanocompósitos e do BPEAD puro: (a) BPEAD puro (X 15000), (b) BPEAD/3\%NCC (X 5000) e (c) BPEAD/3\%CO/3\%NCC (X 5000) 159

Figura 76. Imagens de MEV da superfície fraturada dos nanocompósitos e do BPEAD puro: (a) BPEAD/6\%NCC (X 5000), (b) BPEAD/6\%CO/6\%NCC (X 5000) e (c) BPEAD/9\%NCC (X 5000) e (d) BPEAD/9\%CO/9\%NCC (X 5000). 160

Figura 77. Módulo de Armazenamento em função da temperatura para nanocompósitos de BPEAD reforçados com nanocristais de curauá extrudados. 161

Figura 78. Tan $\delta$ em função da temperatura para nanocompósitos de BPEAD reforçados com nanocristais de curauá extrudados: (a) e (c) -130 a $130{ }^{\circ} \mathrm{C}$; (b) e (d) 130 a $0{ }^{\circ} \mathrm{C}$. 
Figura 79. Curvas TG do NCC liofilizado, polpa de curauá e misturas 1:1 CO/NCC, OSE/NCC e OLE/NCC.

Figura 80. Curvas TG do BPEAD puro e nanocompósitos reforçados com NCC, atmosfera de $\mathrm{N}_{2}$, fluxo de $20 \mathrm{~mL} \mathrm{~min}^{-1}$ e razão de aquecimento de $10^{\circ} \mathrm{C} \mathrm{min}^{-1}$. 168

Figura 81. Curvas DSC para o BPEAD e nanocompósitos reforçados com NCC, atmosfera de $\mathrm{N}_{2}$, fluxo de $20 \mathrm{~mL} \mathrm{~min}^{-1}$ e razão de aquecimento de $10^{\circ} \mathrm{C} \mathrm{min}^{-1}$. 169

Figura 82. Viscosidade versus Taxa de Cisalhamento para nanocompósitos de BPEAD reforçados com nanocristais de curauá: (a) Extrudados e (b) Extrudados/Termoprensados.

Figura 83. G' (preenchido) e G" (aberto) versus frequência angular a $175^{\circ} \mathrm{C}$ para os nanocompósitos: (a), (c), (e), (i) Filmes extrudados e (b), (d), (f), (j) Filmes extrudados/termoprensados.

Figura 84. Fotos de: BPEAD/3\%NCC (Extrudado), BPEAD/3\%NCC (Extrudado/Termoprensado), BPEAD/3\%CO/3\%NCC (Extrudado), BPEAD/3\%OSE/3\%NCC (Extrudado), BPEAD/3\%OLE/3\%NCC (Extrudado), BPEAD/3\%CO/3\%NCC (Extrudado/Termoprensado), BPEAD/3\%OSE/3\%NCC (Extrudado/Termoprensado), BPEAD/3\%OLE/3\%NCC (Extrudado/Termoprensado). 175 Figura 85. Módulo de armazenamento em função da temperatura para os nanocompósitos reforçados com NCC: (a) Filmes extrudados e (b) Filmes extrudados e temoprensados.

Figura 86. Tan $\delta$ em função da temperatura para os nanocompósitos extrudados. .. 179 Figura 87. (1) BPEAD, (2) BPEAD/3\%NCC, (3) BPEAD/3\%CO/3\%NCC, (4) BPEAD/3\%OSE/3\%NCC, (5) BPEAD/3\%CO/3\%NCC, (6) BPEAD/3\%CO, (7) BPEAD/3\%OSE e (8) BPEAD/3\%OLE: (a) Módulo de Young, (b) Resistência à Tração e (c) Deformação na Ruptura. 180 


\section{LISTA DE TABELAS}

Tabela 1. Produção Global e Custo Estimado das Fibras Naturais (2003-2005)............. 40

Tabela 2. Composição química de óleos vegetais em porcentagem de ácido graxo. ... 47

Tabela 3. Fórmula molecular dos principais ácidos graxos presentes na composição de óleos vegetais.

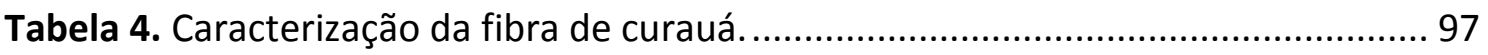

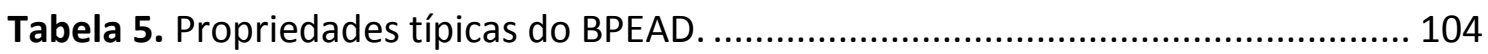

Tabela 6. Temperatura de pico de perda máxima (Tp)......................................... 117

Tabela 7. Entalpias de fusão, razão entre $\Delta \mathrm{H}_{\mathrm{m}}$ e $\varphi_{\mathrm{m}}$, índice de cristalinidade e

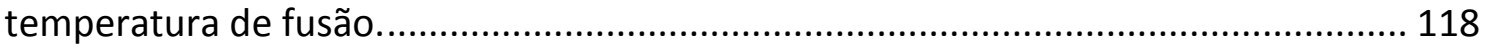

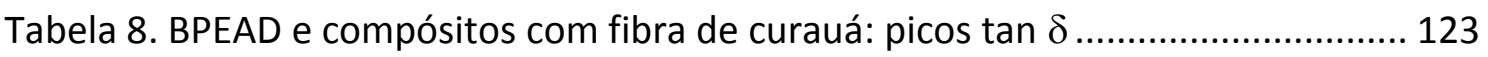

Tabela 9. Entalpias de fusão, razão entre $\Delta \mathrm{H}_{\mathrm{m}}$ e $\varphi_{\mathrm{m}}$, índice de cristalinidade e temperatura de fusão do BPEAD puro e em compósitos preparados por extrusão/injeção.

Tabela 10. BPEAD e compósitos com fibra de curauá: picos tan $\delta$ (desvio entre 0,2 $\left.0,6^{\circ} \mathrm{C}\right)$.

Tabela 11. Temperatura de fusão $\left(T_{m}\right)$ e Índice de Cristalinidade $(X c)$ do BPEAD, BPEAD/NCC e BPEAD/CO/NCC.

Tabela 12. Valores de $\eta_{0}$ para os nanocompósitos e para o BPEAD puro a $175^{\circ} \mathrm{C}$.... 154

Tabela 13. Picos do BPEAD puro e nanocompósitos (Desvio entre $0,3-0,7^{\circ} \mathrm{C}$ ). ....... 163

Tabela 14. Módulo de Young, Resistência à Tração e Deformação na Ruptura.......... 164

Tabela 15. Temperatura de fusão $\left(T_{m}\right)$, entalpia de fusão $\left(\Delta H_{m}\right)$ e Índice de Cristalinidade $(\mathrm{XC})$, de filmes baseados em BPEAD e BPEAD/óleo/NCC. 170

Tabela 16. Valores de $\eta_{0}$ para os nanocompósitos e para o BPEAD puro a $175{ }^{\circ} \mathrm{C}$... 171 Tabela 17. Comparação do módulo de armazenamento (a $30^{\circ} \mathrm{C}$ ) dos nanocompósitos processados por extrusão e dos nanocompósitos processados por extrusão e termoprensados.

Tabela 18. Relaxações para o BPEAD puro e para os nanocompósitos (Desvio entre 0,2 e $0,7^{\circ} \mathrm{C}$ ) 



\section{LISTA DE ABREVIATURAS E SIGLAS}

\begin{tabular}{|c|c|}
\hline $\mathrm{BC}$ & celulose bacteriana \\
\hline BPEAD & biopolietileno de alta densidade \\
\hline CA & óleo de canola \\
\hline $\mathrm{CO}$ & óleo de mamona \\
\hline dTG & primeira derivada da curva termogravimétrica \\
\hline DMA & análise térmica dinâmico-mecânica \\
\hline DSC & calorimetria exploratória diferencial \\
\hline$\Delta \mathrm{H}_{\mathrm{m}}$ & entalpia de fusão \\
\hline$\Delta H_{m}^{0}$ & entalpia de fusão \\
\hline $\mathrm{E}^{\prime}$ & módulo de armazenamento \\
\hline$E^{\prime \prime}$ & módulo de perda \\
\hline Endo & endotérmico \\
\hline EVA & copolímero de etileno-acetato de vinila \\
\hline$G^{\prime}$ & módulo de armazenamento \\
\hline $\mathrm{G}^{\prime \prime}$ & módulo de perda \\
\hline MAPP & polipropileno graftizado com anidrido maléico \\
\hline MEV & microscopia eletrônica de varretura \\
\hline $\mathrm{MFI}$ & índice de fluidez \\
\hline $\mathrm{NaClO}_{2}$ & clorito de sódio \\
\hline $\mathrm{NaOH}$ & hidróxido de sódio \\
\hline NCC & nanocristais de celulose \\
\hline OLE & óleo de linhaça epoxidado \\
\hline OSE & óleo de soja epoxidado \\
\hline$\left(\eta_{0}\right)$ & viscosidade à taxa de cisalhamento zero \\
\hline PALF & folhas curtas de abacaxi \\
\hline $\mathrm{PBHL}$ & polibutadieno líquido hidroxilado \\
\hline PEAD & polietileno de alta densidade \\
\hline PEBD & polietileno de baixa densidade \\
\hline PEMA & polietileno graftizado com anidrido maléico \\
\hline
\end{tabular}




$\begin{array}{ll}\text { PLA } & \text { poli (ácido lático) } \\ \text { (poli (S-co-BuA))copolímero de estireno e acrilato de butila } \\ \text { PPMA } & \text { polipropileno graftizado com anidrido maléico } \\ \text { PP } & \text { polipropileno } \\ \text { PVC } & \text { policloreto de vinila } \\ \text { Tg } & \text { temperatura de transição vítrea } \\ \text { TG } & \text { termogravimetria } \\ \text { Tp } & \text { temperatura de pico de perda máxima } \\ \text { Xc } & \text { índice de cristalinidade }\end{array}$




\section{SUMÁRIO}

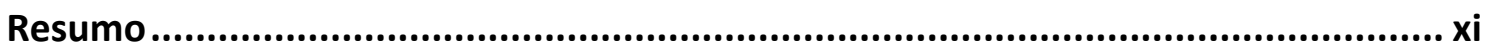

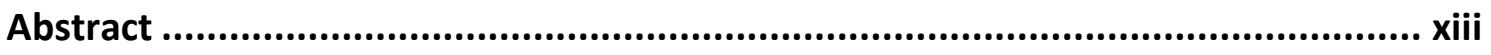

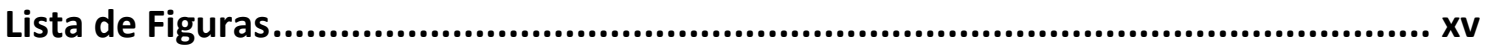

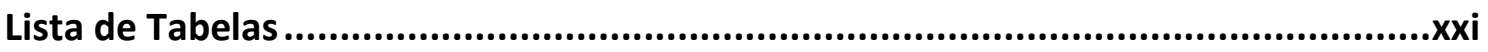

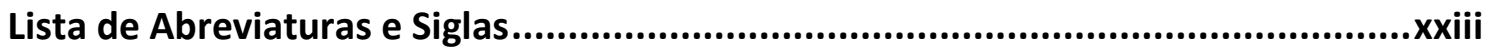

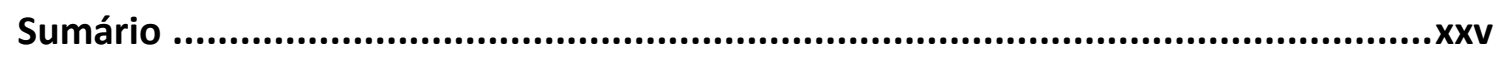

1. Contextualização do trabalho desenvolvido ................................. 29

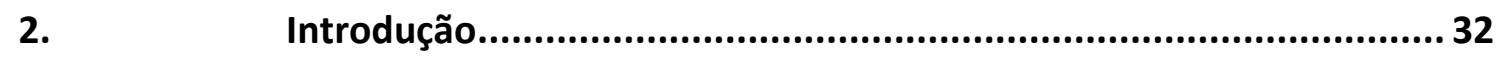

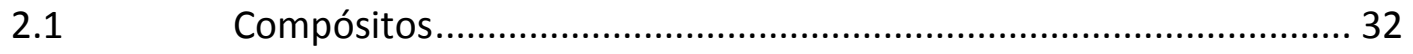

2.1.1 Compósitos de Matriz Termoplástica ........................................... 34

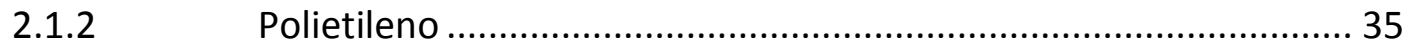

2.1.2.1 Polietileno de Alta Densidade................................................. 35

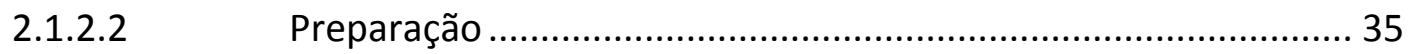

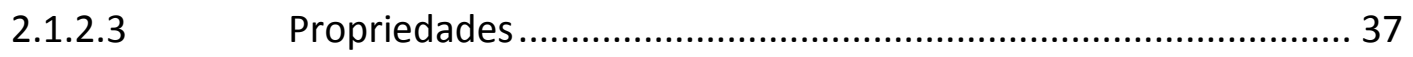

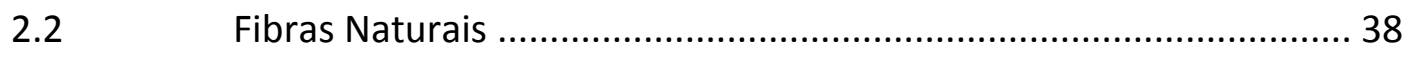

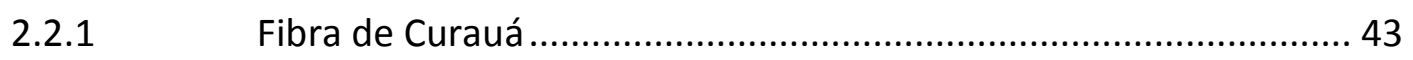

2.3 Interface matriz hidrofóbica- fibra lignocelulósica hidrofílica:

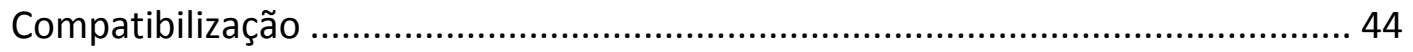

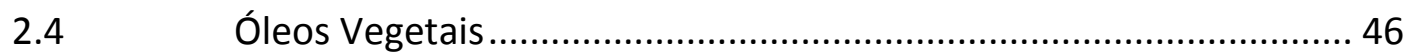

$2.5 \quad$ Processamento de Compósitos ................................................... 53

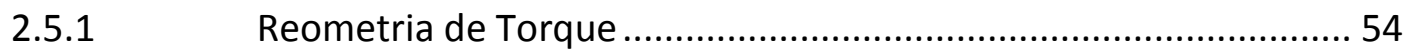

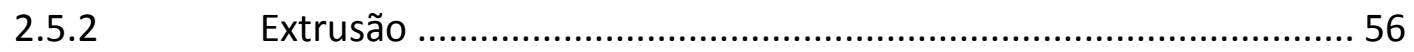

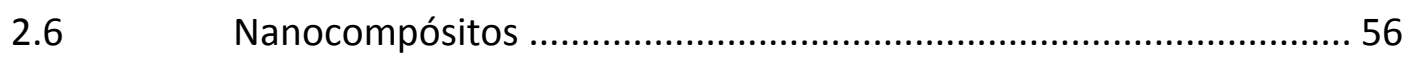

2.6.1 Nanocompósitos de Matriz Termoplástica ................................ 57

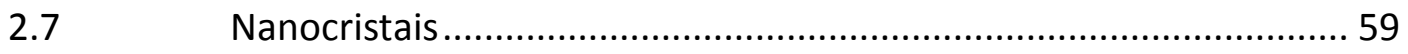


2.7.1 Modificação da Superfície dos Nanocristais ..................................62 62

$2.8 \quad$ Preparação dos Nanocompósitos .................................................... 66

3.

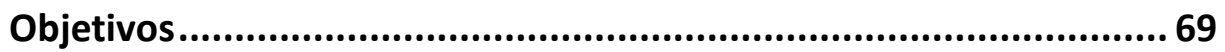

4. Técnicas de Caracterização dos Materiais...................................... 71

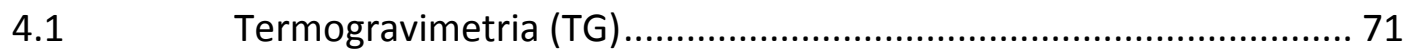

4.2 Calorimetria Exploratória Diferencial (DSC) ............................... 71

4.3 Ensaio de Resistência à Tração ........................................................ 72

4.4 Ensaio de Resistência ao Impacto ................................................ 73

4.5 Resistência à Flexão ................................................................. 75

4.6 Análise Dinâmico-Mecânica (DMA)................................................. 76

4.7 Microscopia Eletrônica de Varredura (MEV) ............................................. 78

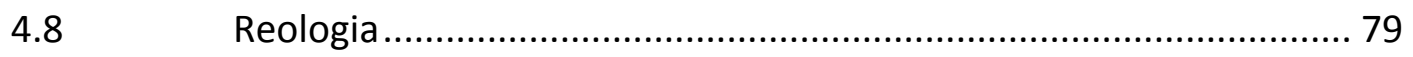

5. Materiais, Métodos e Forma de Análise dos Resultados ................. 85

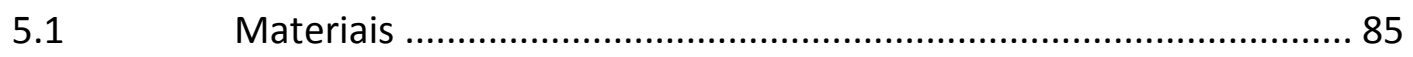

5.2 Preparação dos Nanocristais......................................................... 85

5.3 Caracterização das Fibras e dos Nanocristais de Curauá .................. 86

5.4 Microscopia eletrônica de varredura com fonte de emissão por

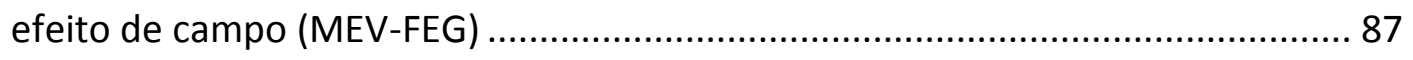

5.5 Determinação do Índice de Cristalinidade .................................. 87

5.6 Preparação dos compósitos .................................................... 88

5.7 Preparação dos filmes de nanocompósitos .....................................90

5.8 Caracterizações dos Compósitos.................................................. 91

5.9 Caracterizações dos Nanocompósitos ........................................... 94

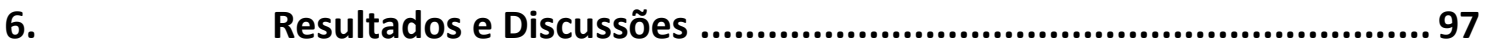

6.1 Caracterização das Fibras de Curauá ............................................. 97

6.1.1 Determinação do Índice de Cristalinidade por Difração de Raios X97

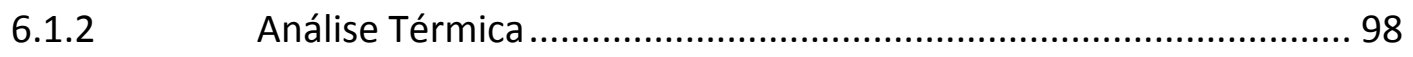

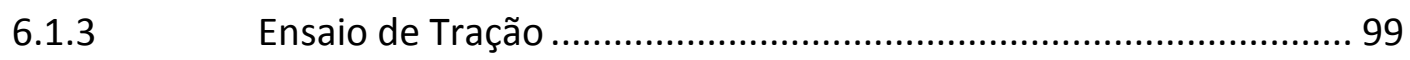


6.1.4 Microscopia Eletrônica de Varredura ........................................ 100

6.2 Caracterização dos Nanocristais ................................................. 101

6.2.1 Determinação do Índice de Cristalinidade por Difração de raios X 101

6.2.2 Análise Térmica 102

6.2.3 Microscopia Eletrônica de Varredura com Fonte de Emissão por Efeito de Campo (SEM-FEG) .............................................................................. 103

6.3 Caracterizações do "polietileno verde" (BPEAD) ............................ 104

6.3.1 Determinação do Índice de Cristalinidade por Difração de Raios X 105

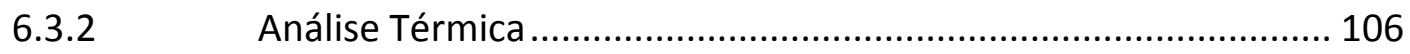

6.3.3 Analise Dinâmico- Mecânica (DMA) ........................................... 106

6.4 Caracterização dos óleos vegetais .............................................. 108

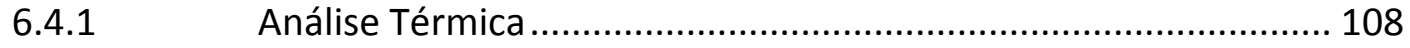

6.5 Compósitos preparados no misturador interno ............................. 111

6.5.1 Preparação das Amostras no Misturador Interno e MFI dos compósitos 111

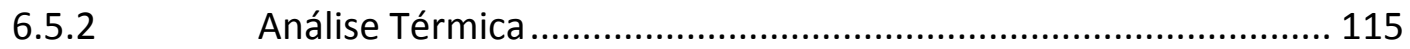

6.5.3 Análise Dinâmico-Mecânica (DMA) ........................................... 119

6.5.4 Resistência ao Impacto ........................................................ 124

6.5.5 Microscopia eletrônica de varredura.......................................... 126

6.5.6 Resistência à Flexão ........................................................... 130

6.6 Compósitos preparados na extrusora ......................................... 133

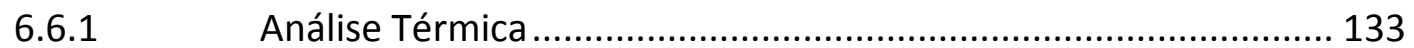

6.6.2 Análise Dinâmico-Mecânica (DMA) …....................................... 136

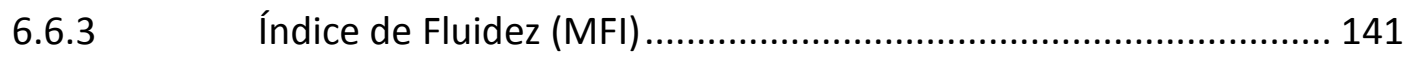

6.6.4 Resistência ao Impacto …..................................................... 142 
6.6.5 Microscopia Eletrônica de Varredura ....................................... 145

6.6.6 Resistência à Flexão ................................................................ 147

6.7 Nanocompósitos reforçados com 3, 6 e $9 \%$ de Nanocristais de Curauá na presença de Óleo de Mamona (Filmes preparados por extrusão) ..... 150

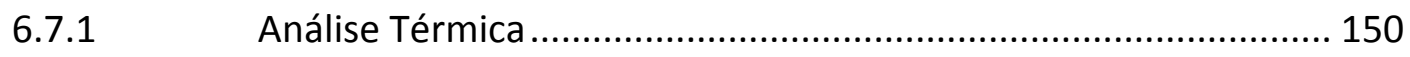

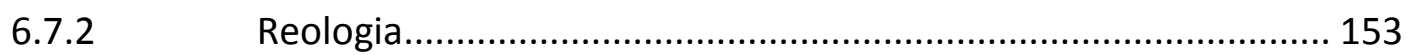

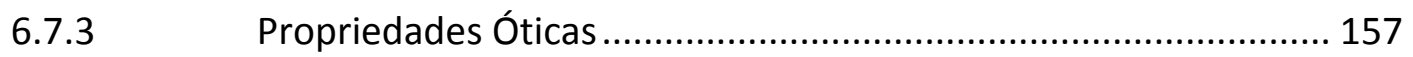

Análise Morfológica ............................................................... 159

6.7.5 Análise Dinâmico-Mecânica....................................................... 161

6.7.6 Resistência à Tração................................................................ 164

6.8 Filmes Nanocompósitos Preparados por Extrusão/Termoprensagem: Comparação de Propriedades de Filmes Extrudados e

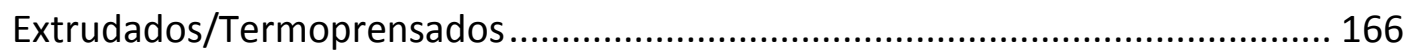

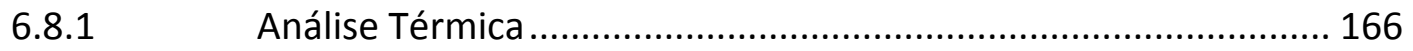

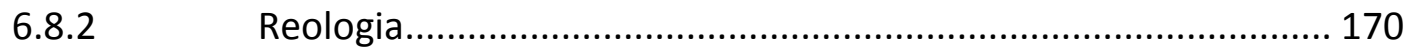

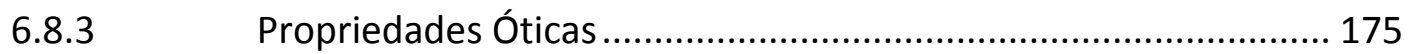

6.8.4 Análise Dinâmico-Mecânica.......................................................... 176

6.8.5 Resistência à Tração........................................................... 180

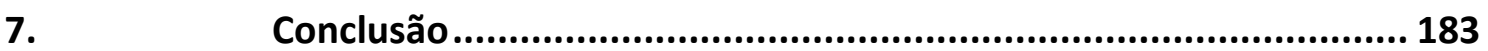

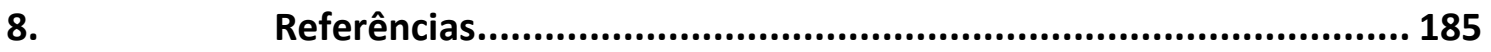




\section{Contextualização do trabalho desenvolvido}

A necessidade de desenvolver e comercializar materiais compósitos baseados em constituintes de origem natural (biocompósitos) é considerado de extrema importância, devido ao impacto que terá na redução da dependência de materiais provenientes de fontes não renováveis (SOYKEABKAEW et al., 2008), assim como no que diz respeito a aspectos ambientais e econômicos (GUNNING et al., 2013).

Durante as duas últimas décadas muitos estudos têm sido dedicados ao tema fibras lignocelulósicas como reforço em matrizes poliméricas, visando substituição de fibras como as de vidro por fibras naturais, em compósitos. A utilização de materiais lignocelulósicos na produção de compósitos poliméricos é particularmente atrativa, pelo seu baixo custo e alto volume de aplicações (HERRERA FRANCO; VALADEZ GONZALEZ; CERVANTESUC, 1997).

A história de plásticos reforçados com fibras naturais começou em 1908, com fibras de celulose reforçando matrizes fenólicas (JOHN; THOMAS, 2008). A Figura 1 mostra a comparação entre a utilização de fibras sintéticas e naturais reforçando compósitos nos diferentes setores industriais, em 2010, ou seja, após praticamente um século do início do uso de fibras naturais reforçando plásticos.

Figura 1. Comparação entre a aplicação de compósitos reforçados com fibras naturais e os compósitos reforçados com fibras de vidro e de carbono usados, nos diferentes setores industriais em 2010.

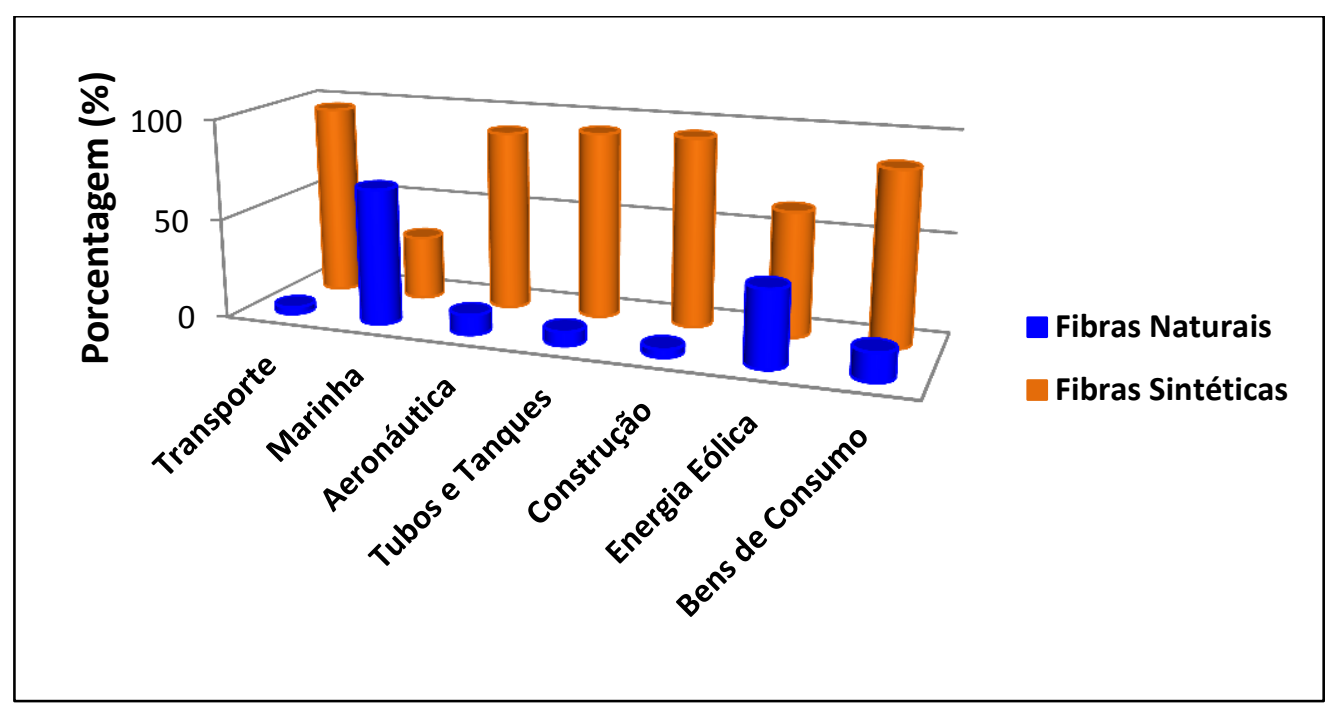

Fonte: disponível em http://www.researchandmarkets.com/reports/1933235/natural_ fiber_composites_market_trend_and/ 
Um estudo feito em 2010 indicou que o mercado mundial de compósitos reforçados com fibras naturais gerou 289,3 milhões dólares e a previsão para 2016 é que o mercado deva crescer 11 \%, gerando 531,3 milhões dólares (FARUK et al., 2014). A Figura 1 mostra que existe amplo espaço para crescimento deste mercado, em setores diversificados.

Os compósitos reforçados com fibras naturais apresentam boas propriedades mecânicas, baixos custo e baixa densidade (PAIVA; FROLLINI, 2006). No entanto, como as fibras de vidro comerciais sem tratamento, as fibras naturais apresentam baixa compatibilidade com os polímeros não polares e uma alta absorção de água, o que pode afetar as propriedades mecânicas dos compósitos (FROLLINI et al., 2013; DE OLIVEIRA SANTOS et al., 2014).

A fim de melhorar a adesão polímero/fibra e reduzir a absorção de água, a superfície das fibras pode ser modificada por métodos físicos ou químicos. As propriedades destes materiais podem ser aprimoradas, se ocorrer intensificação nas interações entre a fibra e a matriz (MEGIATTO et al., 2009).

Nos últimos anos bionanocompósitos baseados em nanocelulose, por exemplo, na forma de nanopartículas, reforçando matrizes têm apresentado um grande potencial de aplicação, em particular, para a utilização em embalagens e materiais biomédicos (SIQUEIRA et al., 2011). Este campo tem atraído atenção tanto da comunidade científica como da industrial, devido à possibilidade de superar as limitações apresentadas pelos tradicionais compósitos reforçados com fibras (macroescala).

As nanofibras e nanopartículas podem apresentar boas propriedades, como resultado do efeito de reforço na escala nanométrica. Assim, o objetivo principal em usar nanoescala como elemento de reforço é eliminar as falhas macroscópicas presentes nas fibras naturais, desintegrando as mesmas e separando as fibrilas altamente cristalinas e quase sem defeitos, atingindo a escala nanométrica (BONDESON; MATHEW; OKSMAN, 2006).

Os nanocristais naturais obtidos a partir de fontes renováveis, como polissacarídeos se tornaram importantes componentes em bionanocompósitos devido às suas vantagens como não toxicidade, baixo custo, disponibilidade no mundo todo, 
fácil processabilidade e fácil modificação química, física e mecânica (GRUNERT; WINTER, 2002).

O desenvolvimento de nanocompósitos de celulose é limitado pela não disponibilidade de nanopartículas em larga escala. Adicionalmente, a forte tendência dessas nanopartículas em formar agregados, dificultando sua dispersão homogênea na matriz, corresponde a um obstáculo que deve ser superado (PETERSSON; OKSMAN, 2006; DUFRESNE, 2008)

A aplicação de nanocelulose em matrizes poliméricas apolares ou de baixa polaridade, ou seja, hidrofóbicas leva a fracas interações na interface entre os polímeros e o reforço hidrofílico. Muitas pesquisas têm sido realizadas visando melhorar a compatibilidade entre os NCCs (nanocristais de celulose) e as matrizes poliméricas por meio de modificações químicas da superfície dos NCCs (THIELEMANS; BELGACEM; DUFRESNE, 2006; HASANI et al., 2008). No entanto, estas modificações químicas podem envolver reagentes que, pelo menos em parte, diminuem o impacto de se usar matéria prima oriunda de fonte renovável na preparação de materiais, pois muitos reagentes são obtidos por rotas petroquímicas.

Devido à limitada estabilidade térmica das fibras e dos nanocristais de origem vegetal, somente termoplásticos que apresentam temperatura de fusão abaixo de $200^{\circ} \mathrm{C}$ são comumente usados em compósitos reforçados por estes materiais.

As poliolefinas, como polietileno e polipropileno, são amplamente utilizadas em aplicações nos setores de embalagens, automotivo e elétrico, nos quais as propriedades de resistência térmica e mecânica possuem grande importância. As propriedades finais dos produtos obtidos a partir de poliolefinas estão intimamente relacionadas à morfologia desses materiais desenvolvida durante o processamento (COUTINHO; MELLO; SANTA MARIA, 2003). Poliolefinas, incluindo polietileno e polipropileno, representam mais da metade dos polímeros comerciais produzidos no mundo (CHUNG, 2013). No Brasil, as poliolefinas representam cerca de $65 \%$, dos quais $43 \%$ correspondem aos polietilenos (FISCH et al., 2011). Assim, torna-se importante buscar condições que levem há compósitos de matrizes apolares poliolefínicas, reforçados com fibras naturais hidrofílicas (macro ou nanoescala) com boas interações na interface, assim como com distribuição homogênea do reforço na matriz. 
Neste trabalho foi utilizado como matriz o "polietileno verde", ou biopolietileno (BPEAD), obtido a partir de eteno, por sua vez gerado pela fermentação e destilação do caldo da cana, que produz inicialmente o etanol. Na fase seguinte, o etanol é desidratado e transformado em eteno.

No contexto previamente mencionado, no presente estudo, com o objetivo de melhorar as interações nas interfaces dos compósitos reforçados com as fibras lignocelulósicas de curauá (macroescala) e com os nanocristais (obtidos a partir da mesma fibra), óleo de mamona (CO), óleo de canola (CA), óleo de linhaça epoxidado (OLE) e óleo de soja epoxidado (OSE) foram usados na preparação de compósitos. Desta forma, materiais baseados principalmente em matérias-primas provenientes de fontes naturais, foram preparados visando à valorização dos materiais gerados.

\section{Introdução}

\subsection{Compósitos}

De forma simplificada, um compósito pode ser definido como um material que apresenta duas ou mais fases distintas, sendo, portanto, um material heterogêneo (HERAKOVICH, 1998). Um dos componentes é descontínuo, sendo o principal responsável pela resistência ao esforço (componente estrutural ou reforço) e o constituinte que é contínuo e está frequentemente, mas nem sempre, presente em maior quantidade no compósito é denominado de matriz. As propriedades dos compósitos dependem das propriedades das fases constituintes, das suas quantidades relativas e da geometria da fase dispersa (CALLISTER, 2002).

As matrizes podem ser cerâmicas, poliméricas ou metálicas. As matrizes poliméricas podem ser divididas em termorrígidas ou termoplásticas.

Compósitos com matrizes poliméricas podem ser utilizados na indústria automotiva, naval, aeroespacial, esportiva e na construção civil (WAMBUA; IVENS; VERPOEST, 2003). Neste contexto os materiais poliméricos podem ser considerados como indispensáveis à vida moderna. Devido às vantagens no processamento dos polímeros em relação às cerâmicas e os metais, assim como ao baixo custo, e ao mesmo tempo versatilidade, a aplicabilidade dos compósitos com matrizes poliméricas 
cresceu rapidamente e logo estes foram aceitos tanto pelas indústrias como pelo mercado consumidor (RAMIRES et al., 2010).

Esta diversidade de aplicações deve-se ao extenso número de combinações possíveis quando se mistura um material de reforço em matrizes poliméricas. Portanto, compósitos de matriz polimérica podem ser entendidos como a combinação de dois ou mais materiais, por exemplo, um reforço envolvido por uma matriz polimérica, com propriedades superiores a de seus constituintes (ALAM et al., 2011; RUEDA et al., 2013).

O componente descontínuo (reforço) pode ser fibroso, particulado ou estrutural, e podem ser classificados de acordo com o esquema mostrado na Figura 2:

Figura 2. Classificação dos reforços utilizados em compósitos.

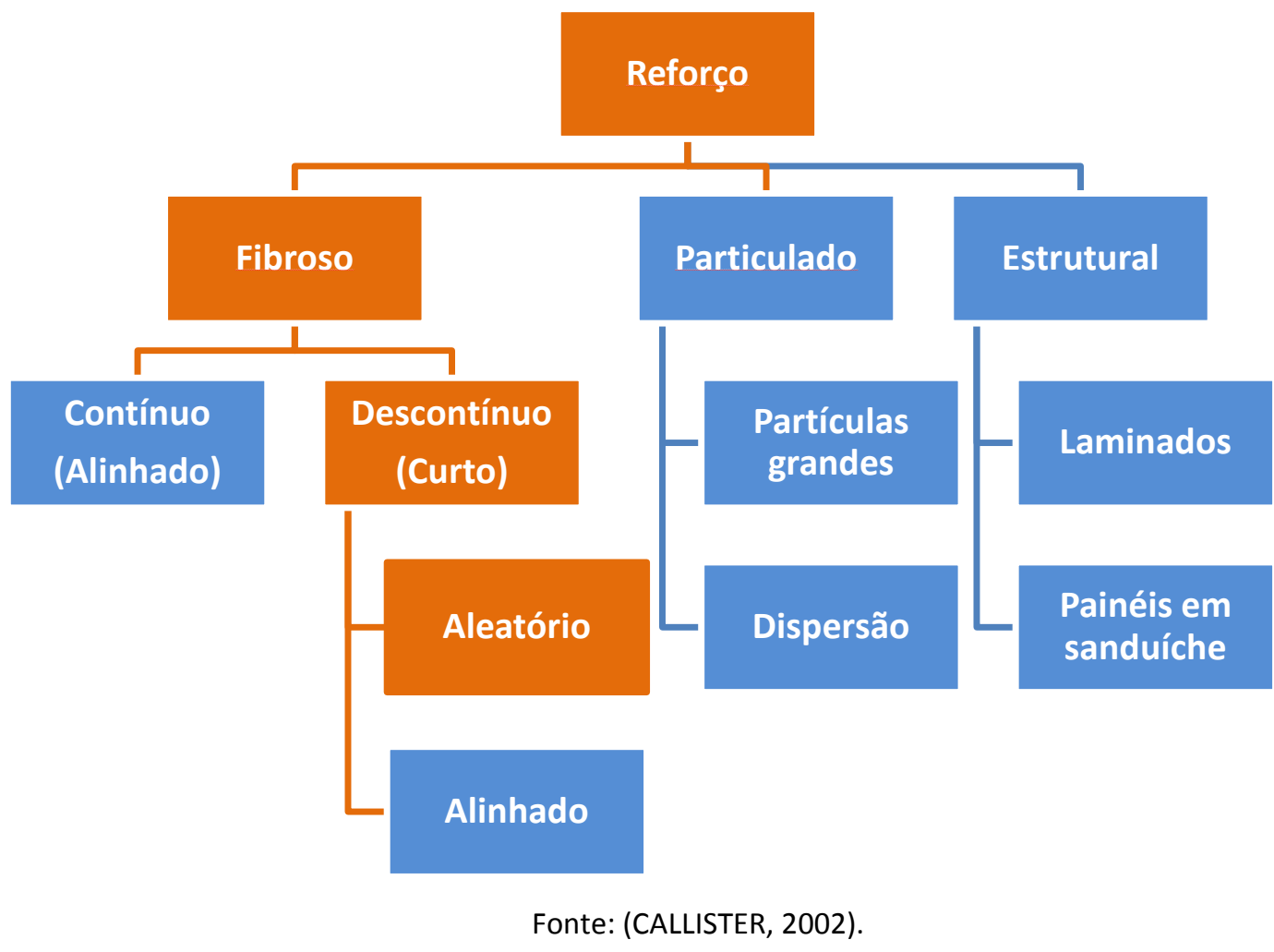

Para que ocorra uma interação na mistura de dois componentes de natureza química diversa, é essencial a existência de áreas de contato entre eles. Agentes compatibilizantes fibra-matriz ou tratamentos químicos são sugeridos para intensificar 
a adesão fibra-matriz e reduzir a absorção de água de compósitos reforçados por fibras naturais (MEGIATTO et al., 2009).

No presente trabalho, foram preparados compósitos de matriz polimérica termoplástica, reforçados por fibras descontínuas, com distribuição aleatória.

\subsubsection{Compósitos de Matriz Termoplástica}

Compósitos com matrizes poliméricas possuem diversas aplicações, desde a indústria automotiva, naval e aeroespacial, passando por aplicações militares, dentre outras (DE OLIVEIRA SANTOS et al., 2014).

BPEAD foi usado no presente trabalho para preparar compósitos de matriz polimérica termoplástica.

As fibras lignocelulósicas e as poliolefinas apresentam caráter hidrofílico e hidrofóbico, respectivamente, resultando em regiões de aglomeração das fibras, além da transferência da tensão ser prejudicada pela fraca adesão nas interfaces polímero/fibra (HILL; ABDUL KHALIL, 2000; KALIA; VASHISTHA, 2011). A introdução de agentes compatibilizantes permite uma maior adesão na interface desses sistemas, 0 qual resulta em mudanças nas propriedades finais. A intensificação da adesão entre estas fases pode ocorrer via processos que aumentem a compatibilização entre fibra e matriz. Por exemplo, a fibra e/ou polímero podem ser modificados quimicamente. Com este objetivo, encontra-se na literatura estudos em que o polipropileno foi enxertado com anidrido maléico ou com ácido acrílico, visando intensificar as interações fibra/matriz na interface (WU et al., 2009; SHIBULAL; NASKAR, 2012).

Araújo et al. (2010) investigaram compósitos baseados em fibra de curauá (20\%) e PEAD (processo de extrusão). PEMA (polietileno graftizado com anidrido maléico) ou EVA (copolímero de etileno - acetato de vinila) foram misturados ao PEAD, visando aumentar a compatibilização na interface polímero/fibra. $O$ agente compatibilizante mais eficiente foi o PEMA, que promoveu um aumento de $15 \%$ na resistência ao impacto do compósito $\left(65 \mathrm{~J} \mathrm{~m}^{-1}\right)$, em relação ao compósito reforçado com $20 \%$ de fibra de curauá $\left(58 \mathrm{~J} \mathrm{~m}^{-1}\right.$ ). 


\subsubsection{Polietileno}

O polietileno tem a estrutura mais simples dentre os hidrocarbonetos poliméricos (Figura 3).

Figura 3. Estrutura Química do Polietileno.<smiles>CC(C)(C)CCC(C)(C)[In]</smiles>

Os polietilenos são inertes à maioria dos produtos químicos comuns, devido à sua natureza apolar, e à sua estrutura parcialmente cristalina. Em condições normais, os polímeros etilênicos não são tóxicos, podendo inclusive ser usados em contato com produtos alimentícios e farmacêuticos (COUTINHO; MELLO; SANTA MARIA, 2003).

Existem muitos tipos de polietileno, as variações estão relacionadas às diferentes ramificações que podem estar presentes, modificando a natureza do material. Dependendo das condições reacionais e do sistema catalítico empregado na polimerização, tipos diferentes de polietileno podem ser produzidos, os quais diferem entre si quanto ao teor de ramificação das cadeias.

\subsubsection{Polietileno de Alta Densidade}

\subsubsection{Preparação}

Polietilenos de alta densidade, como os usados no presente estudo, são produzidos com catalisadores organometálicos, como os Ziegler-Natta (por exemplo, combinação de trietil-alumínio e tetracloreto de titânio), é um dos métodos mais utilizados comercialmente para a produção do polietileno de alta densidade. Esses sistemas catalíticos são ativos o suficiente para permitir que a reação ocorra, inclusive, à pressão atmosférica e temperaturas inferiores a $100^{\circ} \mathrm{C}$. A Figura 4 ilustra de forma 
simplificada um mecanismo proposto para a obtenção do polietileno de alta densidade.

Figura 4. Polimerização do etileno utilizando os catalisadores de Ziegler-Natta.
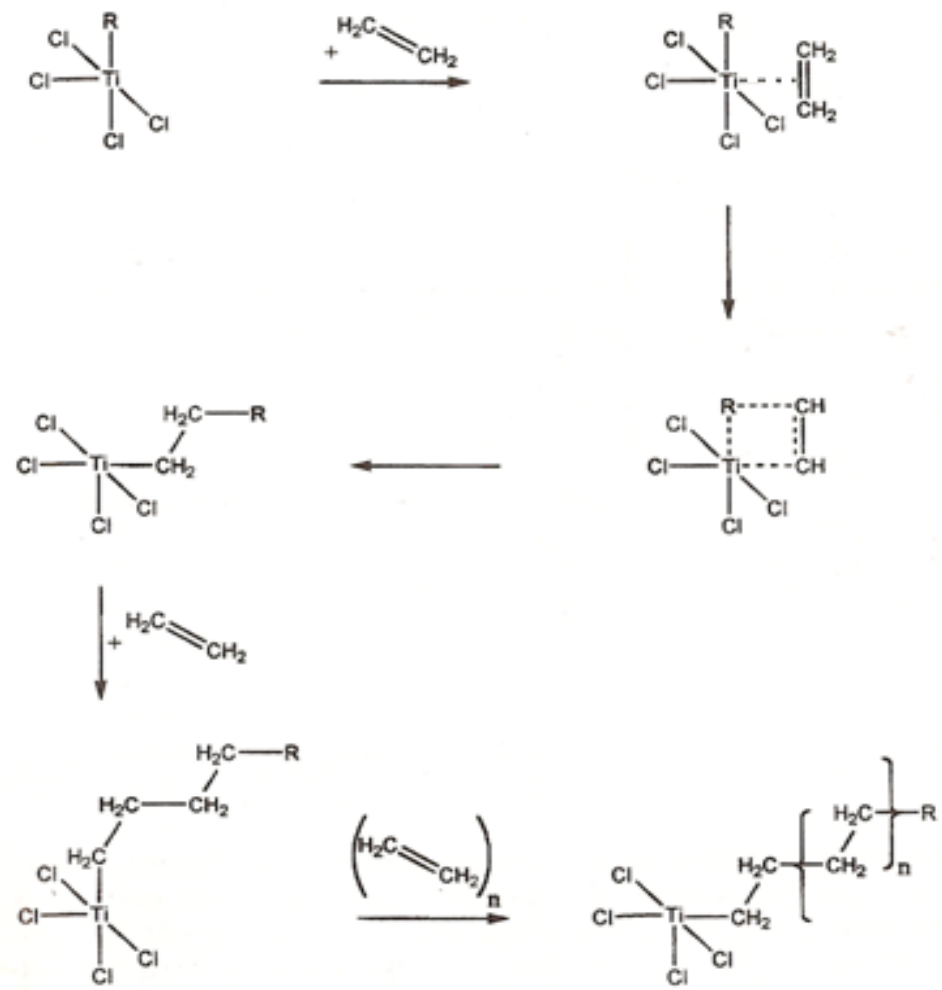

Fonte: (PEACOCK, 2000).

De forma simplificada, o centro ativo do catalisador de Ziegler e Natta contêm um átomo de titânio coordenado com 4 átomos de cloro e um grupo alquila em uma configuração octaédrica, possuindo uma região que corresponde a um "orbital vazio", ou seja, região apta a receber densidade eletrônica. Pode-se considerar que a molécula de etileno se coordena com esta região do catalisador, usando seus elétrons $\pi$. O grupo $R$ se rearranja, ligando-se a um dos átomos de $C$ do etileno, que usa seus elétrons $\pi$ para definitivamente se ligar ao Ti, através do outro átomo de $C$, sendo que o complexo formado reagirá com novas moléculas de etileno, obtendo-se assim, o polietileno de alta densidade (Figura 4) (PEACOCK, 2000). 


\subsubsection{Propriedades}

A temperatura de transição vítrea (Tg) é um importante parâmetro que pode ser utilizado para a caracterização de plásticos e outros materiais não cristalinos ou semicristalinos. Nesta transição, ocorre a passagem do material do estado vítreo para um estado borrachoso, sem que ocorra uma mudança estrutural. A Tg para o polietileno de alta densidade varia de -90 a $-120^{\circ} \mathrm{C}$, pois depende de fatores como massa molar média sendo consequência de rotações em torno de ligações, envolvendo segmentos das cadeias presentes na fase não cristalina do polietileno (CALLISTER, 2002).

O polietileno de alta densidade é um polímero altamente cristalino (entre 60 e $80 \%)$ sendo composto por ramificações curtas e com poucas irregularidades. Esse polímero contém menos de uma ramificação por 200 átomos de carbono da cadeia principal; a densidade encontra-se na faixa entre 0,94 e 0,97 $\mathrm{g} \mathrm{cm}^{-3}$ e a temperatura de fusão cristalina $\left(T_{m}\right)$ situa-se entre 125 e $135^{\circ} \mathrm{C}$. A linearidade das cadeias e, consequentemente, a maior densidade do PEAD faz com que a orientação, o alinhamento, e o empacotamento das cadeias sejam mais eficientes, permitindo que as forças intermoleculares possam agir mais intensamente e, dessa forma, levar a uma maior cristalinidade, comparativamente a polietilenos de menor densidade (PEACOCK, 2000).

O polietileno de alta densidade apresenta elevada rigidez, resistência à fluência, à abrasão e ao impacto, o PEAD encontra aplicações em diferentes segmentos da indústria de transformação de plásticos, abrangendo os processos de extrusão, moldagem por sopro e moldagem por injeção. Por extrusão, o PEAD é utilizado principalmente em sacos para lixo, sacolas de supermercados, revestimento de tubulações metálicas e tubos para redes de saneamento e de distribuição de gás. Pelo processo de sopro, destaca-se a transformação em frascos para a indústria alimentícia, higiene e limpeza. No processo de injeção, é usado para a fabricação de brinquedos, potes, tampas para garrafas, entre outros (CALLISTER, 2002).

Neste trabalho foi utilizado um PEAD, chamado por muitos de "polietileno verde", ou biopolietileno (BPEAD) devido ao fato de o mesmo ser obtido a partir de eteno gerado pela fermentação e destilação do caldo da cana, que produz 
inicialmente o etanol, que por sua vez é desidratado e transformado em eteno (Figura 5).

Figura 5. Esquema indicativo do processo de obtenção do BPEAD a partir da cana de açúcar. I: cana-deaçúcar, II: Moagem, III: Preparação do caldo, IV: Fermentação, V: Destilação, VI: Etanol, VII: Eteno e VIII: Biopolietileno.
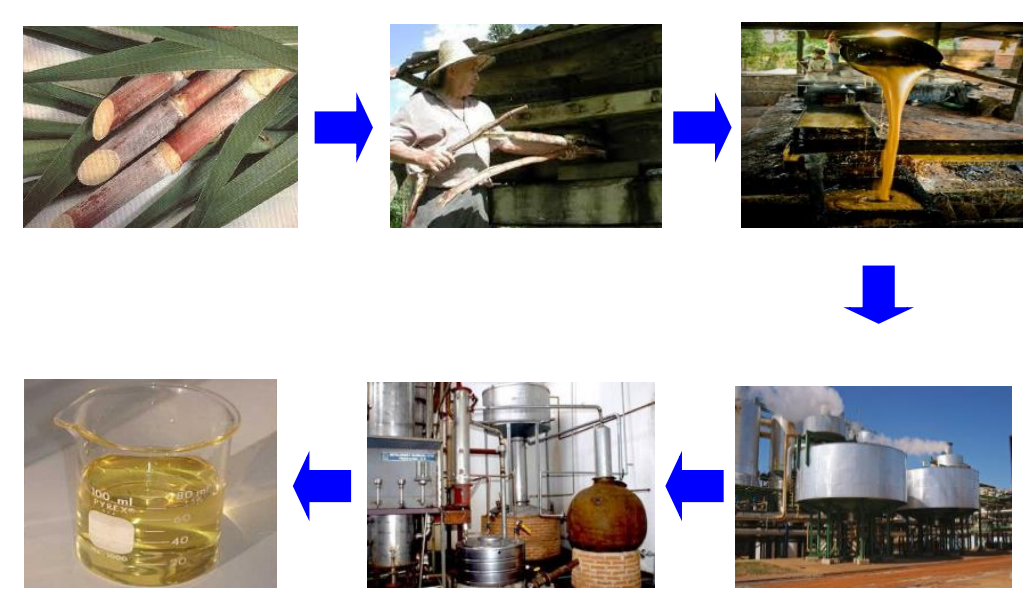

Desidratação

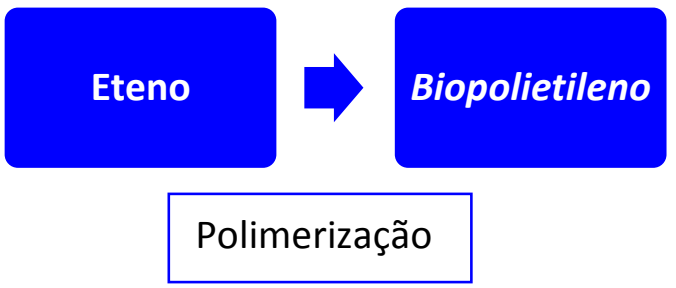

O BPEAD logicamente tem estrutura semelhante ao polímero originado a partir do eteno oriundo de rota petroquímica, mas corresponde a uma inovação tecnológica, pois além de ocorrer absorção de $\mathrm{CO}_{2}$ da atmosfera no ciclo de produção, ainda reduz a dependência de matérias-primas de origem fóssil para fabricação de produtos plásticos (disponível em <http://www.braskem.com.br/>).

\subsection{Fibras Naturais}

Fibras sintéticas, como fibras de vidro, fibras de carbono e fibras metálicas são rotineiramente utilizados pela indústria como agentes de reforço em 
compósitos de matriz polimérica para obter materiais com melhores propriedades mecânicas. No entanto, estas fibras sintéticas apresentam várias desvantagens, tal como o consumo de energia elevada para a sua produção, elevados custos em comparação com outros enchimentos, abrasão ao equipamento de processamento e não degradabilidade (SHI et al., 2012).

Durante os últimos anos muitos estudos têm se dedicado ao uso de fibras lignocelulósicas como reforço em matrizes poliméricas, substituindo as tradicionais fibras de vidro. Devido às recentes restrições ambientais, esforços vêm sendo feitos para disponibilizar para a indústria de polímeros novos materiais que causem menor impacto ambiental. As fibras lignocelulósicas extraídas de plantas cultivadas como sisal, curauá, juta, cânhamo, coco, linho, madeira, abacaxi, banana e buriti são exemplos típicos de materiais naturais. A utilização de materiais lignocelulósicos na produção de compósitos poliméricos é particularmente atrativa, pelo seu baixo custo, grande variedade disponível na natureza e alto volume de aplicações (MONTEIRO et al., 2009).

O uso de fibras naturais como aditivos em compósitos apresenta um grande potencial para melhorar o seu desempenho e aplicação tecnológica, devido a seu baixo custo, abundância e biodegradabilidade. Além disso, devido à sua baixa densidade, as fibras naturais devem reduzir o peso do compósito, o que é importante para aplicações em automóveis, construção, dentre outros (MOHANTY; MISRA; HINRICHSEN, 2000).

De acordo com a Organização das Nações Unidas para a Alimentação e Agricultura (FAO), a cada ano os agricultores colhem cerca de 35 milhões de toneladas de fibras naturais de uma grande variedade de plantas e animais. Estas fibras são usadas para formar tecidos, cordas e fios, que têm desempenhado um papel fundamental na sociedade desde os primórdios da civilização. Além disso, os rendimentos obtidos com a venda e exportação de fibras naturais contribuem para a redução da pobreza mundial. A produção mundial e custo médio das principais fontes de fibras naturais durante o período que varia 2003-2005 estão resumidos na Tabela 1.

A produção mundial de fibras naturais é de cerca de 32 milhões de toneladas e gera custos de cerca de 36 milhões de dólares. 
A Ásia e a América do Sul são os mais importantes produtores, com uma grande variedade de fibras. O Brasil tem um elevado potencial para a produção de fibras naturais e produz um número elevado de fibras lignocelulósicas diferentes. Por exemplo, cerca de 200 mil toneladas de sisal são produzidas a cada ano no Brasil, o qual é o maior produtor mundial desta fibra (disponível em <http:// www.fao.org/>).

Tabela 1. Produção Global e Custo Estimado das Fibras Naturais (2003-2005).

\begin{tabular}{|c|c|c|c|c|c|}
\hline \multirow[t]{2}{*}{ Fibras Naturais } & \multirow[t]{2}{*}{ Principal País Produtor } & Produção & Mundial & Custos & \multirow{2}{*}{$\begin{array}{c}\text { Produção } \\
\%\end{array}$} \\
\hline & & Toneladas em milhão & $\%$ & $\begin{array}{c}\text { Milhões } \\
\text { (Dólares) }\end{array}$ & \\
\hline Algodão & $\begin{array}{c}\text { China, EUA, Índia, } \\
\text { Paquistão, } \\
\text { Uzbequistão, Brasil }\end{array}$ & 25 & 78.8 & 31.20 & 85.8 \\
\hline Juta & Índia, Bangladesh & 2.7 & 8.5 & 0.48 & 1.3 \\
\hline Linho & $\begin{array}{c}\text { China, França, Bélgica, } \\
\text { Belarus, Ucrânia }\end{array}$ & 0.08 & 0.2 & 0.43 & 1.2 \\
\hline Kenaf & Países Asiáticos & 0.05 & 1.6 & n.d. & n.d. \\
\hline Coco & $\begin{array}{l}\text { Índia, Sri Lanka, } \\
\text { Tailândia, Malásia }\end{array}$ & 0.45 & 1.4 & n.d. & n.d. \\
\hline Sisal & Brasil, Tanzânia, China & 0.30 & 0.9 & 0.08 & 0.2 \\
\hline Rami & China & 0.15 & 0.5 & 0.17 & 0.5 \\
\hline Abacá & $\begin{array}{c}\text { Filipinas, Equador, } \\
\text { China, Espanha }\end{array}$ & 0.08 & 0.3 & 0.03 & 0.1 \\
\hline Cânhamo & Rússia, Chile & 0.09 & 0.3 & 0.03 & 0.1 \\
\hline Lã & $\begin{array}{c}\text { Austrália, China e Nova } \\
\text { Zelândia }\end{array}$ & 2.20 & 6.9 & 2.96 & 8.1 \\
\hline Seda & China, Índia & 0.14 & 0.4 & 0.98 & 2.7 \\
\hline Total & & 31.69 & 100 & 36.35 & 100 \\
\hline
\end{tabular}

n.d. = não disponível

Fonte: (SIQUEIRA; BRAS; DUFRESNE, 2010a).

As fibras lignocelulósicas são constituídas de celulose, hemicelulose (ou polioses), lignina, pectina, cera e substâncias solúveis em água, sendo os três primeiros componentes majoritários e os responsáveis pelas propriedades físicas das fibras, além de terem forte influência sobre as propriedades mecânicas dos compósitos reforçados por fibras lignocelulósicas (SILVA et al., 2009).

A celulose é o material de origem vegetal mais abundante da Terra, sendo o componente orgânico principal das fibras naturais é um polissacarídeo semicristalino que contém ligações $\beta$ glicosídicas. A presença de três grupos hidroxila em cada unidade repetitiva da celulose (Figura 6) resulta em um caráter hidrofílico (MOSIER et al., 2005). 
Figura 6. Estrutura da celobiose.

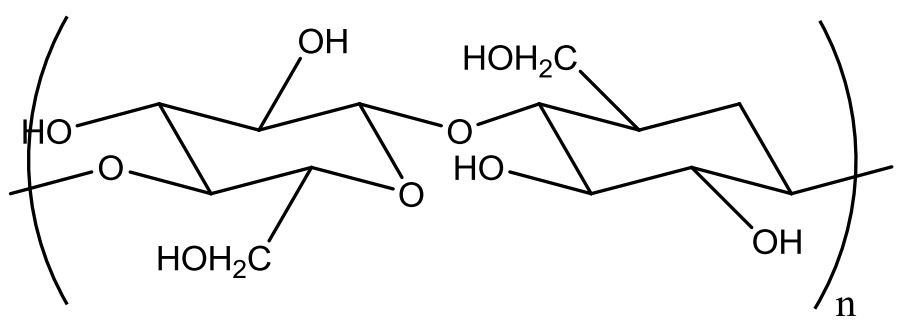

Fonte: (FENGEL; WEGENER, 1989).

O conjunto de cadeias de celulose são chamados de microfibrilas (Figura 7) e formam a unidade básica estrutural da parede celular das plantas. Cada microfibrila pode ser considerada como uma sequência de cristalitos de celulose, ligados ao longo do eixo da cadeia por domínios não-cristalinos. Estas microfibrilas agregam ainda mais para formar as fibras lignocelulósicas. As microfibrilas têm diâmetro que varia de aproximadamente $2 \mathrm{~nm}$ a $20 \mathrm{~nm}$ e comprimento que pode alcançar dezenas de micrômetros (DUFRESNE, 2010).

Figura 7. Esquema da parece celular de uma planta e a organização de uma microfibrila.

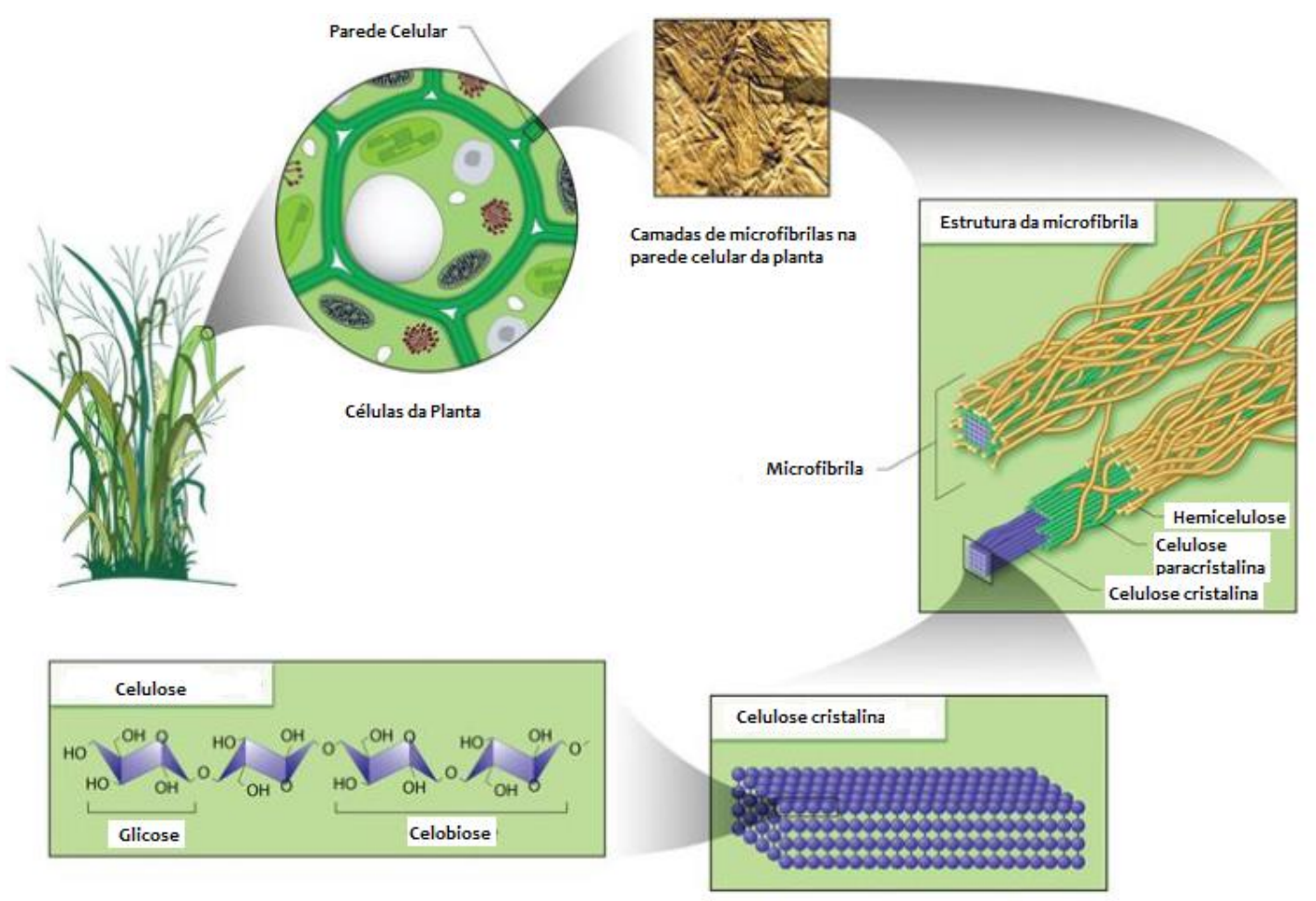

Fonte: (DUFRESNE, 2010). 
As hemiceluloses, também chamadas de polioses, correspondem a polissacarídeos com grau de polimerização menor (da ordem de 10 a 100 vezes) com relação ao da celulose (FENGEL; WEGENER, 1989).

A lignina apresenta em sua estrutura grupos aromáticos e alifáticos, com vários anéis fenilpropânicos substituídos, ligados através de diferentes tipos de ligações, como do tipo éter ou carbono-carbono. Costuma-se dividir a lignina em duas classes: guaiacila e guaiacila-siringila. Nas guaiacilas, existem principalmente unidades guaiacila e nas guaiacila-siringila existem unidades guaiacila e siringila em proporções aproximadas (Figura 8), sendo que ambas as classes possuem proporções menores de unidades para-hidroxifenila. No entanto, a estrutura específica da lignina varia com a espécie a partir da qual ela é obtida, pois cada espécie produz uma lignina rica em um tipo de unidade (guaiacila, siringila e para-hidroxifenila), e algumas vezes as estruturas são afetadas pelo método utilizado para extração (FENGEL; WEGENER, 1989).

Figura 8. Unidades presentes na lignina: a) p- hidroxi-fenila, b) Guaiacila e c) Siringila.

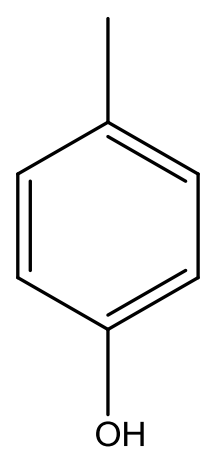

(a)

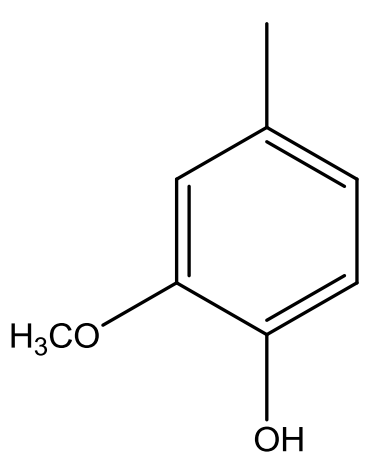

(b)<smiles>COc1cc(C)cc(OC)c1O</smiles>

(c)

Fonte: (FENGEL; WEGENER, 1989).

A composição química das fibras pode apresentar proporções diferentes devido à origem das mesmas, assim devido às diferentes condições de cultivo a que as plantas são submetidas, uma das principais desvantagens é a variação das propriedades mecânicas relacionadas com as condições climáticas (TRINDADE et al., 2008). 


\subsubsection{Fibra de Curauá}

A Ananas erictifolius, conhecida popularmente por curauá, é uma espécie encontrada principalmente na região amazônica. É semelhante ao abacaxi, no entanto, o interesse dos agricultores está em suas fibras, e não no fruto (MOTHE; DE ARAUJO; WANG, 2009). A Figura 9 ilustra, respectivamente, o aspecto da planta de curauá (a) e fibras extraídas das folhas (b).

Figura 9. Planta (a) e Fibras de Curauá (b).

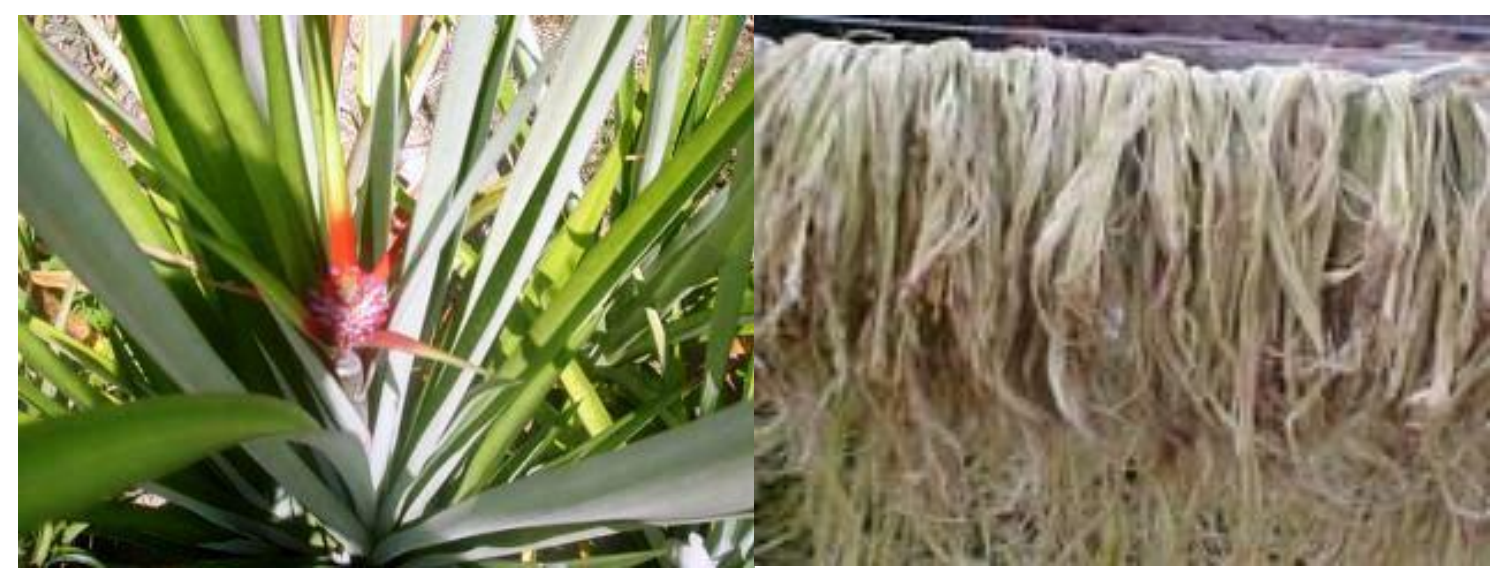

(a)

(b)

A fibra de curauá é a terceira classificada em uma análise econômica realizada no país, após sisal e juta (CASTRO COIMBRA CORDEIRO et al., 2009). Estas fibras são utilizadas pela população indígena para a confecção de redes para dormir, cordas, linhas de pesca, entre outros. Tendo em média um metro de comprimento e quatro centímetros de largura, suas folhas são duras, eretas e possuem uma superfície plana com espinhos em toda a sua extensão. Cada hectare tem cerca de dez mil plantas e cada planta produz cerca de cinquenta - sessenta folhas por ano (SATYANARAYANA; GUILMARAES; WYPYCH, 2007).

O curauá pode ser encontrado próximo aos rios Xingu, Tocantins, Tapajós, Marcuru, Trombetas, Paru, Acara e Guama, em áreas onde o índice pluviométrico é de 2000 mm/ano aproximadamente, que é o índice mínimo necessário para o cultivo da planta. Existem quatro tipos conhecidos de curauá: o branco, cujo broto possui uma coloração luminosa e várias fibras resistentes; o púrpura, o vermelho e o branco 
brilhante. As fibras são especialmente indicadas para a fabricação de barbantes e cordas finas (TRINDADE et al., 2005).

A substituição de fibras de vidro por fibras naturais, por exemplo, na indústria automobilística, pode gerar benefícios econômicos, ambientais e sociais. Há vantagens econômicas e sociais da aplicação de compósitos reforçados com fibras em peças de automóveis. Além de custar $50 \%$ menos do que fibra de vidro, a utilização de fibras de curauá pode promover o desenvolvimento regional da Amazônia (ZAH et al., 2007).

As características desta fibra vêm despertando os interesses da indústria automobilística. As fibras de curauá e outras fibras naturais misturadas com plástico podem ser usadas, por exemplo, em painéis de cabines de carro (GOMES et al., 2007a). Existe um interesse crescente no uso de fibras naturais como componentes de reforço em materiais compósitos, por serem baratas, menos abrasivas, biodegradáveis, quando comparadas com fibras inorgânicas.

No presente trabalho, o curauá foi utilizado (fibra curta, aleatoriamente distribuída na matriz) como agente de reforço de matriz termoplástica poliolefínica (BPEAD).

\subsection{Interface matriz hidrofóbica- fibra lignocelulósica hidrofílica: Compatibilização}

As fibras lignocelulósicas são higroscópicas, devido à presença de hidroxila e outros grupos polares em seus constituintes. Sua superfície é incompatível com as matrizes poliméricas apolares, o que pode levar a presença de vazios na interface ("voids"), devido às fracas interações, o que pode prejudicar as propriedades mecânicas do compósito. Portanto, muitos estudos têm sido feitos para minimizar essas deficiências e melhorar as propriedades mecânicas dos compósitos, via modificações químicas da superfície da fibra e/ou do polímero, conforme já mencionado (LEÃO; CARASCHI, 2000; EL-SABBAGH, 2014).

O desenvolvimento de uma ligação química ou interação física, na região interfacial, com a utilização de agentes compatibilizantes ou modificadores de superfície (BRIGIDA et al., 2010), promove a adesão necessária entre a fibra e a matriz, produzindo compósitos com melhores propriedades. 
George et al. (1998) estudaram o potencial de compósitos de polietileno de baixa densidade reforçados com folhas curtas de abacaxi (PALF). As propriedades mecânicas e a absorção de água dos compósitos foram estudadas para avaliar a viabilidade do uso destas fibras como reforço em PEBD. Foi utilizado como compatibilizante o silano (Figura 10), o que levou a diminuição na absorção de água na presença do produto final e a melhora da resistência à tração.

Figura 10. Estrutura química da interface para o compósito PEBD/PALF tratado com silano.

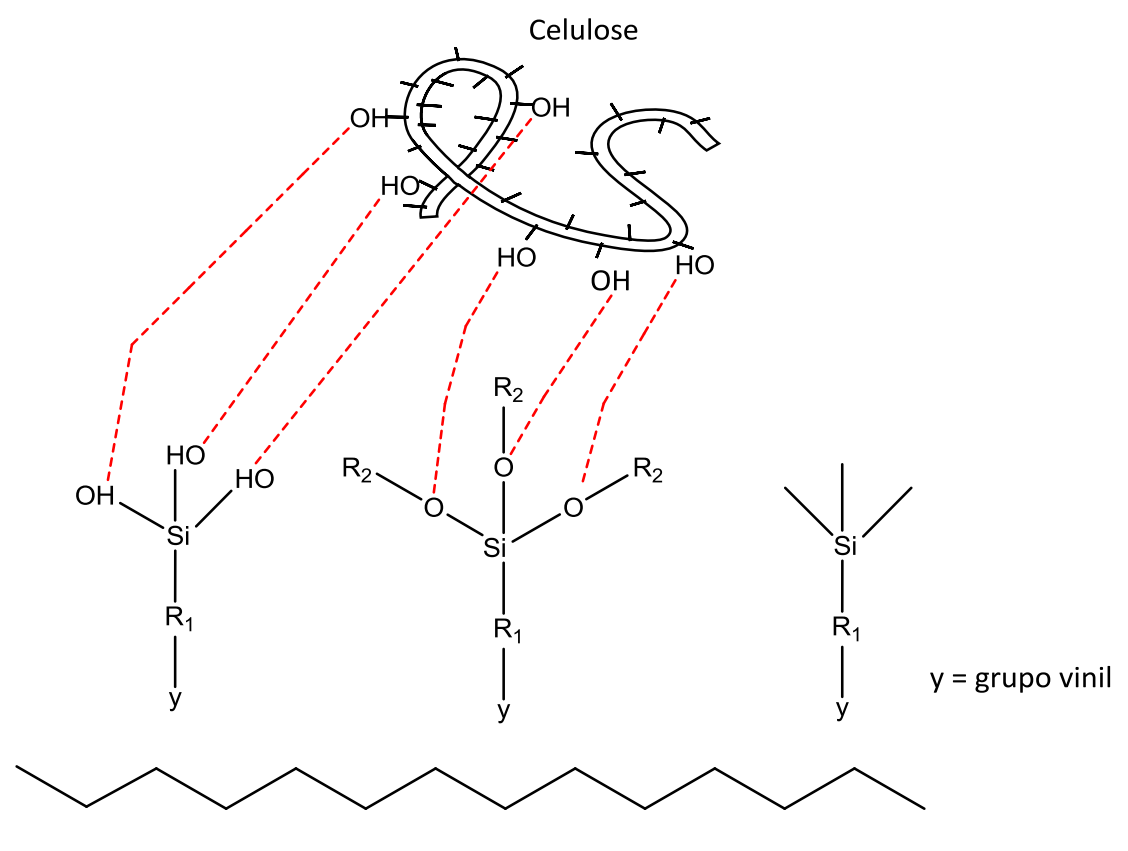

Polietileno de Baixa Densidade (PEBD)

Fonte: (GEORGE; BHAGAWAN; THOMAS, 1998).

Fibras de kenaf foram modificadas com doze diferentes combinações de isocianato e acrilato de óleo de soja epoxidado. As fibras não tratadas e tratadas foram utilizadas como reforço em compósitos de poliéster insaturado (UPE), sendo os compósitos processados por extrusão. As modificações das fibras de kenaf com agentes compatibilizantes levaram a compósitos com propriedades mecânicas significantemente melhoradas. Os compósitos de fibras de kenaf-UPE e 5\% em massa de isocianato apresentaram resistência à flexão de $153 \mathrm{MPa}$ e módulo de flexão de 12,7 GPa, enquanto o compósito sem a presença de de isocianato apresentou resistência à flexão de $121 \mathrm{MPa}$ e módulo de flexão de 11,5 GPa. Observou-se uma melhoria da adesão interfacial entre as fibras e resina através da microscopia eletrônica de varredura (REN; LI, 2013). 
A modificação consiste em uma etapa adicional na preparação dos compósitos, aumentando o custo de produção. Tendo isso em vista, um importante aspecto a ser considerado é que idealmente os reagentes utilizados nas modificações não devem ter alto custo e as modificações devem envolver compostos provenientes de fontes renováveis. Quando se trata de modificação química a utilização de reagentes obtidos de fontes não renováveis pode anular o benefício oriundo da utilização de fibras vegetais (MEGIATTO et al., 2008). Pode-se afirmar que para as modificações na superfície das fibras serem bem sucedidas devem ser eficazes e de baixo custo, a fim de gerar produtos também de baixo custo e com boas propriedades. Caso contrário, a partir de um ponto de vista econômico, a substituição dos sintéticos por fibras naturais não serão de interesse, pois as fibras vegetais em geral, têm baixa resistência se comparada às fibras sintéticas (LEÃO; CARASCHI, 2000).

Neste contexto se insere o presente estudo, que tem como um dos objetivos melhorar a interação entre fibra e matriz, usando principalmente agentes obtidos a partir de biomassa.

Assim, com o objetivo de melhorar o desempenho dos compósitos reforçados com as fibras de curauá, óleos vegetais foram usados. Óleo de mamona (CO), óleo de canola (CA), óleo de linhaça epoxidado (OLE) e óleo de soja epoxidado (OSE) foram adicionados ao BPEAD, para que atuassem como agente compatibilizante. $O$ objetivo final consistiu em preparar compósitos usando matérias primas obtidas a partir de recursos renováveis (BPEAD, curauá, óleos vegetais).

\section{4 Óleos Vegetais}

Nos últimos anos, óleos naturais têm atraído atenção como matéria-prima para a preparação de resinas e materiais poliméricos, visando substituir os tradicionais polímeros de origem fóssil. Óleos vegetais correspondem a produtos químicos importantes, devido à sua disponibilidade universal e baixo custo (SHARMA; KUNDU, 2006).

Os óleos vegetais são substâncias insolúveis em água, formados predominantemente por ésteres de triacilgliceróis, produtos resultantes da esterificação entre o glicerol e ácidos graxos. Além de triacilgliceróis, os óleos contêm 
vários componentes em menor proporção, como mono e diglicerídeos (importantes como emulsionantes), ácidos graxos livres, tocoferol (importante antioxidante), proteínas, esteróis e vitaminas.

A composição de ácidos graxos nos óleos vegetais varia, dependendo da planta, da colheita, da estação, e das condições de crescimento. A Tabela 2 apresenta a composição química de alguns óleos vegetais em porcentagem dos principais ácidos graxos e a Tabela 3 mostra a estrutura molecular dos mesmos.

Tabela 2. Composição química de óleos vegetais em porcentagem de ácido graxo.

\begin{tabular}{ccccc}
\hline Ácido graxo & Linhaça (\%) & Soja (\%) & Mamona (\%) & Canola (\%) \\
\hline Palmítico & 6 & $7-14$ & 1,5 & $2,5-6,5$ \\
Esteárico & 4 & $1,4-5,5$ & 0,5 & $0,8-3$ \\
Ricinoléico & 0 & 0 & 89,5 & 0 \\
Oléico & $13-37$ & $19-30$ & 5,0 & $53-70$ \\
Linoléico & $2-23$ & $44-62$ & 4,0 & $15-30$ \\
Linolênico & $26-58$ & $4-11$ & 0,5 & $5-13$ \\
\hline \multicolumn{5}{r}{} \\
\hline
\end{tabular}

Tabela 3. Fórmula molecular dos principais ácidos graxos presentes na composição de óleos vegetais.

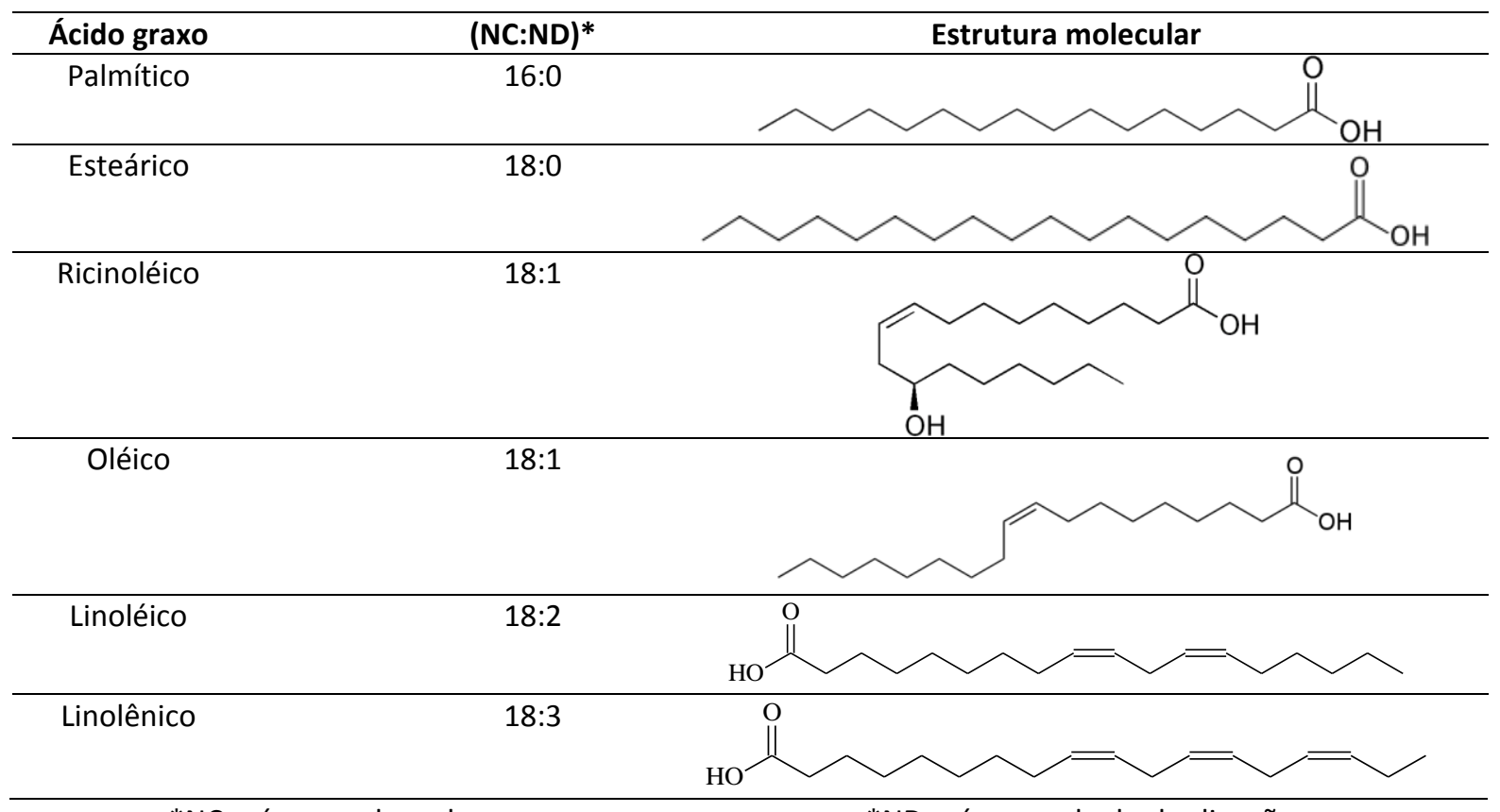

*NC: números de carbonos

*ND: números de duplas ligações

Fonte: (COSTA et al., 2004; MILINSK, 2007). 
Como pode ser observado nas Tabela 2 e 3, os ácidos graxos, constituintes dos triglicerídeos, diferem entre si pelo tamanho da cadeia carbônica e número de ligações duplas. Os óleos vegetais mais comuns possuem de 14 a 22 carbonos e podem ser saturados ou insaturados.

As diferenças funcionais entre os ácidos graxos presentes na composição dos óleos vegetais determinam as diferenças entre as propriedades destes óleos, tais como, ponto de fusão, calor específico, viscosidade, solubilidade e reatividade química.

Os óleos vegetais podem atuar como agentes compatibilizantes em compósitos de matriz poliolefínica e fibra lignocelulósica como reforço, pois apresentam cadeias hidrocarbônicas, com afinidade por polímeros como o polietileno, e grupos hidroxilas com afinidade por grupos presentes nas fibras lignocelulósicas.

O óleo de mamona (CO) é um líquido viscoso obtido por um processo de prensagem das sementes da planta Ricinus communis, e é constituído principalmente por cerca de 89,5 \% de ácido ricinoléico (Tabela 3). O grupo hidroxila confere ao óleo de mamona a propriedade de álcool que é estável em diversas condições de pressão e temperatura, atóxico, dentre outras características (COSTA et al., 2004).

As aplicações do óleo são inúmeras, sendo utilizado como lubrificante na aeronáutica, como base na manufatura de cosméticos e de muitos tipos de drogas farmacêuticas (COSTA et al., 2004).

O nome canola é derivado de CANadian Oil Low Acid, a primeira variedade de canola foi chamada Tower, lançada em 1974, foi desenvolvida por pesquisadores canadenses através do cruzamento de duas plantas encontradas na natureza (GHAZANI; MARANGONI, 2013).

A Canola (Brassica napus L. e Brassica rapa L.) é uma planta da família das crucíferas (mesma do repolho e das couves). Embora ainda pouco semeada no Brasil, em 2006 apenas 33 mil hectares, mundialmente, é a terceira planta oleaginosa mais produzida. Os grãos de canola produzidos no Brasil possuem de 24 a 27 \% de proteína e em média $38 \%$ de óleo. Dos grãos de canola, além de óleo, usado para consumo humano ou para produção de biodiesel, se extrai o farelo, que possui de 34 a $38 \%$ de proteínas, sendo utilizada na formulação de ração para animais (GHAZANI; MARANGONI, 2013). 
A composição química do óleo de canola depende das condições ambientais e do método de extração. Em geral, o óleo de canola contém 5-13\% de ácido linolênico, 53-70\% de ácido oléico (Tabela 2).

A insaturação característica dos óleos vegetais pode ser utilizada para introduzir vários grupos funcionais importantes. Entre eles, os derivados epoxidados são altamente desejáveis, podem ser utilizados como plastificantes do PVC, intermediários para a produção de poliuretanos, detergentes sintéticos e revestimentos. Os epóxidos podem também ser utilizados como lubrificantes de altas temperaturas, e os produtos obtidos a partir da abertura de anel podem ser utilizados como lubrificantes. Assim, a epoxidação catalítica de olefinas de cadeia longa, tais como óleo de soja e correlatos, tem sido objeto de várias investigações acadêmicas e industriais (FARIAS; MARTINELLI; ROLIM, 2011).

Os epóxidos apresentam elevada reatividade, devido à sua tensão conformacional, que é aliviada por ataques nucleofílicos ao carbono da ligação C-O causando a quebra das mesma e consequente abertura do anel. Esta reatividade diferenciada torna os epóxidos substâncias de grande interesse sintético (FOGASSY et al., 2011).

O óleo de linhaça e de soja epoxidados são produzidos pela epoxidação de óleos vegetais, sendo que esta reação emprega, em geral, peróxido de hidrogênio ou ácido peracético.

A reação de epoxidação de alceno com uso de peróxido de hidrogênio é mostrada na Figura 11:

Figura 11. Reação de epoxidação de alceno.

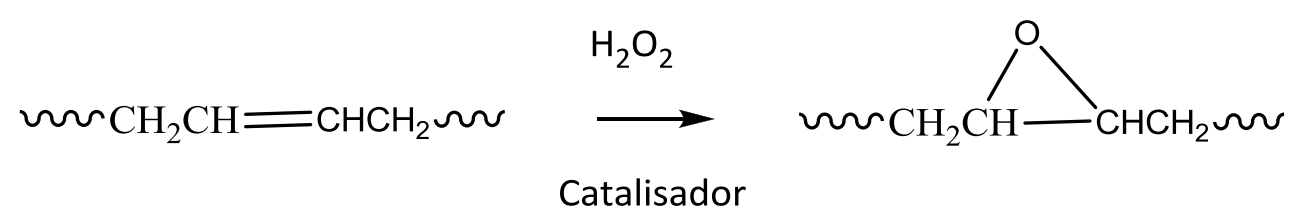

Este mesmo processo pode ser empregado para outras fontes de ácidos graxos, por exemplo, os demais óleos vegetais insaturados e até as gorduras de origem animal. Gamage et al. (2009), em seu estudo, desenvolveram a epoxidação do éster do óleo de neem (um extrato vegetal obtido a partir dos frutos e sementes de nim "Azadirachta 
indica") com a obtenção de um plasticicante que apresentou grande interesse comercial e técnico ao mercado do PVC.

Figura 12. Fórmula estrutural do OSE.

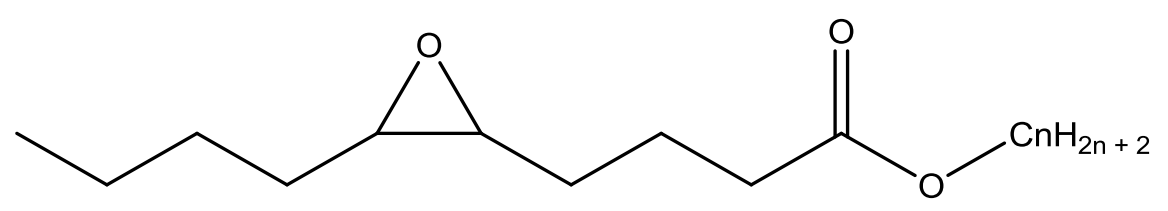

O óleo de linhaça é destinado a aplicações em formulações de compostos de PVC, usado na confecção de embalagens dos segmentos alimentícios e farmacêuticos.

O óleo de soja (Figura 12) é destinado aos compostos de PVC flexíveis com finalidade de garantir a flexibilidade mesmo a baixas temperaturas.

A União Internacional de Química Pura e Aplicada (International Union of Pure and Applied Chemistry, IUPAC) define um plastificante como uma substância ou material incorporado em um material (usualmente um plástico ou elastômero) para aumentar sua flexibilidade, trabalhabilidade, ou distensibilidade (GODWIN, 2011).

Neste texto, as discussões envolvendo possíveis ações de plastificantes seguirão esta definição da IUPAC.

Destaca-se que a definição da IUPAC para plastificante não relaciona a ação do mesmo com propriedades do material polimérico como transição vítrea, embora seja possível observar uma diminuição nesta temperatura, assim como na viscosidade do material fundido, ou no módulo elástico do material (GODWIN, 2000).

Plastificantes diferem de lubrificantes, embora ambos atuem no sentido de diminuir a resistência à movimentação dos segmentos de uma cadeia polimérica. Um plastificante é usado em quantidades consideravelmente superiores àquelas do lubrificante, e promovem mudanças perceptíveis em propriedades do material polimérico, enquanto que o mesmo não ocorre com lubrificantes. Alguns plastificantes podem atuar como lubrificantes, quando usados em quantidade consideravelmente reduzida, comparativamente ao uso como plastificante (GROSSMAN, 2001).

O uso de plastificantes no PVC é conhecido desde os anos 50, sendo empregados em vários produtos, como filmes alimentícios, mangueiras, laminados, 
brinquedos e calçados, sendo os da família dos ftalatos de maior uso mundial. Porém, alguns ftalatos apresentam restrição de uso para algumas aplicações. Desta forma, muitos trabalhos buscam por plastificantes alternativos aos ftalatos no mercado mundial. Assim, muitos estudos utilizam óleos vegetais epoxidados como plastificantes do PVC (MUELLER; YAMASHITA; LAURINDO, 2008).

Schlemmer et al. (2010) utilizaram óleos vegetais (buriti, macaúba e pequi) do Cerrado brasileiro como plastificantes de filmes de amido termoplástico. Os resultados sugeririam que os óleos vegetais do Cerrado brasileiro são recursos naturais que podem ser usados como alternativa para a produção de materiais e apresentaram um bom efeito plastificante para o amido. Os filmes obtidos foram homogêneos e apresentaram boas propriedades térmicas.

As introduções de uma pequena quantidade de óleo, como óleo de mamona e óleo de soja epoxidado como segunda fase à matriz, podem atuar como agente compatibilizante, já que as cadeias hidrocarbônicas têm afinidade com o polietileno e os grupos hidroxilas podem interagir com os grupos polares presentes nas fibras lignocelulósicas (Figuras 13 e 14).

Figura 13. Representação esquemática das interações entre os componentes dos compósitos (CO-Fibra) e (CO- BPEAD).

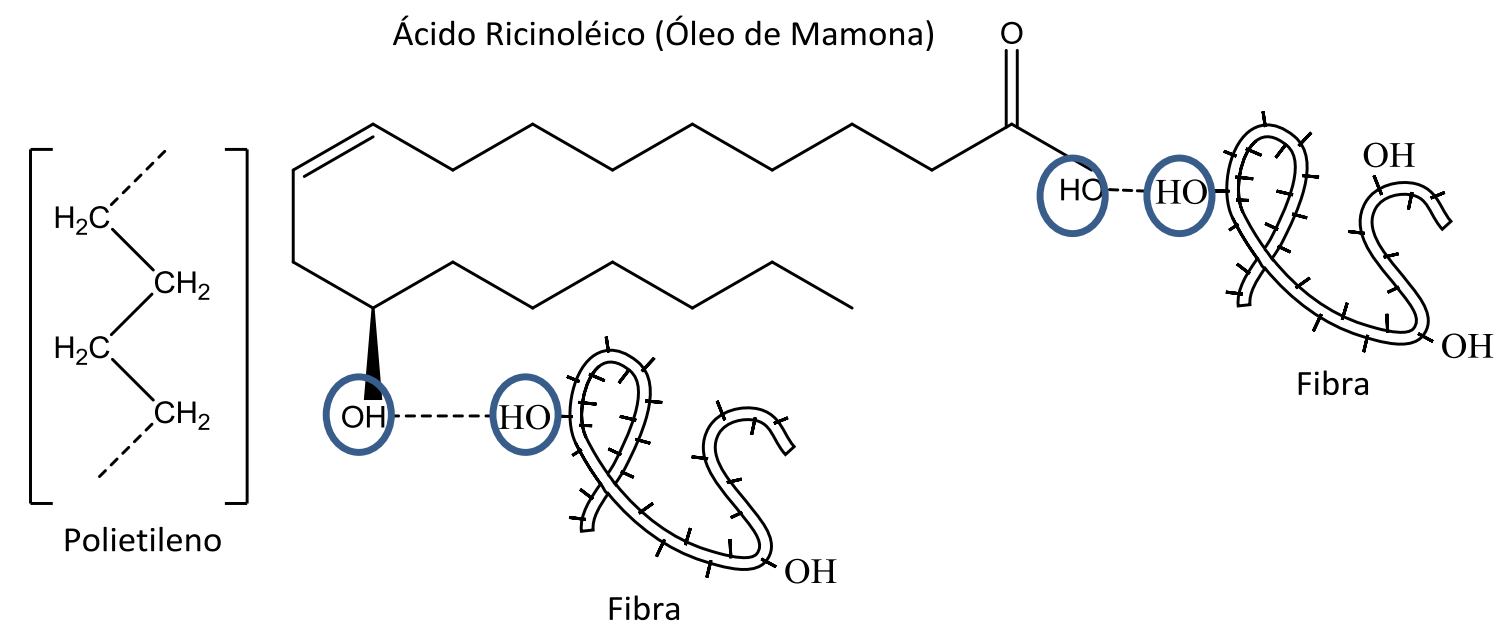


Figura 14. Representação esquemática das interações entre os componentes dos compósitos (OSEFibra) e (OSE- BPEAD).<smiles>CCCCCCCCCCCCC</smiles>

Polietileno

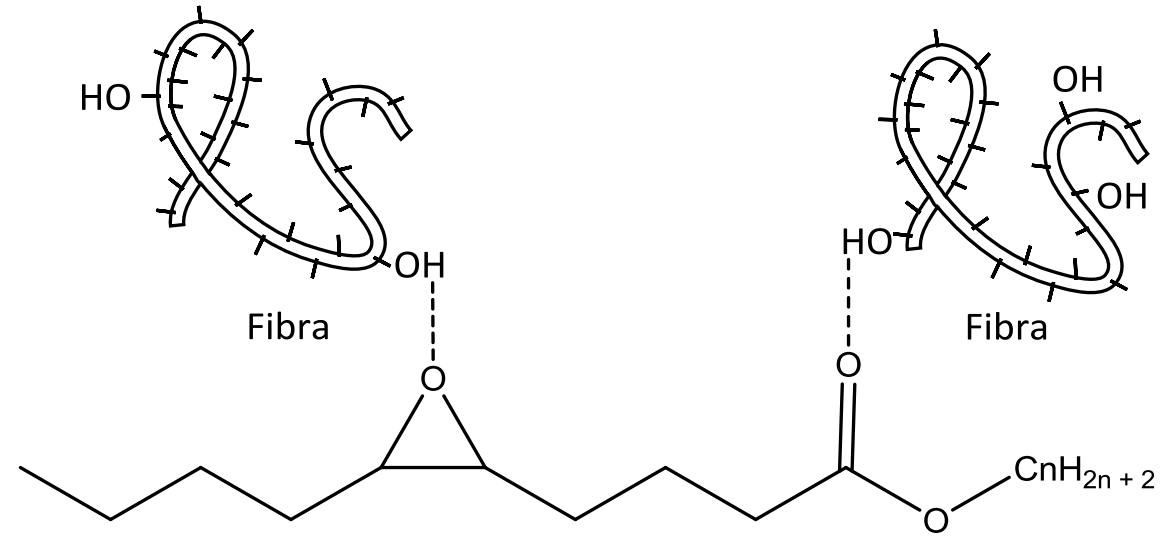

Óleo de Soja Epoxidado

Além das interações intermoleculares que podem ocorrer entre os grupos polares presentes na superfície das fibras lignocelulósicas com os grupos polares presentes nos óleos vegetais, devido à elevada reatividade do epóxido presente no óleo de soja, o grupo hidroxila presente na superfície das fibras pode agir como um nucleófilo e promover a abertura do anel epóxido (Figura 15).

Figura 15. Mecanismo de abertura do epóxido.

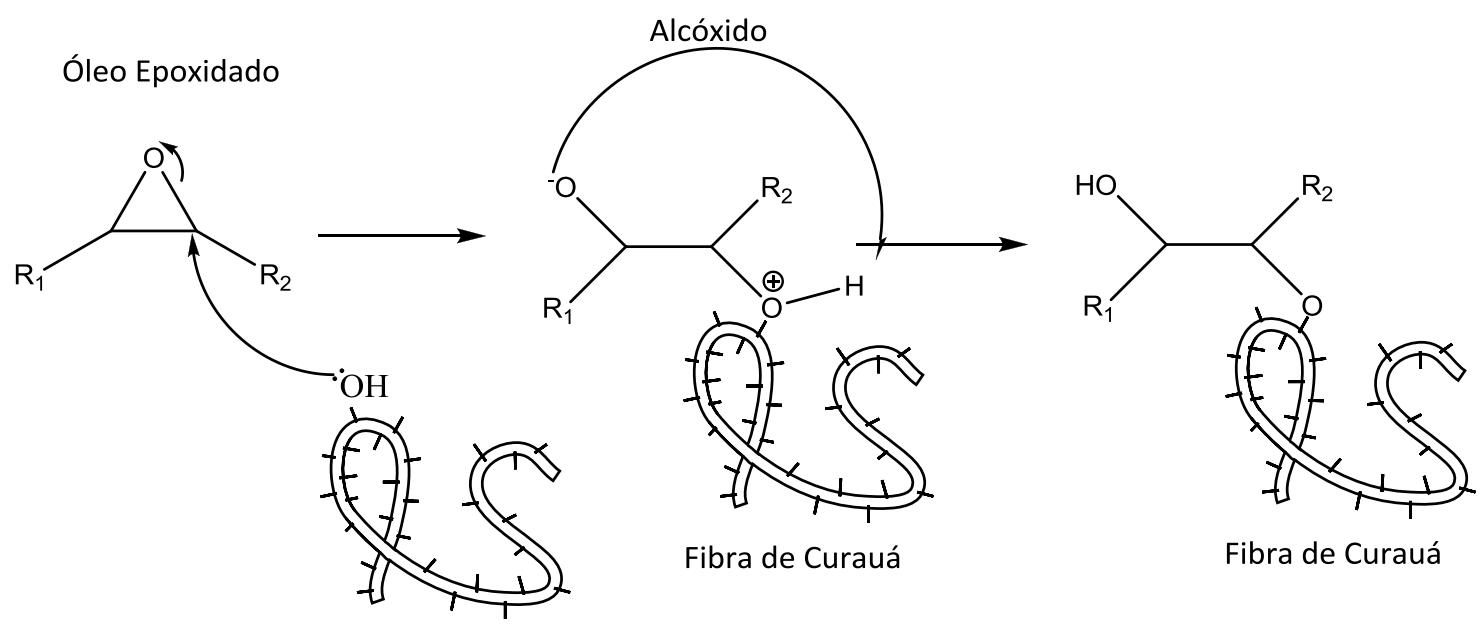

Fibra de Curauá

No presente trabalho, buscou-se uma alternativa às mudanças estruturais no polímero e/ou fibra. Modificações químicas podem significar um aumento nos custos do processamento e/ou a piora nas propriedades mecânicas da fibra conforme já 
mencionado. Assim, neste estudo, óleos de origem natural foram empregados, os quais podem atuar como compatibilizantes fibra/matriz, devido à presença de grupos polares nestes aditivos, tornando-os capazes de estabelecer interações tanto com as fibras de curauá quanto com a matriz de BPEAD.

Em estudos anteriores foi avaliado o efeito da adição de PBHL (polibutadieno hidroxilado líquido) em compósitos de biopolietileno reforçados com fibras de curauá. Este estudo teve como objetivo a redução da propagação de trincas durante o ensaio de impacto dos compósitos. Verificou-se também a atuação como agentes compatibilizantes do PBHL, uma vez que o PBHL possui cadeias hidrocarbônicas com afinidades com o biopolietileno, e grupos hidroxilas com afinidades com os grupos polares presentes nas fibras lignocelulósicas. Neste estudo foi possível concluir que a adição de PBHL levou a uma melhor adesão e distribuição das fibras na matriz termoplástica. Assim, houve uma melhora nas propriedades mecânicas destes compósitos, particularmente na resistência ao impacto, comparativamente ao compósito preparado sem PBHL (CASTRO; RUVOLO-FILHO; FROLLINI, 2012).

\subsection{Processamento de Compósitos}

Os polímeros passam por uma ou mais fases de processamento para chegar ao seu formato final. Durante o processamento, estão sujeitos às variações de temperatura, ao esforço de cisalhamento e a exposição ao oxigênio. O tempo e o grau de aplicação de cada um destes efeitos dependem do método de processamento ao qual o material é submetido (DE PAOLI, 2008).

De um modo geral, classifica-se o processamento de termoplásticos como: termoformagem, moldagem por compressão, calandragem, extrusão, extrusão e sopro, injeção, injeção seguida de sopro e rotomoldagem (DE PAOLI, 2008).

Há uma ampla variedade de equipamentos de mistura que podem ser utilizados para preparação de compósitos celulósicos termoplásticos, como os considerados no presente estudo, tais como misturadores internos e extrusoras de rosca simples ou dupla. Para o processamento, a umidade da fibra deve ser removida, o que pode ser feito num processo de secagem em estufa (SANTOS et al., 2007). 
A temperatura de processamento é um fator extremamente importante para o estabelecimento das condições ótimas. Em temperaturas acima de $160^{\circ} \mathrm{C}$, e na presença de oxigênio, as fibras podem sofrer termo-oxidação levando ao escurecimento, e acima de $230^{\circ} \mathrm{C}$ ocorre decomposição térmica da mesma, com consequente perda de propriedades (IANNACE; ALI; NICOLAIS, 2001).

Neste trabalho, para a preparação de compósitos de matriz BPEAD reforçada com fibra de curauá, foi utilizado um misturador interno acoplado a um reômetro de torque Haake, sendo os materiais finais obtidos via termoprensagem. A fim de comparar a influência da forma de processamento nas propriedades dos compósitos, estes também foram processados em extrusora dupla rosca, sendo os corpos de prova injetados.

\subsubsection{Reometria de Torque}

O reômetro de torque (Figura 16) é um equipamento que reproduz, em menor escala, as geometrias dos equipamentos utilizados industrialmente no processamento de polímeros (ANUAR et al., 2008).

Figura 16. Misturador interno acoplado ao reômetro de torque Haake.

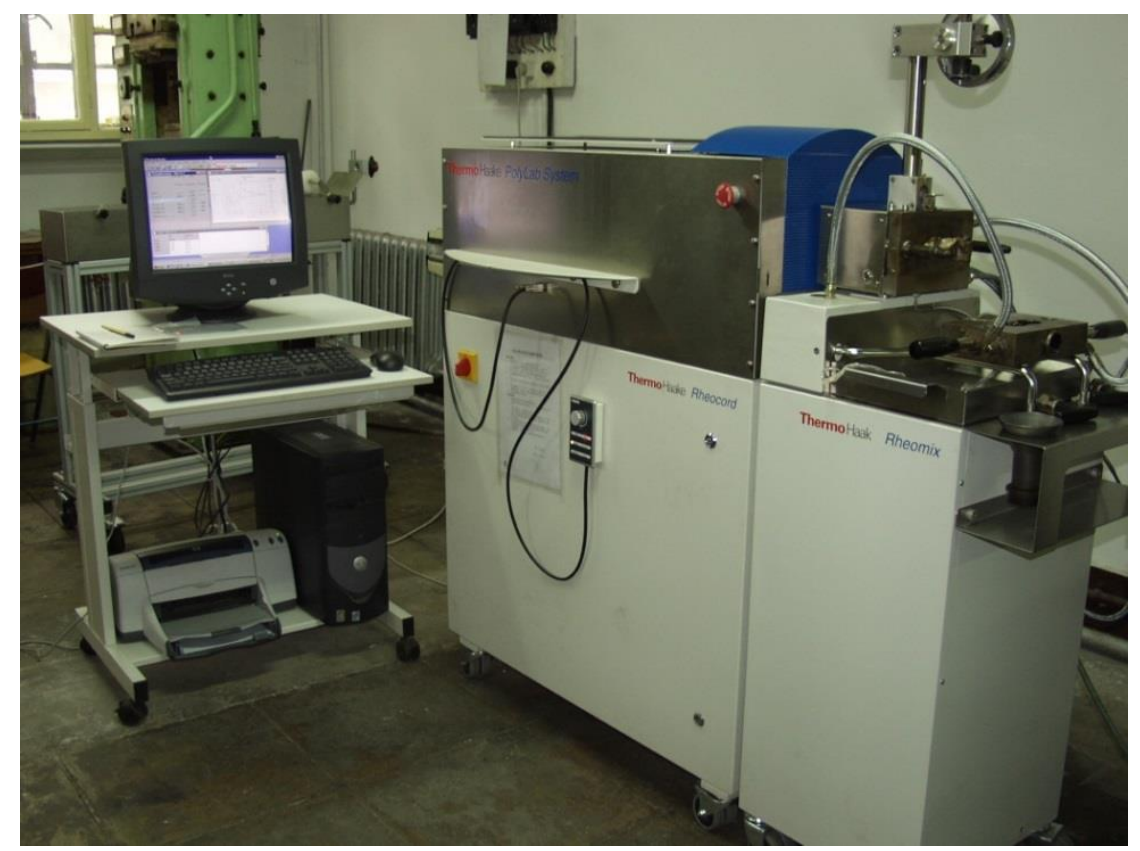

Fonte: disponível em <http://www.dema.ufscar.br/> 
Este reômetro é acoplado a uma câmara misturadora, na qual são inseridos dois rotores. Os rotores giram a uma velocidade constante, e o torque necessário para manter essa velocidade é medido (Figura 17). As medidas podem ser feitas isotermicamente ou sob uma rampa de temperatura. Assim, na câmara misturadora ocorre a mistura do polímero fundido com a fibra natural, com o monitoramento do torque e da temperatura em função do tempo. Ao longo de cada processamento, curvas de torque e de temperatura em função do tempo de mistura são registradas, com a finalidade de se avaliar o comportamento de fluxo da mistura. A área sob as curvas de torque podem ser relacionadas à energia absorvida pelo material durante 0 processamento, permitindo analisar o comportamento reológico do material (o qual está relacionado à viscosidade do material fundido)(PEARSON, 1985).

Figura 17. Representação esquemática do corte transversal do misturador interno.

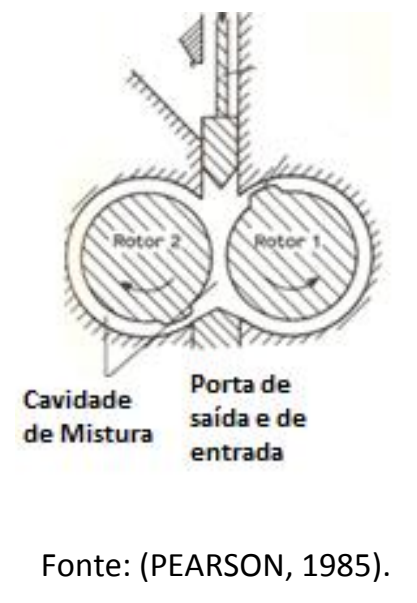

Trata-se de um método de processamento vantajoso, pois fornece respostas imediatas, sobre variação do torque e da temperatura em função do tempo, utilizando volume menor de amostra quando comparado com o processamento em extrusora (ANUAR et al., 2008).

Neste trabalho, a reometria de torque foi considerada no processamento de compósitos, usando-se um misturador interno acoplado a um reômetro de torque Haake. 


\subsubsection{Extrusão}

Para compósitos termoplásticos reforçados com fibra natural, o processo de extrusão é o mais reportado em artigos científicos e também muito utilizado nas indústrias (MORTON-JONES, 1989; KARNANI; KRISHNAN; NARAYAN, 1997; OKSMAN; SKRIFVARS; SELIN, 2003; FARUK et al., 2014). As extrusoras podem ser classificas da seguinte maneira:

- Extrusora Mono-Rosca: Possui apenas uma rosca com elementos de transporte e alguns pontos de amassamento.

- Extrusora Dupla-Rosca Co-Rotante: Possui duas roscas com o mesmo sentido de rotação, são indicadas para mistura e produção de perfis em que elevados índices de produtividade são necessários.

- Extrusora Dupla-Rosca Contra-Rotante: Possui um par de roscas sem fim e com sentido de rotação contrário.

Neste estudo, utilizou-se uma Extrusora Dupla-Rosca Co-Rotante, já que esta apresenta uma mistura mais eficiente, se comparada a Extrusora Mono-Rosca e a Extrusora Dupla-Rosca Co-Rotante, devido a maior alternância de fluxo de uma rosca para outra (MORTON-JONES, 1989).

Os fatores que mais influenciam a extrusão de compósitos termoplásticos estão relacionados com a umidade presente durante o processamento, à temperatura utilizada e a velocidade de rotação da rosca (BLEDZKI; GASSAN, 1999).

A técnica de extrusão foi usada no presente trabalho, no processamento dos compósitos de BPEAD reforçado por fibras de curauá.

\subsection{Nanocompósitos}

No presente estudo, nanocompósitos também foram considerados. Estes materiais correspondem a uma classe de compósitos cujos reforços possuem pelo menos uma dimensão em escala nanométrica $\left(10^{-9} \mathrm{~m}\right)$ e, consequentemente, elevada razão de aspecto. Dessa forma, maior será a área superficial de contato com a matriz polimérica, se comparado ao reforço com dimensões na escala macro e, se as 
interações interfaciais forem positivas, maior será o reforço proporcionado (SIQUEIRA; BRAS; DUFRESNE, 2010a).

Durante a última década, os nanocompósitos têm atraído grande atenção da comunidade científica e industrial, uma vez que apresentam a possibilidade de significativa melhoria nas propriedades mecânicas, de processabilidade, de estabilidade térmica e biodegradabilidade em comparação aos polímeros puros e aos compósitos tradicionais (GRUNERT; WINTER, 2002; DURAN; LEMES; SEABRA, 2012; ZHANG et al., 2014).

Os nanocompósitos poliméricos geralmente envolvem baixo teor de nanopartículas dispersas, já que não é necessário utilizar elevadas quantidades de enchimento para obter boas propriedades mecânicas. Assim, as nanopartículas em geral são consideradas excelentes possibilidades para o desenvolvimento de compósitos de alto desempenho (SIQUEIRA; BRAS; DUFRESNE, 2010a).

O uso de nanopartículas de celulose como reforço em nanocompósitos é uma área de interesse relativamente nova. Além do baixo custo da matéria-prima, o uso de nanopartículas de celulose como uma fase de reforço em nanocompósitos apresenta inúmeras vantagens bem conhecidas, por exemplo, a baixa densidade, natureza renovável, boas propriedades mecânicas, baixo consumo de energia, biodegradabilidade e superfície relativamente reativa, que pode ser usada para enxertia de grupos específicos. Para aplicações como reforço, as nanopartículas de celulose apresentam algumas desvantagens, por exemplo, uma elevada absorção de umidade, incompatibilidade com a maioria das matrizes poliméricas e limitação da temperatura de processamento (WAMBUA; IVENS; VERPOEST, 2003; TSERKI et al., 2005), devido à decomposição térmica de celulose.

Outra importante desvantagem relacionada com a utilização de nanocristais em nanocompósitos corresponde à dificuldade para dispersar as nanopartículas em meios não polares, devido a sua superfície polar (OKSMAN et al., 2006).

\subsubsection{Nanocompósitos de Matriz Termoplástica}

Materiais poliméricos são considerados indispensáveis à vida moderna, no entanto, devido ao contínuo desenvolvimento de novas tecnologias, torna-se cada vez 
mais difícil encontrar um polímero que possua todas as características necessárias para uma determinada aplicação, seja devido às propriedades mecânicas, formas de obtenção ou custo (RAMIRES; DE OLIVEIRA; FROLLINI, 2013).

A obtenção de nanocompósitos de polietileno/NCC ainda é um grande desafio, uma vez que as poliolefinas são hidrofóbicas e há carências de interações apropriadas com a superfície polar do NCC.

$\mathrm{Na}$ literatura alguns trabalhos são encontrados cujos objetivos se relaciona ao desempenho de nanocristais de celulose como reforço em nanocompósitos de matriz termoplástica.

De Menezes et al. (2009) avaliaram a modificação da superfície dos nanocristais de celulose através da graftização com cloretos de ácidos orgânicos. Estes nanocristais foram posteriormente utilizados como reforço de matriz de polietileno de baixa densidade (PEBD) na produção dos bionanocompósitos. As propriedades termomecânicas dos nanocompósitos foram avaliadas por calorimetria exploratória diferencial (DSC), análise térmica dinâmico-mecânica (DMA) e ensaios de tração. Uma melhoria significativa em termos de alongamento na ruptura foi observada quando nanopartículas graftizadas foram utilizadas, atribuída à melhoria da dispersão das nanopartículas na matriz de PEBD em comparação com nanopartículas sem modificação.

Khoshkava et al. (2013) observaram a interação de celulose nanocristalina (NCC) modificada com anidrido succínico com polipropileno (PP) e poli (ácido lático) (PLA) como matrizes. Uma investigação termodinâmica foi realizada para estimar a energia de dispersão, com base em medições da energia de superfície às temperaturas ambiente e elevada. A modificação da superfície do NCC apresentou um efeito negativo sobre a compatibilidade entre os NCCs e o PLA, por outro lado, teve uma influência positiva sobre a compatibilidade entre o PP e o NCCs.

BPEAD foi usado no presente trabalho para preparar nanocompósitos de matriz polimérica termoplástica reforçada com nanocristais. 


\subsection{Nanocristais}

Os materiais celulósicos podem ser extraídos de diversas espécies de plantas. Através da extração pode-se isolar a celulose microcristalina, a celulose nanofibrilada e os nanocristais ou nanowhiskers de celulose.

As principais etapas envolvidas na preparação dos nanocristais de celulose e da celulose microfibrilada são apresentas na Figura 18, embora existam outros métodos de preparação descritos na literatura (ANDRESEN; STENIUS, 2007; BRAUN; DORGAN; CHANDLER, 2008). As fibras são primeiramente moídas e, em seguida, submetidas a tratamentos alcalinos e branqueamento com $\mathrm{NaClO}_{2}$. Estas medidas permitem à eliminação de lignina e hemicelulose. Assim, as fibras branqueadas, constituidas majoritariamente por celulose, estão prontas para serem hidrolisadas (hidrólise ácida) ou desintegradas (agitação mecânica a alta pressão) (BRITO et al., 2012).

Figura 18. Principais etapas envolvidas na preparação de nanocristais e de celulose microfibrilada.

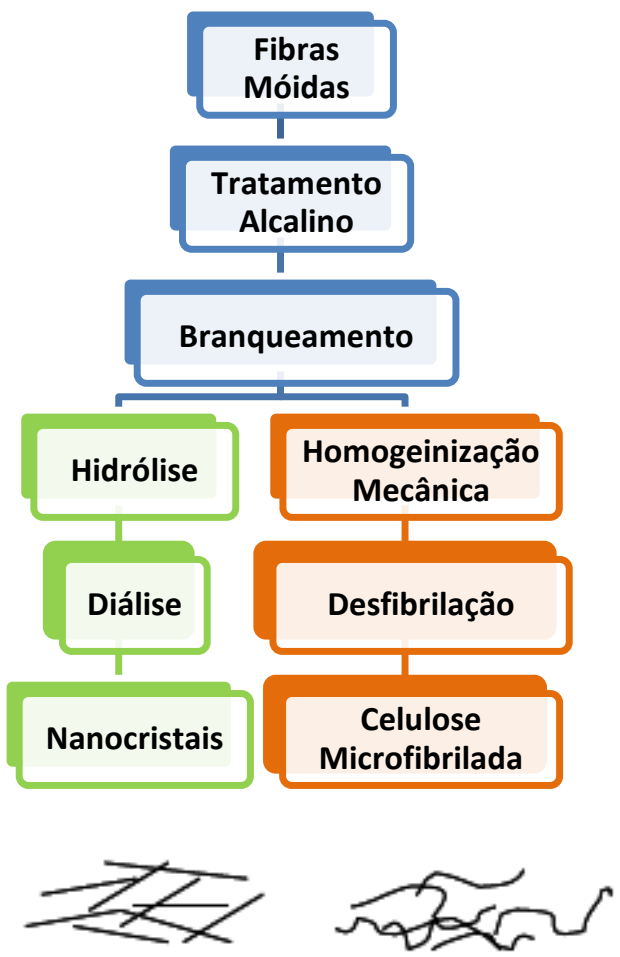

Fonte: (SIQUEIRA; BRAS; DUFRESNE, 2010a). 
Sob condições controladas, a hidrólise ácida consiste na reação com cadeias principalmente presentes nas regiões não cristalinas, que envolvem e permeiam as microfibrilas de celulose, enquanto os domínios cristalinos são preservados nos estágios iniciais da reação. Na hidrólise ácida, íons hidrônio podem penetrar entre as cadeias de celulose nas regiões não cristalinas, promover a clivagem hidrolítica de ligações glicosídicas e isolar as estruturas cristalinas no formato acicular, denominados nanocristais de celulose (BECK-CANDANEDO; ROMAN; GRAY, 2005).

Ranby et al. (1951) e Battista et al. (1962) foram os pioneiros a produzirem suspensões coloidais estáveis de celulose cristalina por hidrólise ácida, a partir da celulose da madeira e do algodão.

Dong et al. (1998) foram os primeiros pesquisadores a estudar o efeito das condições de hidrólise sobre as propriedades dos nanocristais de celulose. Mostraram que o maior tempo de hidrólise conduz a cristais mais curtos e também a um aumento de cargas na suspensão aquosa, devido à presença de grupos sulfatos na superfície dos NCCs, provenientes de reações entre grupos hidroxila da celulose e o ácido sulfúrico (Figura 19).

A estabilidade das suspensões aquosas dos NCCs depende da dimensão das partículas suspensas e da sua polidispersividade, assim como da carga superficial presente nas mesmas. Segundo Samir et al.(2005), NCCs extraídos através de hidrólise ácida feita com ácido sulfúrico formam suspensões aquosas mais estáveis do que aqueles obtidos a partir de ácido clorídrico, devido à presença de cargas negativas na superfície dos NCC (grupos sulfato), que levam a estabilidade, decorrente das forças de repulsão entre elas (Figura 19). Porém essa individualização dos NCCs é muito difícil de ser mantida após a secagem dos mesmos, uma vez que as fortes ligações hidrogênio existentes favorecem a aglomeração dos mesmos. A introdução de grupos sulfato tende a comprometer a estabilidade térmica dos NCCs, pois sob aquecimento pode ocorrer dessulfatação e a degradação dos NCC pode ocorrer a temperaturas inferiores, comparativamente à situação em que este grupos estão presentes (TAIPINA; FERRAREZI; GONCALVES, 2012).

Putaux et al. (2003) avaliaram a hidrólise ácida de nanocristais de celulose com ácido clorídrico e obtiveram NCC termicamente mais estáveis se comparados aos NCC 
obtidos através da hidrólise com ácido sulfúrico, no entanto, não houve a formação de uma suspensão estável.

O primeiro estudo envolvendo a análise do efeito da adição de nanocristais de celulose como reforço em materiais nanocompósitos foi realizado por Favier et al. (1995). Um notável aumento no módulo de armazenamento pode ser observado quando o copolímero de estireno e acrilato de butila (poli(S-co-BuA)) foi reforçado com as nanopartículas, mesmo em baixas concentrações. $O$ excelente efeito de reforço dos whiskers de celulose foi atribuído ao fenômeno de percolação. Acima do chamado "limiar de percolação", os NWCs se conectam, formando uma estrutura tridimensional continua ao longo do material, resultado das fortes interações entre os NWCs.

Figura 19. Representação da inserção do grupo sulfato proveniente da hidrólise com ácido sulfúrico na cadeia de celulose.
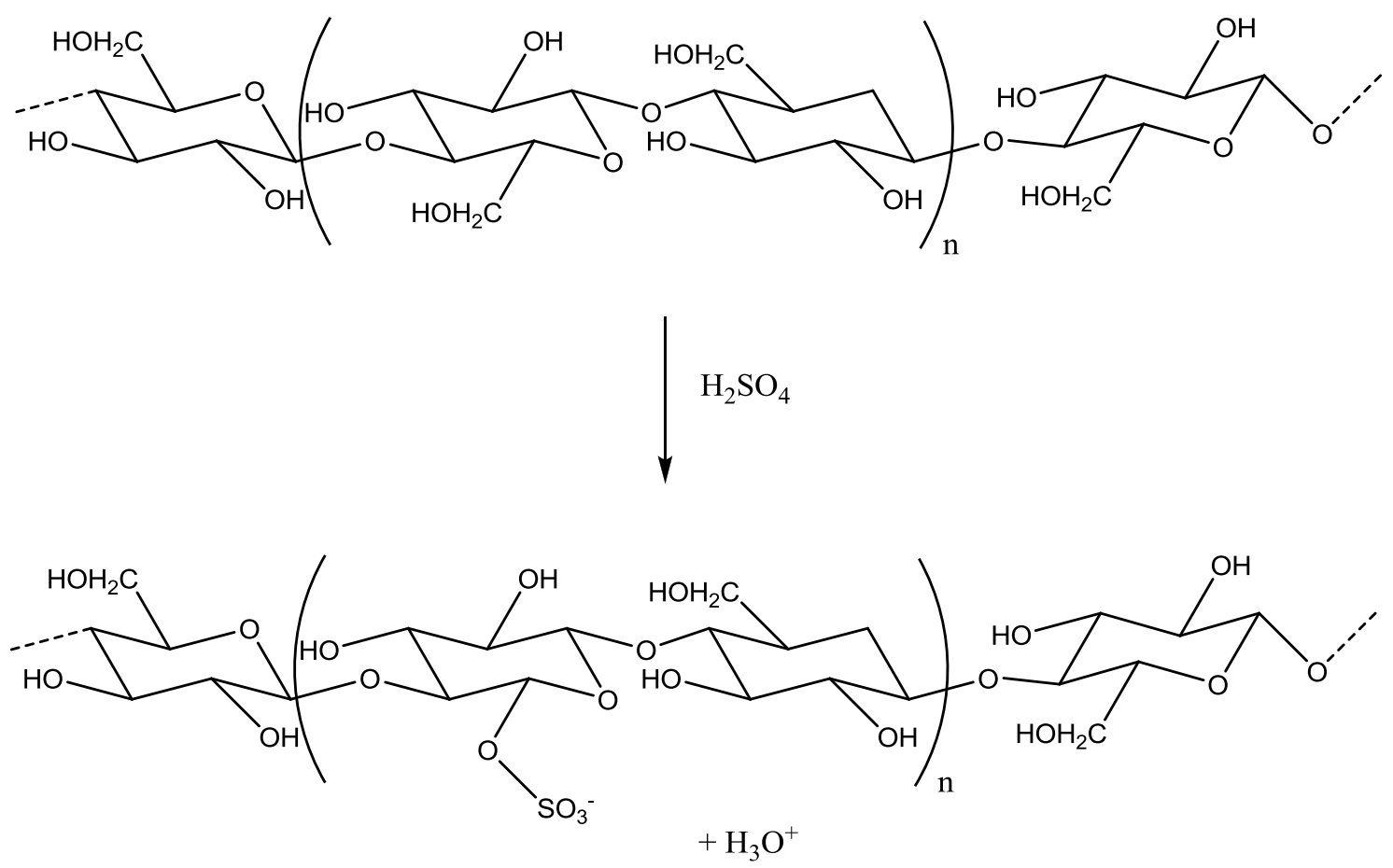

Fonte: (TAIPINA; FERRAREZI; GONCALVES, 2012).

Wang et al. (2008) avaliaram o efeito da obtenção de nanocristais de celulose utilizando ácido sulfúrico, ácido clorídrico e ultrassom. A combinação de ácidos foi utilizada com o objetivo da obtenção de NCCs mais estáveis e também termicamente mais resistentes. No entanto, os NCCs obtidos apresentaram morfologia esférica, o 
que pode estar associado com a maior interação destes com o ácido, que promove a hidrólise no interior da estrutura da celulose.

Filson et al. (2009) demonstraram que é possível a utilização da hidrólise enzimática, seguida por ultrassom para obter nanofibras de celulose a partir de polpa reciclada. Eles usaram uma mistura de enzimas multicomponentes com atividade predominantemente endoglucanase (Celluclast L, Novozymes) e observaram a influência de condições experimentais, tais como temperatura, que influencia na geometria e polidispersividade dos NCCs e $\mathrm{pH}$, que pode aumentar a eficiência das enzimas para um maior rendimento dos nanocristais. Estes nanocristais tiveram largura entre 30 e $80 \mathrm{~nm}$ e comprimento de $100 \mathrm{~nm}$ a $180 \mathrm{~nm}$.

De Campos et al. (2013) obtiveram nanocelulose através da hidrólise enzimática, utilizando a endoglucanase e uma mistura de hemicelulases e pectinases. Neste estudo, curauá e bagaço de cana de açúcar foram branqueados antes da ação enzimática. A razão entre estas duas enzimas foi variada. A extração de nanofibras de celulose a partir do bagaço de cana de açúcar resultou em nanopartículas sem que houvesse a despolimerização das cadeias de celulose. Por outro lado, as fibras de curauá necessitaram uma maior concentração de enzimas e as nanofibras obtidas apresentaram um decréscimo de cristalinidade quando comparadas as fibras de curauá, sugerindo que a estrutura cristalina da celulose foi comprometida.

As características geométricas, tais como tamanho, dimensões e forma dos nanocristais de celulose dependem da natureza da fonte de celulose, bem como das condições de hidrólise, tais como tempo de reação, temperatura, uso de tratamentos, como o de ultrassom, e da pureza dos materiais (ANGLES; DUFRESNE, 2000).

\subsubsection{Modificação da Superfície dos Nanocristais}

Devido à natureza hidrofílica da celulose, os nanocristais não podem ser dispersos uniformemente na maioria das matrizes poliméricas hidrofóbicas. A fim de superar estes inconvenientes associados com o baixo desempenho nas composições correspondentes, os NCCs são geralmente submetidos a diferentes modificações na superfície. Os objetivos principais das modificações superficiais específicas são, por um lado, proporcionar uma barreira hidrófobica eficiente e, por outro lado, minimizar a 
energia interfacial entre os NCCs e a matriz polímerica não polar, assim gerando uma boa adesão NCC/matriz. Os processos químicos aplicados para esta finalidade são os mesmos que os utilizados para preparar os derivados de celulose, mas o seu impacto é limitado às camadas superficiais do cristal, uma vez que, as propriedades mecânicas dos elementos de reforço são preservadas, enquanto as propriedades da superfície são modificadas para assegurar uma ótima compatibilidade com a matriz. Apesar dos muitos métodos já propostos para modificação da superfície dos NCCs, a modificação da superfície das nanoceluloses é ainda limitada (MISSOUM; BELGACEM; BRAS, 2013).

Diferentes estratégias de modificação foram descritas na literatura, uma vez que a melhoria da resistência interfacial e do carácter hidrofóbico pode ser alcançado por várias vias, como reações químicas, tal como graftização, incluindo (i) compatibilização de superfície dos NCCs e da matriz usando frações hidrofóbicas, (ii) co-polimerização com a matriz utilizando moléculas bi-funcionais capazes de reagir com os grupos $\mathrm{OH}$ da superfície da celulose, e deixando a sua segunda função disponível para uma maior exploração, e (iii) enxertia de longas cadeias anexados à superfície dos NCCs. A estratégia (ii), idealmente gera uma continuidade de ligações covalentes entre as cadeias de celulose e a superfície da matriz, assim, proporcionando um melhor desempenho mecânico (LIN; HUANG; DUFRESNE, 2012).

A Figura 20 apresenta algumas das modificações utilizadas para os NCCs. 
Figura 20. Lista de reagentes utilizados para a modificação de NCCs : (i) adsorção física, (ii) modificação da superfície da molécula e (iii) graftização do polímero.

(1) Cloreto de Poli-dialildimetilamônio (poli-DADMAC); (2) Polietilenimina (PEI); (3) Polihidroxialcanoato (PHA); (4) Ácido Perfluoro-octadecanóico; (5) Brometo de Cetiltrimetilamônio (CTAB); (6) Brometo de Didecildimetilamônio (DDDAB); (7) Brometo de Dihexadecildimetilamônio (DHDAB); (8) Diclorodimetilsilano; (9) Anidrido Acético; (10) Anidrido Butírico; (11) Amino Silano (APS); (12) Anidrido Isobutírico; (13) Propargilamina; (14) Glicidoxipropiltrimetoxissilano (GPS); (15) Anidrido Hexanóico; (16) Hexametildissilazana; (17) Palmitoil; (18) Isocianato de Octadecil; (19) N-(5-aminopentil)-5(dimetilamino) naftaleno-1-sulfonamida; (20) Metacrilato de Glicidila (GMA); (21) Acrilato de Etila (EA); (22) Metil Metacrilato (MMA); (23) Acrilato (BuA); (24) Metacrilato de 2-hidroxietilo e (25) Policaprolactona (PCL).

(1)<smiles>CCCC1C[N+](C)(C)CC1CC(C)(C)C</smiles>

(4)<smiles>[13CH3]C(=O)O</smiles><smiles>CCCCC(CN)C(C)(C)Cl</smiles>

(5)<smiles>CCC(C)(CC)[N+](C)(C)Br</smiles>

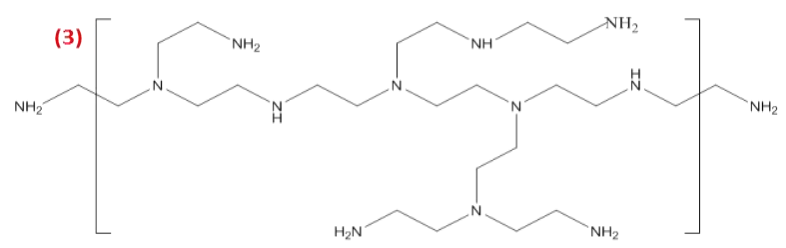

(6) $\mathrm{CH}_{2}\left(\mathrm{CH}_{2}\right)_{10} \mathrm{CH}_{3}$

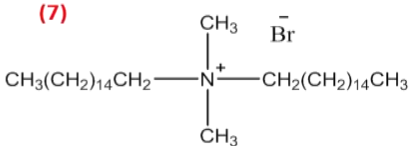

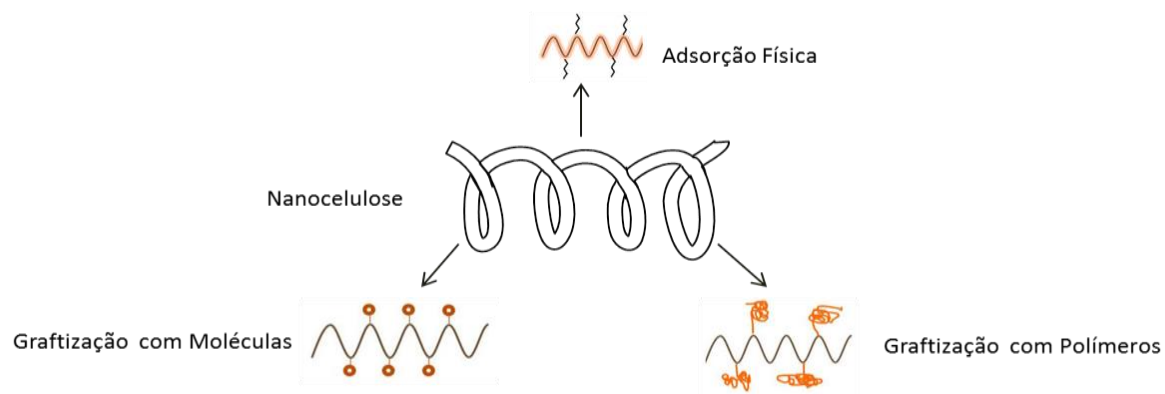

(20)<smiles>CC(C)(C)C(C(=O)OCC1CO1)(C(C)(C)C)C(C)(C)C</smiles><smiles>CCCC(C)(C)C(C(=O)OCCO)(C(C)C)C(C)(C)C</smiles>

(22)<smiles>CCOC(=O)C(CC(C)(C)C)C(C)(C)C</smiles><smiles>CCC(=O)OC(=O)CCCCCCCOCC1CO1</smiles>

(25)<smiles>COCCCCCC(=O)OCCOCCOC(=O)CCCCCOC</smiles><smiles>CCC(=O)O</smiles>
(18)

(19)<smiles>C#CCNCc1ccccc1</smiles>

Fonte: (MISSOUM; BELGACEM; BRAS, 2013). 
A superfície das nanopartículas de celulose pode ser modificada utilizando surfactantes ou polieletrólitos de adsorção. Wagberg et al. (2008) modificaram a superfície de nanocristais de celulose utilizando três diferentes polieletrólitos. Observou-se a formação de camadas bem definidas de NCC com os eletrólitos. Um polieletrólito com uma estrutura tridimensional leva à acumulação de camadas espessas de NCC, já o polieletrólito linear conduz a formação de camadas mais finas de NCC. Assim, as nanopartículas de NCC podem ser modificadas com polieletrólitos e podem ser utilizadas em materiais sensores.

A superfície da celulose pode ser modificada através do processo de esterificação dos NCCs, utilizando ácidos carboxílicos, ácidos anidridos ou cloretos de acila. Nos estudos de Kim et al. (2002) celulose bacteriana (BC) foi parcialmente modificada com ácido acético anidro, utilizando tolueno como solvente. A modificação teve um forte impacto sobre as propriedades do material, como um aumento da rigidez e da capacidade de deformação do filme de BC acetilado. As propriedades mecânicas do BC podem ser ajustadas, dependendo do grau de substituição.

Lin et al. (2009) graftizaram nanocristais de celulose com policaprolactona $(P C L)$, através da polimerização por abertura de anel assistida por microondas. As nanopartículas resultantes foram incorporadas à matriz de poli (ácido lático) (PLA). 0 melhor desempenho mecânico foi apresentado para os nanocompósitos contendo 8 \% de NCC modificado.

Siqueira et al. (2010b) conduziram a modificação da superfície de nanocristais e de nanofibras de celulose com octadecil isocianato por meio troca da solvente. Os autores concluíram que o sistema de troca de solvente pode ser uma opção para evitar dificuldades de dispersão das cargas na matriz apolar. Os resultados obtidos por análise elementar apontaram que a graftização das nanofibras de celulose foi eficiente.

De Castro, Ruvolo-Filho e Frollini (2011) estudaram o efeito da adição de PBHL e óleo de mamona em compósitos de biopolietileno reforçados com fibras de curauá. Este estudo teve como objetivo a redução da propagação de trincas durante o ensaio de impacto dos compósitos. Verificou-se também a atuação como agentes de acoplamento do PBHL e do óleo de mamona, uma vez que o PBHL e o óleo de mamona 
possuem cadeias hidrocarbônicas com afinidades com o biopolietileno, e grupos hidroxilas com afinidades com os grupos polares presentes nas fibras lignocelulósicas. Neste estudo foi possível concluir também que a adição de PBHL e óleo de mamona levaram a uma melhor adesão e distribuição das fibras na matriz termoplástica. Assim, houve uma melhora nas propriedades mecânicas destes compósitos, particularmente na resistência ao impacto. A partir dos resultados deste estudo considerou-se como possibilidade o uso de óleos vegetais como agentes de compatibilização em nanocompósitos reforçados com NCC.

Uma modificação química (do polímero e/ou do reforço) consiste em uma etapa adicional na preparação dos compósitos, aumentando o custo de produção. Neste estudo, visando evitar a introdução de etapas envolvendo reações químicas, utilizou-se óleo de mamona, de soja e linhaça epoxidados como agente de compatibilização, com o objetivo de melhorar a interação entre os NCCs e matriz. Utilizando-se o biopolietileno como matriz e nanocristais de curauá como reforço, foi possível preparar materiais baseados principalmente em matéria prima proveniente de fontes renováveis, ou seja, materiais do tipo biocompósitos.

\subsection{Preparação dos Nanocompósitos}

Duas principais técnicas podem ser usadas para preparar filmes poliméricos contendo nanopartículas de celulose:

- Deposição via espalhamento de solução (casting, ocorrendo evaporação de solvente orgânico ou água) e

- Extrusão do polímero com nanopartículas de celulose liofilizadas.

A primeira técnica é a mais utilizada, e três sistemas podem ser distinguidos de acordo com o polímero utilizado como matriz: (i) polímeros solúveis em água, (ii) emulsões poliméricas, e (iii) polímeros não solúveis em água.

No que se refere ao último caso, duas vias podem ser utilizadas a fim de se obter dispersões não floculadas de nanocristais de celulose em meio orgânico apropriado:

- Revestimento da superfície dos nanocristais de celulose com surfactantes, que possuem cabeças polares e longas caudas hidrofóbicas; 
- Graftização de cadeias hidrofóbicas na superfície dos nanocristais de celulose.

A Figura 21 ilustra as diferentes estratégias usadas para preparar filmes de nanocompósitos por casting.

Figura 21. Esquema geral das estratégias utilizadas para a preparação de nanocompósitos de nanocelulose por casting.

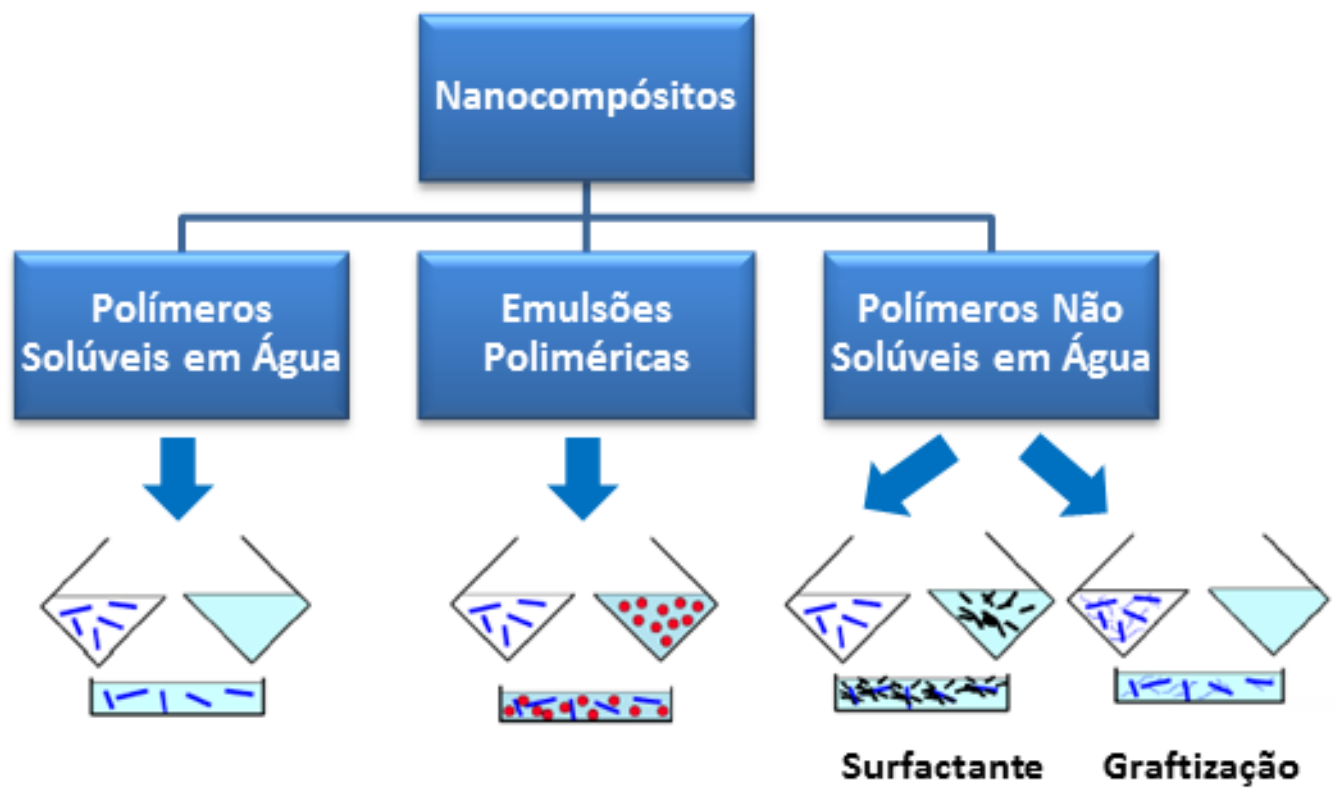

Fonte: (SIQUEIRA; BRAS; DUFRESNE, 2010a).

A extrusão é um método mais recente usado para preparar nanocompósitos, muito estudos têm sido realizados nesta área, correspondendo a uma possibilidade de se dimensionar o trabalho para a escala industrial. O problema principal de se trabalhar com nanopartículas de celulose liofilizadas está relacionado com o fato de que estas estão na maior parte do tempo agregadas, devido à presença de fortes ligações de hidrogênio (BONDESON; OKSMAN, 2007).

A técnica de extrusão foi usada no presente trabalho, no processamento dos nanocompósitos de BPEAD reforçado por nanocristais de curauá. 



\section{Objetivos}

As metas do presente estudo consistiram:

-No desenvolvimento e caracterização de compósitos gerados a partir de matriz de biopolietileno de alta densidade (BPEAD), reforçadas com fibras de curauá. Adicionalmente, óleos de origem vegetal, como mamona (CO), canola (CA), soja epoxidado (OSE) e linhaça epoxidado (OLE), foram acrescentadas à formulação do material. Estes óleos vegetais foram escolhidos por serem oriundos de fontes renováveis, assim como por possuírem grupos nas respectivas estruturas com afinidade com grupos presentes em ambos, fibra e matriz, ou seja, buscando a ação como compatibilizantes. No presente estudo diferentes porcentagens de fibra e de óleos vegetais foram utilizadas e processados via misturador interno (Haake). Visando comparar o efeito de processamento sobre as propriedades dos materiais, uma composição foi selecionada para ser processada por extrusão e moldada por injeção.

-Avaliação do potencial de aplicação de nanocristais de celulose como reforço em filmes baseados em BPEAD, CO, OSE e OLE foram usados visando ação dos mesmos na dispersão dos NCCs quando adicionados à matriz polimérica apolar (BPEAD). NCC na presença ou não de óleos vegetais foram processados por extrusão, ou seja, através de um processo de maior reprodutibilidade em escala industrial.

-Visando melhorar as propriedades mecânicas dos nanocompósitos, parâmetros de processamento também foram modificados, utilizando a termoprensa para a obtenção de filmes, ao invés de calandragem. Desta forma, pôde-se comparar as propriedades dos filmes baseados em BPEAD, óleos vegetais e NCC obtidos por extrusão/calandragem e extrusão/termoprensagem.

Desta forma, materiais baseados principalmente em matérias-primas provenientes de fontes naturais, foram preparados visando à valorização de materiais gerado. 



\section{Técnicas de Caracterização dos Materiais}

\subsection{Termogravimetria (TG)}

A termogravimetria (TG) é uma técnica termoanalítica na qual a variação de massa da amostra (perda ou ganho) é determinada em função da temperatura ou do tempo. Esta técnica possibilita conhecer as alterações que o aquecimento pode provocar na massa das substâncias, permitindo estabelecer a faixa de temperatura em que elas adquirem composição química fixa, definida e constante, a temperatura em que começam a se decompor, acompanhar o andamento de reações de desidratação, oxidação, combustão, decomposição, dentre outras (CANEVAROLO JUNIOR, 2004).

No presente estudo foi usada para determinar a perda de água associada com a umidade de fibras como a de curauá, o início da decomposição térmica de um termoplástico, como BPEAD, de fibras e de óleos vegetais. Define o intervalo de temperatura que poderá ser considerado no processamento de compósitos, além de definir a temperatura máxima para aplicação destes, como BPEAD reforçado por curauá, na presença ou não de óleos vegetais (RAMIAH, 1970).

\subsection{Calorimetria Exploratória Diferencial (DSC)}

Quando uma substância passa por uma mudança física ou química, pode ser observada uma variação na entalpia. Se o processo for promovido por uma variação controlada de temperatura, isto constitui a base da técnica conhecida como calorimetria exploratória diferencial (DSC), na qual é medida a variação de entalpia entre o material em estudo e uma amostra inerte (referência ou padrão) (LACEY; NIKOLOPOULOS; READING, 1997).

Numa curva DSC típica, três tipos básicos de transformações podem ser detectadas: transformações endotérmicas, transformações exotérmicas e transições de segunda ordem, como a temperatura de transição vítrea $(\mathrm{Tg})$, na qual a entalpia não sofre variação, mas o calor específico sofre uma mudança repentina, que é detectada por uma simples descontinuidade no fluxo de calor, observada como uma 
alteração na linha base da curva de DSC. Como exemplo de transição endotérmica pode-se citar reações de decomposição (SCHAWE, 1998).

As análises via DSC podem fornecer a temperatura de fusão $\left(T_{m}\right)$, a entalpia de fusão $\left(\Delta \mathrm{H}_{m}\right)$ e o grau de cristalinidade $\left(X_{c}\right)$, para polímeros que apresentam essas transições. No presente trabalho, a partir das curvas DSC obtidas para o BPEAD nos compósitos e BPEAD puro, pode-se avaliar os valores das $\Delta \mathrm{H}_{\mathrm{m}}$ para os compósitos reforçados com fibra de curauá e com diferentes porcentagens de CO, CA, OSE, OLE. O índice de cristalinidade para os compósitos e para o BPEAD pode ser calculado usando a seguinte relação:

$\mathrm{Xc}=\frac{\Delta \mathrm{H}_{\mathrm{m}}}{\Delta \mathrm{H}^{0} \mathrm{~m} \varphi_{\mathrm{m}}} \times 100$

Sendo, $\mathrm{Xc}$ o índice de cristalinidade, $\Delta \mathrm{H}_{\mathrm{m}}$ a entalpia de fusão, $\Delta \mathrm{H}_{\mathrm{m}}^{0}$ a entalpia de fusão do PEAD $100 \%$ cristalino e $\varphi_{w}$ a fração em massa de BPEAD nos compósitos. $O$ índice de cristalinidade pode ser calculado para as diferentes amostras usando a entalpia de fusão para o PEAD 100\% cristalino que é de $293 \mathrm{~J} \mathrm{~g}^{-1}$ (PEREZ; MANRICH; MANRICH, 2008). Nesse cálculo, considera-se que $\Delta \mathrm{H}^{\circ}{ }_{\mathrm{m}}$ é o mesmo para o PEAD e para o BPEAD, pois a diferença entre os dois polímeros consiste somente na rota usada na preparação do monômero (etileno), conforme já mencionado.

\subsection{Ensaio de Resistência à Tração}

Através do ensaio de tração é possível determinar a resistência, a elasticidade, o alongamento e o ponto de ruptura de diversos materiais. As propriedades de tensão são indicadores da resistência mecânica de um material, pois, a resposta destes às influências mecânicas externas, manifestadas pela capacidade de desenvolverem deformações reversíveis e irreversíveis, e de resistirem à fratura, é importante para se indicar uma possível aplicação (IAN M. WARD, 2004).

A massa molar, a cristalinidade, o processamento e a pré-deformação por estiramento podem influenciar a resistência à tração dos materiais poliméricos (CALLISTER, 2002). 
Geralmente, a resistência à tração dos compósitos é melhorada pela adição de fibras a uma matriz polimérica uma vez que as fibras apresentam rigidez muito maior do que as matrizes poliméricas (KU et al., 2011).

A resistência à tração dos compósitos reforçados por fibras naturais dependem de uma série de parâmetros, tais como o volume de fibras, a razão de aspecto das fibras, a adesão das fibras na matriz, da transferência de tensão na interface, e da orientação. Em geral, um teor de fibra mais elevado é desejado para atingir um alto desempenho dos compósitos poliméricos reforçados com fibras curtas. A maioria dos estudos sobre compósitos de fibras naturais envolvem estudos de propriedades mecânicas, incluindo resistência à tração, em função do teor de fibras, do efeito de vários tratamentos das fibras, e do uso de agentes compatibilizantes (SAHEB; JOG, 1999).

\subsection{Ensaio de Resistência ao Impacto}

O conhecimento da resistência ao impacto de um material é muito importante porque falhas devido a cargas repentinas são muito comuns em condições de uso, e ocorrem frequentemente. As forças de impacto são aplicadas tão rapidamente que as relaxações da estrutura molecular não acompanham o processo, resultando em fratura ocasionada pela quebra da cadeia e/ou separação das interfaces (SAHEB; JOG, 1999).

Os testes de impacto com pêndulos mais utilizados são os ensaios do tipo Izod e Charpy, que permitem a comparação de vários níveis de tenacidade entre materiais plásticos, através da quebra de corpos de prova entalhados e não entalhados sob condições inteiramente padronizadas. Nestes ensaios, a energia cinética do martelo é relativamente maior do que a energia requerida para fraturar o corpo de prova. Os resultados são expressos em termos de energia cinética consumida pelo pêndulo durante a ruptura do corpo-de-prova. A foto do equipamento utilizado para o ensaio de resistência ao impacto Izod no presente trabalho é apresentada na Figura 22. 
Figura 22. Foto do equipamento utilizado no ensaio de impacto Izod.

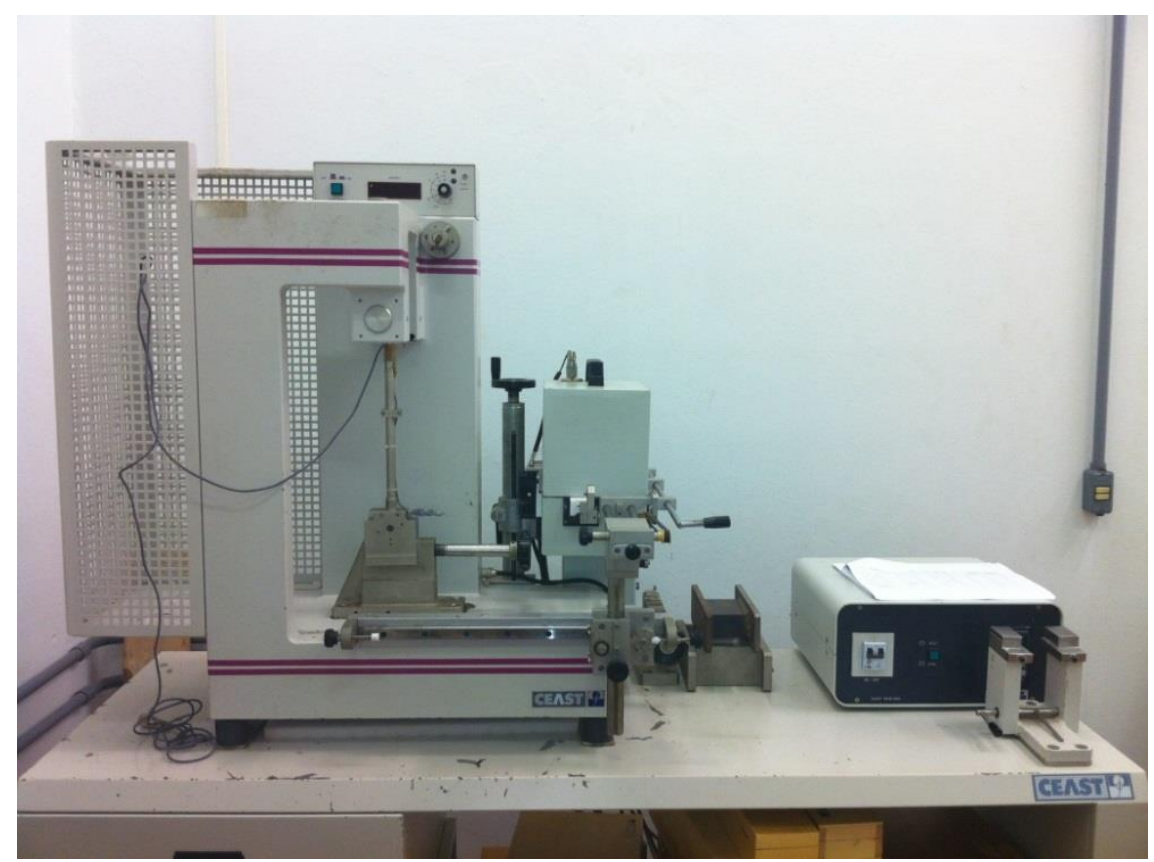

No caso da análise de compósitos, os principais mecanismos de falhas desses materiais, e que podem ser observados durante o ensaio de resistência ao impacto, são (MEGIATTO et al., 2009):

- "Pull-Out" ou Arrancamento: ocorre o arrancamento da fibra de dentro da matriz, geralmente, após a propagação da trinca.

- "Fiber Bridging": ocorrem normalmente em compósitos poliméricos reforçados com fibras frágeis, matrizes dúcteis e interface envolvendo interações intensas. Desta maneira, a trinca se propaga pela matriz e a fibra forma uma ponte interligando as duas superfícies da matriz fraturada.

- "Debonding" ou Descolamento: caracteriza-se pelo descolamento entre a fibra e a matriz, devido à presença de uma interface fraca.

- Falha da Fibra: ocorre na região na qual se concentram tensões, poderá levar a falha da fibra devido a sua fragilidade.

No presente trabalho, foram realizados ensaios de impacto do tipo Izod, os quais se destinam à avaliação de corpos de prova sob esforço mediante impacto, assim como à avaliação da fragilidade ou tenacidade dentro dos limites das condições de ensaio. A avaliação da resistência ao impacto de materiais poliméricos é um fator 
decisivo na seleção de materiais, tendo em vista a aplicação dos mesmos (CHAWLA, 1998).

\subsection{Resistência à Flexão}

Estes ensaios são aplicados a materiais poliméricos rígidos e semi-rígidos. 0 corpo de prova é defletido até que sua ruptura ocorra na superfície oposta ao carregamento, ou até que uma deformação máxima de 5,0\% seja alcançada. Em um ensaio de flexão em três pontos, a deflexão na qual a máxima deformação permitida $(5,0 \%)$ irá ocorrer pode ser calculada através da seguinte equação, adotando-se $r$ igual a $0,05 \mathrm{~mm} / \mathrm{mm}$ (CALLISTER, 2002):

$D=\frac{r L^{2}}{6 d}$

Sendo: $D$ a deflexão no ponto médio entre os apoios, $r$ a deformação, $L$ a distância entre os apoios e $d$ a profundidade do corpo de provas.

A velocidade do ensaio pode ser calcula através da Equação 3:

$R=\frac{Z L^{2}}{6 d}$

Sendo: $R$ a velocidade da travessa fixa, $Z$ a taxa de deformação na superfície oposto ao carregamento, $L$ a distância entre os apoios e $d$ a espessura do corpo de provas.

A resistência à flexão $\left(\sigma_{\max }\right)$ é a máxima tensão sob flexão sustentada pelo corpo de prova durante o ensaio de flexão. Para um ensaio em três pontos, a resistência à flexão é dada pela Equação 4 (CALLISTER, 2002).

$\sigma_{\max }=\frac{3 P_{\max L}}{2 b d^{2}}$

Sendo: $\sigma_{\max }$ a resistência à flexão, $\mathrm{P}_{\max }$ a carga máxima de ruptura, $L$ a distância entre os apoios e $d$ a profundidade do corpo de provas e b a largura do corpo de prova.

O módulo de flexão $\left(E_{f}\right)$ é a razão dentro do limite de elasticidade entre a tensão de flexão e a deformação correspondente, calculado através da tangente na porção linear inicial da curva versus deflexão, utilizando a Equação 5 (CALLISTER, 2002).

$\mathrm{E}_{\mathrm{f}}=\frac{L^{3} m}{4 b d^{3}}$ 
A Figura 23 exibe foto do equipamento usado no ensaio de flexão dos compósitos preparados a partir de BPEAD e fibra de curauá.

Figura 23. Foto do equipamento utilizado no ensaio de resistência à flexão.

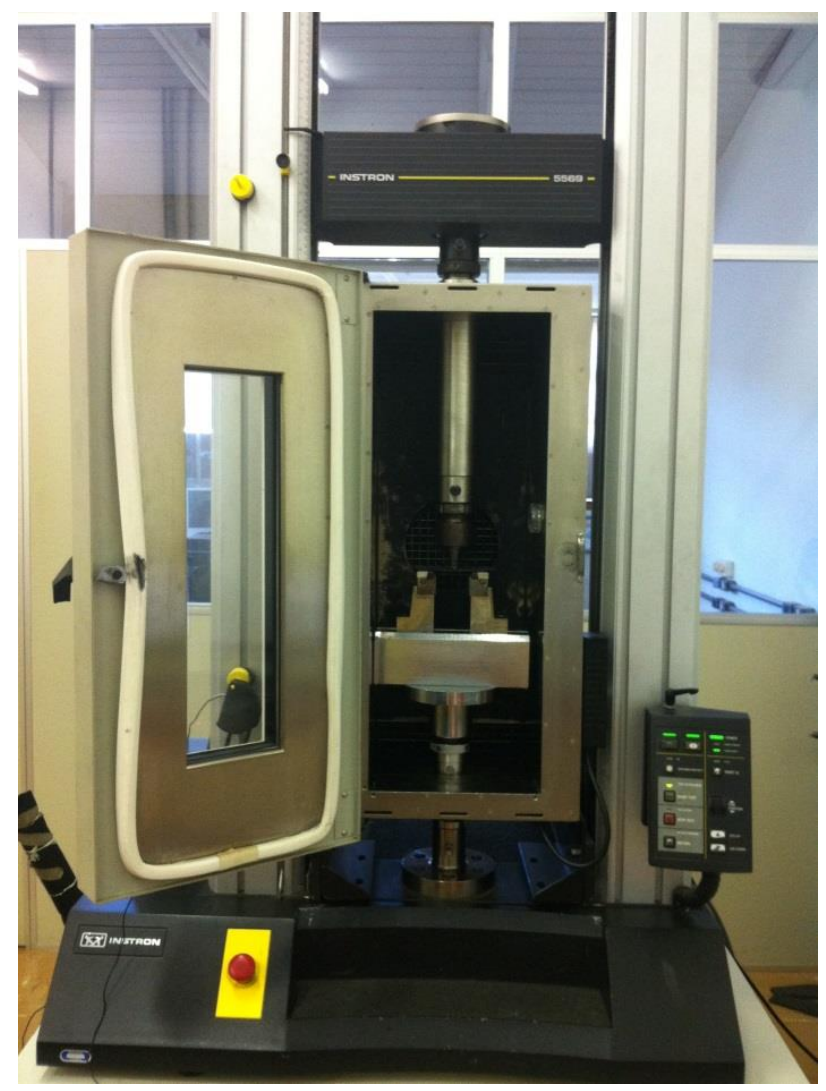

Os dados obtidos em um ensaio de resistência à flexão são muitas vezes utilizados para selecionar os materiais para o preparo de peças que irão suportar elevadas cargas. O módulo de flexão é usado como indicativo da rigidez de um material quando flexionado (CASTRO; RUVOLO-FILHO; FROLLINI, 2012). Uma vez que as propriedades dos materiais termoplásticos podem variar dependendo da temperatura ambiente, pode ser necessário realizar testes em ambientes com temperatura controlada, simulando as condições do uso pretendido.

\subsection{Análise Dinâmico-Mecânica (DMA)}

A análise de DMA fornece informações a respeito do comportamento viscoelástico do sistema, que é desmembrado em duas componentes: a contribuição 
elástica e a viscosa. Os materiais elásticos têm a capacidade de armazenar energia mecânica, sem dissipação de energia (obedecem a Lei de Hook). Por outro lado, fluidos viscosos tem a capacidade de dissipar energia, mas não de armazená-la (obedecem a Lei de Newton). Levando em conta a estrutura interna dos polímeros, seu alongamento é divido em duas partes: uma elástica, devido ao alongamento dos novelos, e outra viscosa, devido ao deslizamento das macromoléculas. Por este motivo o comportamento mecânico dos polímeros é denominado viscoelástico, pois o mesmo tem características tanto de líquidos viscosos, como sólidos elásticos (CALLISTER, 2002).

O módulo oriundo da componente tensão resposta em fase com a deformação, $E^{\prime}$, é denominado módulo de armazenamento e o módulo oriundo da componente de tensão resposta $90^{\circ}$ fora de fase com a deformação, E", é denominado módulo de perda.

A razão entre os valores de módulo de perda, E", e módulo de armazenamento, $\mathrm{E}^{\prime}$, define uma grandeza denominada tangente de perda, $\tan \delta$.

A tangente de perda, também denominada friç̧ão interna ou amortecimento, é a razão entre a energia dissipada por ciclo e a energia potencial máxima armazenada durante o ciclo. Assim materiais mais rígidos irão apresentar valores de $\tan \delta$ menores e, materiais mais flexíveis irão apresentar valores de $\tan \delta$ maiores. As grandezas E', E" e $\tan \delta$ são dadas em função da temperatura ou da frequência em um ensaio de DMA (LUCAS; SOARES; MONTEIRO, 2001).

Os métodos dinâmico-mecânicos são muito sensíveis às transformações que ocorrem em nível molecular, sendo capazes de detectar movimentos discretos como relaxações secundárias. Nos compósitos, as interações envolvendo matriz e/ou óleos vegetais com as fibras, pode influir nas relaxações das cadeias presentes na interface fibra-matriz, o que pode ser detectado por deslocamento nas curvas de $E^{\prime \prime}$ e $\tan \delta$, quando comparadas às amostras sem fibras.

As transições que ocorrem nas moléculas podem ser divididas em transições que ocorrem na fase cristalina e transições que ocorrem na fase não cristalina. As relaxações primárias são descrita pela letra $\alpha$, assim, a transição relacionada à temperatura de transição vítrea, que é a relaxação acentuada da fase não cristalina, é representada por $\alpha_{\mathrm{a}}$. A transição relacionada à temperatura de fusão, que corresponde 
a relaxação acentuada na fase cristalina, sendo representada por $\alpha_{c}$. Relaxações secundárias, que ocorrem abaixo de $\alpha_{c}$ e acima de $\alpha_{a}$, estão relacionadas com a parte cristalina e são representadas por $\alpha_{c}^{\prime}$. Transições que ocorrem abaixo de $\alpha_{a}$ estão relacionadas com a parte não cristalina do material e são representadas pelas letras $\beta_{\alpha}$, $\gamma_{\alpha}, \delta_{\alpha}$, entre outros, da mais alta para a mais baixa temperatura. Estas transições são melhores observadas pelos picos formados nas curvas de $E^{\prime \prime}$ ou $\tan \delta$ (MOHANTY; VERMA; NAYAK, 2006).

Esta técnica é importante para avaliar a intensidade de interação na interface reforço/matriz, pois o módulo de armazenamento é diretamente proporcional a esta intensidade (MATTHEWS; WARD; CAPACCIO, 1999; DE OLIVEIRA SANTOS et al., 2014). Assim, as curvas dos compósitos de matriz de polietileno reforçados com fibras de curauá, pôde-se obter informações sobre as respectivas intensidades na interface.

\subsection{Microscopia Eletrônica de Varredura (MEV)}

A microscopia eletrônica de varredura (MEV) é utilizada para o estudo de estruturas superficiais ou sub superficiais de amostras com dimensões relativamente grandes. O microscópio eletrônico de varredura utiliza elétrons para formação de imagem. As imagens têm alta profundidade de foco, o que significa obter diferentes relevos da superfície da amostra simultaneamente em foco, ou seja, imagens tridimensionais, o que facilita a sua interpretação. O MEV também produz imagens de alta resolução, o que garante obter alta ampliação de detalhes próximos sem perda de nitidez (CANEVAROLO JUNIOR, 2004).

Um aspecto atrativo da microscopia eletrônica de varredura é a facilidade de preparação de amostra. Materiais não condutores, como as fibras naturais e a maioria dos polímeros, requerem em geral apenas revestimentos condutivos, ou o uso de baixa voltagem de aceleração do feixe (LI; MAI; YE, 2005). Como a topografia da superfície é geralmente a principal característica de interesse na análise, a espessura da amostra não é um aspecto crítico, como acontece em outras técnicas de microscopia. A montagem da amostra é feita sobre suportes metálicos, utilizando adesivos condutivos, tais como fitas de carbono ou suspensões coloidais de prata ou carbono. O revestimento da amostra por um filme condutor tem como objetivo evitar 
o acúmulo de carga negativa, no caso da mesma ser formada por um material não condutor. A camada de metal deve ser suficientemente continua e fina (menor que 20 $\mathrm{nm}$ ) para não mascarar a topografia da superfície, porém, deve ser adequada para conduzir o excesso de carga negativa. A evaporação de metal e a metalização por sputtering são as técnicas mais comuns para esta finalidade. Os metais mais utilizados são ouro, liga ouro-paládio, platina, alumínio e carbono (CANEVAROLO JUNIOR, 2004).

A microscopia eletrônica de varredura é a técnica de imagem mais utilizada para o estudo de fratura de compósitos contendo fibras longas e curtas. No presente trabalho, permitiu analisar as morfologias das superfícies de fratura dos corpos-deprova dos compósitos reforçados com fibras de curauá, após serem submetidas ao ensaio de impacto (TRINDADE et al., 2004).

\subsection{Reologia}

Reologia pode ser definida como a ciência que estuda a deformação e o fluxo da matéria, provocadas pela aplicação de uma tensão ou deformação. Dessa maneira, o estudo da reologia permite analisar quantitativamente o comportamento de um fluido em interação com um sistema de processamento, através da formulação e resolução de equações que descrevem o processo (SCHRAMM, 2006).

A presença de tensão em um corpo produz deformação e esta é descrita em termos de deslocamento entre pontos vizinhos. O cisalhamento e o alongamento simples são os dois tipos básicos de deformação.

O cisalhamento simples pode ser representado pela Equação 6:

$\tau=\frac{F}{A}$

Sendo $\tau$ a tensão de cisalhamento, $\mathrm{F}$ a força paralela à face cisalhada e $\mathrm{A}$ é a área onde atua a força $F$.

O ângulo de deformação $\alpha$ está relacionado com a deformação pela Equação 7: $\gamma=\tan \alpha$

Define-se como módulo de cisalhamento ou módulo de rigidez (G) a razão entre $\tau$ e $\gamma$ :

$G=\frac{\tau}{\gamma}$ 
Quando a tensão de cisalhamento é mantida por um tempo t atuando sobre o corpo, poderá ocorrer deformação contínua desse material com uma velocidade constante de deformação, e poderá ocorrer movimento diferenciado entre as camadas do material. O gradiente de velocidades entre as camadas é chamado de taxa de cisalhamento $(\dot{\gamma})$ (SCHRAMM, 2006).

A relação entre a tensão de cisalhamento e a taxa de cisalhamento é dada pela Equação 9 que as relaciona com a viscosidade do material:

$\tau=n \dot{\gamma}$

A viscosidade de um material é uma medida da resistência que este material oferece à deformação. Portanto, um material de alta viscosidade apresentará maior resistência à deformação ou escoamento. Os materiais podem ser classificados de acordo com as suas reações a deformações e ao escoamento. Os dois casos ideais são aqueles nos quais há um fator de proporcionalidade entre a tensão e a deformação por cisalhamento $\gamma$ (fluídos Hookeanos) ou há um fator de proporcionalidade entre a tensão e a taxa de cisalhamento $\dot{\gamma}$ (corpos Newtonianos), mantendo-se em ambos os casos o tempo constante (SCHRAMM, 2006).

O comportamento pseudoplástico é o mais comum em polímeros fundidos e é consequência do desenovelamento e da orientação das macromoléculas, promovidas pelas taxas de cisalhamento aplicadas. Quando essas taxas são baixas, o gradiente de velocidade não é alto o suficiente para desenovelar as macromoléculas e a viscosidade é elevada; quando essas taxas aumentam, as macromoléculas começam a desfazer os nós entre elas e a viscosidade começa a diminuir. Quando as taxas são elevadas, as macromoléculas já desfizeram quase todos os nós entre elas e se orientarão na direção do fluxo, diminuindo a viscosidade. As variações da viscosidade de um polímero puro, ou de um compósito polimérico sob faixas específicas de taxas de cisalhamento, podem ser expressas por diversos modelos matemáticos baseados em simplificações de equações constitutivas que descrevam apenas o comportamento viscoso do polímero. Dentre tais modelos, o mais comumente utilizado para diversos tipos de polímeros e compósitos termoplásticos é o modelo da Lei das Potências, expresso pela relação (HUNT; BLACKIE, 1993): 
$\tau=n_{\alpha} \dot{\gamma}^{n}$

$n_{\alpha}$ indica o grau de resistência do fluido diante do escoamento. O valor de $\mathrm{n}$ é uma medida do grau de pseudoplasticidade do polímero. Quando $n=1$, a Equação 10 fica equivalente à do fluido Newtoniano, já que a viscosidade torna-se constante. Quando $\mathrm{n}<1$, a viscosidade diminui com o aumento da taxa de cisalhamento e 0 polímero apresenta comportamento pseudoplástico; quanto mais $\mathrm{n}$ tende a 0 , maior a pseudoplasticidade do polímero (HUNT; BLACKIE, 1993).

O módulo complexo $\left(G^{*}\right)$ é uma medida da resistência à deformação total do material e pode ser representado por:

$G^{*}=G^{\prime}+i G^{\prime \prime}$

Sendo G" o módulo de perda (vinculado com a viscosidade do polímero) e G' é o módulo de armazenamento (vinculado com a elasticidade do polímero). A razão entre os módulos de perda ( $\left.G^{\prime \prime}\right)$ e de armazenamento $\left(G^{\prime}\right)$ representa uma medida de amortecimento do material e é dada por:

$\tan \delta=\frac{G^{\prime \prime}}{G^{\prime}}$

Em compósitos poliméricos, as propriedades reológicas são altamente afetadas pela presença de cargas ou fibras, e o estudo de tais propriedades permite analisar interações entre fases e mudança na morfologia, entre outros (KALAPRASAD et al., 2003). A Figura 24 apresenta o reômetro utilizado para os experimentos deste estudo.

Figura 24. Foto do reômetro Ares da Rheometric Scientific.

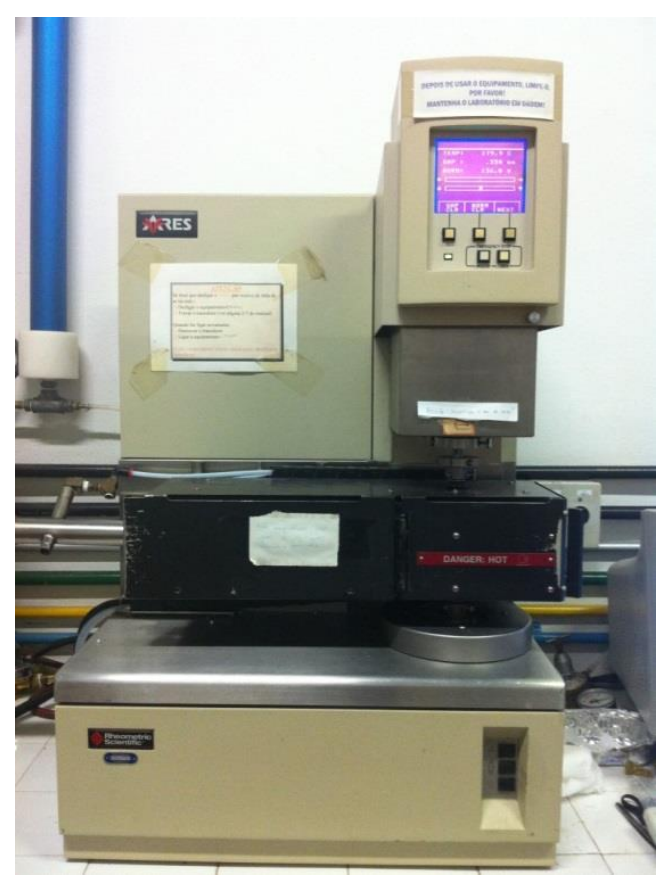


Medidas viscoelásticas são importantes para um correto processamento dos polímeros. As medidas das propriedades reológicas dos compósitos também podem ser utilizadas como método de caracterização da dispersão das fibras na matriz polimérica (MARINI; SUMAN BRETAS, 2013). As principais medidas reológicas utilizadas na caracterização de compósitos são:

- Propriedades em Regime Permanente: o aumento da fração volumétrica de carga pode levar a um aumento na viscosidade à taxa de cisalhamento zero $\left(\eta_{0}\right)$, além da presença de uma tensão de escoamento e de uma maior pseudoplasticidade quando o compósito apresenta boa dispersão das partículas pela matriz. $\mathrm{O}$ aumento em $\eta_{0}$ pode ser observado em sistemas dispersos e com estrutura percolada. A estrutura percolada é resultado da presença de interações entre as camadas de fibra, que fica ancorada pela matriz e pelas demais fibras, restringindo a relaxação das cadeias poliméricas da matriz, sob cisalhamento, aumentando, portanto, a resistência à deformação do compósito, em relação à matriz polimérica pura (ZHAOA; MORGANB; HARRISC, 2005).

- Propriedades em Regime Oscilatório: a resposta viscoelástica de compósitos depende do grau de dispersão dos agregados, quando presentes. Curvas de G' $x \omega$ (módulo de armazenamento em função da frequência de oscilação) de polímeros puros apresentam uma declividade próxima de 2 quando $\omega \rightarrow 0$ (zona terminal); nessa mesma situação, a inclinação das curvas $G^{\prime \prime} \times \omega$ (módulo de perda em função da frequência de oscilação) apresenta declividade próxima a 1. Em compósitos, quanto maior a quantidade e melhor a dispersão da fibra, maior é a diminuição observada nessas declividades, podendo-se observar um comportamento pseudo-sólido (ZHAOA; MORGANB; HARRISC, 2005).

- Propriedades em Regime Transiente: em compósitos observa-se a mesma tendência de aumento no pico de stress overshoot (crescimento de tensões antes de atingir regime permanente de cisalhamento) com o aumento da taxa de cisalhamento verificada para polímeros puros; porém, a presença de maiores forças atrativas em um compósito disperso faz com que as intensidades dos picos sejam maiores. O comportamento de relaxação de 
tensão depois de cessado o cisalhamento também é influenciado pela interação polímero-fibra. Observa-se um maior tempo de relaxação para o sistema com boa interação (ZHAOA; MORGANB; HARRISC, 2005). 



\section{Materiais, Métodos e Forma de Análise dos Resultados}

Este trabalho foi desenvolvido em cooperação com Professor Adhemar Colla Ruvolo Filho do Departamento de Engenharia de Materiais da Universidade Federal de São Carlos (UFSCar, São Carlos, SP).

\subsection{Materiais}

O "polietileno verde", também chamado de biopolietileno é um material comercial de procedência BRASKEM e foi gentilmente cedido por esta empresa (Triunfo, RS). BPEAD foi usado no presente trabalho.

As fibras de curauá utilizadas foram gentilmente cedidas pela Pematec Triangel do Brasil Ltda. (São Paulo, SP).

O óleo de mamona utilizado neste trabalho foi adquirido de Azevedo Indústria e Comércio de Óleos Ltda. (São Paulo, SP), possui índice de hidroxila de $155 \mathrm{mg} \mathrm{KOH} \mathrm{g}^{-1}$ e $\mathrm{Mn}_{\mathrm{n}} \cong 980 \mathrm{~g} \mathrm{~mol}^{-1}$.

O óleo de canola adquirido de Cargill Incorporated (São Paulo, SP).

O óleo de soja e o óleo de linhaça epoxidados foram adquiridos de Inbra Indústrias Químicas Ltda. (Diadema, SP). Apresentam 6,40 g de epóxidos/100 g e 6,20 g de epóxidos $/ 100 \mathrm{~g}$, respectivamente.

A preparação de nanocristais e de nanocompósitos foi desenvolvida em cooperação com Professor Alain Dufresne do Institut Polytechnique de Grenoble (INP) - Ecole internationale du papier, de la communication imprimée et de biomatériaux (Pagora), Grenoble, França.

\subsection{Preparação dos Nanocristais}

Os nanocristais de celulose foram obtidos a partir de fibra de curauá. Para a obtenção dos nanocristais, as fibras de curauá (50 g) foram primeiramente submetidas ao tratamento com $\mathrm{NaOH}(1000 \mathrm{~mL}$ à $4 \%)$, a $80^{\circ} \mathrm{C}$ por $2 \mathrm{~h}$. Este tratamento foi repetido três vezes sobre a mesma amostra, visando isolar a celulose, eliminando a lignina, 
hemicelulose e outros constituintes das fibras. A celulose branqueada foi então dispersa em água, e a suspensão resultante foi submetida à hidrólise ácida, com ácido sulfúrico concentrado $(65 \%)$ a $45^{\circ} \mathrm{C}$ durante $75 \mathrm{~min}$. A suspensão resultante foi subsequentemente diluída com água e lavada via sucessivas centrifugações. O ácido livre nesta dispersão foi removido por diálise com água destilada, e a dispersão completa dos nanocristais foi obtida através da sonicação em um Branson sonificador por 2 min a baixa potência. Após filtração, para remover os agregados residuais, a dispersão foi armazenada sob-refrigeração. Uma parte da suspensão de nanocristal foi liofilizada para posterior caracterização e para a preparação dos filmes dos nanocompósitos BPEAD/NCC.

Em seguida, os nanocristais foram centrifugados a $10000 \mathrm{rpm}$, a $4^{\circ} \mathrm{C}$ por $10 \mathrm{~min}$ na presença de etanol, para promover a troca da suspensão de nanocristais em água por etanol. Após quatro ciclos, promoveu-se uma nova troca de solvente, desta vez etanol por óleo de mamona (CO). O mesmo procedimento foi realizado com óleo de linhaça e de soja epoxidados (OLE e OSE), visando promover a dispersão dos nanocristais de curauá em diferentes óleos vegetais.

\subsection{Caracterização das Fibras e dos Nanocristais de Curauá}

As análises mencionadas a seguir foram feitas em triplicata para a fibra de curauá e para a polpa obtida após o tratamento do curauá com hidróxido de sódio. Para a determinação do teor de umidade da fibra a norma ABNT (NBR9656) foi seguida.

O teor de lignina foi determinado pelo método Klason (FENGEL; WEGENER, 1984), fundamentado na hidrólise ácida dos polissacarídeos e, consequente separação e determinação gravimétrica da lignina insolúvel em ácido sulfúrico (72\%).

Para determinar o teor de cinzas da fibra e da polpa de curauá, a norma TAPPI T211 om-85 [ASH, 1991] foi seguida.

A determinação do teor de holocelulose (celulose + hemicelulose) foi realizada de acordo com o método descrito na norma TAPPI T19 om-54, baseado na eliminação de lignina via reação com clorito de sódio. 
A determinação do teor de celulose foi realizada com as amostras resultantes da determinação do teor de holocelulose. Colocou-se 1,0 g de amostra obtida para determinação de holocelulose em um béquer com $10 \mathrm{~mL}$ de solução de $\mathrm{NaOH}$ 17,5 \%, deixou-se em repouso por 2 min, em seguida, com um bastão de vidro, mascerou-se a amostra. Após, adicionou-se mais $10 \mathrm{~mL}$ de solução de $\mathrm{NaOH} 17,5 \%$ e deixou-se a mistura em repouso por $20 \mathrm{~min}$. Em seguida, adicionou-se $40 \mathrm{~mL}$ de água destilada, filtrou-se a mistura em funil de vidro sinterizado previamente tarado, lavando o precipitado com solução de ácido acético diluído 50 \% filtrou-se novamente e, em seguida lavou-se com água destilada até neutralizar o excesso de ácido. A fração de amostra insolúvel em solução de $\mathrm{NaOH} 17,5 \%$ corresponde a $\alpha$-celulose. Secou-se a celulose obtida em estufa de circulação de $\operatorname{ar}\left(105^{\circ} \mathrm{C}\right)$ até massa constante. $\mathrm{O}$ teor de a-celulose foi calculado pela diferença de massa, antes e após o tratamento da amostra com solução de $\mathrm{NaOH} 17,5 \%$.

\subsection{Microscopia eletrônica de varredura com fonte de emissão por efeito de campo (MEV-FEG)}

O microscópio eletrônico de varredura (MEV) é um equipamento que permite a obtenção de informações morfológicas dos materiais. A caracterização morfológica dos NCCs foi realizada utilizando microscopia eletrônica de varredura (MEV) com fonte de emissão por efeito de campo (FEG Zeiss Ultra 55). As amostras foram revestidas com ouro/paládio antes das observações, já que a celulose é um material não condutor de elétrons.

\subsection{Determinação do Índice de Cristalinidade}

O índice de cristalinidade (Ic) das fibras, dos nanocristais e do termoplástico foi avaliado por difração de raios $X$.

Pelo difratograma de raios $X$ da fibra e do nanocristal é possível observar a presença de picos característicos da celulose, referente aos planos cristalográficos,

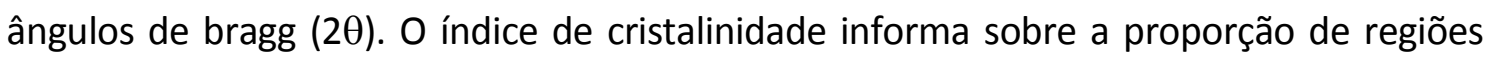
cristalinas com relação às não cristalinas presentes na amostra. Este é um dado 
importante, pois em materiais lignocelulósicos, a acessibilidade dos grupos hidroxila da celulose se relaciona de maneira direta com a cristalinidade da mesma, isto é, nas regiões cristalinas o acesso de reagentes e solventes aos grupos hidroxilas é dificultado, em relação às regiões não cristalinas. O índice de cristalinidade é calculado utilizando-se a Equação 13 (BUSCHLE-DILLER; ZERONIAN, 1992).

$I_{c}=1-\frac{I_{1}}{I_{2}}$

$I_{\mathrm{c}}=$ índice de cristalinidade;

$I_{1}=$ intensidade do mínimo de difração;

$I_{2}=$ intensidade do máximo de difração.

Para o BPEAD, o cálculo do grau de cristalinidade foi realizado pelo método estabelecido por (RULLAND, 1974). Esse método permite calcular a cristalinidade de um polímero pela Equação 14:

$\% C=\frac{I c}{(I c+K I a)} \times 100$

Sendo \%C a cristalinidade em porcentagem, la é a área sob o halo amorfo, Ic é o resultado da integração dos picos de difração ou as áreas dos picos cristalinos e $\mathrm{K}$ é uma constante de proporcionalidade para cada polímero.

As análises de raios $X$ para as fibras de curauá e para o BPEAD tratados e não tratados, foram feitas em um difratômetro RIGAKU com tubo de cobre selado, radiação $(k \alpha)$ e comprimento de onda $1542(k \alpha) \hat{A}$. As medidas foram realizadas à velocidade de $2^{\circ} \mathrm{min}^{-1}$, no intervalo angular de $5-50^{\circ}$ (ângulo de Bragg $2 \theta$ ), potência de $40 \mathrm{~mA}$ e $40 \mathrm{kV}$.

\subsection{Preparação dos compósitos}

Processados no Haake e termoprensados: Nesta etapa, foram introduzidas diferentes frações de CO, CA, $\operatorname{OSE}$ e $\operatorname{OLE}(5,10,15$ e 20\% em relação à massa total do compósito a ser preparado) à fibra de curauá (5, 10, 15 e 20\%), com comprimento médio de $1 \mathrm{~cm}$ (este comprimento foi escolhido devido a dificuldade de se utilizar comprimentos maiores no misturador interno). As fibras foram cortadas com auxílio de uma guilhotina. O BPEAD e a mistura CO, CA, OSE ou OLE/Fibra de curauá obtidas foram processados em um reômetro de torque Haake, modelo Rheomix 600p, 
equipado com rotores do tipo "roller", com capacidade de $45 \mathrm{~g}$ a $180^{\circ} \mathrm{C}$ e $60 \mathrm{rpm}$, com a vantagem de poder ser processada no mesmo equipamento que é utilizado para os termoplásticos. A seguir, o material obtido foi cortado em pedaços pequenos para facilitar a termoprensagem.

Aproximadamente $45 \mathrm{~g}$ da mistura de BPEAD/CO, CA, OSE ou OLE/Fibras de curauá obtido foi colocado entre duas placas de aço inox, na forma de "sanduíche" entre películas de teflon, sobre as quais foi colocada uma moldura de alumínio, para garantir a regularidade da espessura final desejada. Este conjunto foi levado a uma termoprensa "home made", previamente aquecida à temperatura de $180^{\circ} \mathrm{C}$, por um intervalo curto de tempo (em torno de $3 \mathrm{~min}$ ), sendo então submetidos à força de 2 toneladas por mais $1 \mathrm{~min}$. Nesta etapa, ocorreu a fusão do polietileno (em torno de $130^{\circ} \mathrm{C}$ ), sendo a fibra impregnada pelo termoplástico/óleo. Em seguida, o conjunto foi resfriado a temperatura ambiente pela circulação de água através do sistema. Placas $(12 \times 13 \mathrm{~cm})$ com espessura em torno de $2 \mathrm{~mm}$ foram obtidas. A Figura 25 mostra a representação esquemática da termoprensa utilizada neste estudo.

Figura 25. Representação esquemática de uma termoprensa.

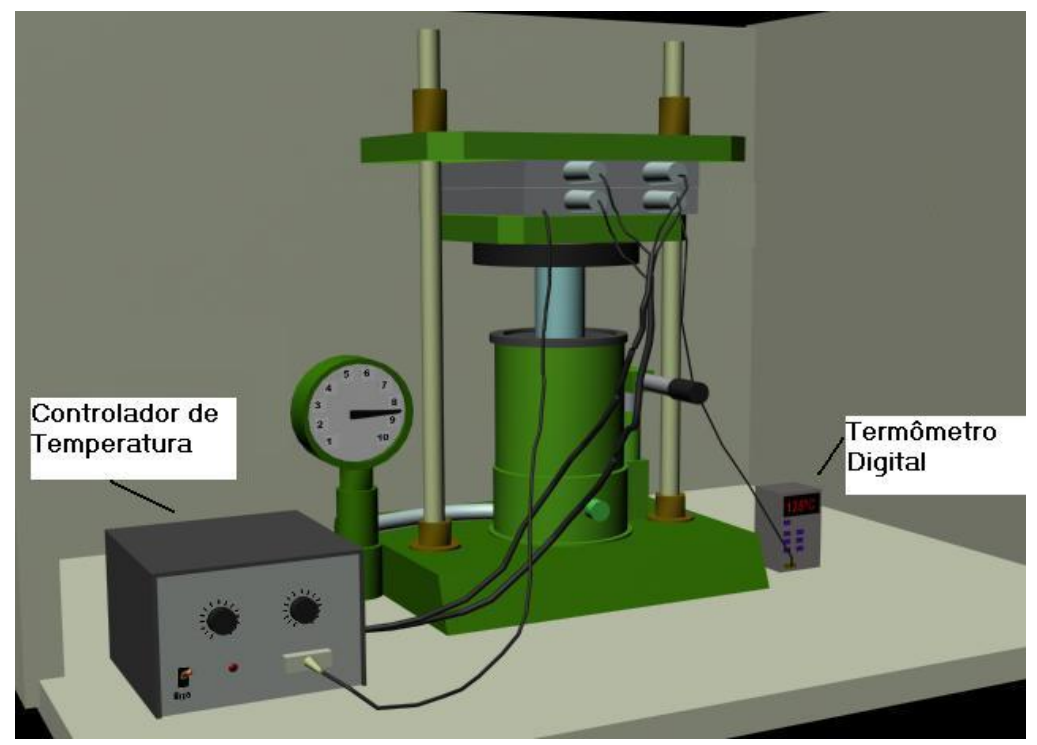

Processados por extrusão e moldados por injeção: Os materiais foram preparados a partir do polímero no estado fundido, extrusora dupla-rosca corotacional MT19TC da marca B\&P Process Equipament and Systems com diâmetro de $19,0 \mathrm{~mm}$ e L/D = 25 velocidade das roscas de $80 \mathrm{rpm}$ e com temperatura de perfil de 
$160^{\circ} \mathrm{C} / 170^{\circ} \mathrm{C} / 180^{\circ} \mathrm{C} / 180^{\circ} \mathrm{C} / 190^{\circ} \mathrm{C}$ (Figura 26). Então, os compósitos BPEAD/5\% CO, CA ou OSE/ 10\% de Fibra (fibra com um comprimento médio de $3 \mathrm{~mm}$ foi utilizada, sendo o limite máximo de comprimento permitido para processamento dos compósitos na extrusora) foram preparados a partir de moldagem por injeção, utilizando uma injetora Arburg Allrounder. Os corpos de prova foram moldados por injeção de acordo com ASTM 790-03 para o teste de flexão e ASTM D256 para o ensaio de impacto Izod. O perfil de temperatura usado foi de $205^{\circ} \mathrm{C} / 210^{\circ} \mathrm{C} / 215^{\circ} \mathrm{C} / 215^{\circ} \mathrm{C} / 215^{\circ} \mathrm{C}$. A pressão de injeção média foi de 1000 bar e a temperatura do molde foi estabilizada a $50^{\circ} \mathrm{C} \mathrm{com} \mathrm{o}$ tempo do ciclo de $48 \mathrm{~s}$. Devido à quantidade de material necessária para este processamento, o número de compósitos processados foi menor que via Haake/termoprensa (compósitos BPEAD/5\%CO, OSE e CA/10\%Fibra).

Figura 26. Perfil da extrusora.

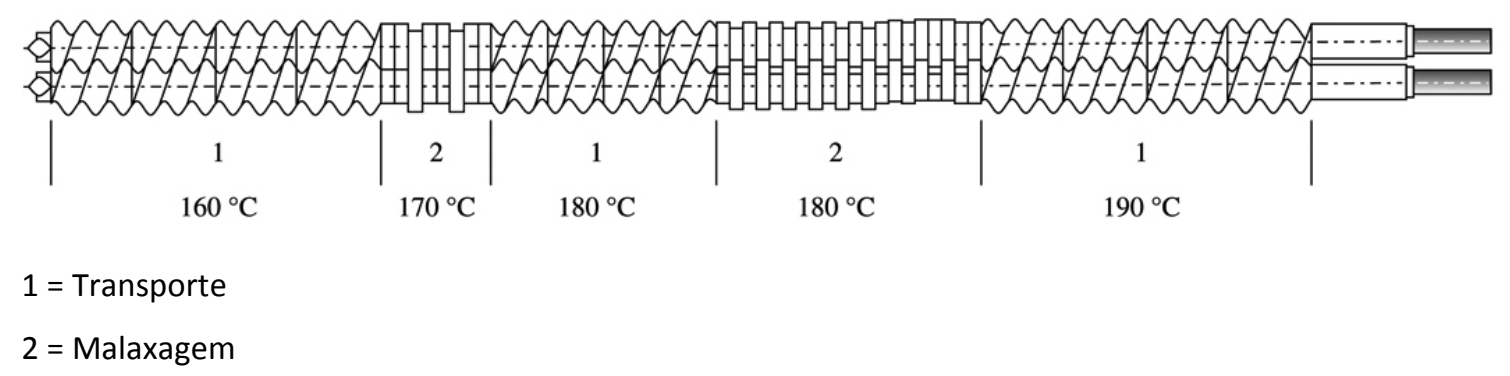

5.7 Preparação dos filmes de nanocompósitos

Processados por extrusão: O biopolietileno e a mistura nanocristais/CO, OSE ou OLE foram introduzidos na extrusora dupla-rosca DSM Micro 15 compounder (Figura 27) e fundidos a $175^{\circ} \mathrm{C}$. A velocidade da mistura foi de $100 \mathrm{rpm}$ por $10 \mathrm{~min}$. A extrusão foi realizada com uma fenda de 0,6 $\mathrm{mm}$ de abertura e de $1 \mathrm{~cm}$ de comprimento. A porcentagem de nanocristais e de óleo de mamona variou entre 3, 6 e $9 \%$ em massa de cada um dos componentes (CO e NCC). Já a porcentagem de óleo de soja e de linhaça epoxidados foi de $3 \%$ em massa. 
Figura 27. Extrusora dupla-rosca DSM Micro 15 compounder.

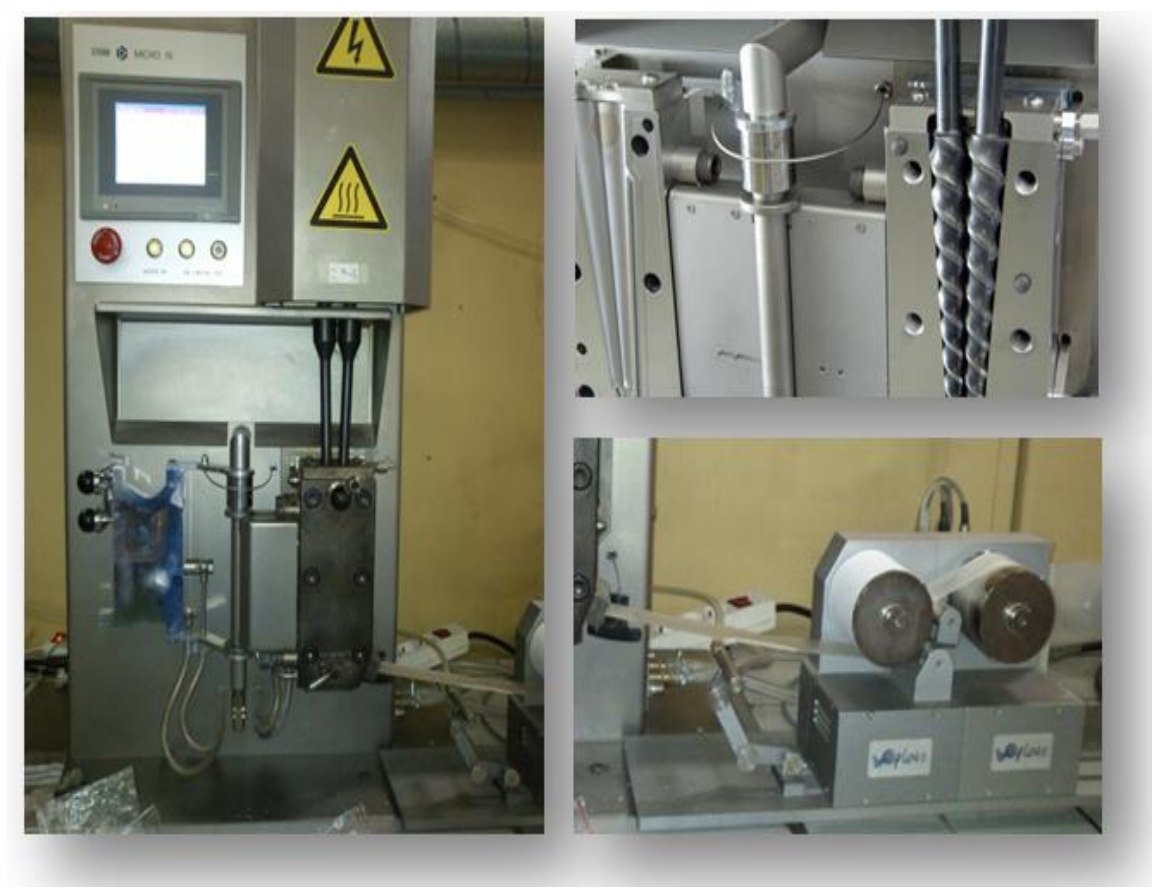

\subsection{Caracterizações dos Compósitos}

\subsection{1 Índice de Fluidez}

$\mathrm{Na}$ indústria de processamento de termoplásticos o índice de fluidez é um importante parâmetro, amplamente usado para caracterizar a propriedade de escoamento, devido a sua fácil medição. Para verificar possíveis efeitos do processamento sobre a massa molar média do polímero o índice de fluidez, pode ser tomado como indicativo da massa molar para os diferentes processamentos utilizados. Ainda, efeitos de plastificantes sobre o índice de fluidez podem ser avaliados.

$\mathrm{O}$ índice de fluidez foi medido em um Plastômetro Ml-3, pertencente ao Departamento de Engenharia de Materiais (DEMA) da Universidade Federal de São Carlos - UFSCar (São Carlos, SP), segundo a ASTM D 1238 (temperatura de $190^{\circ} \mathrm{C}$, carga de 2,16 kg), com o seguinte procedimento: preenchimento do polímero ou do compósito no barril do Plastômetro a $190^{\circ} \mathrm{C}$; após esse preenchimento, coloca-se a haste e o peso normalizado, sendo que ambos fornecem a massa total de 2,16 kg; aguarda-se o escoamento do material até que a haste atinja a região recomendada para os cortes; em seguida, utiliza-se o tempo de $10 \mathrm{~s}$ para efetuar os cortes. Espera-se 
resfriar e pesa-se. Os resultados de cada medida foram obtidos da média de 10 cortes para o BPEAD, compósitos BPEAD/Fibra e compósitos BPEAD/CO, CA, OSE e OLE/Fibra, processados no misturador interno e na extrusora.

\subsubsection{Microscopia Eletrônica de Varredura (MEV)}

A microscopia eletrônica de varredura foi realizada com o auxílio de um MEV DSM 940 Zeiss modelo 440; voltagem de aceleração de $20 \mathrm{keV}$. As amostras foram coladas em um porta amostra com base de alumínio, sendo previamente secas em estufa de circulação de $\operatorname{ar}\left(105^{\circ} \mathrm{C}\right)$, em seguida, submetidas a um fino recobrimento com ouro usando um sistema denominado "Spitter Coat", sendo analisadas as fibras de curauá e os compósitos reforçados com estas fibras e diferentes óleos vegetais, tendo como matriz o BPEAD.

\subsubsection{Calorimetria Exploratória Diferencial (DSC)}

As curvas DSC foram obtidas com auxílio de um equipamento ShimadzuTA$50 \mathrm{WSI}$, com razão de aquecimento de $10^{\circ} \mathrm{C} \mathrm{min}^{-1}$, em atmosfera de $\mathrm{N}_{2}\left(20 \mathrm{~mL} \mathrm{~min}^{-1}\right)$, e intervalo de temperatura de 30 a $200^{\circ} \mathrm{C}$, utilizando as fibras de curauá, o BPEAD e os compósitos reforçados com a fibra de curauá.

\subsubsection{Termogravimetria}

As curvas TG foram obtidas com auxílio de um equipamento Shimadzu TG modelo 50, segundo a norma NBR 14692. As amostras (aproximadamente $5 \mathrm{mg}$ ) foram colocadas em cadinhos abertos de alumina e aquecidas de 20 a $800^{\circ} \mathrm{C}\left(10^{\circ} \mathrm{C} \mathrm{min}-\right.$ $\left.{ }^{1}\right)$ em atmosfera de $\mathrm{N}_{2}\left(10 \mathrm{~mL} \mathrm{~min}^{-1}\right)$. 


\subsubsection{Ensaio de Resistência ao Impacto}

As medidas de resistência ao impacto foram realizadas seguindo a norma ASTM D256, para os corpos de prova do tipo Izod com entalhe. O equipamento utilizado foi o da marca CEAST Resil 25 (temperatura ambiente, velocidade de impacto de $4 \mathrm{~ms}^{-1}$ ) do Departamento de Engenharia de Materiais (DEMA) da Universidade Federal de São Carlos - UFSCar (São Carlos, SP).

\subsubsection{Ensaio de Resistência à Flexão}

Os ensaios de resistência à flexão foram realizados para um conjunto de 5 corpos de prova seguindo a norma ASTM 790-03, utilizando o ensaio de flexão de três pontos. Os corpos de prova foram cortados nas seguintes dimensões: $127 \mathrm{~mm}$ de comprimento, $12,7 \mathrm{~mm}$ de largura e $3,2 \mathrm{~mm}$ de espessura e submetidos ao ensaio de flexão. Utilizou-se uma máquina de ensaios universal INSTRON, modelo 5569 do Departamento de Engenharia de Materiais (DEMa) da Universidade Federal de São Carlos - UFSCar (São Carlos, SP).

\subsubsection{Análise Dinâmico-Mecânica (DMA)}

Os ensaios dinâmicos térmicos mecânico dos compósitos obtidos foram realizados no equipamento da TA Instruments, modelo Q800 DMA, (modo de flexão, amplitude de oscilação de $20 \mu \mathrm{m}$, frequência de $1 \mathrm{~Hz}$, razão de aquecimento de $2^{\circ} \mathrm{C}$ min ${ }^{1}$, de -130 a $105^{\circ} \mathrm{C}$ ). Os corpos de prova foram cortados nas seguintes dimensões: 63 $\mathrm{mm}$ de comprimento, $12,7 \mathrm{~mm}$ de largura e 3,2 $\mathrm{mm}$ de espessura e submetidos ao ensaio. 


\subsection{Caracterizações dos Nanocompósitos}

\subsubsection{Microscopia Eletrônica de Varredura (MEV)}

A microscopia eletrônica de varredura foi realizada com o auxílio de um MEV DSM 940 Zeiss modelo 440; voltagem de aceleração de $20 \mathrm{keV}$. As amostras foram coladas em um porta amostra com base de alumínio, em seguida, submetidas a um fino recobrimento com ouro usando um sistema denominado "Spitter Coat", sendo analisadas os nanocompósitos reforçados com NCC e óleo de mamona, tendo como matriz o BPEAD.

\subsubsection{Termogravimetria}

As curvas TG foram realizadas com auxílio de um equipamento STA 6000, Perkin Elmer Instruments model, USA. As amostras (aproximadamente $5 \mathrm{mg}$ ) foram colocadas em cadinhos apropriados e aquecidas de 30 a $800^{\circ} \mathrm{C}\left(10^{\circ} \mathrm{C} \mathrm{min}^{-1}\right) \mathrm{em}$ atmosfera de $\mathrm{N}_{2}\left(20 \mathrm{~mL} \mathrm{~min}^{-1}\right)$.

\subsubsection{Calorimetria Exploratória Diferencial (DSC)}

As curvas DSC foram realizadas com auxílio de um equipamento TA/DSC Q100 com razão de aquecimento de $10^{\circ} \mathrm{C} \mathrm{min}^{-1}$, em atmosfera de $\mathrm{N}_{2}\left(20 \mathrm{~mL} \mathrm{~min}^{-1}\right)$, e intervalo de temperatura de -150 a $200^{\circ} \mathrm{C}$.

\subsubsection{Ensaio de Resistência à Tração}

Com o objetivo de analisar o comportamento de módulo elástico na tração, a resistência à tração e alongamento na ruptura em função da carga, os nanocompósitos foram analisados por ensaios de tração em um DMA TA Intruments modelo Q800. Os ensaios de tração foram realizados sob a velocidade de $1 \mathrm{~N} \mathrm{~min}{ }^{-1}$. Foram analisados para cada nanocompósito o mínimo cinco corpos de prova, com dimensões de $30 \mathrm{~mm}$ de largura, 5,3 $\mathrm{mm}$ de comprimento e 0,5 $\mathrm{mm}$ de espessura. 


\subsubsection{Reologia}

O comportamento viscoelástico do BPEAD e dos nanocompósitos foi analisado através de medidas em reômetro Ares da Rheometric Scientific, em regime dinâmico (oscilatório). Os testes foram realizados a $180^{\circ} \mathrm{C}$, usando geometria de placas paralelas, com diâmetro de placa de $25 \mathrm{~mm}$, distância entre as placas de 0,55 mm e atmosfera inerte de nitrogênio. O módulo de armazenamento ( $\left.G^{\prime}\right)$ e o módulo de perda ( $\left.G^{\prime \prime}\right)$ dos materiais foram avaliados em função da frequência na faixa de 0,01 a 100rad/s. A tensão aplicada em cada ensaio foi definida de acordo com o material, assegurando que os ensaios fossem conduzidos em suas regiões de comportamento viscoelástico linear.

A estabilidade estrutural dos materiais foi avaliada através de ensaios de viscosidade em função do tempo, realizadas em um reômetro de deformação controlada ARES, da Rheometric Scientific, em regime dinâmico. Os testes foram realizados a $180^{\circ} \mathrm{C}$, usando geometria de placas paralelas, com diâmetro de placa de $25 \mathrm{~mm}$, distância entre as placas de 0,55 mm e atmosfera inerte de nitrogênio. Foram feitas medidas durante $2000 \mathrm{~s}$, a uma frequência de oscilação de $1 \mathrm{rad} / \mathrm{s}$.

Utilizou-se reômetro do Departamento de Engenharia de Materiais (DEMA) da Universidade Federal de São Carlos - UFSCar (São Carlos, SP).

\subsubsection{Análise Dinâmico-Mecânica (DMA)}

Os ensaios dinâmicos térmicos mecânico dos compósitos obtidos foram realizados no equipamento DMA, modelo 2980 da TA instruments (modo de flexão, amplitude de oscilação de $20 \mu \mathrm{m}$, frequência de $1 \mathrm{~Hz}$, taxa de aquecimento de $2^{\circ} \mathrm{C} \min ^{-}$ ${ }^{1}$, de -130 a $105^{\circ} \mathrm{C}$ ). Os filmes com $0,50 \pm 0,1 \mathrm{~mm}$ de espessura foram cortados nas seguintes dimensões: $30 \mathrm{~mm}$ de comprimento, 5,3 $\mathrm{mm}$ de largura e submetidos ao ensaio. 



\section{Resultados e Discussões}

\subsection{Caracterização das Fibras de Curauá}

As fibras de curauá, assim como as demais fibras lignocelulósicas, são constituídas de celulose, hemicelulose (ou polioses), lignina, pectina, cera e substâncias solúveis em água, sendo os três primeiros componentes majoritários e responsáveis pelas propriedades físicas das fibras (FENGEL; WEGENER, 1984). A Tabela 4 relaciona os valores médios dos componentes encontrados para a fibra de curauá utilizada no presente trabalho, sendo os dados referentes à fibra livre de umidade.

Tabela 4. Caracterização da fibra de curauá.

\begin{tabular}{cc}
\hline Propriedades & Teor (\%) \\
\hline Umidade & $8,0 \pm 0,2$ \\
Cinzas & $0,5 \pm 0,1$ \\
Holocelulose & $93 \pm 1$ \\
$\alpha$ celulose & $63,4 \pm 0,9$ \\
Hemicelulose & $29,6 \pm 0,2$ \\
Lignina Klason insolúvel & $4,7 \pm 0,1$ \\
Lignina Klason solúvel & $0,50 \pm 0,02$ \\
Lignina Klason total & $5,2 \pm 0,1$ \\
\hline
\end{tabular}

Trindade et al. (2008) caracterizaram as fibras de curauá obtendo proporções de $83,5 \%$ de holocelulose, $73,6 \%$ de $\alpha$ celulose e 9,9 \% de hemicelulose. Assim, o teor de hemicelulose e $\alpha$ celulose encontrados no presente trabalho foram superiores ao da fibra utilizada em trabalhos prévios.

A composição química das fibras, mesmo as de mesma natureza, pode apresentar proporções diferentes devido às diferentes condições de cultivo a que as plantas são submetidas (GOMES et al., 2007b).

\subsubsection{Determinação do Índice de Cristalinidade por Difração de Raios X}

Foi obtido o difratograma de raios $X$ das fibras de curauá (Figura 28). $O$ índice de cristalinidade foi determinado pela relação entre as intensidades máxima (Imáx) e 
mínima (Imín), de acordo com Equação 13 (mostrada na parte de Materiais e Métodos).

Figura 28. Difratograma de raios $\mathrm{X}$ das fibras de curauá.

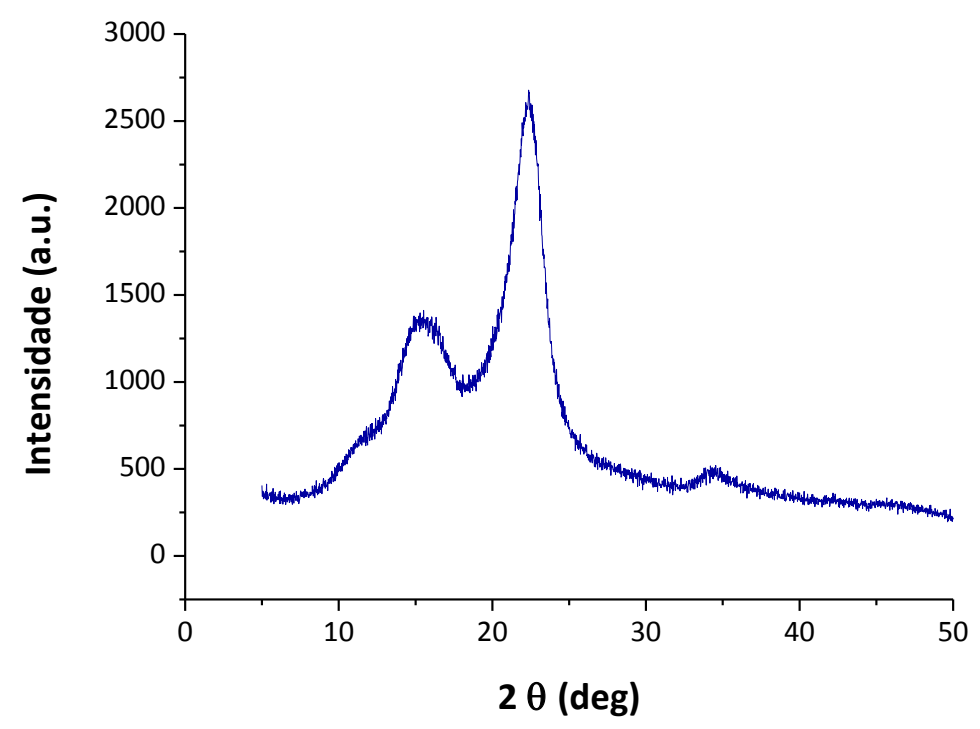

O índice de cristalinidade da fibra de curauá foi de $64 \%$ (63,4 \% como teor de $\alpha$ celulose, Tabela 4) o resultado obtido foi próximo aos de trabalhos prévios encontrados na literatura. Trindade et al. (2005) caracterizaram as fibras de curauá obtendo o índice de cristalinidade de $67 \%$ (73,6 \% como teor de $\alpha$ celulose).

\subsubsection{Análise Térmica}

O DSC da fibra de curauá (Figura 29a) exibiu um pico exotérmico em torno de $346^{\circ} \mathrm{C}$ decorrente da decomposição térmica da hemicelulose e da celulose presentes na fibra de curauá. $\mathrm{O}$ pico observado acima de $450^{\circ} \mathrm{C}$ foi atribuído à decomposição térmica da lignina. 
Figura 29. (a) Curva DSC para a fibra de curauá e (b) Curvas TG e de primeira derivada da TG da fibra de curauá, atmosfera de $\mathrm{N}_{2}$, vazão de $20 \mathrm{~mL} \mathrm{~min}{ }^{-1}$ e razão de aquecimento de $10{ }^{\circ} \mathrm{C} \mathrm{min}^{-1}$.

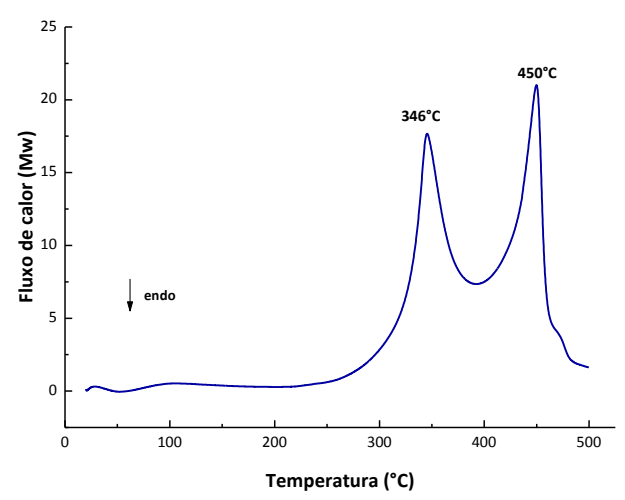

(a)

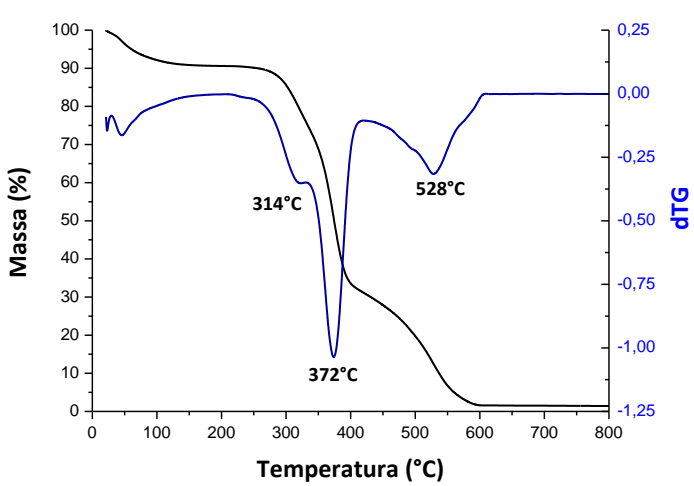

(b)

Estes eventos observados nas curvas DSC podem ser detectados nas curvas TG, pelas perdas de massa identificadas.

A curva TG (Figura 29b) mostrou perda de massa de $5 \%$ em torno de $100^{\circ} \mathrm{C}$, atribuída à perda de água aderida as fibras de curauá, devido ao caráter hidrofílico desta. Até em torno de $260^{\circ} \mathrm{C}$ às fibras de curauá apresentaram estabilidade térmica, quando então ocorreu o início da decomposição da hemicelulose $\left(258^{\circ} \mathrm{C}\right)$, seguida da celulose $\left(334^{\circ} \mathrm{C}\right)$ (TRINDADE et al., 2005).

Em torno de $400^{\circ} \mathrm{C}$ observou-se processo de decomposição envolvendo quebra das ligações $\mathrm{C}-\mathrm{C}$ da lignina $\left(\mathrm{Tp}=528^{\circ} \mathrm{C}\right)$, liberação de água, $\mathrm{CO}$ e $\mathrm{CO}_{2}$ (TOMCZAK; SATYANARAYANA; SYDENSTRICKER, 2007). Assim, a temperatura de $260^{\circ} \mathrm{C}$ pode ser considerada a temperatura máxima para a aplicação das fibras de curauá, pois a partir desta temperatura houve elevada perda de massa com a decomposição térmica das fibras.

\subsubsection{Ensaio de Tração}

As fibras foram caracterizadas quanto à resistência a tração e porcentagem de alongamento. A resistência à tração foi de $442 \pm 40 \mathrm{MPa}$ e o alongamento foi de 0,90 $\pm 0,08 \%$ 
Os resultados obtidos estão mais baixos se comparados aos de trabalhos prévios, em que outros lotes de curauá foram utilizados. Trindade et al. (2005) obtiveram resistência à tração de $636 \mathrm{MPa}$ e alongamento de 0,8 \%, enquanto Gomes et al. (2007b) determinaram um valor de resistência à tração de $913 \mathrm{MPa}$ e alongamento de $3,9 \%$.

\subsubsection{Microscopia Eletrônica de Varredura}

Foram realizadas análises de microscopia eletrônica de varredura (MEV) para as fibras de curauá (Figura 30). Observou-se na Figura 30b a presença de alguns fragmentos na superfície da fibra, provavelmente provenientes de resíduos de células parênquimas, nas quais a fibra estava ligada (MEGIATTO et al., 2008).

Figura 30. (a) e (b) Micrografia dos feixes de fibra de curauá.

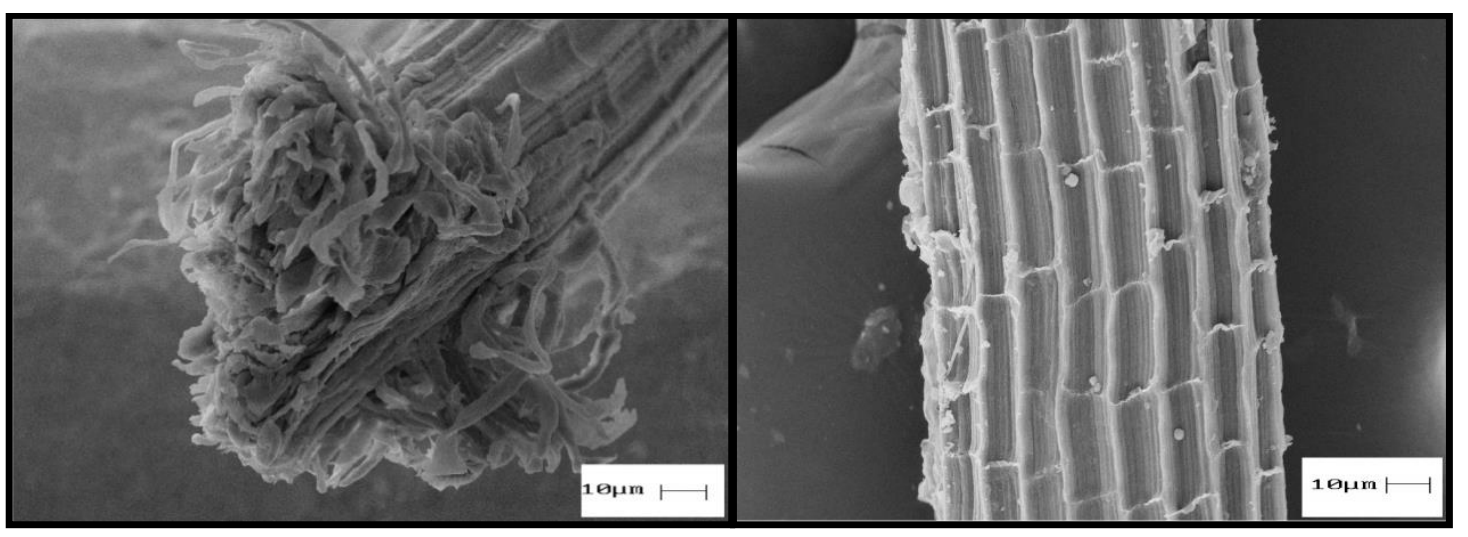

(a)

(b)

Na imagem da Figura 30a se observa o interior das fibras de curauá, composto por uma estrutura fibrilar formado pela união de feixes de fibrilas, os quais, por sua vez, são constituídos por um grande número de células, justapostas e ligadas por substâncias de origem péctica. As fibrilas são ocas, constituídas por macromoléculas de celulose, recobertas e aderidas umas as outras por uma matriz de lignina e hemicelulose. Cada fibrila possui uma complexa estrutura em camadas em que uma fina casca envolve uma segunda camada mais interna e espessa, sendo que o conjunto de fibrilas forma espirais ao longo do eixo das fibras (SILVA; AQUINO, 2008). 


\subsection{Caracterização dos Nanocristais}

O objetivo do tratamento alcalino das fibras de curauá foi à remoção de hemicelulose e lignina das fibras naturais, para posterior hidrólise ácida da polpa de celulose visando à obtenção dos nanocristais de celulose. A composição das fibras (lignina, hemicelulose e celulose) depende da fonte, devido a circunstâncias diferentes em que em que as plantas crescem. As fibras de curauá (Figura 31) contêm 63,4 \% de celulose, 29,6\% de hemicelulose e 5,2\% de lignina (Tabela 4).

Figura 31. Caracterização da Fibra de Curauá e da Polpa tratada com NaOH.

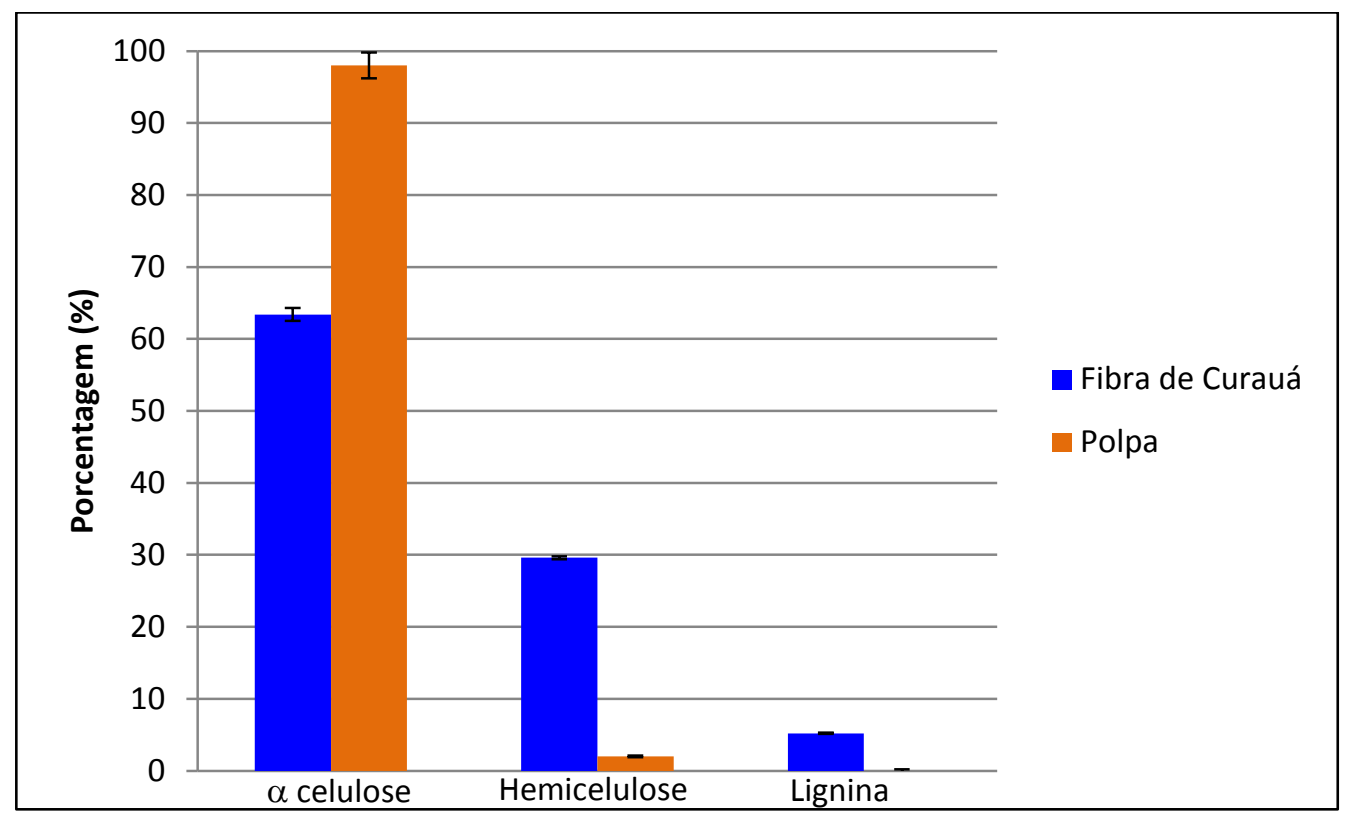

A fibra de curauá foi submetida a tratamentos sucessivos. O tratamento da fibra com (três ciclos). A polpa obtida contêm 98\% de $\alpha$ celulose, $2 \%$ de hemicelulose, sendo que lignina não foi detectada nas condições de análise (Figura 31).

\subsubsection{Determinação do Índice de Cristalinidade por Difração de raios X}

Foi obtido o difratograma de raios $X$ dos nanocristais de curauá (Figura 32), obtidos por hidrólise ácida da polpa de curauá. O índice de cristalinidade foi determinado pela relação entre as intensidades máxima (Imáx) e mínima (Imín), de acordo com a Equação 14 (mostrada na parte de Materiais e Métodos). 
Figura 32. Difratograma de Raios $X$ dos nanocristais de curauá.

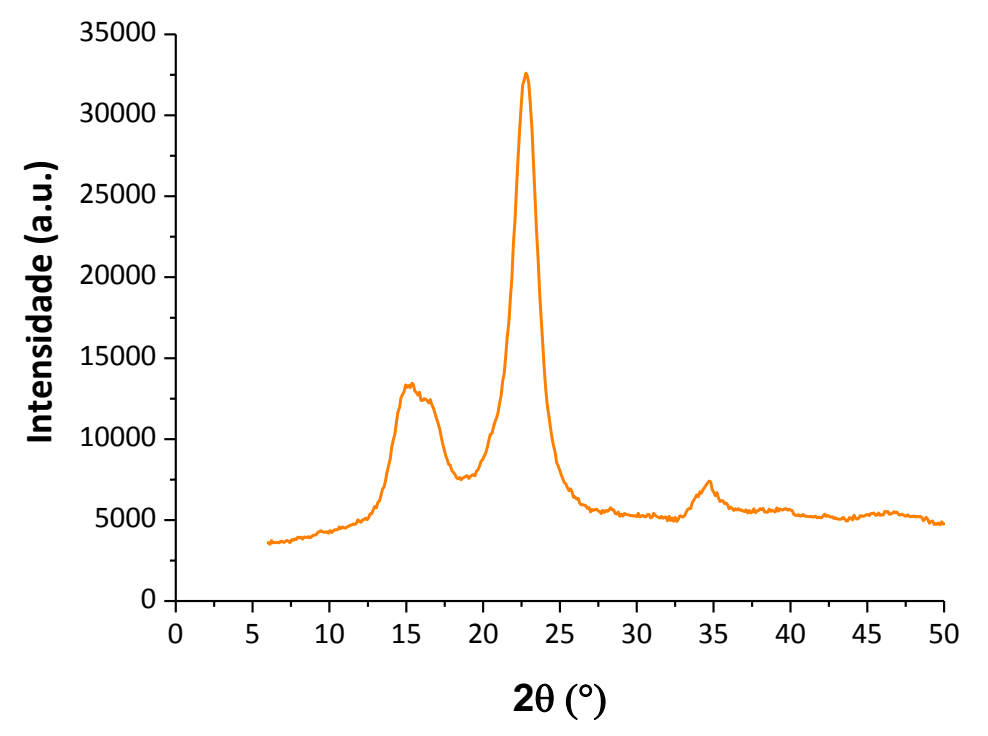

Os nanocristais de curauá apresentaram picos de difração $2 \theta$ típicos em 15, 23 e $35^{\circ}$. O grau de cristalinidade para a fibra de curauá foi de $64 \%$ e para os nanocristais foi de $76,6 \%$. O aumento do grau de cristalinidade dos nanocristais indicou que houve a remoção de celulose não cristalina e de outros resíduos não cristalinos como consequência da hidrólise ácida da polpa de celulose, que resultou nos nanocristais.

\subsubsection{Análise Térmica}

A análise termogravimétrica dos NCCs é apresentada na Figura 33.

Figura 33. Curvas TG e de primeira derivada da TG dos nanocristais de curauá, atmosfera de $\mathrm{N}_{2}$, vazão de $20 \mathrm{~mL} \mathrm{~min}^{-1}$ e razão de aquecimento de $10^{\circ} \mathrm{C} \mathrm{min}^{-1}$.

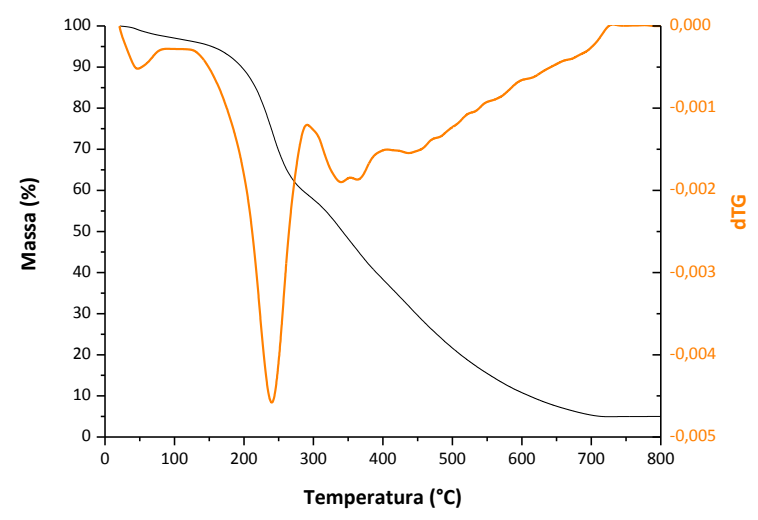


A primeira perda de massa das curvas TG, entre 30 e $100^{\circ} \mathrm{C}$ é referente à evaporação de água. Através das curvas TG, observou-se que até em torno de $198^{\circ} \mathrm{C}$ os NCCs de curauá apresentaram estabilidade térmica, já as fibras de curauá apresentam estabilidade térmica até $260^{\circ} \mathrm{C}$ (Figura 29b). A hidrólise ácida com ácido sulfúrico diminuiu a temperatura em que iniciou a perda de massa. O ácido sulfúrico é o mais usado para o isolamento dos NCCs e produz uma suspensão estável de NCCs, o que se deve à repulsão eletrostática causada pela presença de grupos sulfatos na superfície dos mesmos (BECK-CANDANEDO; ROMAN; GRAY, 2005).

\subsubsection{Microscopia Eletrônica de Varredura com Fonte de Emissão por Efeito de Campo (SEM-FEG)}

A morfologia dos nanocristais de curauá foi caracterizada utilizando microscopia eletrônica de varredura com fonte de emissão por efeito de campo (SEMFEG). A Figura 34 mostra a micrografia obtida da suspensão de nanocristais diluídos em água obtidos por meio de hidrólise ácida da polpa celulósica.

Figura 34. Micrografia obtida por SEM-FEG para solução diluída de nanocristais de curauá.

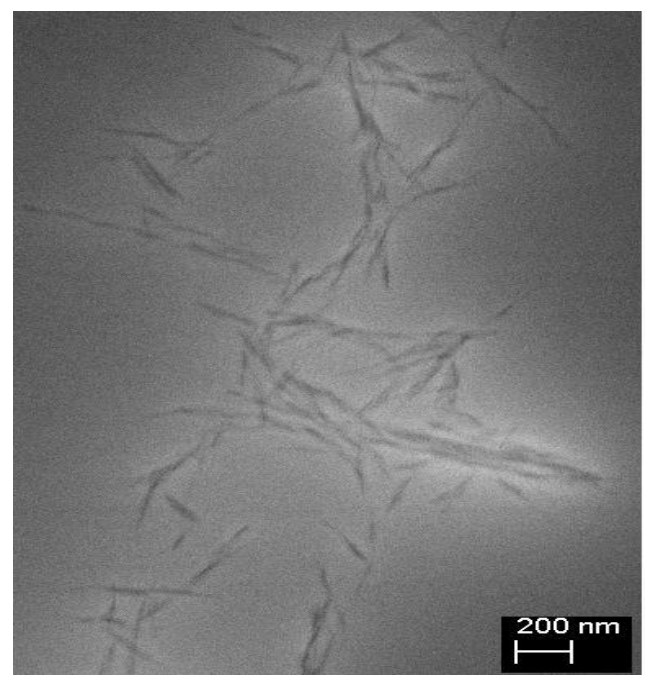

Os nanocristais de curauá apresentaram estrutura de agulhas e pôde ser caracterizado com espessura média de $10 \pm 2 \mathrm{~nm}$ e comprimento médio de $187 \pm 3$ $\mathrm{nm}$, utilizando Image J, um programa apropriado para tal tendo sido realizadas 50 
medidas. Estes valores foram próximos das dimensões de nanofibras de curauá encontrados na literatura, Corrêa et al. (2010) obtiveram nanofibras de curauá com espessura entre 6 e $10 \mathrm{~nm}$ e comprimento médio de 80 e $170 \mathrm{~nm}$.

A razão de aspecto (L/D razão entre o comprimento e o diâmetro) dos nanocristais de curauá foi de 19. Zhang et al. (2007) relataram que menores diâmetros das nanopartículas (celulose microfibrilada ou nanocristais) podem estar associados com maiores quantidades de hemicelulose presentes na fibra, que limitam a organização das cadeias de celulose. Já o comprimento dos NCCs pode estar associado ao seu grau de polimerização, que depende da origem do material de partida. Taipina et al. (2012) obtiveram nanocristais de curauá com razão de aspecto menor (17) que o valor encontrado no presente estudo, indicando a importância da origem do material de partida.

\subsection{Caracterizações do "polietileno verde" (BPEAD)}

O BPEAD foi utilizado como matriz polimérica para a produção dos compósitos. Na Tabela 5 encontram-se os valores de alguns parâmetros avaliados para o BPEAD.

Tabela 5. Propriedades típicas do BPEAD.

\begin{tabular}{cccc}
\hline Propriedade & Método ASTM & Unidade & Valor \\
\hline Índice de Fluidez & D-1238 & $\mathrm{g}\left(10 \mathrm{~min}^{-1}\right.$ & $0,10 \pm 0,01$ \\
\hline Resistência ao impacto IZOD com entalhe & $\mathrm{D}-256$ & $\mathrm{~J} \mathrm{~m}^{-1}$ & $224 \pm 31$ \\
\hline Módulo de Flexão & ASTM D790-02 & $\mathrm{GPa}$ & $0,52 \pm 0,03$ \\
\hline Resistência à Flexão & ASTM D790-03 & $\mathrm{MPa}$ & $16 \pm 1$ \\
\hline
\end{tabular}

$\mathrm{Na}$ indústria de processamento de termoplásticos o índice de fluidez é um importante parâmetro, amplamente usado para caracterizar a propriedade de escoamento, devido a sua fácil medição. $O$ índice de fluidez do BPEAD foi de 0,10 $\mathrm{g}(10 \mathrm{~min})^{-1}$. O polietileno de alta densidade apresenta boas propriedades mecânicas, quando comparado aos demais polietilenos (baixa e média densidade). O polietileno de baixa densidade apresenta resistência ao impacto IZOD com entalhe de $21 \mathrm{~J} \mathrm{~m}^{-1}$ e o polietileno de média densidade de $75 \mathrm{~J} \mathrm{~m}^{-1}$ (disponível em <http://www.braskem.com.br/>). A resistência ao impacto foi de $224 \mathrm{~J} \mathrm{~m}^{-1}$, módulo de flexão de 0,52 MPa e resistência à flexão de 16,5 MPa (Tabela 5). 


\subsubsection{Determinação do Índice de Cristalinidade por Difração de Raios X}

A Figura 35 apresenta o difratograma de raios $X$ do BPEAD. $O$ índice de cristalinidade foi determinado pelo cálculo da área sob o halo amorfo $I_{a}$, pela integração dos picos de difração $I_{C}$, usando a constante de proporcionalidade para o polietileno de alta densidade $\mathrm{K}$, de acordo com a Equação 14 (mostrada na parte Materiais e Métodos).

Figura 35. Difratograma de Raios X do BPEAD.

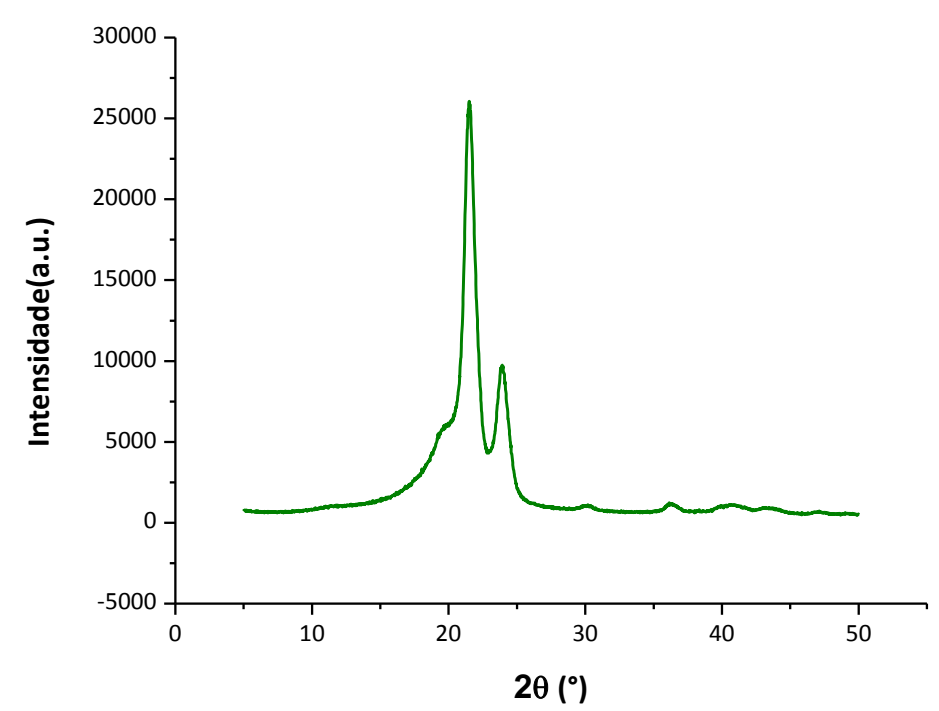

$\mathrm{O}$ espectro de difração por raios $\mathrm{X}$ do polietileno de alta densidade apresentou dois picos bastante intensos juntamente com um halo não cristalino entre os ângulos $15^{\circ}$ e $26^{\circ}$ e outros picos bem menos intensos entre os ângulos $26^{\circ}$ e $50^{\circ}$ como pode ser observado na Figura 35. O índice de cristalinidade do BPEAD neste estudo foi de $76 \%$ (CASTRO et al., 2013), Ueki et al. (1997) obtiveram índice de cristalinidade (através do espectro de difração por raios X) para o polietileno de alta densidade de $68 \%$. 


\subsubsection{Análise Térmica}

A Figura 36a mostra as curvas termogravimétricas para as amostras de BPEAD. Devido ao caráter hidrofóbico do BPEAD não houve praticamente interação com as moléculas de água, não sendo observada praticamente perda de massa até aproximadamente $350^{\circ} \mathrm{C}$, quando o $\mathrm{BPEAD}$ inicia de composição em uma única etapa que se completa em $530^{\circ} \mathrm{C}$ sem resíduo no suporte de amostra.

Figura 36. (a) Curva TG e de derivada primeira da TG do BPEAD e (b) Curva DSC do BPEAD, atmosfera de $\mathrm{N}_{2}$, fluxo de $20 \mathrm{~mL} \mathrm{~min}^{-1}$ e razão de aquecimento de $10^{\circ} \mathrm{C} \mathrm{min}^{-1}$.

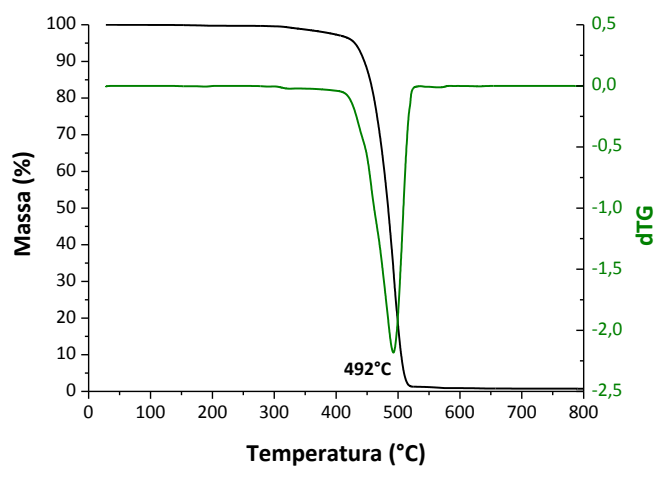

(a)

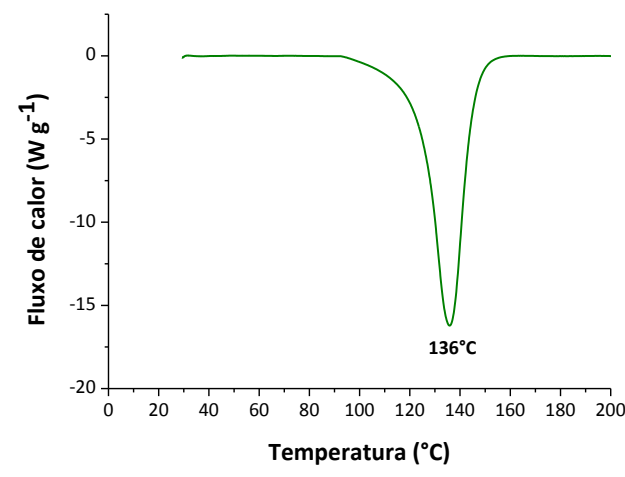

(b)

Na Figura 36b é apresentada a curva de DSC para o BPEAD. Observou-se um pico endotérmico em torno de $130^{\circ} \mathrm{C}$ relacionado com a temperatura de fusão do BPEAD.

Pelo cálculo da área do pico da temperatura de fusão da curva de DSC, foi obtida a entalpia de fusão de $196 \mathrm{~J} \mathrm{~g}^{-1}$ e utilizando a Equação 1 (mostrada na parte Materiais e Métodos) pôde-se calcular a cristalinidade do BPEAD que foi de $66 \%$. Este valor é inferior ao encontrado via difração de raios X (76\%), mencionado previamente.

\subsubsection{Analise Dinâmico- Mecânica (DMA)}

A analise térmica dinâmico- mecânica (DMA) fornece informações a respeito do módulo de elasticidade ou armazenamento ( $\left.E^{\prime}\right)$, do modulo de dissipação viscosa ou 
perda ( $\left.E^{\prime \prime}\right)$ e do amortecimento mecânico ou atrito interno ( $\left.\tan \delta=E^{\prime \prime} / E^{\prime}\right)$ de um material, quando sujeito a uma solicitação dinâmica.

Na Figura 37 estão mostradas curvas, para o módulo de armazenamento ( $\left.E^{\prime}\right)$, para o módulo de perda ( $E^{\prime \prime}$ ) e para $\tan \delta$ em função da temperatura, obtido no ensaio dinâmico-mecânico.

Figura 37. Curvas DMA do BPEAD: $E^{\prime} ; E^{\prime \prime}$ e $\tan \delta$ versus temperatura.

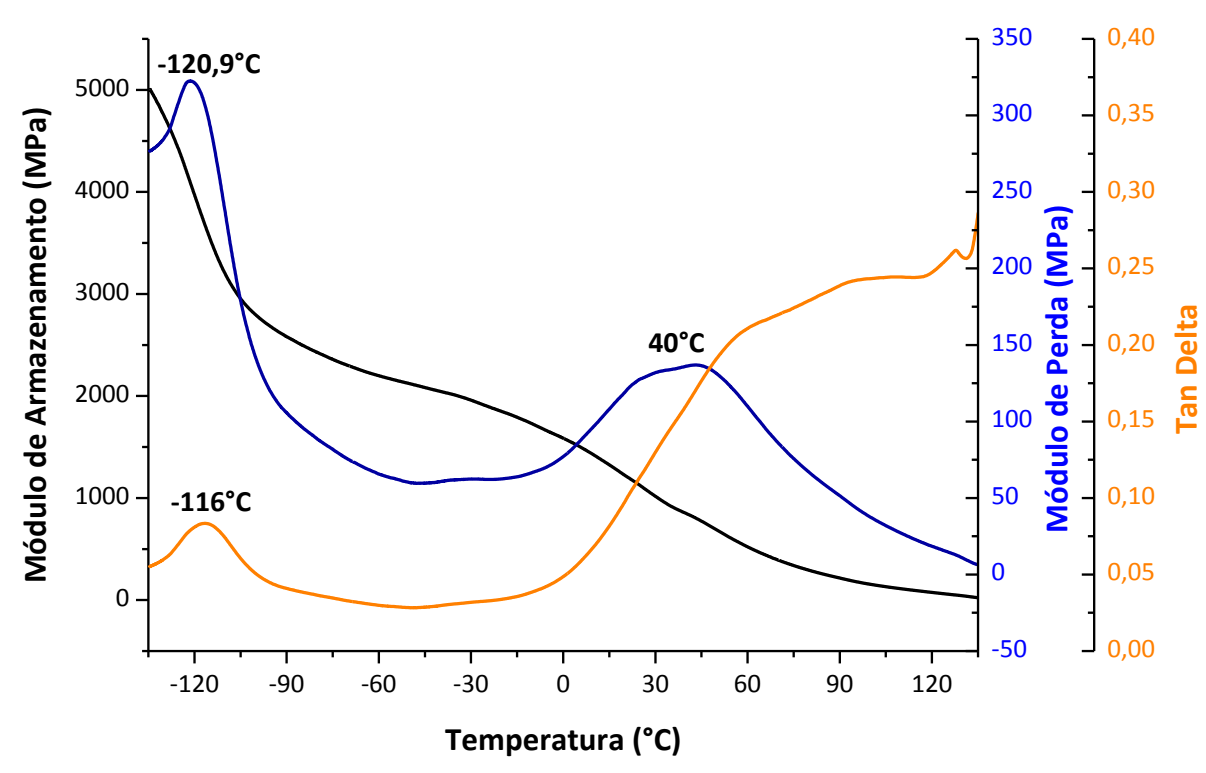

O polietileno de alta densidade pode apresentar uma relaxação em torno de $120^{\circ} \mathrm{C}$, como a observada na Figura 37 , relacionada à região não cristalina e associada à transição vítrea $\left(\operatorname{Tg}, \alpha_{a}\right)$ por pesquisadores (MOORE; MATSUOKA, 1964). Na curva de $E^{\prime \prime}$, o pico referente a esta transição é observado a $-120,9^{\circ} \mathrm{C}$ para o BPEAD. Destaca-se que até aproximadamente $30^{\circ} \mathrm{C}$ nenhum outro pico foi observado, o que reforça a atribuição de transição vítrea ao pico observado a $-120,9^{\circ} \mathrm{C}$. Na curva de $\tan \delta$ o pico referente a esta transição é observado a $-116^{\circ} \mathrm{C}$.

O pico em torno de $40^{\circ} \mathrm{C}$ na curva de $\mathrm{E}^{\prime \prime}\left(-94^{\circ} \mathrm{C}\right.$ na curva de $\tan \delta$ ), acima de $\mathrm{Tg}$ e abaixo de $\mathrm{Tm}$ (temperatura de fusão, em torno de $135^{\circ} \mathrm{C}$ ) pode ser considerado decorrente de uma transição do tipo $\alpha_{c}^{\prime}$, e relacionado com a mobilidade das unidades das cadeias poliméricas dentro da fase cristalina, ou seja, associada com um processo de cisalhamento interlamelar (KAJIYAMA et al., 1973; SUEHIRO et al., 1979). 
Polietilenos também podem apresentar uma relaxação entre $-50^{\circ} \mathrm{C}$ e $0^{\circ} \mathrm{C}$, atribuída ao movimento de cadeias com conformações menos estendidas, sendo, mais acentuada para polietilenos de baixa densidade (KYU et al., 1976). Nenhum pico foi observado nesta região para o BPEAD (Figura 37).

\subsection{Caracterização dos óleos vegetais}

\subsubsection{Análise Térmica}

No presente trabalho, buscando melhorar o desempenho dos compósitos poliméricos reforçados com fibras de curauá, óleos vegetais foram usados na formulação do compósito, com a possibilidade de atuarem, além de como plastificante, também como agentes compatibilizantes, devido à afinidade, em termos de estrutura química, tanto com BPEAD como com a fibra lignocelulósica, conforme já mencionado.

A Figura 38 mostra as curvas DSC para o óleo de mamona (CO), óleo de canola (CA), óleo de soja epoxidado (OSE) e óleo de linhaça epoxidado (OLE) no intervalo de $100+100^{\circ} \mathrm{C}$.

Figura 38. Curvas DSC para os óleos vegetais (a) CO, (b) CA, (c) OLE, e (d) OSE, atmosfera de $\mathrm{N}_{2}$, fluxo de $20 \mathrm{~mL} \mathrm{~min}^{-1}$ e razão de aquecimento de $10^{\circ} \mathrm{C} \mathrm{min}^{-1}$.

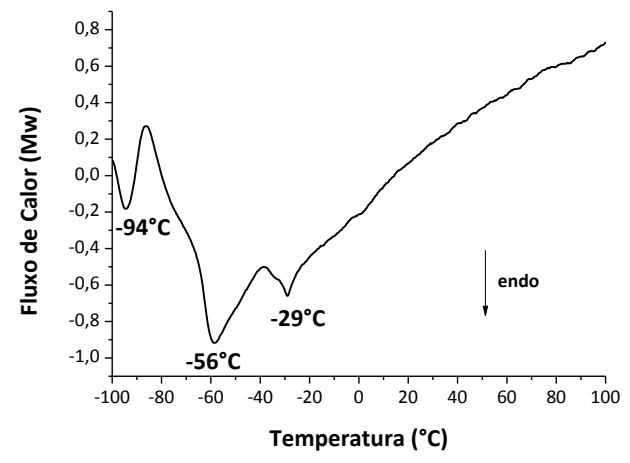

(a)

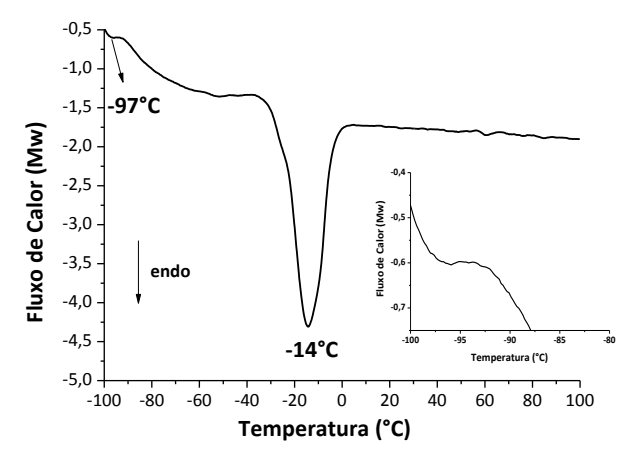

(b) 


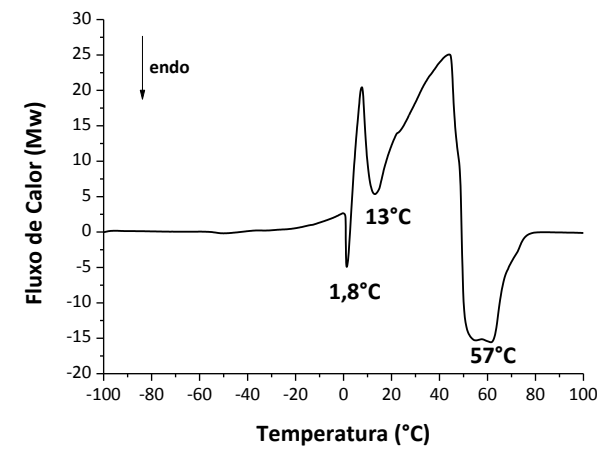

(c)

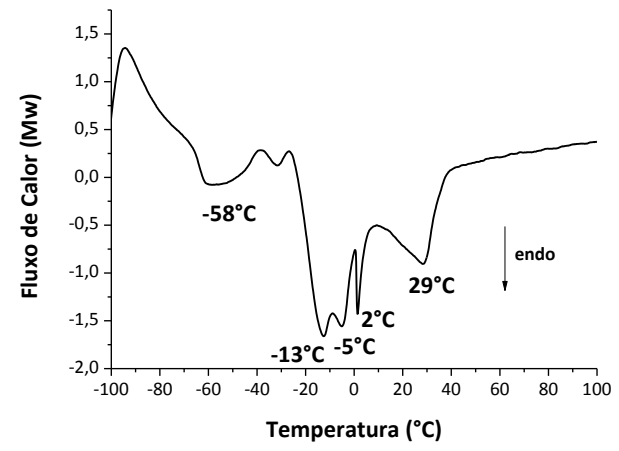

(d)

As diferentes temperaturas de fusão e formas das curvas representaram os efeitos combinados da composição dos ácidos graxos. Portanto, os óleos vegetais não apresentaram um ponto de fusão específico, apresentaram uma ampla transição na região -100 a $50^{\circ} \mathrm{C}$ com vários picos endotérmicos. Assim, uma análise exata dos perfis térmicos para óleos vegetais por DSC é bastante complexa devido à grande variedade e distribuição da composição dos ácidos graxos (SAMYN et al., 2011).

O óleo de mamona apresentou três picos endotérmicos $\left(-94,-56\right.$ e $\left.-29^{\circ} \mathrm{C}\right)$, relacionados com a fusão do ácido ricinoléico e dos demais ácidos graxos presentes no CO. Samyn et al. (2011) observaram dois picos endotérmicos de fusão o primeiro em $23^{\circ} \mathrm{C}$ e o segundo em $-7^{\circ} \mathrm{C}$. O número de picos endotérmicos depende da composição de ácidos graxos no $\mathrm{CO}$, dependendo da planta, da colheita, da estação, e das condições de crescimento.

O óleo de canola apresentou um pico endotérmico $-14^{\circ} \mathrm{C}$, relacionado com a fusão dos ácidos oléico, linoléico e linolênico. Tan et al. (2002) avaliaram as curvas de DSC $\left(-100\right.$ a $\left.100^{\circ} \mathrm{C}\right)$ de diferentes óleos vegetais, dentre eles o óleo de canola e observou a presença de dois picos endotérmicos, um amplo pico a baixas temperaturas $\left(-60^{\circ} \mathrm{C}\right)$ e um pequeno pico em temperaturas mais elevadas $\left(-10^{\circ} \mathrm{C}\right)$ relacionado com a fusão de diferentes ácidos graxos.

O óleo de linhaça epoxidado apresentou três picos endotérmicos $(1,8,13$ e $\left.57^{\circ} \mathrm{C}\right)$, o óleo de soja epoxidado apresentou cinco picos endotérmicos (-58, -13, -5, 2 e $29^{\circ} \mathrm{C}$ ). Os picos endotérmicos que apareceram nas temperaturas mais elevadas são dos 
ácidos linoléicos, oléicos e linolênicos, que são os três principais constituintes destes óleos (Tabela 2). Estes eventos também foram observados por Tan et al. (2002).

A Figura 39 apresenta as curvas de TG e dTG para os óleos vegetais utilizados neste estudo.

Figura 39. Curvas TG e dTG para os óleos vegetais (a) CO, (b) CA, (c) OLE, e (d) OSE, atmosfera de $\mathrm{N}_{2}$, fluxo de $20 \mathrm{~mL} \mathrm{~min}^{-1}$ e razão de aquecimento de $10^{\circ} \mathrm{C} \mathrm{min}^{-1}$.

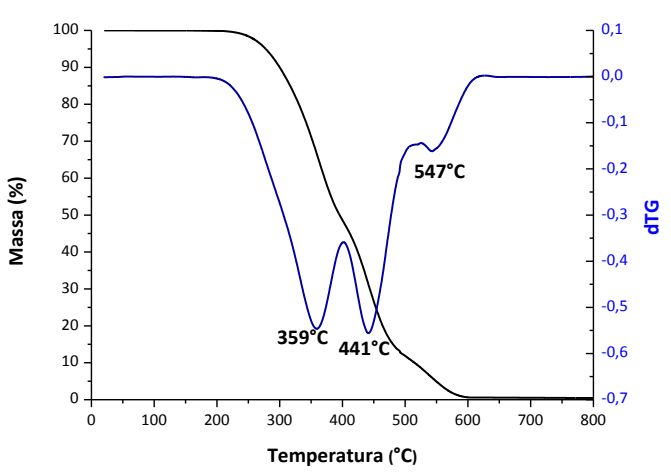

(a)

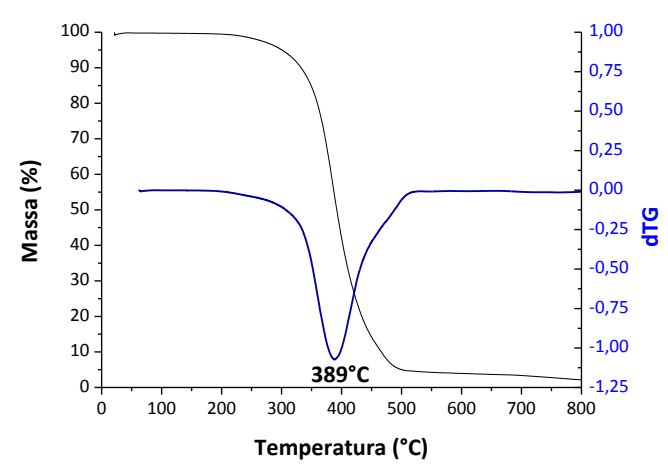

(c)

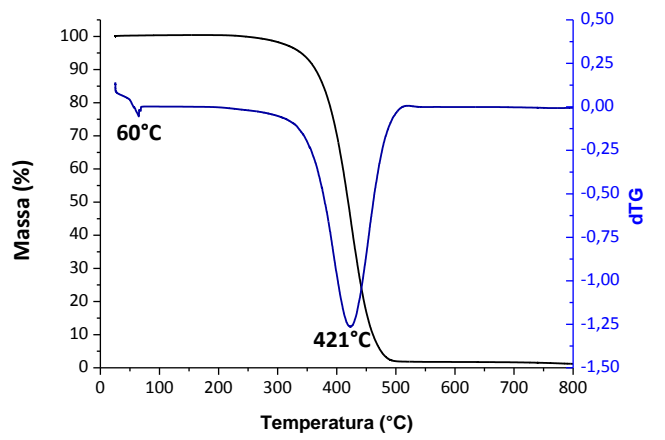

(b)

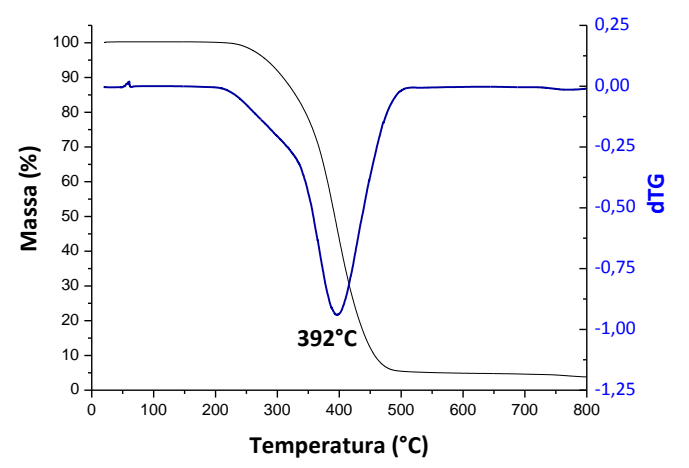

(d)

O óleo de mamona apresentou em sua curva dTG (Figura 39a) três estágios de perda de massa, referentes à decomposição dos ácidos graxos, predominantemente do ácido ricinoléico (CONCEIÇÃO et al., 2007). O primeiro estágio pôde ser observado pelo pico intenso no intervalo de $210-400^{\circ} \mathrm{C}$ e o segundo entre $400-500^{\circ} \mathrm{C}$. O terceiro estágio de perda de massa pôde ser observado pela presença de um pico pouco intenso no intervalo de $503-612^{\circ} \mathrm{C}$, com máximo em $547^{\circ} \mathrm{C}$.

As curvas TG e dTG do CA (Figura 39b), mostra um pico referente à decomposição do ácido oléico, principal constituinte do óleo de canola (GHAZANI; 
MARANGONI, 2013). O pico contido no intervalo de $223-529^{\circ} \mathrm{C}$ é intenso, com máximo em $421^{\circ} \mathrm{C}$.

Pode-se observar através das curvas TG e dTG para o OLE e do OSE (Figura 39 c e d) que há um único estágio de perda de massa significante, contido no intervalo entre $194-521^{\circ} \mathrm{C}$, associado à decomposição dos ácidos oléico, linoléico e linolênico (TAN; AHMAD; CHOW, 2014). A temperatura máxima de decomposição (Tp) observada foi de $389^{\circ} \mathrm{C}$ para o OLE e $392^{\circ} \mathrm{C}$ para o OSE.

\subsection{Compósitos preparados no misturador interno}

\subsubsection{Preparação das Amostras no Misturador Interno e MFI dos compósitos}

O processamento da mistura de BPEAD, CO, CA, OSE, OLE e fibra de curauá foram analisados através da reometria de torque. A Figura 40 mostra as curvas de torque para os compósitos de BPEAD/5\%CO/5\%Fibra, BPEAD/5\%CA/5\%Fibra, BPEAD/5\%OSE/5\%Fibra e BPEAD/5\%OLE/5\%Fibra.

Figura 40. Curvas de processamento dos compósitos no misturador interno Haake: (a) Torque em função do tempo (0-6 min), (b) (0-3 min).
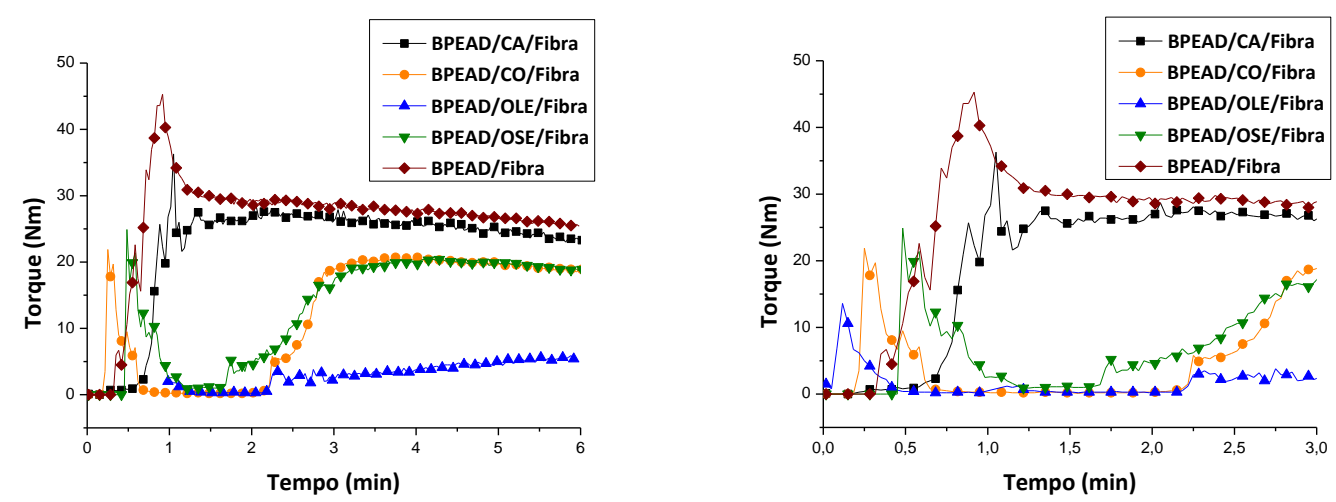

As curvas de torque obtidas durante o processamento no misturador interno apresentaram, em aproximadamente $1 \mathrm{~min}$, um aumento de torque devido à alimentação da mistura. Em seguida, ocorreu uma diminuição devido à fusão do BPEAD na câmara de mistura, e também se observou uma diminuição da viscosidade para os compósitos com óleo de canola, óleo de mamona e óleo de soja epoxidado, 
com relação à BPEAD/fibra. Destaca-se que a diminuição na viscosidade favorece a molhabilidade da fibra pelo BPEAD e óleo (UEKI; ZANIN, 1997; LEl et al., 2007).

Para o compósito com óleo de linhaça epoxidado observou-se uma diminuição do torque em relação aos compósitos com CA, CO e OSE. Possivelmente o OLE atuou mais intensamente entre as partículas e o metal do equipamento, reduzindo o atrito entre material e equipamento (MADALENO et al., 2009).

As curvas de torque (não mostradas) para as misturas com diferentes percentuais de fibra e óleos vegetais são análogas às mostradas na Figura 40.

Os compósitos foram processados a $180^{\circ} \mathrm{C}$ no misturador interno Haake e não se observou queda no torque durante os seis minutos de experimento, indicando que as fibras de curauá não sofreram degradação durante o processamento.

A Figura 41 mostra os valores de torque de equilíbrio após 4 minutos de mistura, quando a viscosidade se torna aproximadamente constante (Figura 40).

Figura 41. Valores de equilíbrio de torque após 4 min de mistura para compósitos preparados no misturador interno Haake.

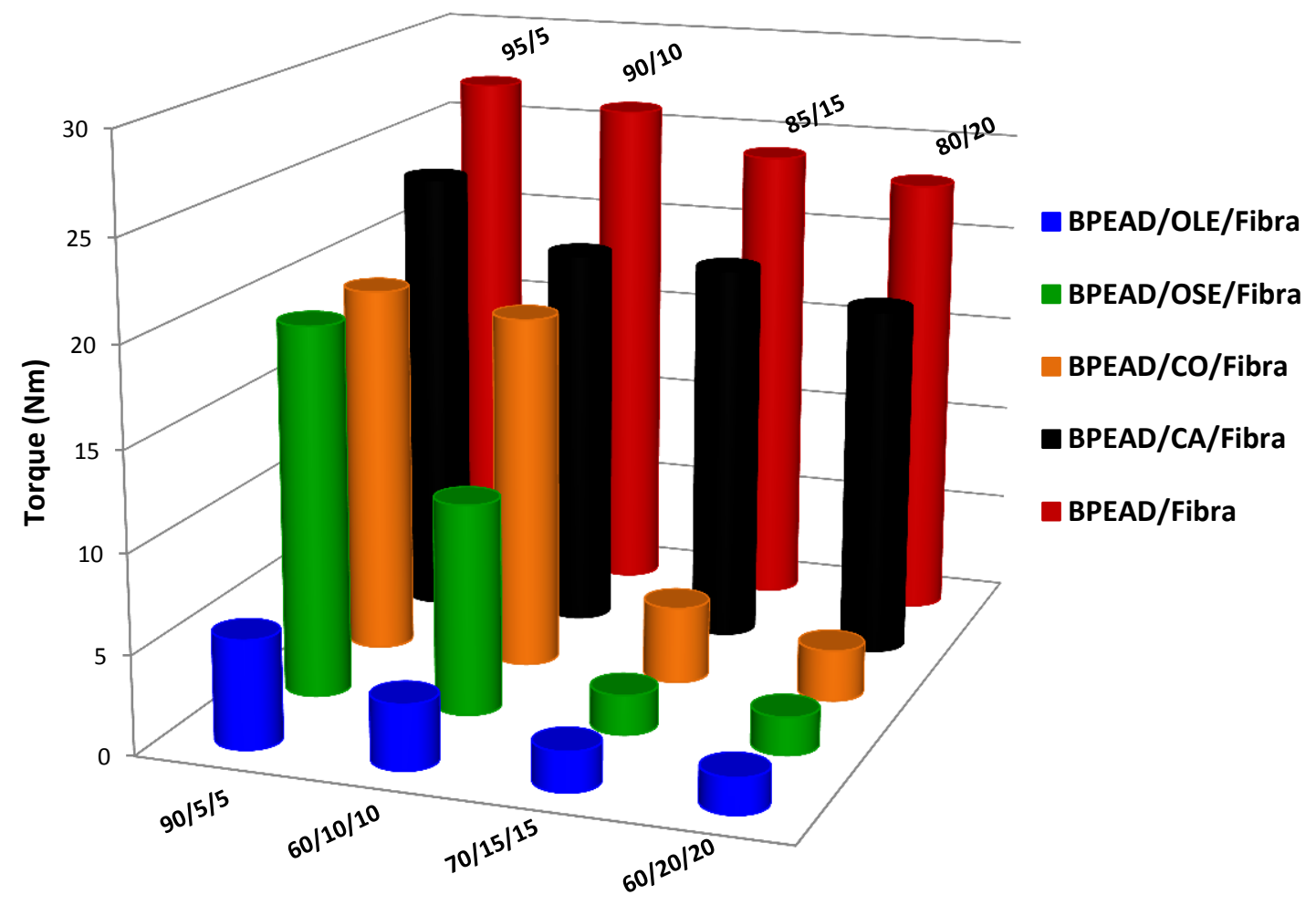


A figura 41 mostra que o valor de equilíbrio para os compósitos BPEAD/Fibra foi maior em comparação com BPEAD/óleos vegetais/Fibra, indicando que o óleo pôde agir como um plastificante e reduziu o atrito entre as partículas e/ou entre estas e o equipamento (MADALENO et al., 2009). Por outro lado, a diminuição nos valores do torque de equilíbrio para todos os compósitos com o aumento da adição de óleos vegetais, indicou que os óleos vegetais dificultaram a aglomeração das fibras. Estes resultados indicaram que possivelmente houve um aumento das interações entre a fibra e a matriz (como mostrado mais tarde no estudo MEV). Zhu et al. (2010) observaram o mesmo efeito em compósitos de resina epóxi, usando 3aminopropiltrietoxissilano como agente compatibilizante e nanofibras de carbono como reforço.

Destaca-se novamente que neste texto seguiu-se a definição da IUPAC, segundo a qual um plastificante corresponde a uma substância incorporada em um material para aumentar sua flexibilidade, trabalhabilidade, ou distensibilidade (Godwin, 2011). Não necessariamente o mesmo atua sobre a transição vítrea do material.

Para todos os compósitos, observou-se visualmente que adicionando $20 \%$ de óleo ao compósito, certa quantidade de CO, CA, OSE ou OLE adicionada ficou retida no misturador interno, o que levou a uma porcentagem real de óleo, menor que $20 \%$ no compósito. A Figura 41 mostra que os resultados para 15 e 20\% de óleo são próximos.

Na Figura 42 estão representados os resultados das análises de índice de fluidez para os compósitos reforçados com fibra de curauá. 
Figura 42. Índice de fluidez para os compósitos BPEAD/CA/Fibra, BPEAD/CO/Fibra, BPEAD/OSE/Fibra, BPEAD/OLE/Fibra e BPEAD/Fibra (desvio padrão entre 5 e $10 \%$ ).

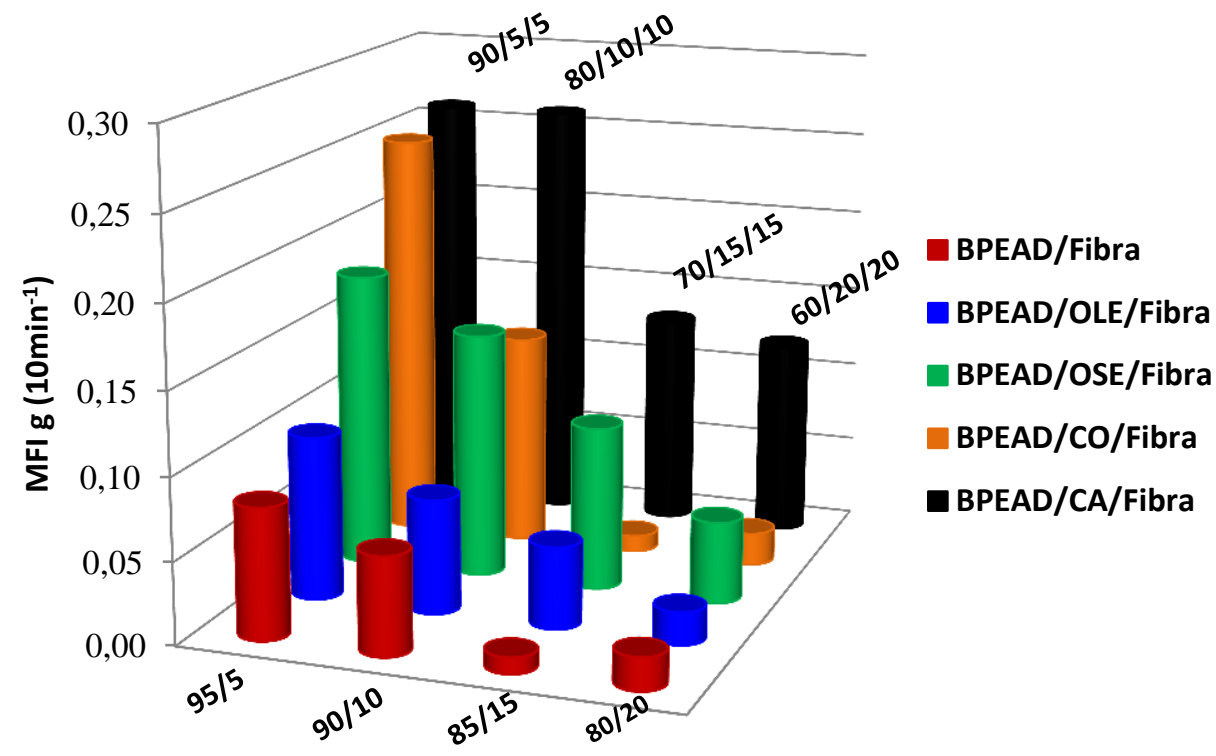

O índice de fluidez para o BPEAD foi de 0,10 $\mathrm{g}(10 \mathrm{~min})^{-1}$ e diminuiu com a adição de fibras nos compósitos BPEAD/Fibra (Figura 42). Este resultado indicou que quanto maior a quantidade de fibras, maior a viscosidade da mistura e também maior foi à dificuldade de processamento, devido à redução da mobilidade molecular (ISLAM; BEG; GUPTA, 2013). A adição dos óleos vegetais aos compósitos reforçados com fibra de curauá gerou um aumento do índice de fluidez, indicando que os óleos vegetais atuaram como plastificante e melhoraram a processabilidade do compósito, já que mais material fluiu em um mesmo intervalo de tempo. Desta forma, a adição dos óleos vegetais pode acarretar ganhos de produtividade reduzindo o tempo de permanência do material fundido dentro dos equipamentos de processamento o que por sua vez pode gerar redução da degradação do compósito durante as etapas de processamento (JOSEPH et al., 2002). A adição do óleo de canola proporcionou o maior aumento no índice de fluidez, seguido do óleo de mamona e do óleo de soja epoxidado.

Quando a viscosidade aumenta, o valor de MFI diminui. Estes resultados estão de acordo com os valores de torque de equlíbrio (Figura 42). No caso dos compósitos com óleos vegetais, o valor de MFI é maior enquanto que a viscosidade é menor, em comparação com os compósitos BPEAD/Fibra. 


\subsubsection{Análise Térmica}

As curvas TG (Figura 43) mostram perda de massa de $5 \%$ em torno de $100^{\circ} \mathrm{C}$, que pode ser atribuída à perda de água aderida as fibras de curauá. Até $260^{\circ} \mathrm{C}$ as fibras de curauá apresentaram estabilidade térmica, quando então ocorreu o início da decomposição da hemicelulose, seguida da celulose. Em torno de $400^{\circ} \mathrm{C}$ observou-se outro processo de decomposição, envolvendo quebra das ligações da lignina, prosseguindo rapidamente com o aumento de temperatura até ocorrer à perda de massa quase total em torno de $600^{\circ} \mathrm{C}$. A decomposição dos compósitos iniciou a temperatura mais baixa comparativamente à matriz termoplástica, devido à presença de fibra lignocelulósica, que inicia a decomposição antes do BPEAD.

As curvas TG mostraram o mesmo perfil para todos os compósitos BPEAD/CO/Fibra, BPEAD/CA/Fibra, BPEAD/OSE/Fibra e BPEAD/OLE/Fibra (Figura 43).

Figura 43. BPEAD, fibra de curauá e compósitos BPEAD/5\% CA,CO,OSE e OLE: (a) Curvas de TG e (b) Curvas de dTG, atmosfera de $\mathrm{N}_{2}$, fluxo de $20 \mathrm{~mL} \mathrm{~min}^{-1}$ e razão de aquecimento de $10{ }^{\circ} \mathrm{C} \mathrm{min}^{-1}$.

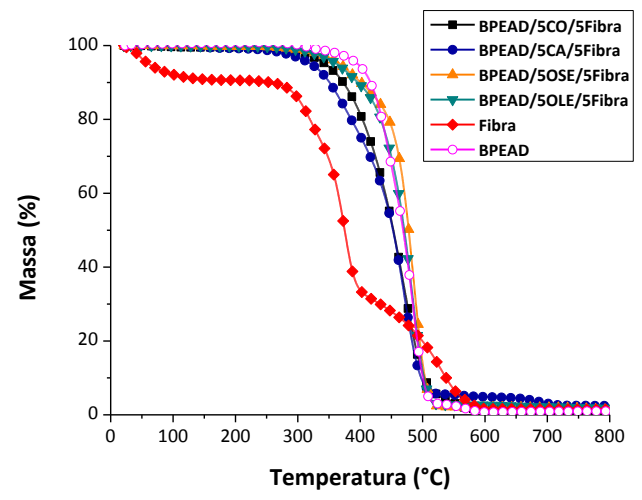

(a)

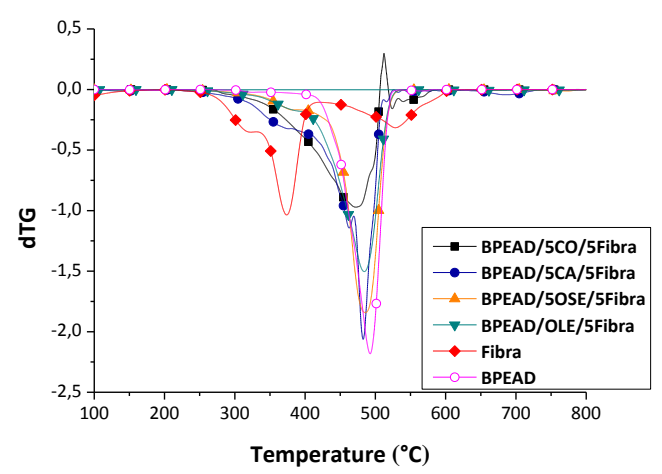

(b)

Através das curvas de dTG (Figura 44), observou-se que a perda de massa máxima dos compósitos ocorreu em temperaturas intermediárias em relação à fibra de curauá (Tpico $\left.(T p)=369^{\circ} \mathrm{C}\right)$ e ao BPEAD $\left(T p=491^{\circ} \mathrm{C}\right.$ ). Isto mostrou que a perda de massa foi inversamente proporcional ao teor de fibra na amostra, devido a este ser o componente menos estável termicamente no compósito. 
Figura 44. Curvas dTG: (a) Compósitos BPEAD/CO/Fibra; (b) Compósitos BPEAD/CA/Fibra; (c) Compósitos BPEAD/OSE/Fibra e (d) Compósitos BPEAD/OLE/Fibra, atmosfera de $\mathrm{N}_{2}$, fluxo de $20 \mathrm{~mL} \mathrm{~min}^{-1}$ e razão de aquecimento de $10{ }^{\circ} \mathrm{C} \mathrm{min}^{-1}$.

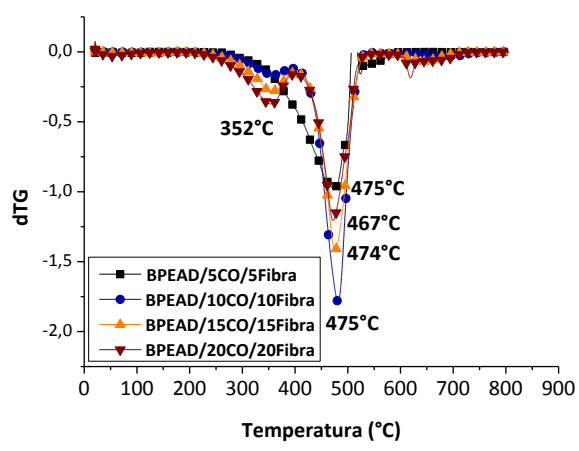

(a)

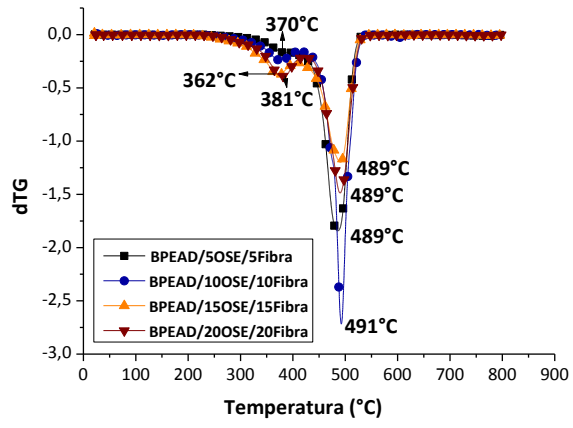

(c)

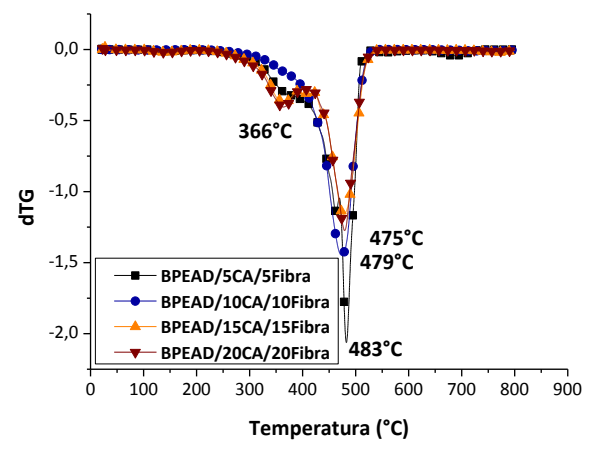

(b)

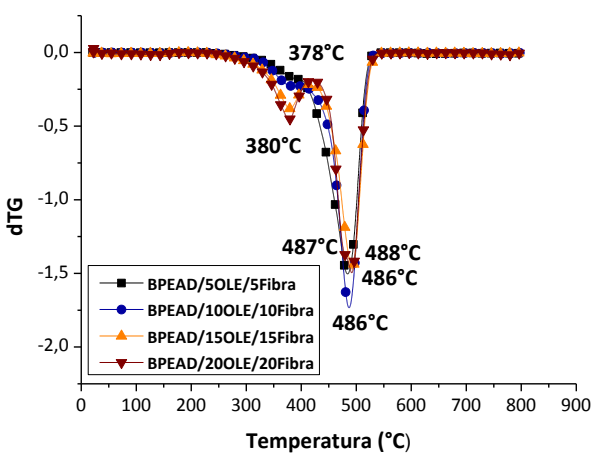

(d)

Notou-se que os compósitos com 5 e $10 \%$ de fibra de curauá (Tabela 6) apresentaram os picos máximos de perda de massa a uma temperatura superior aos com 15 e 20 \% de fibra de curauá. Uma possível explicação para isso é que, pelo fato de os compósitos com 5 e 10 \% de fibra possuírem um maior teor de BPEAD (que envolve as fibras), este agiu como um isolante térmico dificultando a transmissão de calor para as fibras que estavam no centro do produto, retardando assim sua decomposição. Já os compósitos com 15 e 20 \% de fibra possuíam mais fibras expostas na superfície, e a decomposição iniciou a temperaturas mais baixas (SANTOS et al., 2007). 
Tabela 6. Temperatura de pico de perda máxima (Tp).

\begin{tabular}{cc}
\hline Compósito & Temperatura de Perda Máxima ( ${ }^{\circ} \mathrm{C}$ ) \\
\hline Fibra de Curauá & 369 \\
\hline BPEAD & 491 \\
\hline BPEAD/5\%CO/5\%Fibra & 475 \\
BPEAD/10\%CO/10\%Fibra & 475 \\
BPEAD/15\%CO/15\%Fibra & 474 \\
BPEAD/20\%CO/20\%Fibra & 467 \\
\hline BPEAD/5\%CA/5\%Fibra & 483 \\
BPEAD/10\%CA/10\%Fibra & 479 \\
BPEAD/15\%CA/15\%Fibra & 475 \\
BPEAD/20\%CA/20\%Fibra & 475 \\
\hline BPEAD/5\%OSE/5\%Fibra & 489 \\
BPEAD/10\%OSE/10\%Fibra & 491 \\
BPEAD/15\%OSE/15\%Fibra & 489 \\
BPEAD/20\%OSE/20\%Fibra & 489 \\
\hline BPEAD/5\%OLE/5\%Fibra & 486 \\
BPEAD/10\%OLE/10\%Fibra & 486 \\
BPEAD/15\%OLE/15\%Fibra & 487 \\
BPEAD/20\%OLE/20\%Fibra & 488 \\
\hline
\end{tabular}

O primeiro pico na Figura 44 está relacionado com a decomposição da celulose das fibras de curauá e o segundo com a decomposição do óleo vegetal, que é termicamente menos estável que o BPEAD. A temperatura em que a taxa de decomposição máxima ocorreu para o BPEAD puro foi de $491^{\circ} \mathrm{C}$, para o óleo de mamona foi de $359^{\circ} \mathrm{C}$, para o óleo de canola foi de $421^{\circ} \mathrm{C}$, para o óleo de soja epoxidado foi de $392^{\circ} \mathrm{C}$ e para o óleo de linhaça epoxidado foi de $389^{\circ} \mathrm{C}$ (Figura 39). Nos compósitos, esta temperatura foi deslocada (de 467 a $491^{\circ} \mathrm{C}$ ) em função da adição de fibras e de CO, CA, OSE e OLE, de 5 a 20\% em massa, já que estes são os componentes menos estáveis termicamente.

O evento observado nas curvas DSC dos compósitos (Figura 45) correspondeu ao pico endotérmico, relacionado à temperatura de fusão do $\operatorname{BPEAD}\left(136^{\circ} \mathrm{C}\right)$. A presença de um pico estreito é característica de materiais semicristalinos como o BPEAD (MAZUR et al., 2008). 
Figura 45. Curvas DSC para a fibra de curauá, BPEAD e compósitos processados no misturador interno e termoprensados, atmosfera de $\mathrm{N}_{2}$, fluxo de $20 \mathrm{~mL} \mathrm{~min}^{-1}$ e razão de aquecimento de $10{ }^{\circ} \mathrm{C} \mathrm{min}^{-1}$.

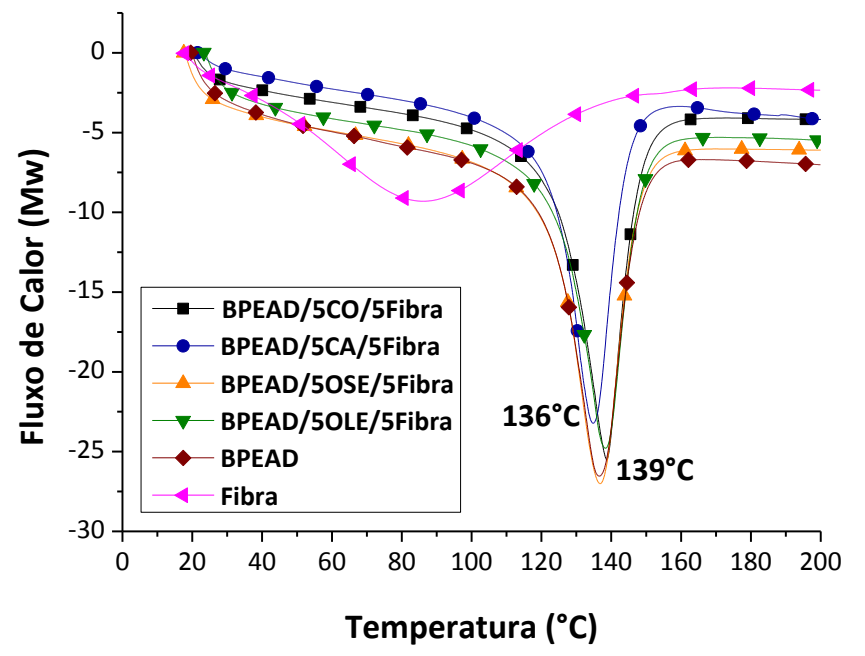

A partir das curvas DSC obtidas para o BPEAD nos compósitos e BPEAD, foram obtidos os valores das $\Delta \mathrm{H}_{\mathrm{m}}$ para os compósitos com diferentes porcentagens de $\mathrm{CO}$, CA, OSE, OLE e com fibra de curauá. O índice de cristalinidade (Tabela 7) para os compósitos e para o BPEAD foi calculado usando a Equação 1, descrita em materiais e métodos.

Tabela 7. Entalpias de fusão, razão entre $\Delta \mathrm{H}_{\mathrm{m}}$ e $\varphi_{\mathrm{m}}$, índice de cristalinidade e temperatura de fusão.

\begin{tabular}{ccccc}
\hline Compósito & $\Delta \mathrm{H}_{\mathrm{m}}\left(\mathrm{J} \mathrm{g}^{-1}\right)$ & $\Delta \mathrm{H}_{\mathrm{m}} / \boldsymbol{\varphi}_{\mathrm{m}}$ & $\mathbf{X c}(\%)$ & $\mathbf{T}_{\mathrm{m}}\left({ }^{\circ} \mathrm{C}\right)$ \\
\hline BPEAD & 196 & 196 & 67 & 136 \\
\hline BPEAD/5\%Fibra & 189 & 199 & 68 & 134 \\
BPEAD/10\%Fibra & 171 & 190 & 65 & 135 \\
BPEAD/15\%Fibra & 158 & 186 & 63 & 134 \\
BPEAD/20\%Fibra & 157 & 196 & 67 & 134 \\
\hline BPEAD/5\%CO/5\%Fibra & 229 & 254 & 87 & 139 \\
BPEAD/10\%CO/10\%Fibra & 207 & 259 & 88 & 134 \\
BPEAD/15\%CO/15\%Fibra & 185 & 265 & 90 & 136 \\
BPEAD/20\%CO/20\%Fibra & 170 & 284 & 97 & 135 \\
\hline BPEAD/5\%CA/5\%Fibra & 199 & 221 & 75 & 136 \\
BPEAD/10\%CA/10\%Fibra & 185 & 231 & 80 & 137 \\
BPEAD/15\%CA/15\%Fibra & 163 & 233 & 80 & 139 \\
BPEAD/20\%CA/20\%Fibra & 158 & 263 & 90 & 135 \\
\hline BPEAD/5\%OSE/5\%Fibra & 225 & 250 & 85 & 139 \\
BPEAD/10\%OSE/10\%Fibra & 204 & 255 & 87 & 135 \\
BPEAD/15\%OSE/15\%Fibra & 186 & 266 & 91 & 138 \\
BPEAD/20\%OSE/20\%Fibra & 153 & 255 & 87 & 136 \\
\hline BPEAD/5\%OLE/5\%Fibra & 222 & 246 & 84 & 136 \\
BPEAD/10\%OLE/10\%Fibra & 201 & 251 & 86 & 135 \\
HDBPE/15\%OLE/15\%Fibra & 183 & 261 & 89 & 137 \\
BPEAD/20\%OLE/20\%Fibra & 167 & 278 & 94 & 134 \\
\hline
\end{tabular}


A incorporação de CO, CA, OSE e OLE à matriz poderia levar a uma diminuição da temperatura de fusão do BPEAD, mas, no presente estudo este óleos puderam atuar como agente de compatibilização na interface fibra/matriz e não foi observada diminuição na temperatura de fusão do BPEAD nos compósitos em que os óleos estavam presentes, em relação ao BPEAD puro e aos compósitos BPEAD/Fibra (Tabela 7).

O índice de cristalinidade do BPEAD nos compósitos foi maior que o do BPEAD, e aumentou com o teor de fibras para as diferentes composições.

A presença das cadeias menores de CO, CA, OSE e OLE podem interferir no rearranjo das cadeias de BPEAD. Os compósitos preparados com maior proporção de óleos e de fibras (15 e 20\%) no geral apresentaram maior cristalinidade que os compósitos em que os óleos não estavam presentes (Tabela 7). O grau de cristalinidade pode ter influência significativa sobre as propriedades mecânicas, pois a mesma afeta a extensão das interações intermoleculares, que ocorrem com maior intensidade nas regiões cristalinas, entre os segmentos de cadeias adjacentes (MACHADO et al., 2010).

\subsubsection{Análise Dinâmico-Mecânica (DMA)}

As propriedades dinâmico-mecânicas dos compósitos são determinadas pelas propriedades de seus componentes, pela morfologia do sistema e pela natureza da interação entre os componentes (ABDELMOULEH et al., 2007). A camada da matriz que recobre as fibras, imediatamente posterior à interface, pode ter propriedades diferentes do restante do material, pois as interações com as fibras podem alterar a mobilidade das cadeias poliméricas da matriz (TRINDADE et al., 2005).

A Figura 46 apresenta as curvas de módulo de armazenamento ( $E^{\prime}$ ) para os compósitos de BPEAD/CO, CA, OSE e OLE/Fibra. Os compósitos BPEAD/Fibra apresentaram curvas semelhantes aos dos compósitos BPEAD/óleo vegetal/Fibra. 
Figura 46. Curvas de módulo de armazenamento versus temperatura: (a) BPEAD/CO/Fibra; (b)

BPEAD/CA/Fibra; (c) BPEAD/OSE/Fibra e (d) BPEAD/OLE/Fibra.

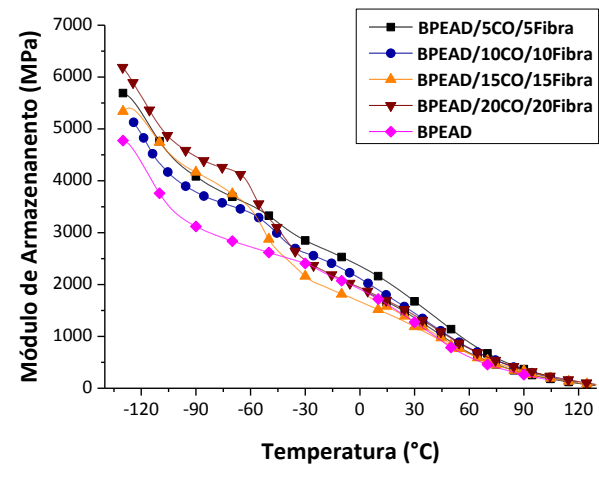

(a)

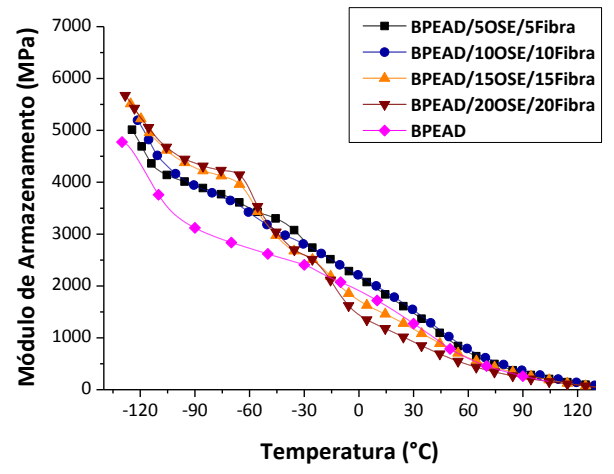

(c)

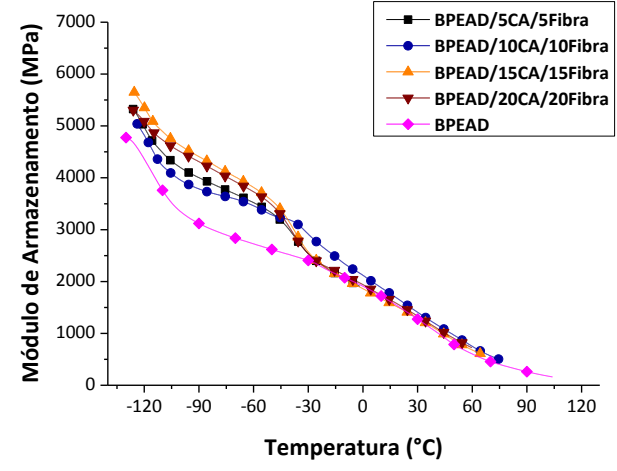

(b)

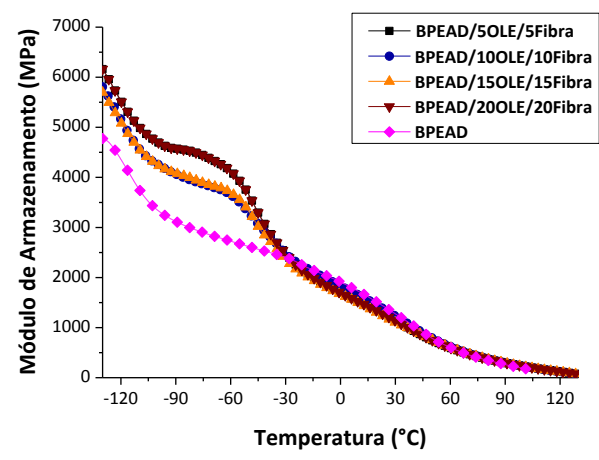

(d)

A incorporação de fibras ou cargas na matriz polimérica pode alterar as propriedades mecânicas dos compósitos. Comparando as curvas do módulo de armazenamento $\left(E^{\prime}\right)$, observou-se que os compósitos com 5, 10, 15 e 20\% de CO, CA, OSE e OLE (Figura 46) adicionados produziram compósitos mais rígidos em relação ao BPEAD (maior valor de $\mathrm{E}^{\prime}$ em todo o intervalo de temperatura considerado).

A Figura 47 mostra o módulo de armazenamento a $30^{\circ} \mathrm{C}$ para os compósitos reforçados com fibra de curauá, processados no misturador interno (Haake). 
Figura 47. Módulo de armazenamento $\left(a 30^{\circ} \mathrm{C}\right)$ dos compósitos preparados por misturador interno (Haake)/termoprensagem.

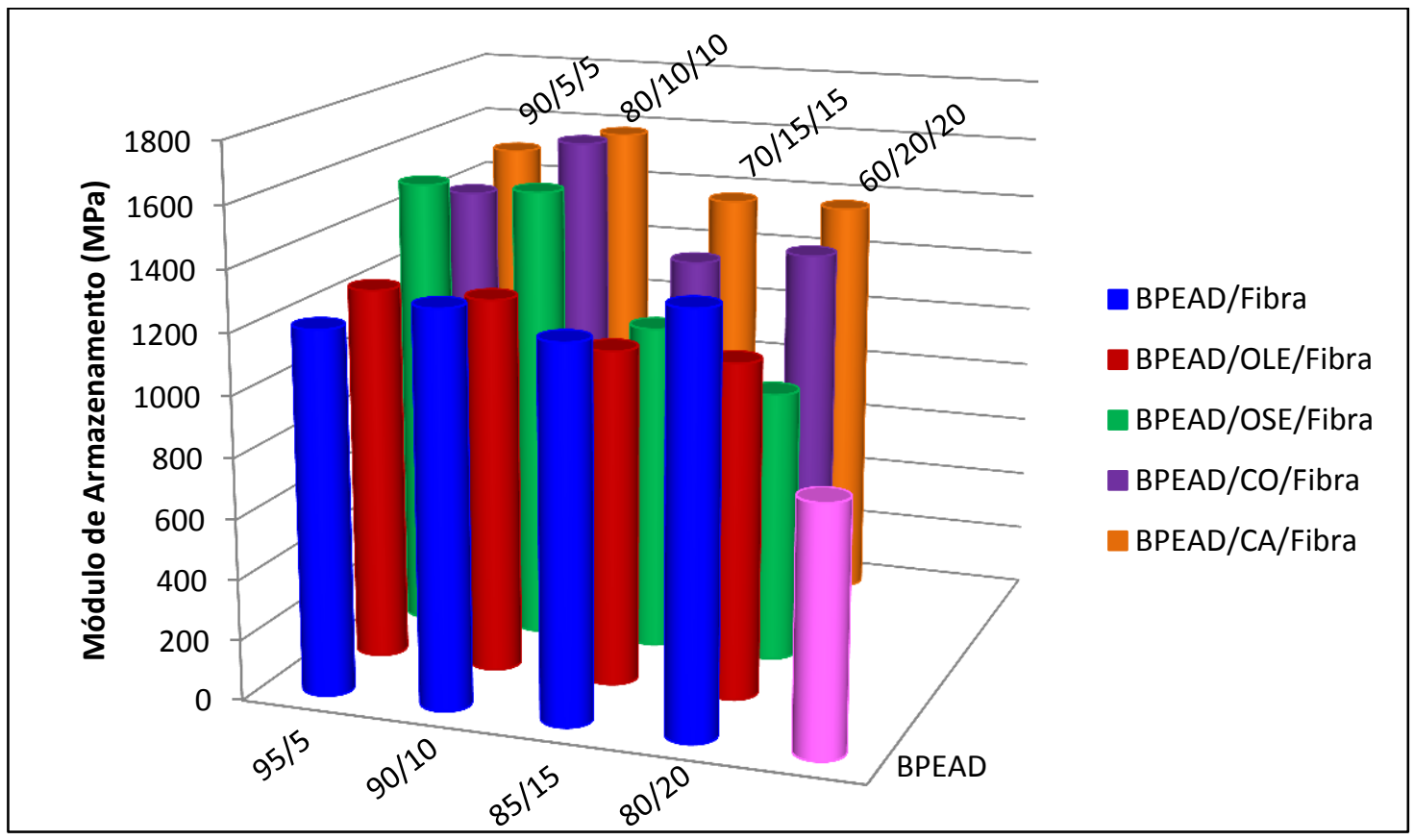

Os módulos de armazenamento $\left(\mathrm{E}^{\prime} 30^{\circ} \mathrm{C}\right)$ dos compósitos BPEAD/OLE/Fibra diminuiram quando comparados aos compósitos BPEAD/Fibra, indicando uma possível ação deste óleo como plastificante sobre a matriz. Já para os compósitos BPEAD/CO, $\mathrm{CA}$ e OLE/Fibra o $\mathrm{E}^{\prime} \mathrm{a} 30^{\circ} \mathrm{C}$ foi maior quando comparado aos compósitos preparados sem adição de óleos vegetais, indicando uma interação fibra/matriz mais intensa na presença do CO, CA e OSE, ou seja, estes óleos agindo preponderantemente como agentes de compatibilização na interface fibra-matriz. Assim, as camadas de matriz próximas à interface teriam movimentação de segmentos restringidos, tornando o material mais rígido (DEVI; BHAGAWAN; THOMAS, 2011; MERLINI; SOLDI; BARRA, 2011).

A Figura 48 mostra $\tan \delta$ em função da temperatura para os compósitos de BPEAD/CO, CA, OSE e OLE/Fibra. 
Figura 48. Curvas tan $\delta$ versus temperatura: (a) e (b) BPEAD/CO/Fibra; (c) e (d) BPEAD/CA/Fibra; (e) e (f) BPEAD/OSE/Fibra e (g) e (h) BPEAD/OLE/Fibra.

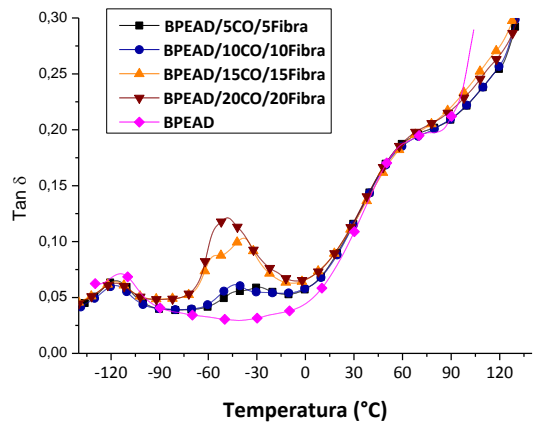

(a)

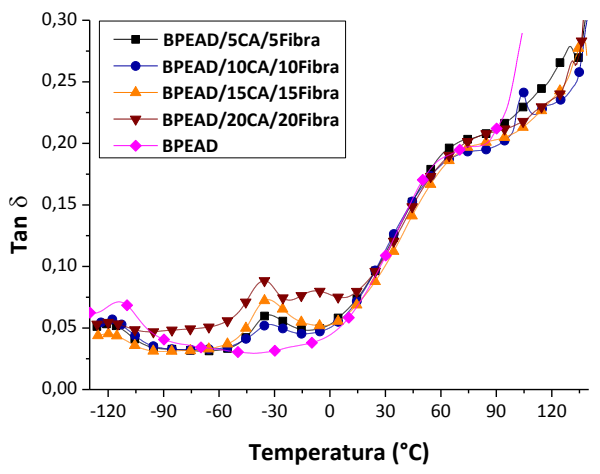

(c)

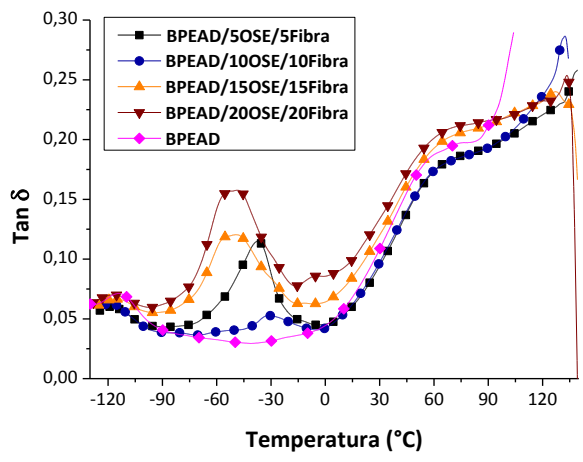

(e)

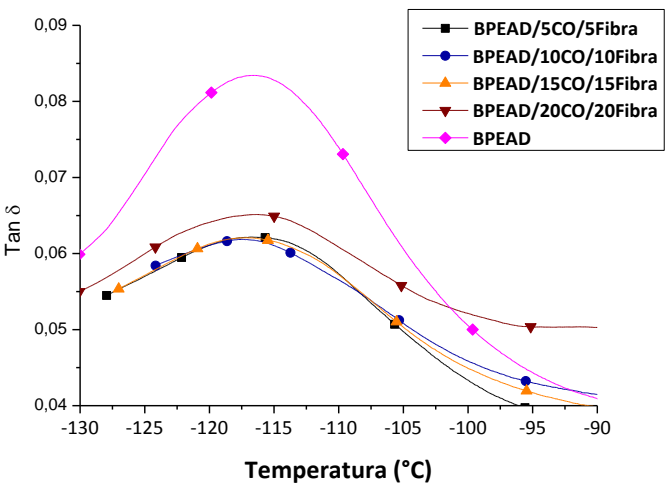

(b)

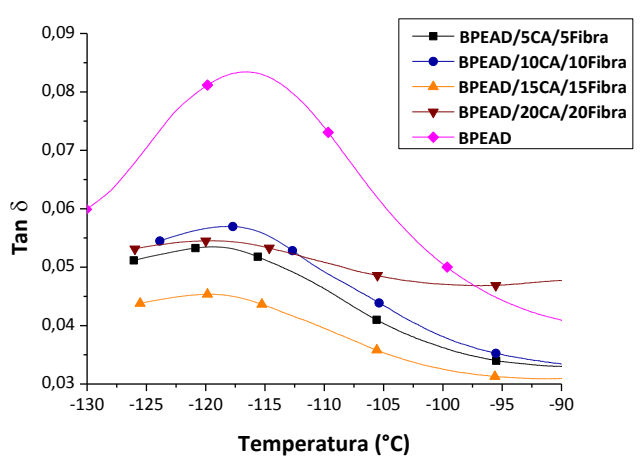

(d)

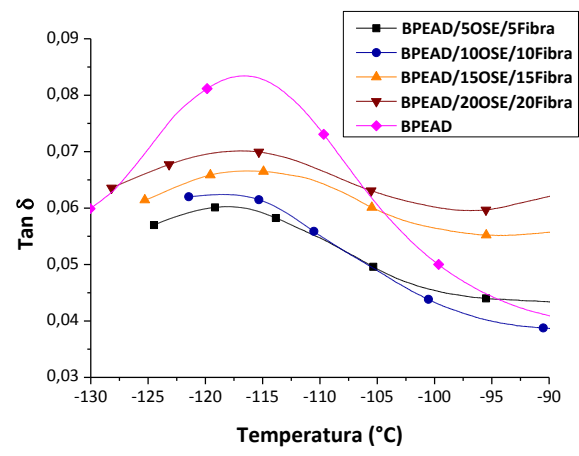

(f) 


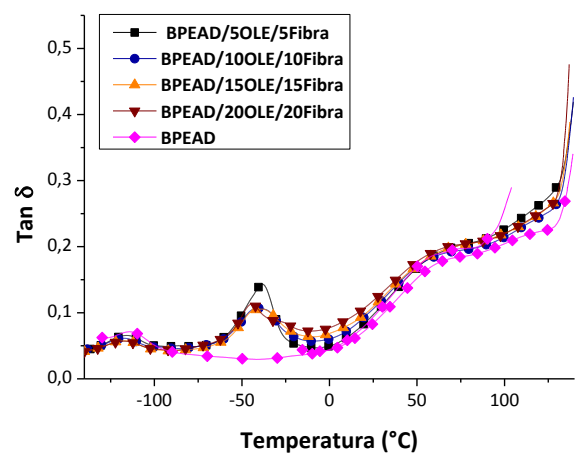

(g)

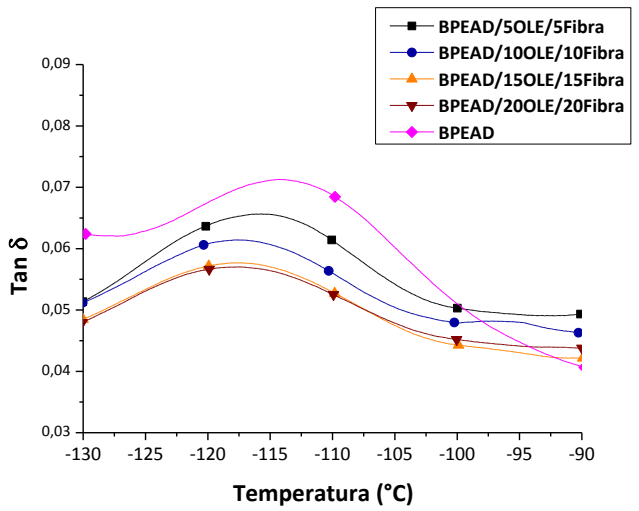

(h)

Como mostrado anteriormente, tipicamente o polietileno de alta densidade, apresentou duas relaxações, uma relaxação em torno de $-116^{\circ} \mathrm{C}$, relacionada à região não cristalina e associada à transição vítrea $\left(\operatorname{Tg}, \alpha_{a}\right)$. A outra relaxação ocorreu entre 50 e $120^{\circ} \mathrm{C}$, acima da $\mathrm{Tg}$ e abaixo de $\mathrm{Tm}$ (temperatura de fusão, em torno de $135^{\circ} \mathrm{C}$ ) pode ser considerado decorrente de uma transição do tipo $\alpha^{\prime}{ }_{\text {. }}$.

Tabela 8. BPEAD e compósitos com fibra de curauá: picos tan $\delta$

\begin{tabular}{cc} 
& Temperatura $\left({ }^{\circ} \mathrm{C}\right)$ \\
\cline { 2 - 2 } BPEAD & Pico 1 \\
\hline BPEAD/5\%Fibra & -116 \\
BPEAD/10\%Fibra & -116 \\
BPEAD/15\%Fibra & -116 \\
BPEAD/20\%Fibra & -116 \\
\hline BPEAD/5\% CO/5\% Fibra & -116 \\
BPEAD/10\% CO /10\% Fibra & -117 \\
BPEAD/15\% CO/15\% Fibra & -117 \\
BPEAD/20\% CO/ 20\% Fibra & -117 \\
\hline BPEAD/5\% CA/5\% Fibra & -117 \\
BPEAD/10\% CA/10\% Fibra & -119 \\
BPEAD/15\% CA/15\% Fibra & -118 \\
BPEAD/20\% CA/20\% Fibra & -119 \\
\hline BPEAD/5\% OSE/5\% Fibra & -118 \\
BPEAD/10\% OSE /10\% Fibra & -118 \\
BPEAD/15\% OSE/15\% Fibra & -118 \\
BPEAD/20\% OSE/ 20\% Fibra & -117 \\
\hline BPEAD/5\% OLE/5\% Fibra & -118 \\
BPEAD/10\% OLE /10\% Fibra & -118 \\
BPEAD/15\% OLE/15\% Fibra & -118 \\
BPEAD/20\% OLE/ 20\% Fibra & -118 \\
\hline & -120 \\
\hline & \\
\hline & \\
\hline
\end{tabular}


Analisando os resultados apresentados na Tabela 8 observa-se que não houve alteração significativa na temperatura de transição vítrea do BPEAD presente nos compósitos com a adição de CA, CO, OSE e OLE. A ação como plastificante nos compósitos poderia levar a uma redução na temperatura de transição vítrea. A atuação como compatibilizante na interface fibra/matriz, pode diminuir a mobilidade dos segmentos das cadeias presentes na interface. A diminuição de mobilidade de segmentos de uma cadeia polimérica no geral desloca Tg para temperaturas mais elevadas. No entanto, no presente estudo deve-se levar em conta dois aspectos: i) a transição vítrea é associada aos domínios não cristalinos, os quais são minoritários no BPEAD, que apresenta alta cristalinidade, ou seja, somente os segmentos dos domínios não cristalinos, próximos à interface, sofreriam este efeito, ii) a Tg observada é consequente da rotação em torno de ligações de segmentos presentes no material como um todo, e não somente daqueles segmentos próximos à interface, e que fazem parte dos domínios não cristalinos. Assim, dependendo das proporções relativas destes segmentos, o efeito sobre $\mathrm{Tg}$ pode não ser observado.

Para os compósitos BPEAD/CO, CA, OSE e OLE/ Fibra o pico entre -75 e $-50^{\circ} \mathrm{C}$ (Figura 48) pode estar relacionado com a fusão de componentes dos óleos vegetais, que são compostos por diferentes ácidos graxos (Figura 39) (TAN; CHE MAN, 2002).

\subsubsection{Resistência ao Impacto}

O BPEAD puro processado no misturador interno e termoprensado apresentou resistência ao impacto de $234 \mathrm{~J} \mathrm{~m}^{-1}$. Os compósitos de matriz termoplástica reforçados com fibras vegetais apresentaram uma queda na resistência ao impacto comparativamente ao BPEAD. Com a adição de fibra ao compósito houve um aumento da rigidez do material, o que pode resultar em uma diminuição da resistência ao impacto do mesmo, já que este se tornou menos dúctil se comparado ao BPEAD. Além disso, a possibilidade de aglomeração de fibra pode levar a regiões de concentração de tensões que requereram menos energia para dar início ou propagar uma trinca (JARUKUMJORN; SUPPAKARN, 2009).

A Figura 49 mostra os resultados obtidos para a resistência ao impacto dos compósitos obtidos variando a porcentagem de fibras, CO, CA, OSE e OLE presentes. 
Para os compósitos BPEAD/CO/Fibra, a adição de $5\left(163 \mathrm{~J} \mathrm{~m}^{-1}\right), 10\left(178 \mathrm{~J} \mathrm{~m}^{-1}\right)$ e $15 \%$ $\left(280 \mathrm{~J} \mathrm{~m}^{-1}\right)$ de fibra de curauá provocou um aumento na resistência ao impacto dos compósitos. Acima de $15 \%$ de fibras, a resistência ao impacto diminuiu, possivelmente devido a maior aglomeração das fibras (SPINACÉ et al., 2009; HARNNECKER; DOS SANTOS ROSA; LENZ, 2011).

Figura 49. Resistência ao impacto Izod dos compósitos (corpos de prova entalhados) processados por misturador interno. Desvio padrão entre 5-10\%.

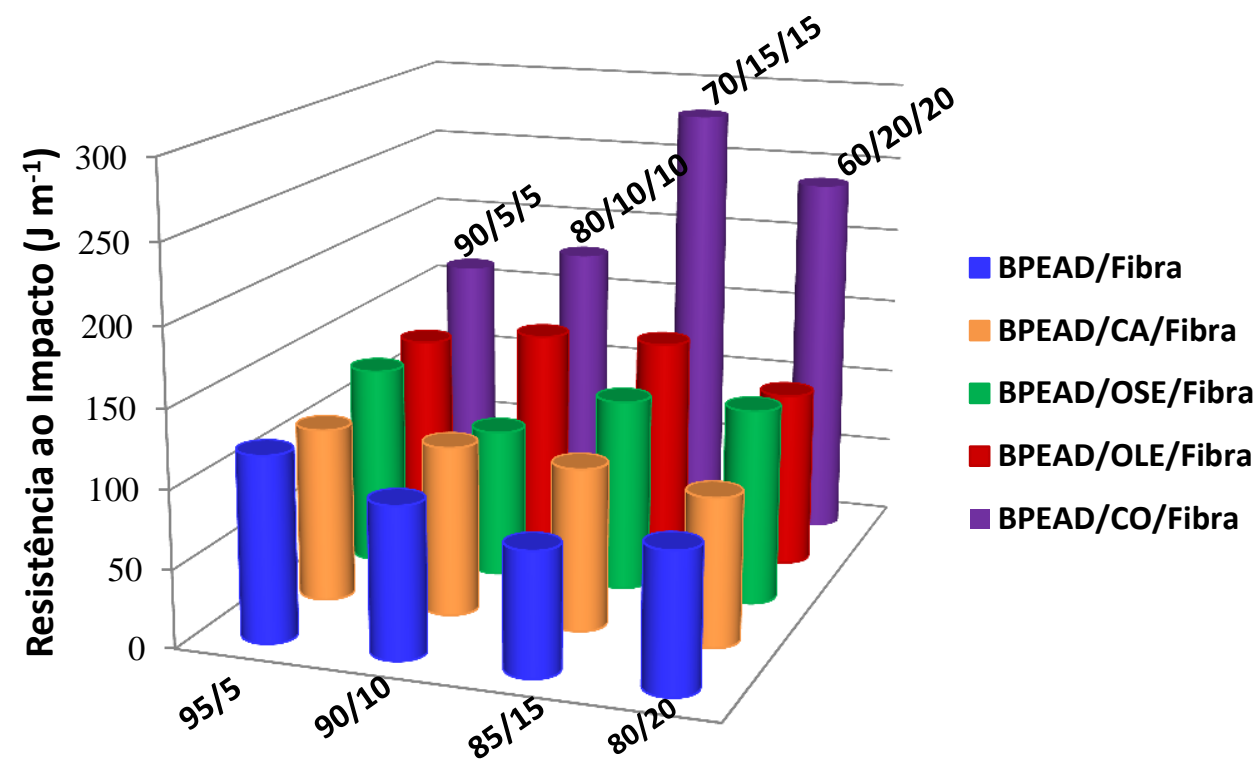

Os resultados de impacto apresentados para os compósitos (Figura 49) mostraram que a incorporação dos óleos nas diferentes composições, principalmente $\mathrm{CO}$, no geral levou a maior resistência ao impacto quando comparados aos compósitos BPEAD/Fibra, indicando uma possível ação dos óleos como compatibilizante na interface fibra/matriz. O compósito BPEAD/15\%CO/15\% Fibra apresentou uma maior resistência ao impacto $\left(280 \mathrm{~J} \mathrm{~m}^{-1}\right)$ se comparado ao $\operatorname{BPEAD}\left(234 \mathrm{~J} \mathrm{~m}^{-1}\right)$, indicando o efeito compatibilizante do CO.

A presença dos óleos viabilizou interações entre os grupos $\mathrm{OH}$ destes com os $\mathrm{OH}$ presentes na superfície das fibras e as cadeias apolares do BPEAD interagindo com os domínios apolares dos óleos (Figuras 13 e 14). Assim, a presença dos óleos também melhorou a resistência ao impacto devido à maior adesão na interface, isto é, a carga foi transferida a partir da matriz para a fibra através desta interface envolvendo interações mais fortes. $O$ agente compatibilizante que apresentou o melhor 
desempenho foi o CO, constituído majoritariamente pelo ácido ricinoléico (Figura 13). A resistência ao impacto dos compósitos aumentou consideravelmente se comparada à mistura de BPEAD/Fibra, a baixa resistência verificada nos compósitos não compatibilizados também é resultante de falhas na interface, ocasionadas pela fraca interação dos constituintes.

A adição dos óleos vegetais levou a um aumento no índice de fluidez (Figura 42 ), indicando que os mesmos também atuaram como plastificantes, no sentido que reduziram a viscosidade e melhoraram a molhabilidade das fibras pelo polímero, o que também influenciou na interface fibra/matriz e, portanto, nas propriedades mecânicas dos compósitos (TURAN; SIRIN; OZKOC, 2011).

Spinacé et al. (2011) avaliaram o efeito da adição de fibra de curauá e fibra de sisal em polietileno de alta densidade (PEAD), utilizando PEMA (polietileno graftizado com anidrido maléico) e polipropileno (PP), utilizando PPMA (polipropileno graftizado com anidrido maléico), pelo processo de extrusão, na proporção de $20 \%$ de fibra. As propriedades mecânicas dos compósitos foram analisadas por resistência à flexão, ao impacto e tração. Para o compósito PEAD/fibra de curauá/PEMA observou-se uma resistência ao impacto Izod (para corpos de prova entalhados) de $65,17 \mathrm{~J} \mathrm{~m}^{-1}$, e para o compósito PEAD/fibra de curauá a resistência ao impacto foi de $62,05 \mathrm{~J} \mathrm{~m}^{-1}$. No presente trabalho, a resistência ao impacto do compósito BPEAD/20\%CO/20\%Fibra foi de $238 \mathrm{~J} \mathrm{~m}^{-1}$ e do compósito BPEAD/20\%Fibra foi de $89 \mathrm{~J} \mathrm{~m}^{-1}$ para amostras entalhadas, misturadas em um reômetro de torque do tipo Haake e termoprensadas, indicando que o CO pode ter atuado como agente compatibilizante, assim como o PEMA atuou no estudo citado.

\subsubsection{Microscopia eletrônica de varredura}

Visando correlacionar os resultados do teste de impacto com a morfologia dos compósitos modificados com CO, CA, OSE e OLE e reforçados com fibra de curauá, a superfície de fratura dos corpos de prova, após ensaio de impacto, foi analisada por microscopia eletrônica de varredura (MEV). As Figuras 50, 51, 52, 53 e 54 mostram as micrografias obtidas. 
A observação da superfície de fratura dos corpos de prova indica que várias fibras sofreram "pull out" (arrancamento da fibra) resultando em "vazios" (Figura 50 a e b), indicando que neste caso o BPEAD foi o principal responsável por suportar o esforço aplicado (SANTOS et al., 2010).

Figura 50. Micrografias obtidas por MEV a partir da superfície de fratura dos compósitos entalhados: (a) BPEAD/5\%Fibra e (b) BPEAD/10\%Fibra.

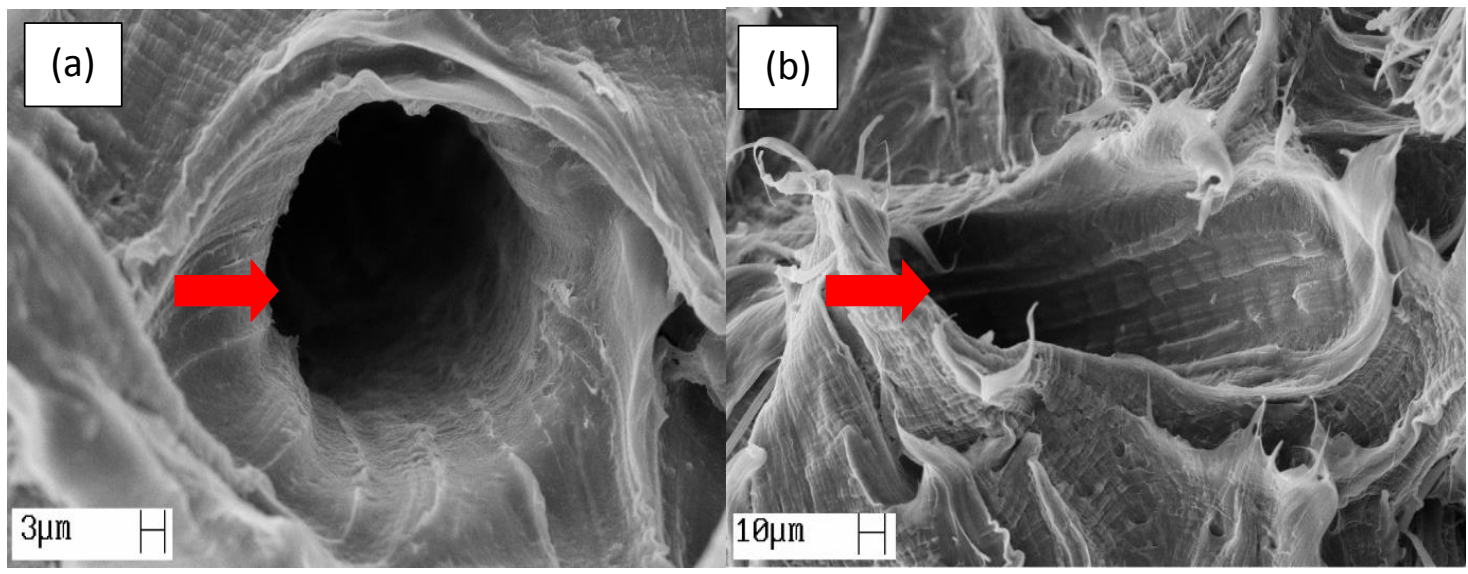

Na Figura 51 mostra que algumas fibras sofreram "descolamento", ao encontrar a fibra, o deslocamento se propaga ao redor desta, contornando-a e indicando uma interação fibra/matriz mais fraca nesta região.

Figura 51. Micrografias obtidas por MEV a partir da superfície de fratura dos compósitos entalhados: (a) BPEAD/15\%Fibra e (b) BPEAD/20\%Fibra.

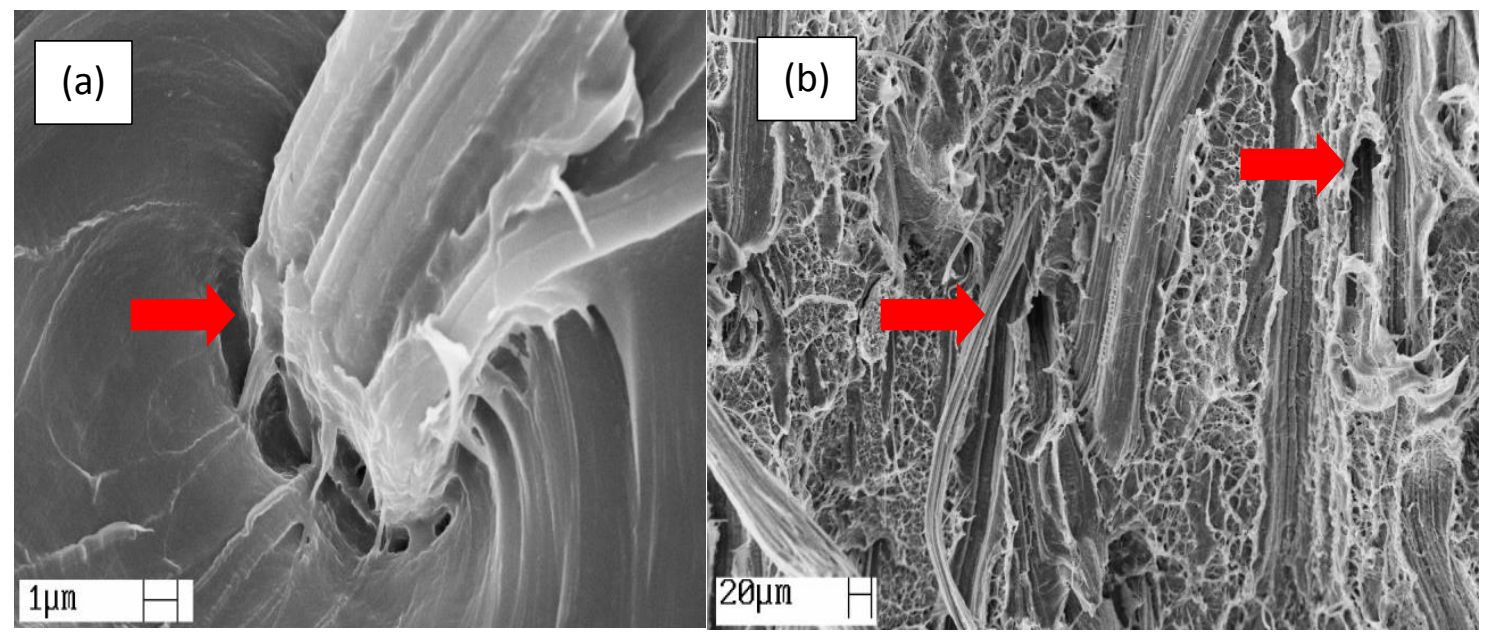

Verificou-se a formação de superfícies pouco homogêneas e bastante deformadas (Figura 51b). Nesses sistemas, devido à fraca adesão interfacial, espaços 
vazios podem ser visualizados em torno das fibras, indicando a baixa molhabilidade da fibra pela matriz.

Observando as imagens obtidas por MEV das fibras de curauá dos compósitos na Figura 52 foi possível observar uma camada recobrindo a superfície da fibra e da matriz, possivelmente constituída por BPEAD, óleo de mamona ou de linhaça epoxidado.

Figura 52. Micrografias obtidas por MEV a partir da superfície de fratura dos compósitos entalhados: (a) BPEAD/5\%CO/5\%Fibra e (b) BPEAD/5\%OLE/5\%Fibra.

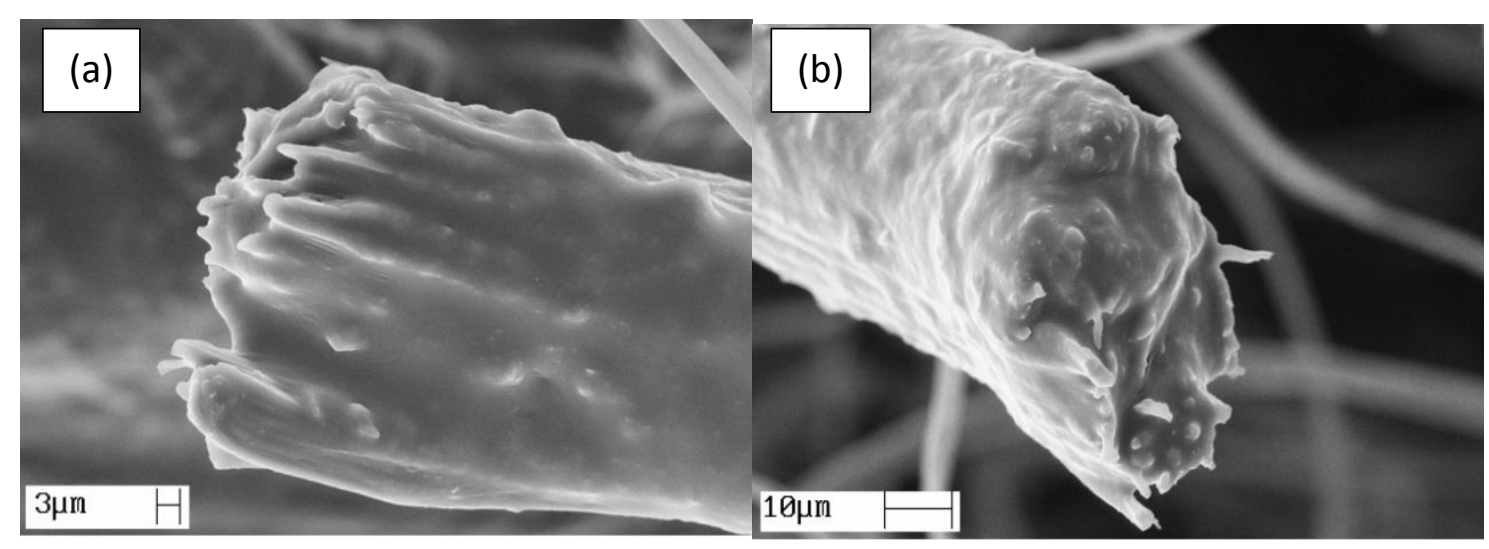

A Figura 53 mostra que o método de processamento proporcionou uma boa dispersão das fibras nas matrizes. Estes resultados indicam que o CO, CA, OSE e OLE puderam também atuar como agente de compatibilização entre as fibras e a matriz, aumentando a adesão fibra/matriz na interface.

Figura 53. Micrografias obtidas por MEV a partir da superfície de fratura dos compósitos entalhados: (a) BPEAD/10\%CO/10\%Fibra; (b) BPEAD/10\%CA/10\%Fibra; (c) BPEAD/10\%OSE/10\%Fibra e (d) BPEAD/10\%OLE/10\%Fibra.

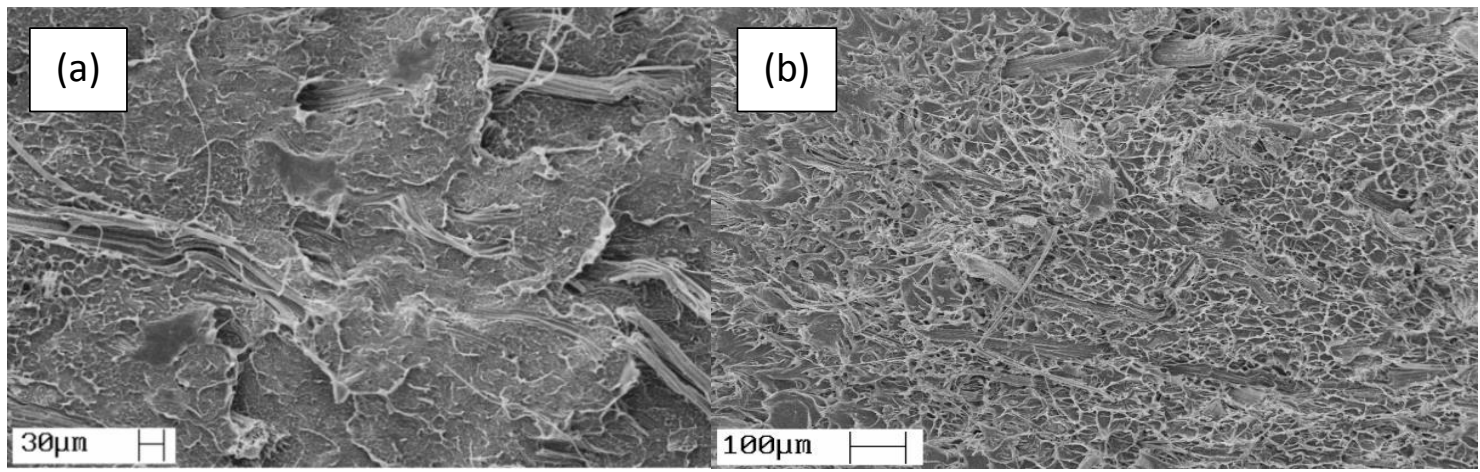




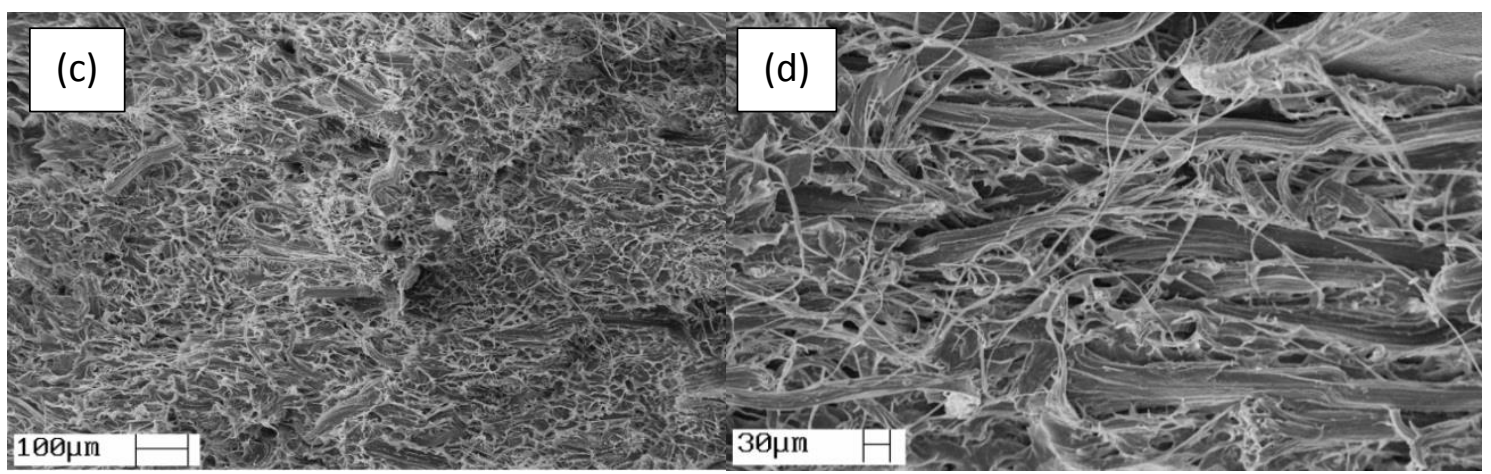

Na micrografia dos compósitos na Figura 54, houve indicação da forte adesão da fibra à matriz, possivelmente, devido a melhora da interface, pelos motivos já mencionados, resultando em certa adesão e em boa transferência da força de uma fase à outra.

Figura 54. Micrografias obtidas por MEV a partir da superfície de fratura dos compósitos entalhados: (a) BPEAD/10\%CO/10\%Fibra; (b) BPEAD/15\%CO/15\%Fibra e (c) BPEAD/15\%OSE/15\%Fibra.
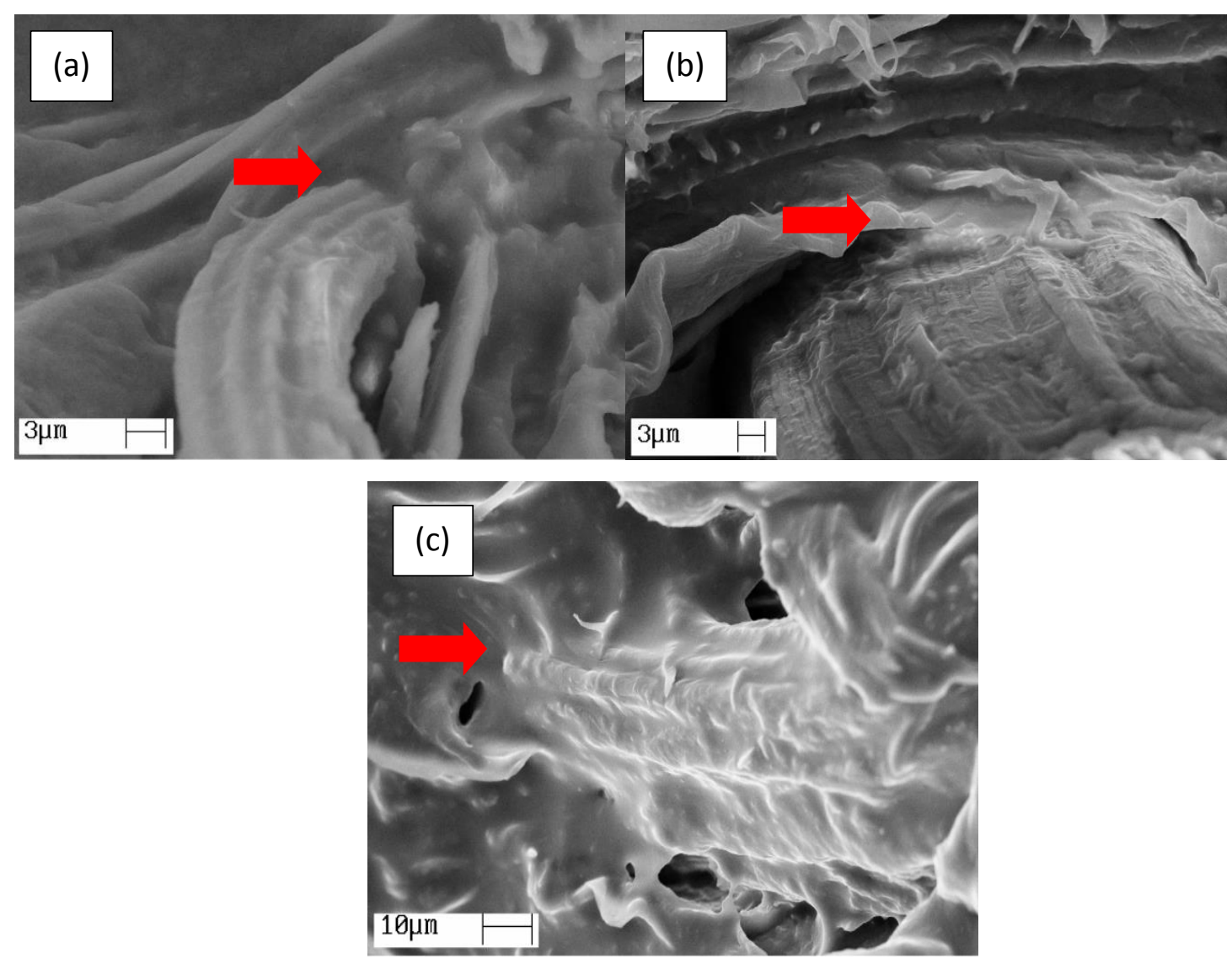
Analisando as imagens das Figuras 50, 51, 52, 53 e 54, observou-se, no geral, que os agentes compatibilizantes utilizados neste trabalho, CO, CA, OSE e OLE promoveram uma melhor interação fibra/matriz para os diferentes compósitos.

\subsubsection{Resistência à Flexão}

A resistência à flexão corresponde à capacidade do material de resistir à força de dobragem aplicada perpendicularmente ao seu eixo longitudinal. Neste trabalho, os compósitos com diferentes porcentagens de fibra de curauá e de CA, CO, OSE e OLE assim como o BPEAD foram analisados por essa técnica. O perfil da curva de tensão versus deformação para o compósito de BPEAD/5\%CO/5\%Fibra é mostrado na Figura 55. O mesmo comportamento foi observado para todos os compósitos e para o BPEAD puro. Estes materiais não romperam até deformações de 5,0\%.

Figura 55. Curva de Tensão versus Deformação para o compósito de BPEAD/5\%CO/5\%Fibra.

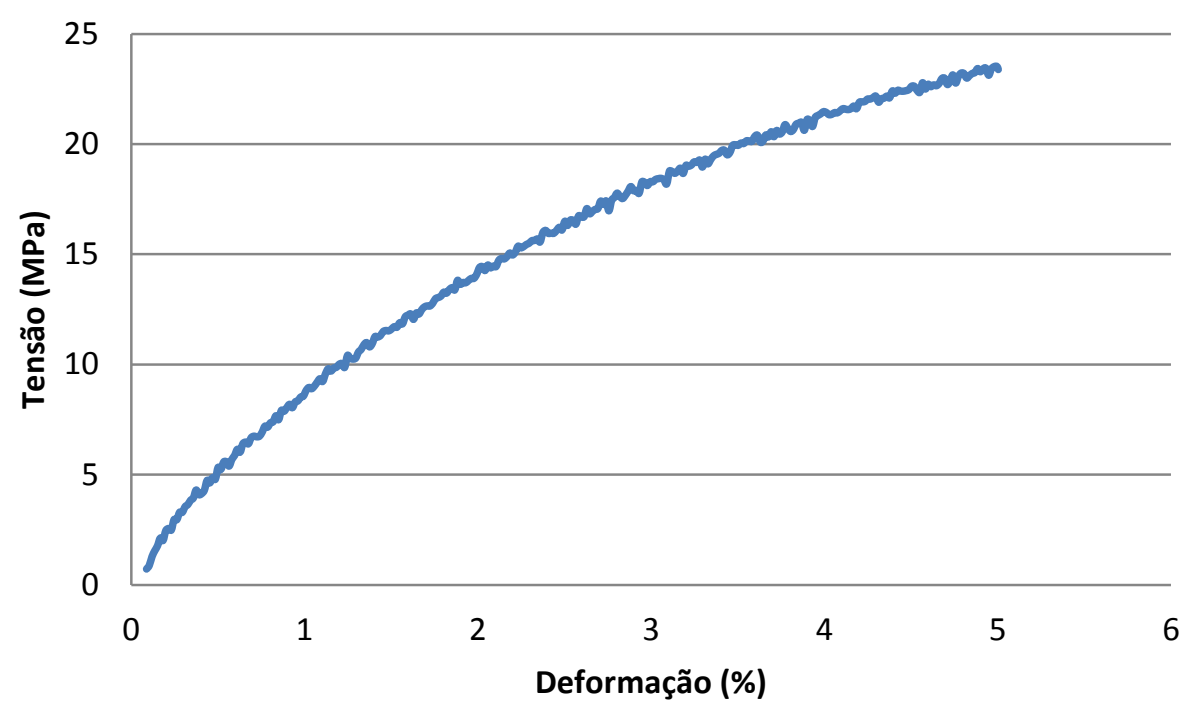

A resistência à flexão a $5 \%$ de deformação (Figura 56) e o módulo de flexão (Figura 57) dos compósitos foi obtida para aqueles com diferentes porcentagens de fibra de curauá, de CO, CA, OSE e OLE bem como para o polímero puro, BPEAD. 
Figura 56. Resistência à flexão dos compósitos, desvio padrão entre 4-10\%.

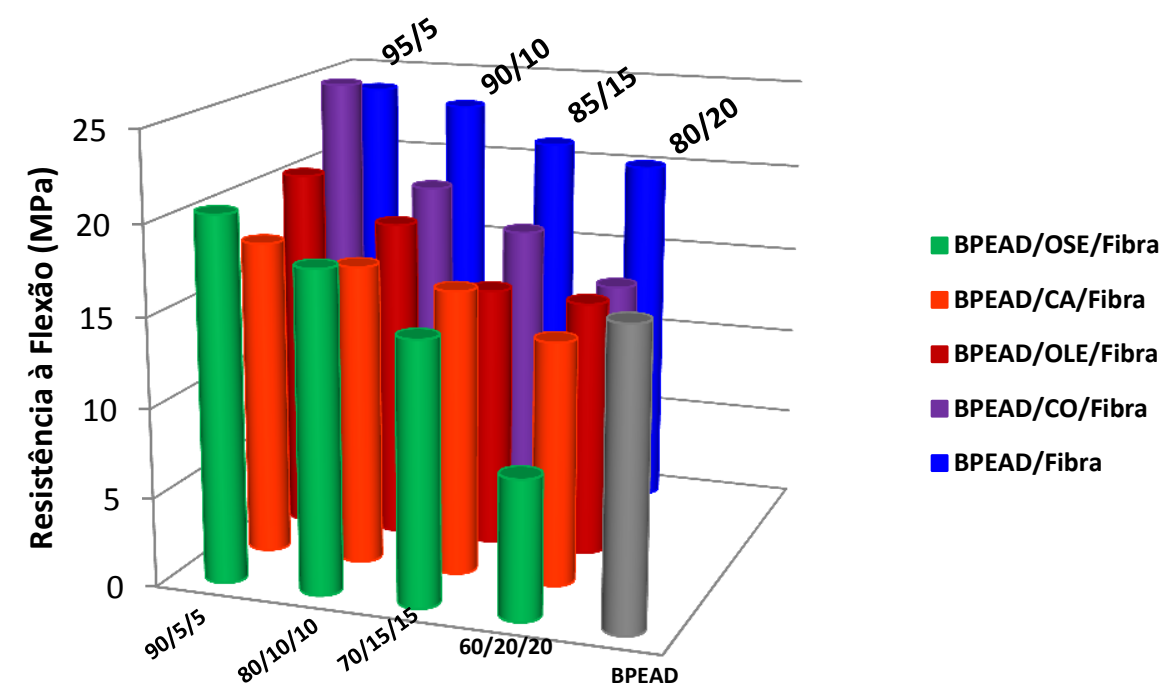

A resistência à flexão a $5 \%$ de deformação do BPEAD foi de $16,5 \mathrm{MPa}$ e o módulo de flexão foi de 0,52 MPa, para o polímero processado no misturador interno (Haake) e moldado por termoprensagem. Para os compósitos BPEAD/5\%OSE/5\%Fibra, BPEAD/5\%OLE/5\%Fibra, BPEAD/5\%CO/5\%Fibra e BPEAD/5\%CA/5\%Fibra e para os compósitos BPEAD/Fibra, a resistência e o módulo de flexão foram maiores se comparadas ao BPEAD puro. O menor teor de fibras facilita uma distribuição mais homogênea das fibras na matriz, aumentando a resistência à flexão a $5 \%$ de deformação (GOULART et al., 2011).

O compósito BPEAD/5\%CO/5\%Fibra apresentou similar resistência e módulo de flexão se comparado aos compósitos BPEAD/Fibra, possivelmente devido às interações entre os grupos polares das fibras com os grupos polares do CO (Figura 57). 
Figura 57. Módulo de flexão dos compósitos, desvio padrão entre 3-10\%.

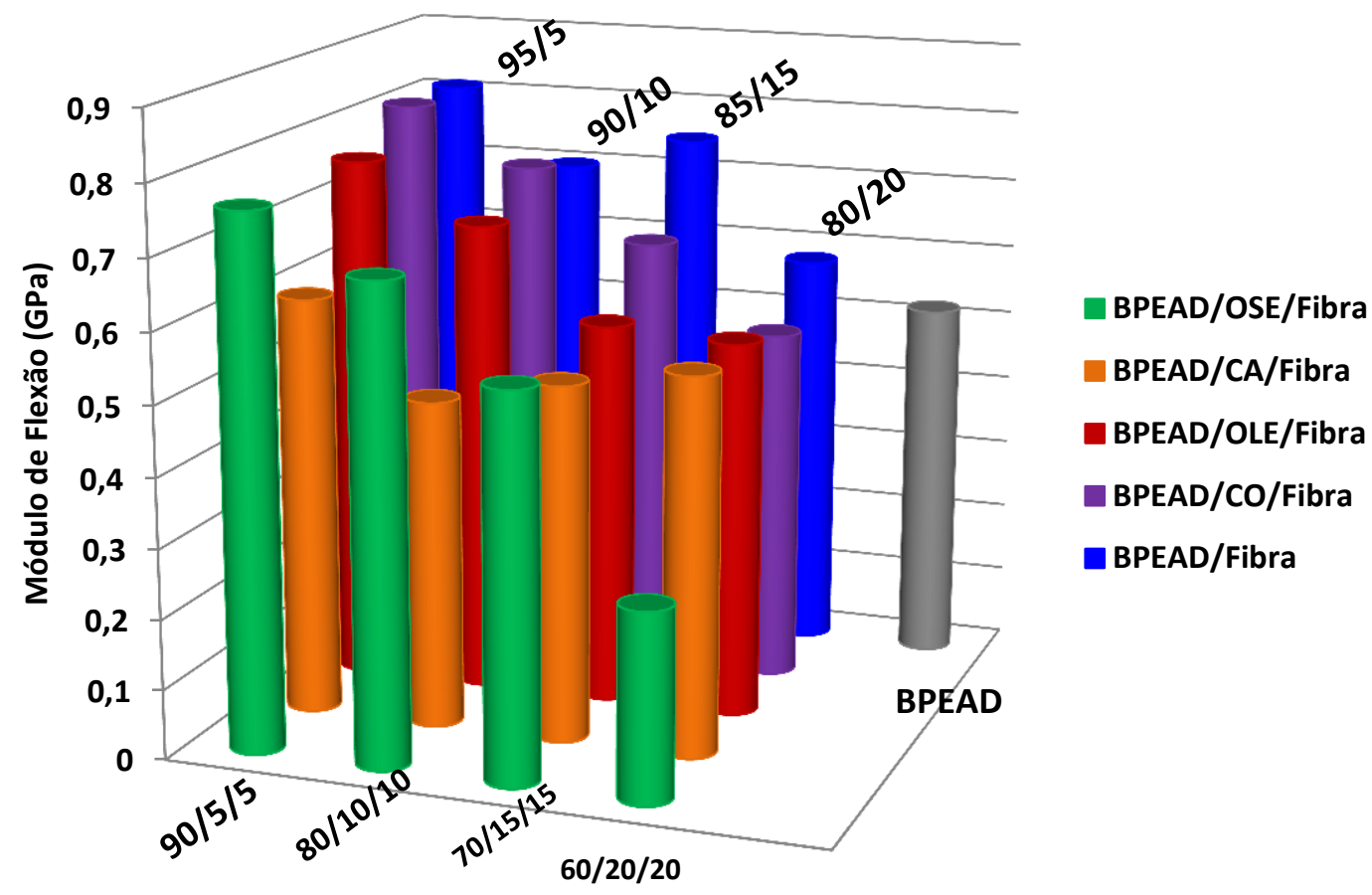

A presença de CO, CA, OSE e OLE levaram a compósitos com menor resistência à flexão (Figura 56). Deve-se destacar os dados representados na Figura 56 correspondem à resistência à flexão até $5 \%$ de deformação, pois os compósitos não quebraram durante o ensaio, o que pode ser atrativo para aplicações em que a resistência à flexão seja importante. Quando os compósitos foram submetidos à tensão de flexão, embora a presença do agente compatibilizante conduzisse a uma maior adesão na interface, o seu comportamento como plastificante levou a um material que requisitou menor força para ser deformado em $5 \%$, quando comparados aos compósitos em que não havia a presença de óleo. Deve-se ressaltar que as propriedades de flexão são influenciadas pelas camadas mais externas do material, que no presente estudo é preponderantemente formada por BPEAD. Assim, para esta propriedade, a ação dos óleos como plastificantes teve maior influência que a ação como compatibilizante, que envolve as regiões de interface fibra/matriz (CASTRO; RUVOLO-FILHO; FROLLINI, 2012). 


\subsection{Compósitos preparados na extrusora}

Em trabalhos anteriores, 5\% de polibutadieno líquido hidroxilado (PBHL) foi introduzido em relação à massa total do compósito, com a finalidade de aumentar a tenacidade da matriz termoplástica (BPEAD) e por consequência, dos compósitos finais obtidos, além de o PBHL poder atuar como agente compatibilizante. Também foram introduzidas diferentes frações de fibra de curauá, com comprimento médio de $1 \mathrm{~cm}$ e com porcentagens diversificadas $(5,10,15$ e $20 \%)$. Neste estudo, foi encontrado que a composição BPEAD/5\%PBHL/10\%Fibra foi facilmente processada no misturador interno (Haake) e moldado por termoprensagem, exibindo boas propriedades de impacto e de flexão. Estas propriedades foram semelhantes ao compósito BPEAD/5\%PBHL/5\%Fibra e melhores do que os compósitos reforçados com quantidades superiores de fibras (15 e $20 \%$ ). Assim, no presente estudo esta composição foi selecionada para ser processada por extrusão e moldada por injeção, utilizando CO, CA e OSE em substituição ao PBHL. As propriedades observadas foram comparadas com aquelas dos compósitos preparados via processamento no misturador interno Haake.

\subsubsection{Análise Térmica}

A ocorrência de decomposição térmica das fibras durante o processamento dos compósitos pode ocasionar grandes mudanças nas propriedades mecânicas dos materiais, geradas por mudanças na estrutura das fibras e pela geração de substâncias voláteis que podem criar espaços vazios nos compósitos.

A Figura 58 mostra os resultados da TG e as curvas dTG do BPEAD, da fibra e dos compósitos extrudados e moldados por injeção. 
Figura 58. Fibra de curauá, BPEAD e compósitos preparados por extrusão/injeção: (a) Curvas TG e (b) Curvas dTG, atmosfera de $\mathrm{N}_{2}$, fluxo de $20 \mathrm{~mL} \mathrm{~min}^{-1}$ e razão de aquecimento de $10{ }^{\circ} \mathrm{Cmin}^{-1}$.

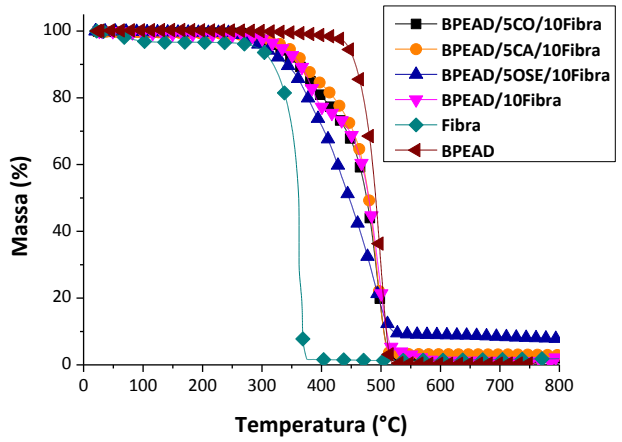

(a)

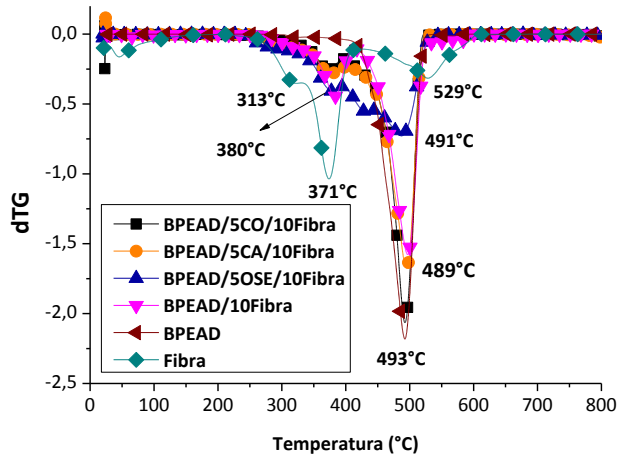

(b)

Como citado anteriormente, para o BPEAD observou-se uma estreita faixa de decomposição que ocorreu em uma única etapa, com o máximo de decomposição ocorrendo em torno de $491^{\circ} \mathrm{C}$.

Para os compósitos, observou-se que o início da decomposição ocorreu a $278^{\circ} \mathrm{C}$ para BPEAD/5\%OSE/10\%Fibra, a $300^{\circ} \mathrm{C}$ para BPEAD/5\%CA/10\%Fibra e BPEAD $/ 5 \% \mathrm{CO} / 10 \%$ Fibra e a $282^{\circ} \mathrm{C}$ para BPEAD/10\%Fibra (Figura 58a). A estabilidade térmica dos compósitos contendo CA e CO foi mais elevada se comparada ao compósito BPEAD/10\%Fibra. Provavelmente houve uma melhora nas interações fibra/matriz na presença de CA e CO, levando a fibras mais recobertas e protegidas, $\mathrm{o}$ que deslocou a temperatura de início de decomposição para maiores valores, comparativamente à fibra isoladamente (Figura 58a). Devido à presença das fibras, a decomposição térmica dos compósitos iniciou antes que a do BPEAD isoladamente (Figura 58a).

Os compósitos processados por extrusão apresentaram estabilidade térmica semelhante em comparação aos compósitos processados no misturador interno (Figura 44). Ainda, destaca-se que o início da decomposição térmica dos compósitos (Figura 58a) ocorreu a temperaturas superiores aquelas do processamento via extrusão $\left(205^{\circ} \mathrm{C}-215^{\circ} \mathrm{C}\right)$.

Considerando o pico exotérmico nas curvas de DSC (Figura 59) relativo à fusão, próximo de $136^{\circ} \mathrm{C}$, pôde-se obter os valores das $\Delta \mathrm{H}_{\mathrm{m}}$ para os compósitos extrudados e 
injetados. As curvas dos compósitos processados por extrusão foram semelhantes aos compósitos processados no misturador interno (Figuras não mostradas).

Na Tabela 9 são apresentadas as entalpias de fusão $\left(\Delta \mathrm{H}_{\mathrm{m}}\right)$ para os compósitos e para o BPEAD, assim como a razão entre $\Delta H_{m}$, a fração mássica $/ \varphi_{m}$ e índice de cristalinidade.

Figura 59. Curvas DSC para a fibra de curauá, BPEAD e compósitos preparados por extrusão/injeção,

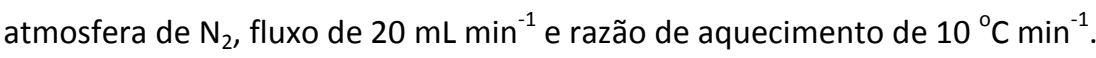

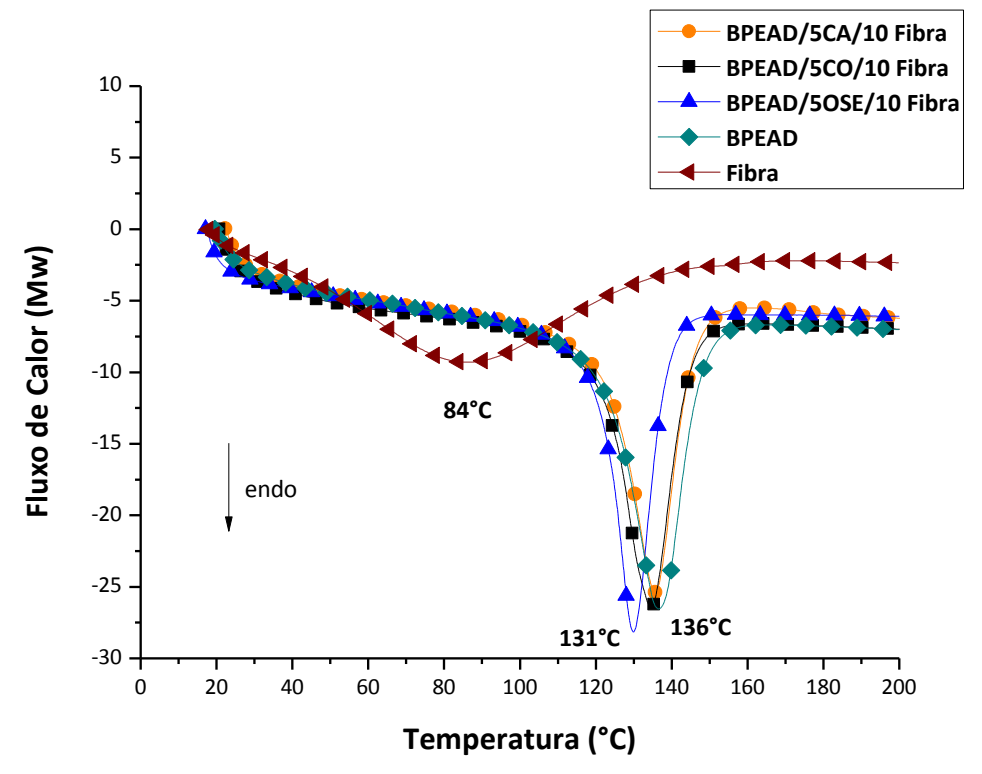

A temperatura de fusão $\left(T_{m}\right)$ é diretamente relacionada à dimensão de áreas cristalinas no BPEAD, e pode ser influenciada pela presença de fibras na superfície do material. A diminuição da $T_{m}$ pode ser a indicação de uma boa distribuição das fibras na matriz e do efeito plastificante dos óleos vegetais na matriz polimérica (MALAININE; MAHROUZ; DUFRESNE, 2004). Os compósitos BPEAD/5\%CO/10\%Fibra (134 $\left.{ }^{\circ} \mathrm{C}\right)$ e BPEAD $/ 5 \% O S E / 10 \%$ Fibra extrudados $\left(130^{\circ} \mathrm{C}\right)$, apresentaram uma pequena diminuição da $T_{m}$ quando comparados a matriz de BPEAD pura $\left(136^{\circ} \mathrm{C}\right)$. Não foram observadas diferenças significativas na $T_{m}$ entre os compósitos preparados por extrusão e aqueles preparados no misturador interno (Tabela 9). 
Tabela 9. Entalpias de fusão, razão entre $\Delta \mathrm{H}_{m}$ e $\varphi_{m}$, índice de cristalinidade e temperatura de fusão do BPEAD puro e em compósitos preparados por extrusão/injeção.

\begin{tabular}{ccccc} 
& \multicolumn{3}{c}{ Extrudado -} & Haake \\
\cline { 2 - 5 } Compósito & $\Delta \mathbf{H}_{\mathrm{m}}\left(\mathbf{J ~ g ~ g}^{-\mathbf{1}}\right)$ & $\Delta \mathbf{H}_{\mathrm{m}} / \boldsymbol{\varphi}_{\boldsymbol{\mu}}$ & $\mathbf{X c}(\%)$ & $\mathbf{T m}$ \\
\hline BPEAD & $197-196$ & $197-196$ & $67-67$ & $136-136$ \\
\hline BPEAD/10\%Fibra & $183-181$ & $203-201$ & $69-67$ & $135-135$ \\
BPEAD/5\%CA/10\%Fibra & $209-206$ & $246-242$ & $84-82$ & $134-135$ \\
BPEAD/5\%CO/10\%Fibra & $214-212$ & $251-249$ & $86-85$ & $136-136$ \\
BPEAD/5\%OSE/10\%Fibra & $212-209$ & $249-245$ & $85-84$ & $130-137$ \\
\hline
\end{tabular}

Foi observado um aumento da cristalinidade na matriz dos compósitos com a adição das fibras, o qual é atribuído ao efeito nucleante que a fibra exerce sobre o BPEAD (DUFRESNE; DUPEYRE; PAILLET, 2003). Um comportamento similar foi observado para os compósitos com 5, 10, 15 e 20\% de CA, CO, OSE e OLE processados no misturador interno (Tabela 7).

Não foram observadas diferenças significativas entre a cristalinidade do BPEAD presente nos compósitos preparados pelos dois processamentos diferentes (Tabela 7).

A presença de CA, CO, OSE e OLE levou a um aumento da cristalinidade dos compósitos (Tabela 9). A possibilidade de alinhamento de segmentos do BPEAD frente às regiões hidrofóbicas dos óleos, e mesmo das fibras, pode favorecer nucleação de domínios cristalinos no BPEAD.

\subsubsection{Análise Dinâmico-Mecânica (DMA)}

Observou-se que a adição de fibra de curauá ao BPEAD levou a um aumento no módulo de armazenamento, conforme mostram as curvas da Figura 60 para os compósitos BPEAD/5\%CO/10\%Fibra, BPEAD/5\%CA/10\%Fibra, BPEAD/5\%OSE/10\%Fibra e BPEAD/10\%Fibra, processados por extrusão, se comparados ao BPEAD. As curvas dos compósitos processados via Haake e termoprensados (Figuras não mostradas) apresentam comportamento análogo aos compósitos processados via extrusão e injetados.

Um decréscimo no módulo foi observado com o aumento da temperatura para todos os compósitos e para o BPEAD, devido ao aumento da mobilidade das cadeias poliméricas (ABDELMOULEH et al., 2007). 
Figura 60. Curva de módulo de armazenamento versus temperatura para os compósitos BPEAD/5\%CO, CA e OSE/10\%Fibra e BPEAD/10\%Fibra, preparados por extrusão/injeção.

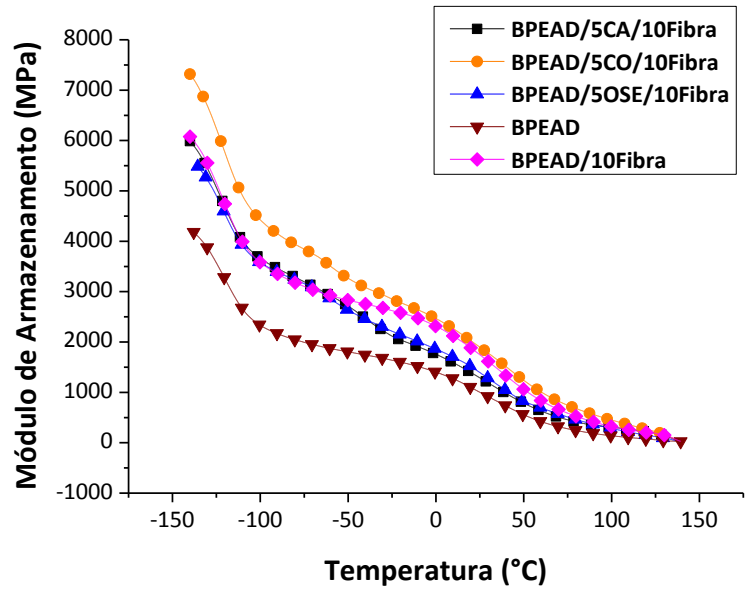

A Figura 61 mostra o módulo de armazenamento a $30^{\circ} \mathrm{C}$ para os compósitos reforçados com fibra de curauá, processados por extrusão e processados no misturador interno (Haake).

Figura 61. Módulo de armazenamento $\left(a 30^{\circ} \mathrm{C}\right)$ dos compósitos preparados por extrusão/injeção e por misturador interno (Haake)/termoprensagem.

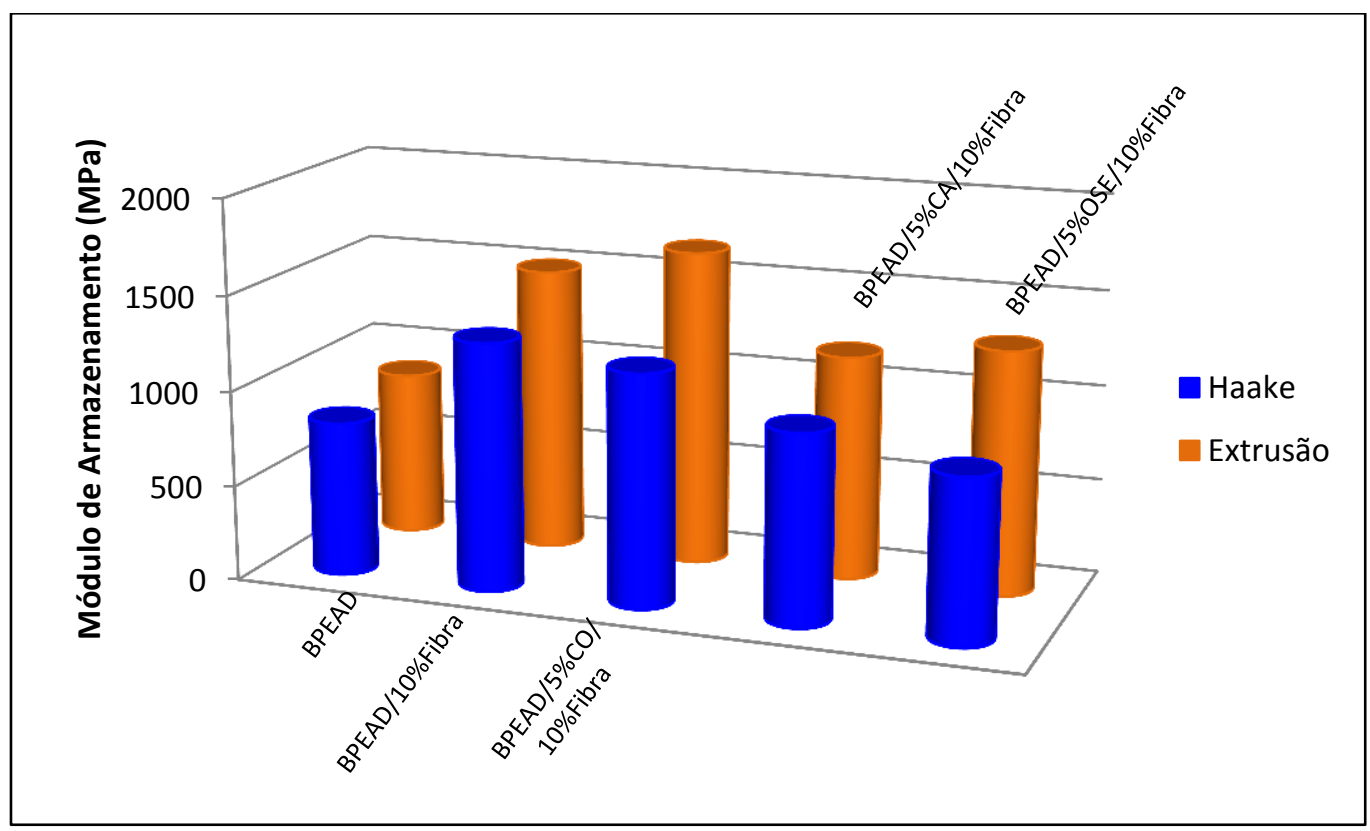

Considerando os compósitos processados por extrusão, os módulos de armazenamento $\left(30^{\circ} \mathrm{C}\right)$ dos compósitos BPEAD/5\%CA/10\%Fibra (1178 MPa) e BPEAD/5\%OSE/10\%Fibra (1280 $\mathrm{MPa})$ são menores que o do compósito 
BPEAD/10\%Fibra (1500 MPa), indicando a preponderância de um possível efeito plastificante destes óleos sobre a matriz, aumentando a mobilidade dos segmentos das cadeias de BPEAD. Já para o compósito BPEAD/5\%CO/10\%Fibra o módulo (1660 MPa) foi ligeiramente superior ao do compósito preparado sem adição de óleos vegetais (BPEAD/10\%Fibra, $1500 \mathrm{MPa}$ ), indicando que neste caso o efeito plastificante foi superado pelo atuação do CO como agente de compatibilização fibra-matriz na interface, que reduz a mobilidade dos segmentos de BPEAD presentes nesta região. Os compósitos processados por extrusão apresentaram $E^{\prime}\left(30^{\circ} \mathrm{C}\right)$ maior, se comparados aos compósitos processados no misturador interno. Estes resultados indicam que o processamento via extrusão/injeção intensificou a molhabilidade das fibras pela matriz, ou pela mistura matriz/óleo, assim como pode ter levado a melhor dispersão das fibras na matriz, comparativamente ao processamento via misturador interno/termoprensagem. Mohanty et al. (2004) avaliaram o efeito da adição de fibra de cânhamo em acetato de celulose, utilizando trietil citrato como plastificante. Foram utilizados dois métodos de processamento, ou seja, extrusão e compressão (acetato de celulose, trietil acetato e fibra foram misturador previamente em um mixer por 30 minutos). Os compósitos extrudados e injetados apresentaram módulo de armazenamento $\left(25^{\circ} \mathrm{C}\right)$ maiores que os compósitos moldados por compressão, assim como observado no presente estudo.

A Figura 62 mostra a tan $\delta$ para o BPEAD e para os compósitos extrudados.

Figura 62. Curvas de $\tan \delta$ versus temperatura para os compósitos BPEAD/5\%CA, CO e OSE/10\%Fibra $(3 \mathrm{~mm})$ extrudados e injetados: (a) -140 a $130^{\circ} \mathrm{C}$ e (b) -140 a $-90^{\circ} \mathrm{C}$.

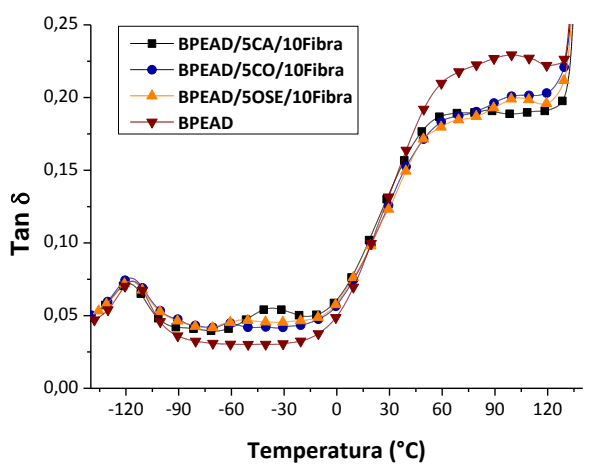

(a)

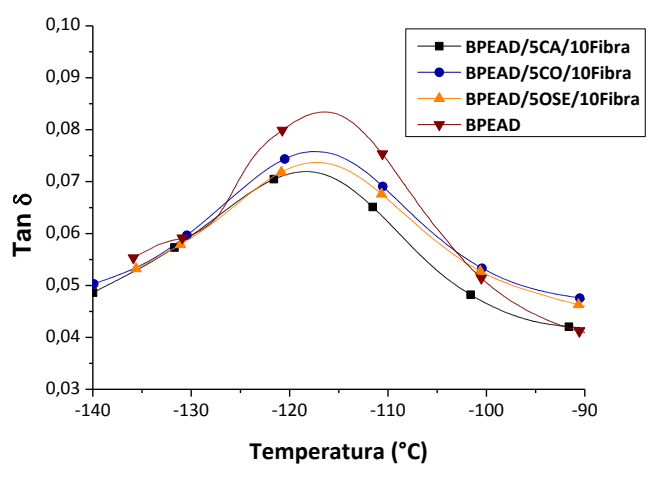

(b) 
Como mostrado anteriormente, tipicamente o polietileno de alta densidade, apresentou duas relaxações, uma relaxação em torno de $-116^{\circ} \mathrm{C}$, relacionada à região não cristalina e associada à transição vítrea $\left(\operatorname{Tg}, \alpha_{a}\right)$ (Pico 1). A outra relaxação ocorreu entre 50 e $120^{\circ} \mathrm{C}$, acima da $\mathrm{Tg}$ e abaixo de $\mathrm{Tm}$ (temperatura de fusão, em torno de $135^{\circ} \mathrm{C}$ ) pode ser considerado decorrente de uma transição do tipo $\alpha^{\prime}{ }_{c}$ (Pico 2).

Tabela 10. BPEAD e compósitos com fibra de curauá: picos tan $\delta$ (desvio entre $0,2-0,6^{\circ} \mathrm{C}$ ).

\begin{tabular}{ccc}
\cline { 2 - 3 } & \multicolumn{1}{c}{ Extrusão/ } & Haake \\
\cline { 2 - 3 } & Temperatura & $\left({ }^{\circ} \mathrm{C}\right)$ \\
\cline { 2 - 3 } & Pico 1 & Pico 2 \\
\hline BPEAD & $-116 /-116$ & $94 / 95$ \\
\hline BPEAD/10\%Fibra & $-117 /-119$ & $93 / 92$ \\
\hline BPEAD/5\% CA/10\% Fibra & $-118 /-120$ & $99 / 97$ \\
\hline BPEAD/5\% CO/10\% Fibra & $-116 /-117$ & $99 / 97$ \\
\hline BPEAD/5\% OSE/10\% Fibra & $-117 /-118$ & $100 / 97$ \\
\hline
\end{tabular}

Conforme mencionado previamente, a observação ou não de um deslocamento em Tg devido à ação de compatibilizantes depende de fatores como proporção de segmentos de cadeias da matriz próximos à interface, sendo que dentre estes somente aqueles dos domínios não cristalinos influenciarão esta transição. No presente estudo, não foram observadas diferenças significativas entre as transições vítreas dos compósitos extrudados e os processados no misturador interno na presença de CA, CO, OSE e OLE (Tabela 10). 
Figura 63. Valores de $\tan \delta$ para os compósitos preparados por / misturador interno (Haake)/ termoprensagem e por extrusão/injeção.

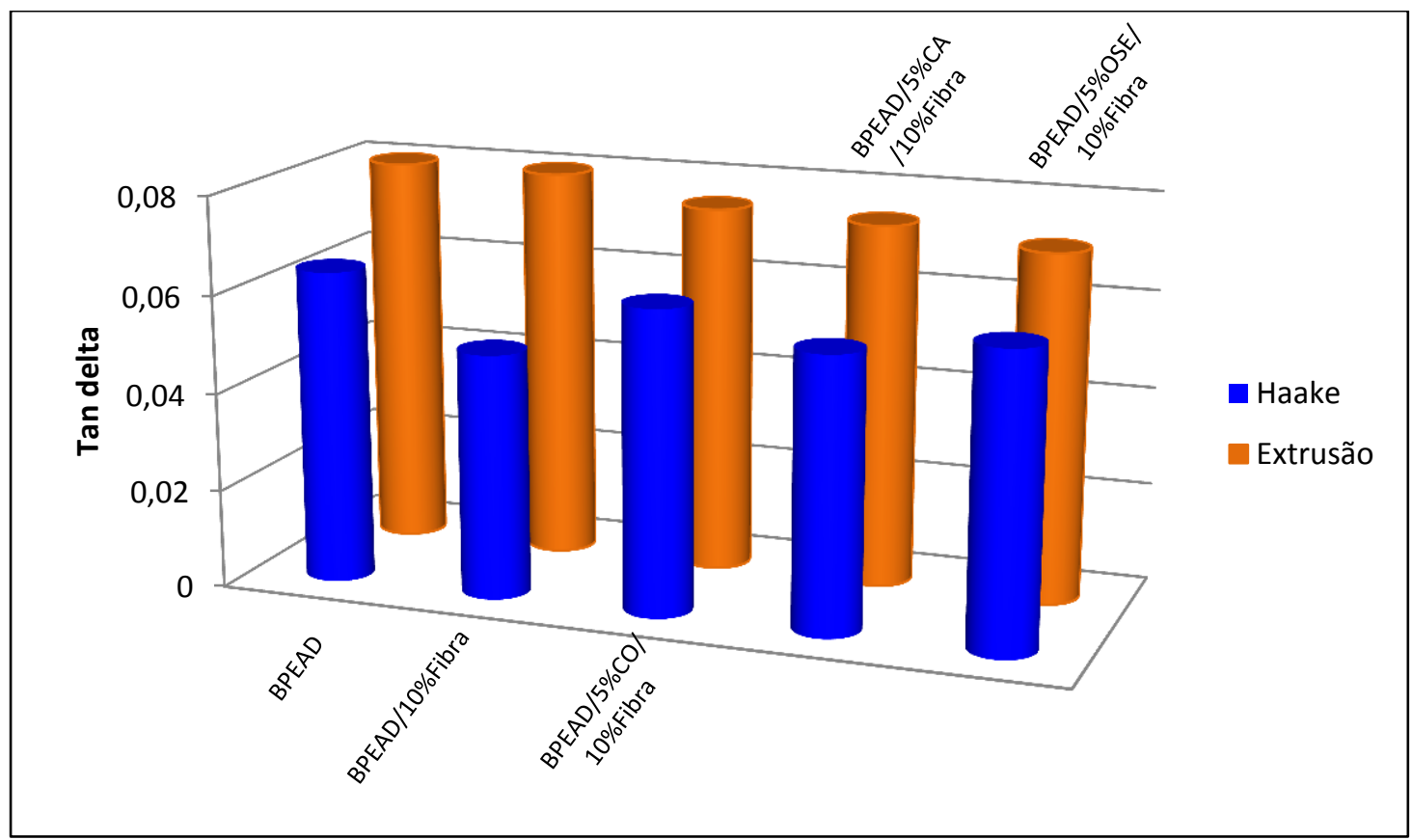

A Figura 63 mostra que a altura do pico de $\tan \delta$ (em torno de $-117^{\circ} \mathrm{C}$ ), para os compósitos extrudados foram menores quando comparados ao BPEAD puro. A presença de fibras de curauá pode ter restringido a mobilidade de segmentos da cadeia, resultando em redução na altura do pico de tan $\delta$, o que pode também estar relacionado com as interações fibra/matriz nos compósitos na presença de $\mathrm{CA}$, $\mathrm{CO}$ e OSE (HUDA et al., 2007).

De Oliveira Santos et al. (2014) prepararam compósitos baseados em poli (tereftalato de etileno) reciclado (PET reciclado) e fibras de sisal. A fim de evitar a decomposição térmica das fibras durante o processamento, os plastificantes acetil tributil citrato $(A T B C)$, tributil citrato (TBC), glicerol, óleo de mamona (CO) e óleo de soja epoxidado (OSE) foram acrescentados às formulações dos compósitos. Adicionalmente, polibutadieno hidroxilado líquido ( $\mathrm{PBHL}$ ) foi acrescentado à formulação do material, visando avaliar sua ação como agente compatibilizante/de acoplamento na interface fibra-matriz. Pôde-se observar que todos os compósitos, exceto o compósito com tributil citrato, apresentaram um aumento na altura do pico de $\tan \delta$ em relação ao PET reciclado, indicando que os plastificantes aumentaram a mobilidade dos segmentos das cadeias de polímero. Já o compósito com TBC 
apresentou uma queda na altura de $\tan \delta$, indicando o efeito compatibilizande do TBC. No presente estudo, para os compósitos extrudados uma queda na altura de $\tan \delta$ foi observada também, indicando uma diminuição da mobilidade dos segmentos das cadeias de polímero e consequentemente o efeito compatibilizante dos óleos vegetais nos compósitos.

Para os compósitos BPEAD/5\%CO/10\%Fibra $(0,062)$, BPEAD/5\%CA/10\%Fibra $(0,056)$ e BPEAD/5\%OSE/10\%Fibra $(0,06)$ processados no misturador interno (Figura 63) a altura do pico de $\tan \delta$ a $-117^{\circ} \mathrm{C}$ foi menor quando comparada aos compósitos BPEAD/5\%CO/10\%Fibra $\quad(0,075), \quad$ BPEAD/5\%CA/10\%Fibra $\quad(0,074) \quad$ e BPEAD/5\%OSE/10\%Fibra $(0,071)$ processados por extrusão, indicando que a extrusão foi um processo mais eficiente para a preparação de compósitos de fibras curtas.

\subsection{3 Índice de Fluidez (MFI)}

Na Figura 64 estão representados os resultados das análises de índice de fluidez para os compósitos reforçados com fibra de curauá preparados via extrusão e via misturador interno.

Figura 64. Índice de Fluidez para os compósitos obtidos via extrusão/injeção e via misturador interno (Haake). (desvio entre 0,01 e 0,03 g10 $\mathrm{min}^{-1}$ ).

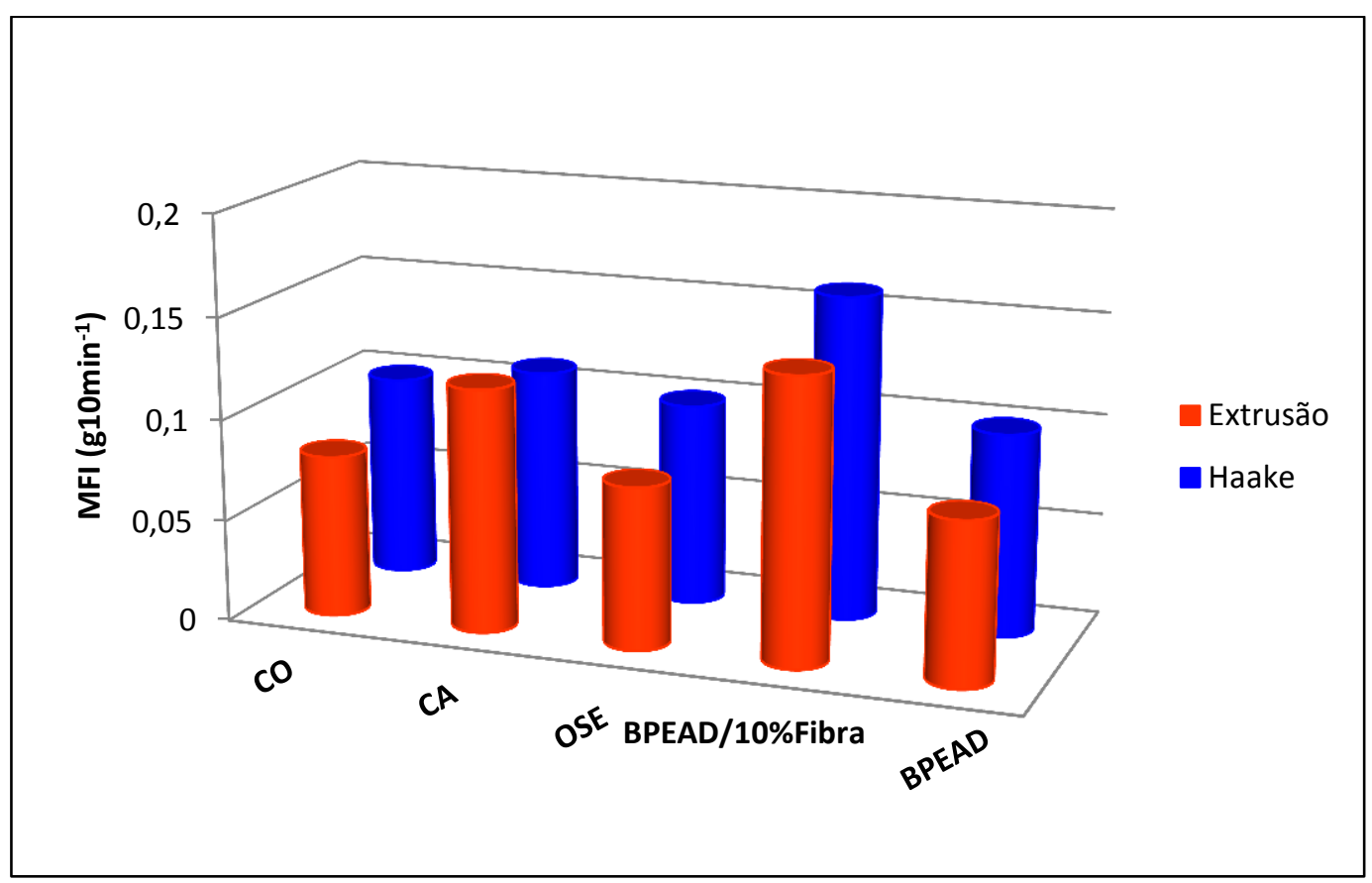


O cisalhamento durante o processamento por extrusão é mais intenso do que no misturador interno (Haake), o que provocou um aumento da viscosidade, que provavelmente conduziu a um MFI do BPEAD extrudado $\left(0,08 \mathrm{~g} 10 \mathrm{~min}^{-1}\right)$ menor se comparado ao processado no misturador interno $\left(0,1 \mathrm{~g} 10 \mathrm{~min}^{-1}\right)$.

Analisando os resultados na Figura 64 foi possível observar uma redução da

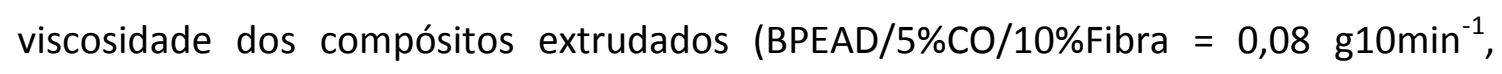
BPEAD $/ 5 \% C A / 10 \% F i b r a=0,12 \mathrm{~g} 10 \mathrm{~min}^{-1}, \mathrm{BPEAD} / 5 \% \mathrm{OSE} / 10 \% \mathrm{Fibra}=0,08 \mathrm{~g} 10 \mathrm{~min}^{-1}$ ) quando comparado aos compósitos processados no misturador interno

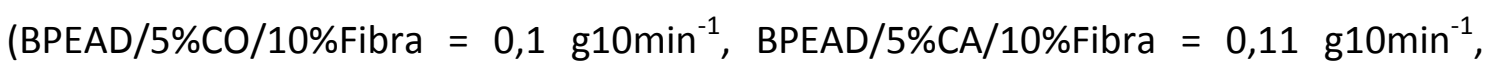
BPEAD/5\%OSE/10\%Fibra $=0,1$ g10 $\mathrm{min}^{-1}$ ), a redução da viscosidade pôde estar relacionada com a melhor interação entre a fibra e a matriz, na presença dos óleos vegetais, como mostrado nos estudos de MEV e de resistência ao impacto. Mohanty et al. (2004) utilizou juta como reforço em compósitos de polipropileno e como compatibilizante polipropileno graftizado com anidrido maléico. Os compósitos foram processados por extrusão. Observou-se cerca de $72,3 \%$ de aumento na resistência à flexão nos compósitos enxertados com anidrido maléico em relação aos compósitos não modificados e através da análise de MFI também se observou uma maior aderência da fibra à matriz, através da diminuição do MFI para os compósitos modificados, assim como observado no presente estudo para os compósitos processados via extrusão.

A partir da análise do MFI dos compósitos observou-se que a viscosidade foi influenciada pelo método de processamento (JOSEPH et al., 2002).

Os compósitos extrudados e injetados apresentaram índices de fluidez maiores que o BPEAD, houve uma diminuição da viscosidade, ou seja, ocorreu um maior escoamento de massa dos compósitos fundidos, em um mesmo intervalo de tempo.

\subsubsection{Resistência ao Impacto}

A Figura 65 mostra que a resistência ao impacto do compósito processado por extrusão/ injeção foi consideravelmente maior do que a do processado por misturador interno (Haake)/termoprensado. O cisalhamento durante o processamento por extrusão foi mais intenso do que no misturador interno (Haake), que provavelmente 
aumentou a impregnação da fibra pelo BPEAD, ou BPEAD/óleo, e conduziu a uma melhor dispersão da fibra no material (SANTOS et al., 2007), favorecendo assim a transferência de carga a partir da matriz para a fibra durante o ensaio de impacto.

Os corpos de provas termoprensados podem apresentar defeitos devido à distribuição não homogênea dos materiais durante a compressão dos compósitos e do BPEAD, assim, a resistência ao impacto do compósito e do BPEAD extrudado e injetado foi maior (499 $\mathrm{J} \mathrm{m}^{-1}$ ) se comparada ao compósito processado no misturador interno e termoprensado $\left(234 \mathrm{~J} \mathrm{~m}^{-1}\right)$. As peças produzidas por injeção apresentam a vantagem de serem confeccionadas com altas taxas de produtividade e não requerem acabamentos.

Figura 65. Resistência ao impacto Izod dos compósitos, corpos de prova entalhados, desvio padrão entre 5-10\%, Compósitos BPEAD/10\%Fibra, BPEAD/5\%CA, CO e OSE/10\%Fibra (3mm) preparados via misturador interno (Haake)/termoprensagem e por extrusão/injeção.

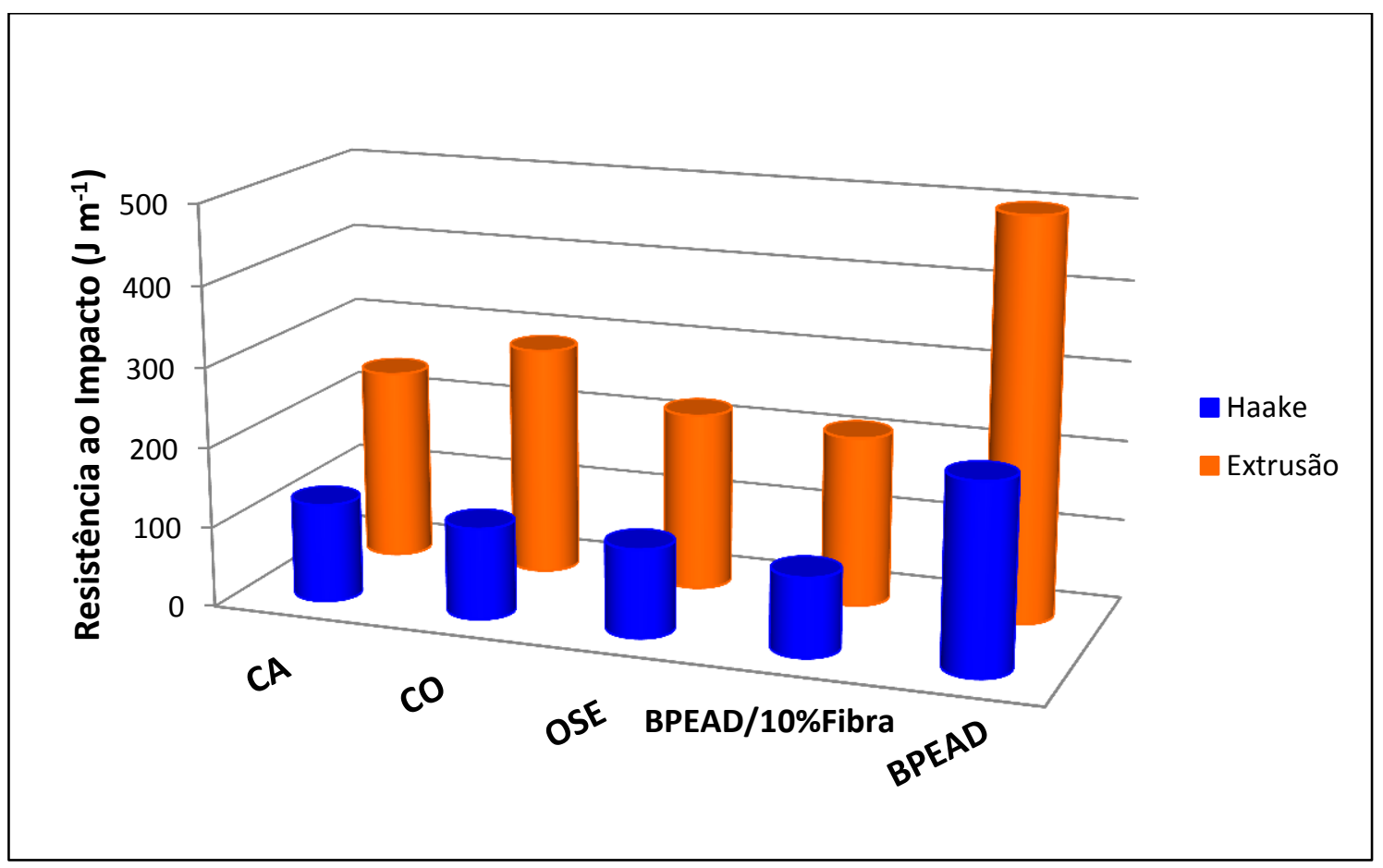

Analisando os resultados apresentados (Figura 65), observou-se que o óleo que apresentou o melhor desempenho foi o $\mathrm{CO}$, cujo compósito teve uma resistência ao impacto de $287 \mathrm{~J} \mathrm{~m}^{-1}$. Todos os óleos melhoraram a molhabilidade da fibra pela matriz e, devido às respectivas estruturas químicas (Tabela 3), também puderam atuar como compatibilizantes na interface fibra-matriz. Estes valores confirmam que os óleos 
vegetais atuaram como agente amortecedor de impacto aumentando a tenacidade do compósito (JARUKUMJORN; SUPPAKARN, 2009; ARAUJO et al., 2010). A presença das fibras viabilizou interações entre os grupos $\mathrm{OH}$ destas e do óleo (Figuras 13 e 14) permitindo que os óleos atuassem no sentido de melhorar o impacto. O óleo de mamona (CO) apresenta vantagens em relação aos demais óleos, pois é constituído majoritariamente pelo ácido ricinoléico, que apresenta em sua estrutura um grupo carboxílico e uma hidroxila, o que deve ter intensificado as interações entre o mesmo e a fibra de curauá.

Quando a viscosidade aumenta, o valor de MFI diminui e compósito com o óleo de mamona apresentou o menor MFI (Figura 64), ou seja, a ação plastificante não é predominante para este óleo. Estes resultados confirmam a ação compatibilizante do CO e estão de acordo comos valores de resitência ao impacto (Figura 65).

Em trabalhos anteriores, $5 \%$ de $\mathrm{PBHL}$ foi introduzido em relação à massa total do compósito, com a finalidade de aumentar a tenacidade da matriz termoplástica (BPEAD) e por consequência, dos compósitos finais obtidos, além de o PBHL poder atuar como agente compatibilizante. Também foi introduzida $10 \%$ de fibra de curauá, com comprimento médio de $3 \mathrm{~mm}$. O compósito foi processado por extrusão e moldado por injeção. As propriedades mecânicas dos compósitos foram analisadas por resistência à flexão e ao impacto. A resistência ao impacto do compósito BPEAD/5\%PBHL/10\%Fibra foi de $296 \mathrm{~J} \mathrm{~m}^{-1}$ e a do compósito BPEAD/5\%CO/10\%Fibra foi de $287 \mathrm{~J} \mathrm{~m}^{-1}$ (presente trabalho). Assim, adição de PBHL e CO levaram uma melhor adesão e distribuição destas fibras na matriz termoplástica. Substituindo PBHL por CO, foi possível preparar materiais baseados principalmente em matéria prima proveniente de fontes naturais, ou seja, materiais do tipo biocompósitos, com boas propriedades.

O compósito BPEAD/10\%Fibra extrudado exibiu resistência ao impacto de $212 \mathrm{~J}$ $\mathrm{m}^{-1}$, enquanto que o compósito de PEAD comercial reforçado com $30 \%$ de fibras de vidro extrudado apresentou resistência ao impacto Izod com entalhe de $70 \mathrm{~J} \mathrm{~m}^{-1}$ (ARAUJO et al., 2010). O compósito BPEAD/5\%CO/10\%Fibra apresentou resistência ao impacto de $287 \mathrm{~J} \mathrm{~m}^{-1}$, o compósito BPEAD/5\%CA/10\%Fibra $222 \mathrm{~J} \mathrm{~m}^{-1}$ e o compósito BPEAD/5\%OSE/10\%Fibra $212 \mathrm{~J} \mathrm{~m}^{-1}$, apontando para uma ação muito positiva do CO, CA e OSE sobre o desempenho dos compósitos. 


\subsubsection{Microscopia Eletrônica de Varredura}

Através da análise morfológica dos compósitos foi possível avaliar a dispersão das fibras nos compósitos bem como a atuação dos agentes compatibilizantes na superfície fibra/matriz.

A Figura 66 mostra as micrografias da superfície de fratura após o ensaio de impacto, para os compósitos BPEAD/10\%Fibra, BPEAD/5\%CA/10\%Fibra, BPEAD/5\%CO/10\%Fibra e BPEAD/5\%OSE/10\%Fibra preparados por extrusão/injeção em comparação com os preparados via misturador interno/termoprensados.

A partir das micrografias das Figura 66 a, d, g, observou-se uma camada de polímero em volta das fibras, indicando uma boa adesão na interface BPEAD/Fibra nos compósitos.

Figura 66. Micrografias obtidas por MEV a partir da superfície de fratura dos compósitos obtidos por extrusão/injeção e entalhados: (a), (b) BPEAD/5\%CA/10\%Fibra; (d), (e) BPEAD/5\%CO/10\%Fibra; (j) BPEAD/10\%Fibra (g), (h) BPEAD/5\%OSE/10\%Fibra e obtidos por misturador interno (Haake)/termoprensagem: (c) BPEAD/5\%CA/10\%Fibra; (f) BPEAD/5\%CO/10\%Fibra e (i) BPEAD/5\%OSE/10\%Fibra.
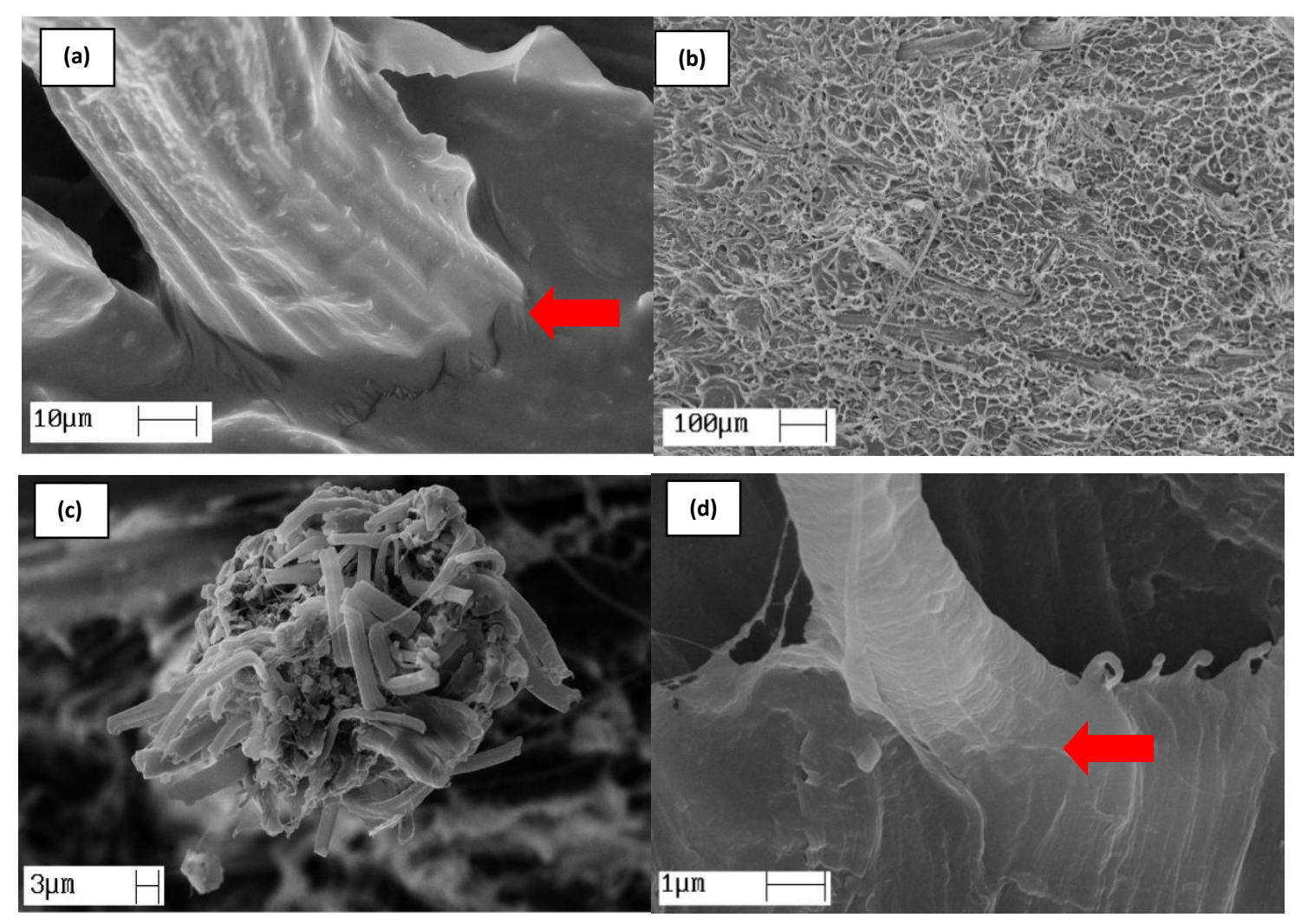

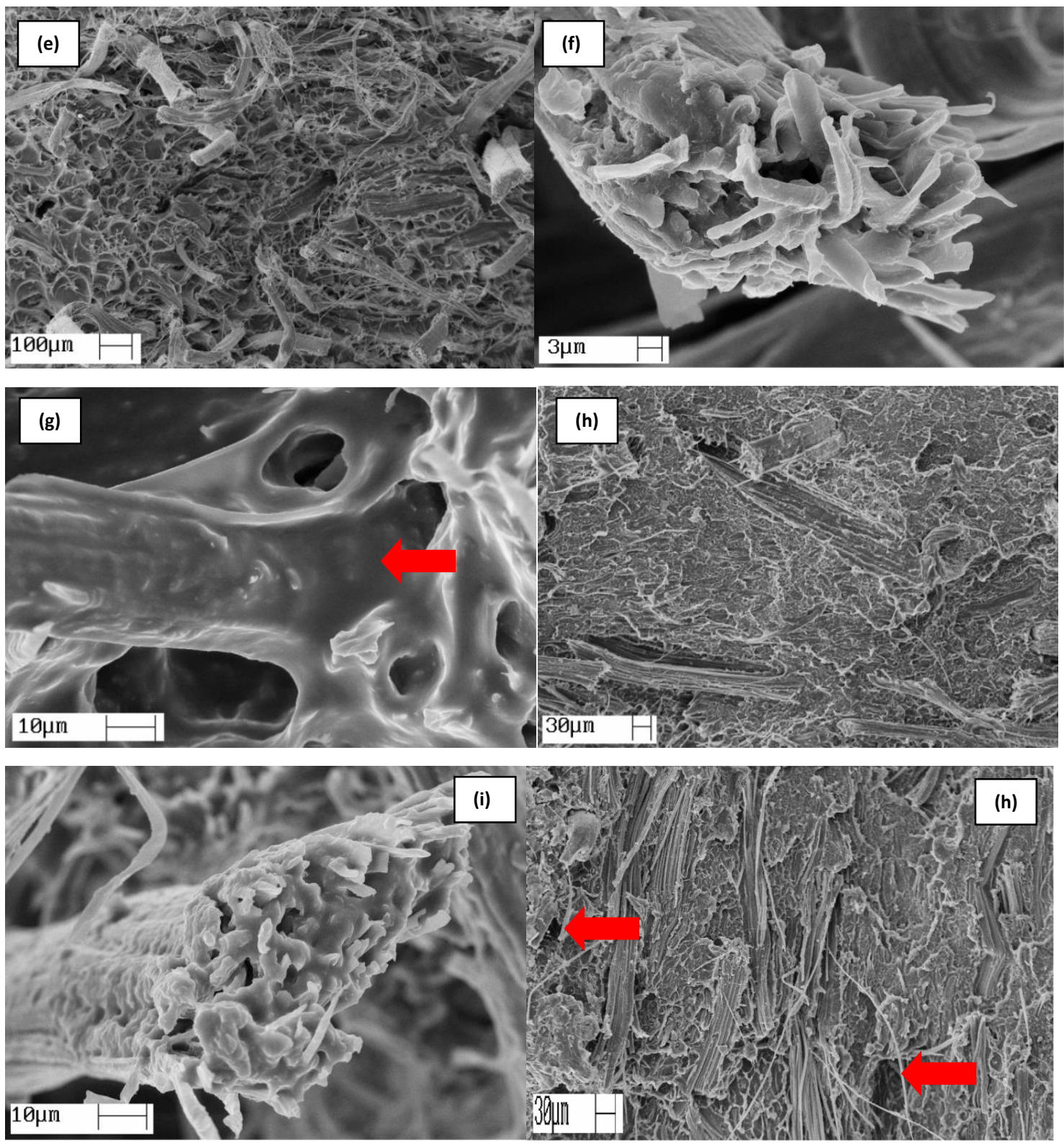

Para os compósitos processados via extrusão/injeção contendo os diferentes agentes compatibilizantes (Figura 66 b,e,h) as superfícies mostraram-se visualmente mais homogêneas se comparadas ao compósito BPEAD/10\%Fibra (Figura 66 j). Foi possível visualizar muitas fibras presas a matriz BPEAD para os compósitos compatibilizados, resultado de forte interação do sistema, ao contrário do compósito BPEAD/10\%Fibra que apresentou vazios em sua superfície como indicado na Figura 66 j.

A observação da superfície de fratura de corpos de prova dos compósitos obtidos via misturador interno/ termoprensagem (fibras com $3 \mathrm{~mm}$ ) indica que houve uma boa dispersão das fibras no polímero; porém as fibras foram apenas parcialmente 
desfibradas (Figura 66 c,f,i). Já nos compósitos processados por extrusão, as fibras $(3 \mathrm{~mm})$ foram desfibradas durante o processamento, ocorrendo boa dispersão das microfibrilas no termoplástico (Figura 66 a,d,g), o que pode ser responsável pela melhora das propriedades mecânicas.

A extrusão foi uma forma de processamento muito adequada para a preparação de compósitos contendo fibras naturais curtas, garantindo uma mistura efetiva e homogênea (MANO et al., 2010).

\subsubsection{Resistência à Flexão}

A Figura 67 mostra à resistência a flexão a 5\% de deformação dos compósitos processados por extrusão/injeção e por o misturador interno (Haake)/ termoprensagem, com CO, CA e OSE.

Figura 67. Resistência à flexão dos compósitos, desvio padrão entre 7-10\%. BPEAD/10\%Fibra, BPEAD/5\%CA, CO ou OSE/10\%Fibra $(3 \mathrm{~mm})$ processados por misturador interno (Haake)/termoprensados e extrusão/injeção.

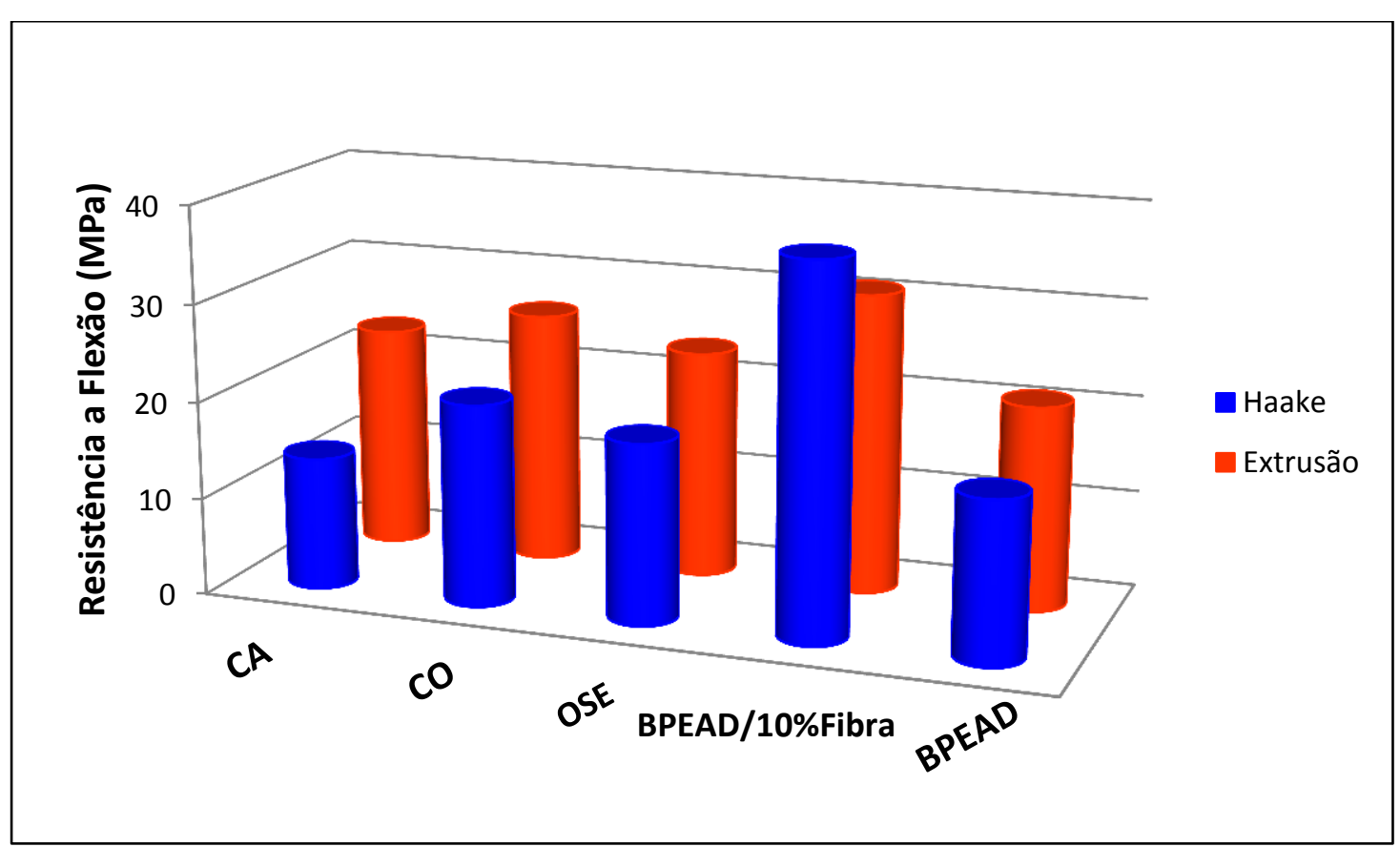

A resistência à flexão do BPEAD a $5 \%$ de deformação foi de $16,5 \mathrm{MPa}$ e o módulo de flexão foi de 0,52 MPa, para o polímero processado no misturador interno (Haake) e moldado por termoprensagem, para o polímero processado via extrusão a 
resistência à flexão foi de $21 \mathrm{MPa}$ e o módulo de flexão foi de 0,62 $\mathrm{MPa}$, o erro experimental pode aproximar esses valores e diminuir as diferenças entre o BPEAD obtido por diferentes processamentos.

A presença de fibras no BPEAD resultou em compósitos que apresentaram maior resistência e módulo de flexão se comparados ao polímero puro (resistência à flexão 30,2 MPa e módulo de flexão 1,67 GPa), tanto para os compósitos BPEAD/10\%Fibra processados via extrusão (resistência à flexão 30,2 MPa e módulo de flexão 1,67 GPa) quanta para os processados por misturador interno (resistência à flexão 37,9 MPa e módulo de flexão 1,1 GPa), relacionado com a capacidade de reforço que a fibra natural apresenta (BENGTSSON; LE BAILLIF; OKSMAN, 2007).

O papel principal dos plastificantes é melhorar a processabilidade dos polímeros (NOR AZOWA et al., 2011). Nas Figuras 67 e 68, observa-se que os compósitos preparados via extrusão/injeção e por misturador interno/termoprensagem, na presença de CA, CO e OSE, apresentaram resistência e o módulo de flexão menor, se comparados aos compósitos BPEAD/10\%Fibra, indicando que a influência da ação dos óleos vegetais como plastificante foi importante para as propriedades de flexão. Destaca-se que a menor diminuição na resistência e módulo de flexão, comparativamente a BPEAD/10\%Fibra, foi observada para o compósito em que CO estava presente. Normalmente, o uso de plastificantes altera a resistência à flexão dos compósitos, como foi observado no presente estudo, diferente dos lubrificantes que normalmente mantém esta propriedade nos compósitos, além de serem adicionados em quantidades menores que os plastificantes.

O óleo de mamona, o óleo de canola e óleo de soja epoxidado foram usados na preparação dos compósitos para também atuarem como agentes compatibilizantes, uma vez que o CO, CA e OSE têm cadeias hidrocarbônicas com afinidade pelo BPEAD e grupos hidroxilas com afinidades pelos grupos polares presentes nas fibras (Figuras 13 e 14). Os compósitos em que CO está presente, em ambos os tipos de processamento, apresentaram uma maior resistência e módulo de flexão, 26 MPa e 0,9 GPa (extrusão), 21 MPa e 0,7 GPa (Haake), respectivamente, se comparado aos compósitos com CA e OSE, provavelmente devido às interações mais eficientes entre os grupos polares das fibras com os grupos polares dos óleos vegetais. 
Figura 68. Módulo de flexão dos compósitos, desvio padrão entre 6-10\%. Comparação entre o compósito BPEAD/5\%CA,CO ou OSE/10\%Fibra ( $3 \mathrm{~mm}$ ) processados no misturador interno (Haake) e extrudados.

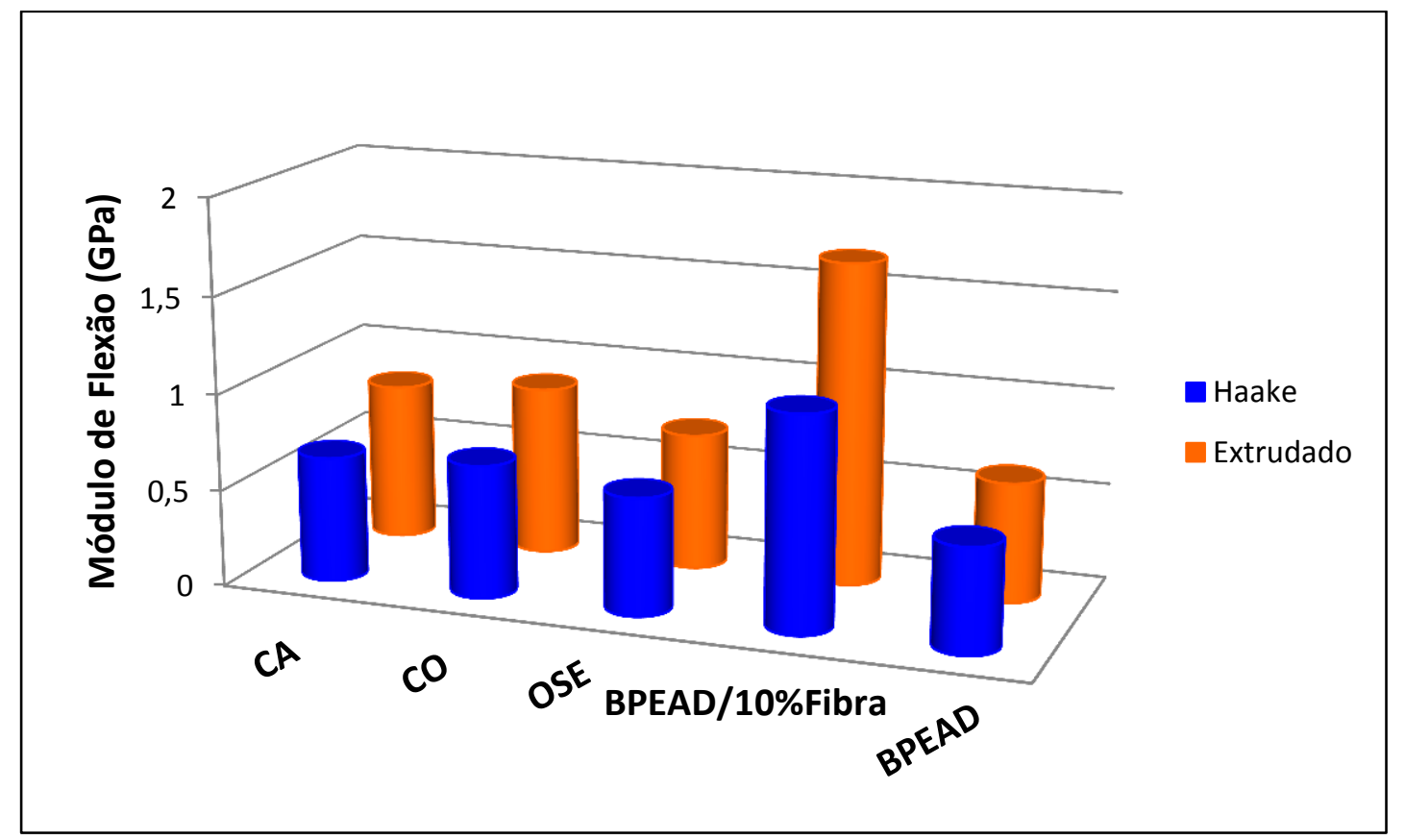

Observou-se um aumento da resistência e do módulo de flexão dos compósitos processados por extrusão se comparado aos processados no Haake. O mesmo efeito foi observado no ensaio de resistência ao impacto, nas análises de DMA e na microscopia eletrônica de varredura, mostrando que a extrusão é um processo mais eficiente para a preparação de compósitos de fibras curtas.

Em trabalhos anteriores, $5 \%$ de PBHL e 10\% de fibra de curauá, com comprimento médio de $3 \mathrm{~mm}$ foram introduzidos em relação à massa total do compósito. O compósito foi processado por extrusão e moldado por injeção. A resistência à flexão deste compósito foi de $19 \mathrm{MPa}$. Substituindo PBHL por CO (26 $\mathrm{MPa}$ ), CA (23 MPa) e OSE (24 MPa), preparou-se materiais baseados em matéria prima proveniente de fontes naturais, com melhor resistência à flexão. 
6.7 Nanocompósitos reforçados com 3, 6 e $9 \%$ de Nanocristais de Curauá na presença de Óleo de Mamona (Filmes preparados por extrusão)

Visando a valorização dos materiais obtidos a partir de fontes renováveis, nanocristais de curauá foram preparados para utilização como material de reforço em bionanocompósitos. A matriz utilizada na preparação dos bionanocompósitos, o BPEAD, também foi obtida a partir de matéria-prima de fonte renovável, conforme já mencionado. Com o objetivo de melhorar a compatibilidade entre os nanocristais de celulose (NCC), que tem caráter hidrofílico, e o BPEAD, que tem caráter hidrofóbico, óleo de mamona (CO) foi adicionado, pois grupos polares e domínios hidrofóbicos presentes na estrutura química do mesmo (Figura 13) podem interagir, respectivamente, com hidroxilas polares presentes nas cadeias de celulose dos nanocristais e as cadeias apolares de BPEAD.

A extrusão é um método mais recente usado para preparar nanocompósitos, e muitos estudos já têm sido realizados nesta área (BONDESON; OKSMAN, 2007; MATHEW et al., 2011; CAMPOS et al., 2013), sendo que corresponde a uma possibilidade de dimensionar o processo para a escala industrial. Assim, neste trabalho a técnica de extrusão foi usada, no processamento dos nanocompósitos de BPEAD reforçado por nanocristais de curauá, visando à produção de filmes.

\subsubsection{Análise Térmica}

A Figura 69, mostra as curvas TG e de dTG obtidas para os nanocristais de curauá liofilizados, BPEAD, mistura 1:1 NCC/CO e para os nanocompósitos BPEAD/3\%CO/3\%NCC, BPEAD/6\%CO/6\%NCC e BPEAD/9\%CO/9\%NCC.

A partir da Figura 69a, observou-se que para o NCC liofilizado, houve uma perda de massa em torno de $100^{\circ} \mathrm{C}$, que foi atribuída à perda de água aderida aos NCCs. O processo de hidrólise com ácido sulfúrico da fibra de curauá, para obtenção dos NCCs, levou à diminuição da temperatura de início de degradação térmica da fibra de curauá de $226^{\circ} \mathrm{C}$ (Figura 29b) para $148^{\circ} \mathrm{C}$ (NCC) devido à presença de grupos sulfato na superfície dos NCC (CAMARERO ESPINOSA et al., 2013). 
Figura 69. NCC liofilizado, BPEAD, BPEAD/3\%CO/3\%NCC, BPEAD/6\%CO/6\%NCC e BPEAD/9\%CO/9\%NCC extrudados: (a) curvas TG, (b) curvas dTG, atmosfera de $\mathrm{N}_{2}$, fluxo de $20 \mathrm{mLmin}^{-1}$ e razão de aquecimento de $10^{\circ} \mathrm{Cmin}^{-1}$.

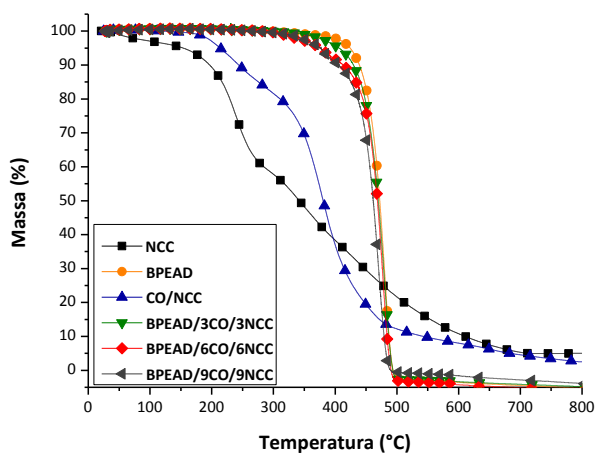

(a)

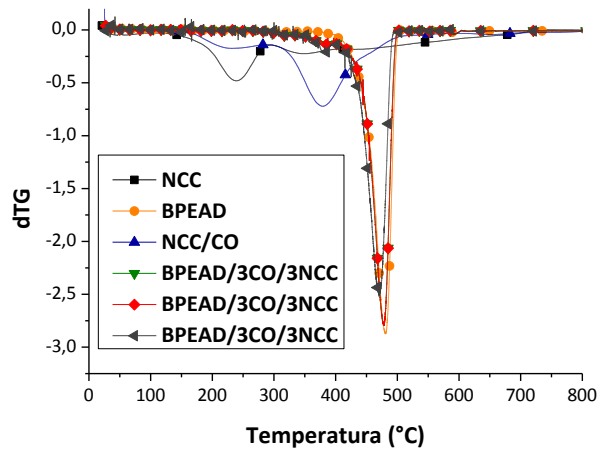

(b)

A decomposição térmica dos nanocristais de curauá iniciou-se a $148^{\circ} \mathrm{C}$, já para a mistura 1:1 CO/NCC, a decomposição térmica iniciou a $180^{\circ} \mathrm{C}$. Entretanto, a temperatura de máxima taxa de decomposição térmica (pico mais intenso da curva da derivada da perda de massa - dTG) da mistura CO/NCC foi de $375^{\circ} \mathrm{C}$. Assim, a mistura $1: 1$ CO/NCC apresentou uma temperatura superior se comparado ao NCC, possivelmente a acessibilidade dos grupos presentes na superfície dos NCCs é diminuída com a adição dos óleos vegetais, já que o CO pôde proteger os grupos sulfatos da superfície dos nanocristais.

As misturas BPEAD/CO e os nanocompósitos BPEAD/NCC (Figuras não mostradas) apresentaram curvas TG e dTG semelhantes aos dos nanocompósitos BPEAD/CO/NCC.

As curvas DSC dos compósitos (Figura 70) mostram um pico endotérmico, relacionado à temperatura de fusão do BPEAD (em torno de $134^{\circ} \mathrm{C}$ ). 
Figura 70. Curvas DSC para o BPEAD e nanocompósitos reforçados com NCC extrudados, atmosfera de $\mathrm{N}_{2}$, fluxo de $20 \mathrm{~mL} \min ^{-1}$ e razão de aquecimento de $10^{\circ} \mathrm{C} \mathrm{min}^{-1}$.

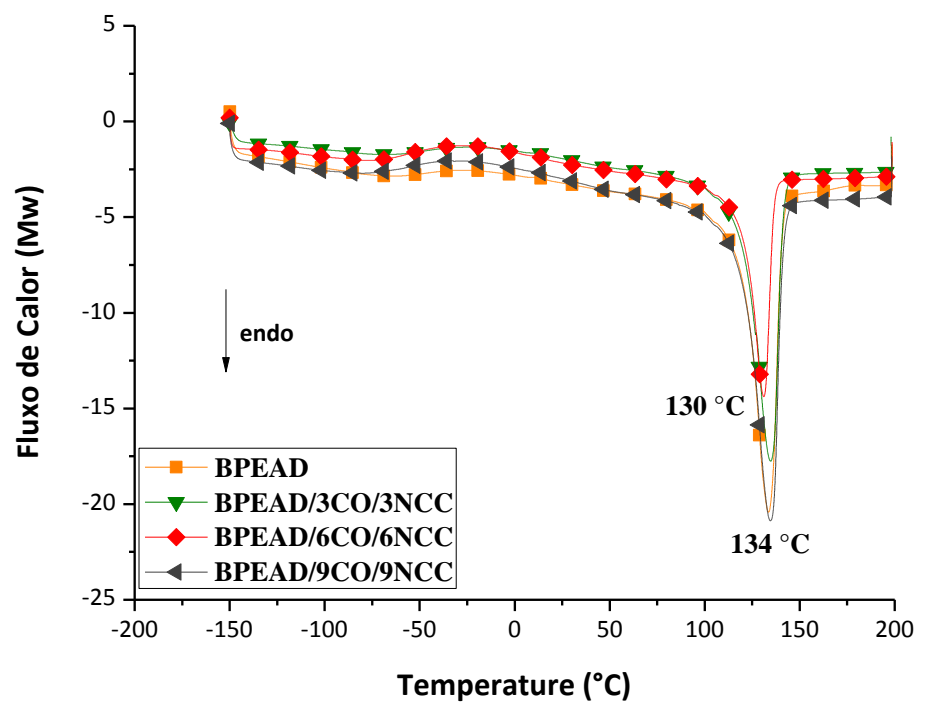

Na Tabela 11 são apresentadas a temperatura de fusão e o índice de cristalinidade dos nanocompósitos BPEAD/CNW (Figura não mostrada), BPEAD/CO/CNW, BPEAD/CO (Figura não mostrada) e para BPEAD.

Tabela 11. Temperatura de fusão $\left(T_{m}\right)$ e Índice de Cristalinidade $(X c)$ do BPEAD, BPEAD/NCC e BPEAD/CO/NCC.

\begin{tabular}{ccc}
\hline Compósitos & $\mathbf{T}_{\mathbf{m}}\left({ }^{\circ} \mathbf{C}\right)$ & $\mathbf{X}_{\mathbf{c}}$ \\
\hline BPEAD & 134 & 71 \\
BPEAD/3\%CO & 132 & 62 \\
BPEAD/6\%CO & 130 & 68 \\
BPEAD/9\%CO & 130 & 70 \\
BPEAD/3\%NCC & 132 & 75 \\
BPEAD/6\%NCC & 133 & 76 \\
BPEAD/9\%NCC & 133 & 73 \\
BPEAD/3\%CO/3\%NCC & 135 & 81 \\
BPEAD/6\%CO/6\%NCC & 131 & 77 \\
BPEAD/9\%CO/9\%NCC & 135 & 79 \\
\hline
\end{tabular}

O ponto de fusão do BPEAD variou entre 130 e $132^{\circ} \mathrm{C}$ com a adição de CO, entre 133 e $132^{\circ} \mathrm{C}$ com a adição de NCC, e entre 131 e $135^{\circ} \mathrm{C}$ quando NCC e CO foram adicionados. A variação não foi significativa, quando os valores são comparados a $134^{\circ} \mathrm{C}$, a temperatura de fusão do BPEAD. O índice de cristalinidade foi calculado, considerando que o BPEAD é o único polímero cristalino nos nanocompósitos. O 
índice de cristalinidade da mistura BPEAD $/ \mathrm{CO}(3 \% \mathrm{CO}=62 \%, 6 \% \mathrm{CO}=68 \%$ e $6 \% \mathrm{CO}=$ $70 \%)$ diminuiu em comparação ao BPEAD (71\%), sendo a maior variação observada para a menor proporção de CO. Este resultado indica que o óleo de mamona agiu como plastificante para o BPEAD, e que uma menor proporção presente na mistura favoreceu a penetração de CO nos domínios cristalinos do BPEAD. Wong et al. (2003) observaram o mesmo efeito em seus estudos, utilizando como matriz o polihidroxibutirato $(\mathrm{PHB})$, fibra de linho como reforço e tributil citrato (TBC) como plastificante.

O Xc do BPEAD nos nanocompósitos foi maior que o do BPEAD, o que pode ser indicativo de aumento de cristalinidade causado pela presença de NCC, os quais puderam atuar como agente de nucleação. Este aumento foi observado quando somente NCC foi adicionado, e foi intensificado quando NCC e CO foram adicionados, possivelmente devido à forte interação entre o NCC e a matriz na presença de agente compatibilizante (CASTRO; RUVOLO-FILHO; FROLLINI, 2012; TEN; JIANG; WOLCOTT, 2012; FRONE et al., 2013), pois na presença de NCC e CO é que se observou o maior aumento na cristalinidade (Tabela 11). Este resultado pode ser considerado como uma indicação que o CO atuou como um agente de compatibilização, na interface fibramatriz, interagindo com ambos os componentes e intensificando as interações na interface.

\subsubsection{Reologia}

Ensaios em regime permanente de viscosidade em função da taxa de cisalhamento foram realizados para analisar o comportamento reológico dos nanocompósitos, buscando verificar a presença de interações entre o NCC e a matriz.

A Figura 71 apresenta a viscosidade versus a taxa de cisalhamento para os nanocompósitos BPEAD/3, 6 e 9\%CO/3, 6 e 9\%NCC e para o BPEAD puro extrudados e calandrados a $175^{\circ} \mathrm{C}$. Os nanocompósitos BPEAD/3, 6 e 9\%NCC e misturas BPEAD/3, 6 e 9\% CO apresentaram comportamento similar, sendo as figuras não apresentadas.

O BPEAD e os nanocompósitos apresentaram um platô newtoniano curto em baixas taxas de cisalhamento, comportando-se como um fluido pseudoplástico em taxas maiores (BEN MABROUK et al., 2011). Os nanocompósitos com 3 e 6 \% de NCC 
apresentaram maior viscosidade quando comparados a matriz. No entanto, a viscosidade do nanocompósito com $9 \%$ de NCC permaneceu mais baixa do que a do BPEAD puro.

Figura 71. Viscosidade versus Taxa de Cisalhamento para nanocompósitos de BPEAD reforçados com nanocristais de curauá extrudados.

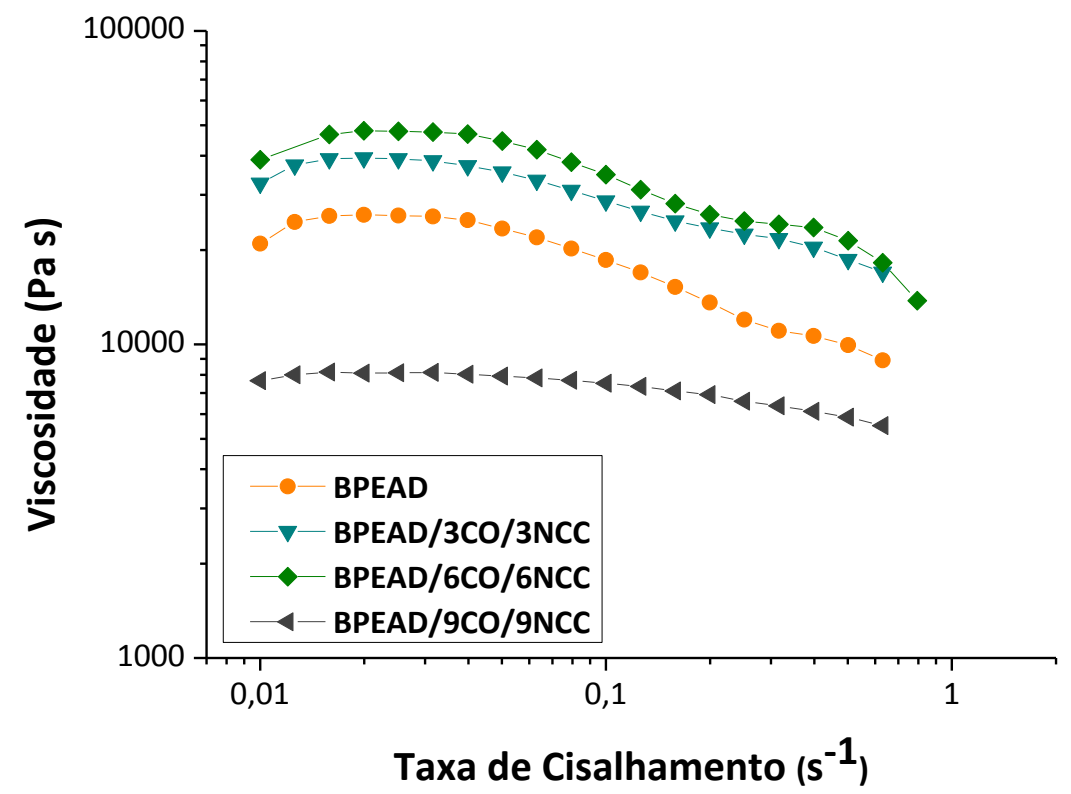

Com a adição de NCC à matriz de BPEAD ocorreram variações nos valores de $\eta_{0}$ (viscosidade Newtoniana, medida à taxa de cisalhamento zero), o que pode ser indício de que os NCCs apresentaram diferentes interações, na presença ou não de agentes compatibilizantes, com a matriz de BPEAD. A Tabela 12 apresenta os valores de $\eta_{0}$ para os sistemas estudados à $175^{\circ} \mathrm{C}$, já que esta foi a temperatura de processamentos dos nanocompósitos.

Tabela 12. Valores de no para os nanocompósitos e para o BPEAD puro a $175^{\circ} \mathrm{C}$.

\begin{tabular}{cc}
\hline Nanocompósito & Viscosidade à taxa de cisalhamento zero $\left(\eta_{\mathbf{0}}\right)$ Pa.s \\
\hline BPEAD & 20958 \\
BPEAD/3\%CO & 23108 \\
BPEAD/6\%CO & 18631 \\
BPEAD/9\%CO & 720 \\
BPEAD/3\%NCC & 40640 \\
BPEAD/6\%NCC & 45841 \\
BPEAD/9\%NCC & 53676 \\
BPEAD/3\%CO/3\%NCC & 39353 \\
BPEAD/6\%CO/6\%NCC & 40612 \\
BPEAD/9\%CO/9\%NCC & 7817 \\
\hline
\end{tabular}


A viscosidade à taxa de cisalhamento zero $\left(\eta_{0}\right)$ das misturas BPEAD/CO diminuiu com a adição de 3 (23108 Pa.s), 6 (18631 Pa.s) e 9 (720 Pa.s) \% de CO, provavelmente, o óleo de mamona agiu como plastificante para o BPEAD (20958 Pa.s).

Para o nanocompósitos BPEAD/NCC, em geral, a viscosidade aumentou com o aumento do teor de carga. Isso resultou em um decréscimo da facilidade com que os nanocompósitos poliméricos podem ser processados (LEE; PARK; KIM, 2013). No presente estudo, o aumento da viscosidade mostrou que a presença de NCC restringiu os movimentos das cadeias poliméricas, como resultado da formação de uma rede BPEAD/NCC (GONZÁLEZ-SÁNCHEZ et al., 2011; SDROBIŞ et al., 2012).

Para os nanocompósitos BPEAD/CO/NCC observou-se uma diminuição de $\eta_{0}$, comparativamente a BPEAD/NCC. Esta diminuição foi pequena para o nanocompósito com $3 \%$ de NCC e um pouco mais intensa para $6 \%$ de NCC. Nestes casos, considerou-se que a presença do óleo diminuiu a aglomeração e melhorou a dispersão dos NCCs em BPEAD, devido à ação do CO como compatibilizante (Tabela 12), fenômeno semelhante foi observado em nanocristais de celulose (NCC) modificados com uma solução aquosa de polioxietileno (PEO) e dispersos na matriz de polietileno (BEN AZOUZ et al., 2012). O tratamento da superfície dos CNCs com PEO melhorou as interações entre os nanocristais e a matriz e reduziram a viscosidade dos nanocompósitos. No presente trabalho, a redução de viscosidade observada para BPEAD/9\%CO/9\%NCC, quando comparado a BPEAD/9\%NCC, sugere que o mais alto teor de CO intensificou a ação como plastificante, como observado para BPEAD/9\%CO (Tabela 12).

Os resultados da caracterização reológica em regime dinâmico das matrizes e dos nanocompósitos encontram-se na Figura 72.

Para o PEAD puro (Figura 72) a componente elástica é muito acentuada, apresentando valor um pouco superior ao da componente viscosa em toda a faixa de frequência analisada (BESBES; MAGNIN; BOUFI, 2011). 
Figura 72. G' (símbolo fechado) e G" (símbolo aberto) versus frequência angular a $175^{\circ} \mathrm{C}$ para nanocompósitos preparados por extrusão.

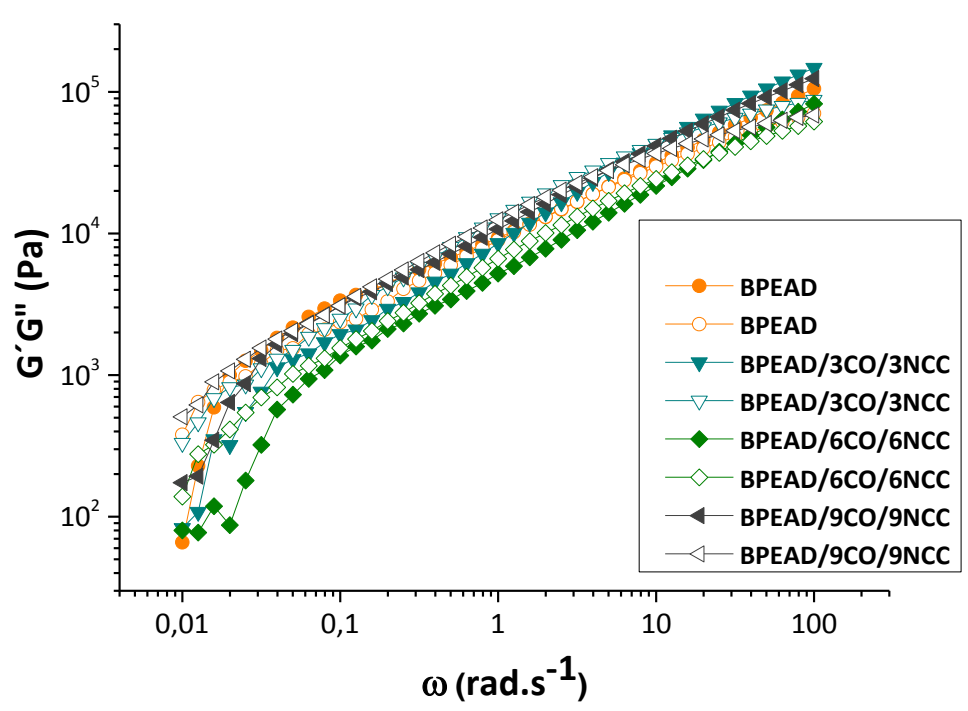

Comparando o comportamento viscoelástico dos nanocompósitos e da matriz, pôde-se observar que os materiais exibiram módulos viscoelásticos semelhantes para todas as composições (perfil semelhante). A Figura 73 mostra uma amplição dos valores experimentais no cruzamento entre $G^{\prime}-G^{\prime \prime}$.

Figura 73. Ampliação na região de cruzamento entre $G^{\prime}-G^{\prime \prime}$.

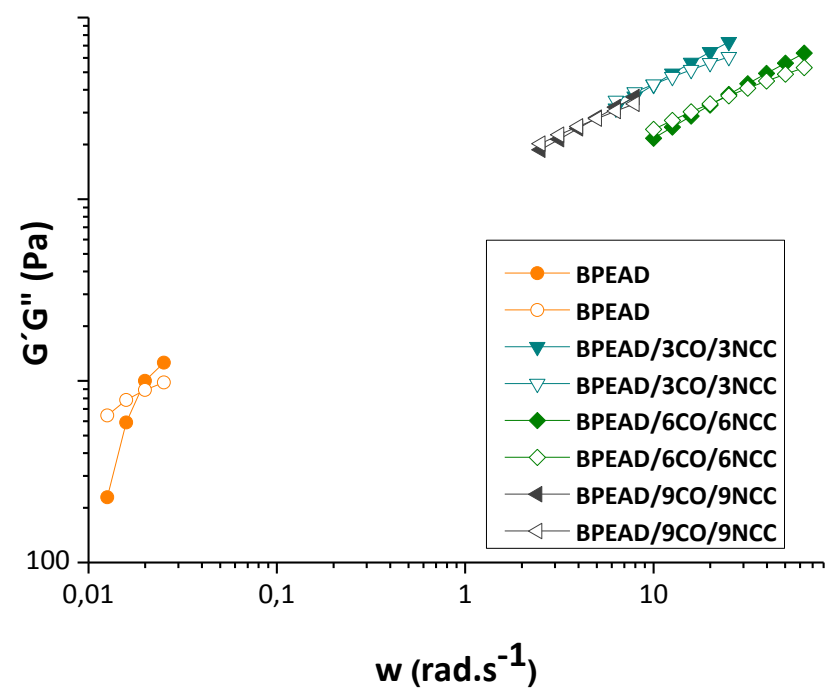


Considerando a resposta viscoelástica dos nanocompósitos BPEAD/CO/NCC a observação mais importante está relacionada com a evolução da frequência correspondente ao ponto de cruzamento do G'- G", que diminuiu com o aumento do teor de NCC (3\% NCC 50088 Pa, 6\% NCC 37589 Pa, 9\% NCC 25497 Pa) indicando uma dinâmica molecular que foi retardada para maiores concentrações de NCC. Isto foi coerente com o que se observou geralmente na literatura para trabalhos com nanopartículas de celulose e este resultado está de acordo com as medidas de viscosidade, discutidas anteriormente (ALLOIN et al., 2011; BEN AZOUZ et al., 2012). Alloin et al. (2011) avaliaram as propriedades mecânicas e reológicas em nanocompósitos de nanocristais de celulose (NCC), utilizando como matriz o polioxietileno (PEO), os nanocompósitos foram preparados por casting e por extrusão. Observou-se como no presente estudo a diminuição do ponto de cruzamento do G'- G" com a adição de NCC.

\subsubsection{Propriedades Óticas}

A Figura 74 mostra as fotografias dos filmes de BPEAD e dos nanocompósitos reforçados com nanocristais de curauá.

Figura 74. Fotos de: BPEAD puro, BPEAD/3\%NCC, BPEAD/3\%CO/3\%NCC, BPEAD/6\%CO/6\%NCC e BPEAD/9\%CO/9\%NCC, filmes obtidos por extrusão.

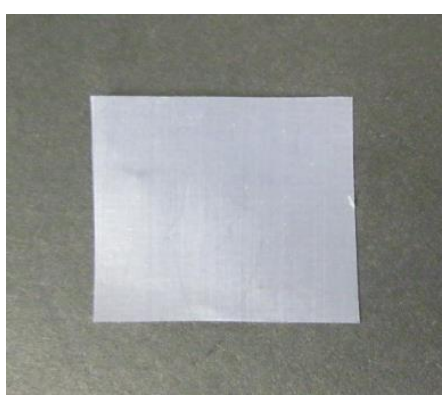

BPEAD-Translúcido

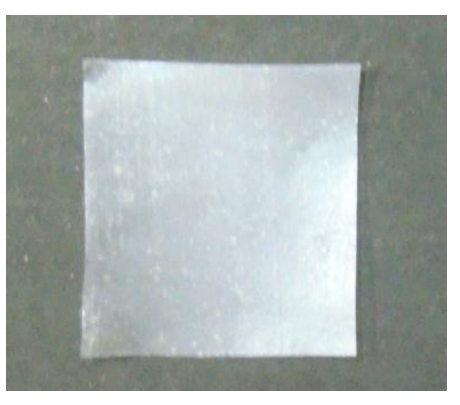

BPEAD/3\%NCC- Opaco

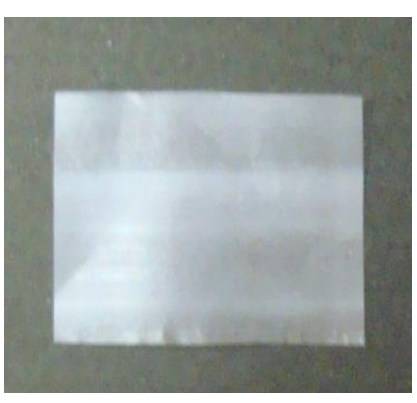

BPEAD/3\%CO/3\%NCC- Translúcido 


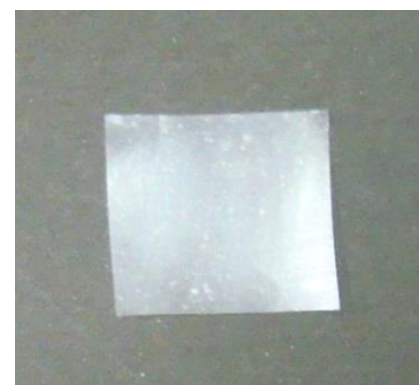

BPEAD/6\%NCC- Opaco

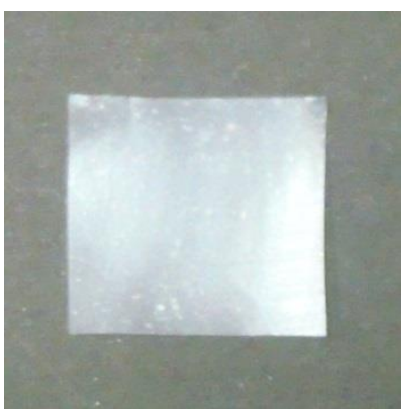

BPEAD/9\%NCC- Opaco

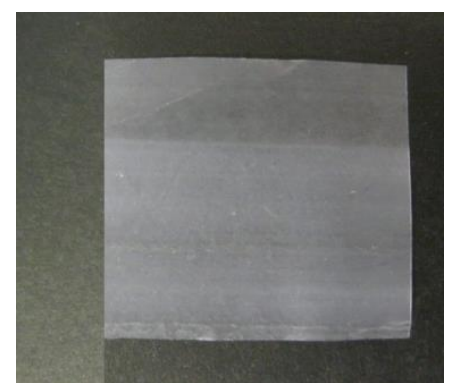

BPEAD/6\%CO/6\%NCC- Translúcido

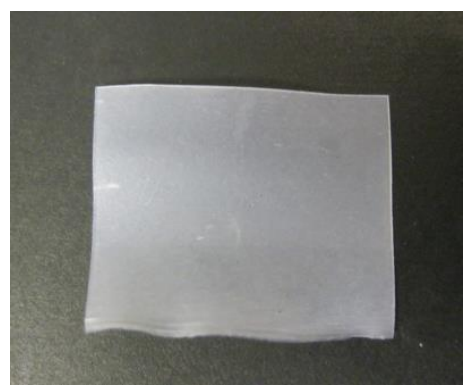

BPEAD/9\%CO/9\%NCC- Opaco

As propriedades óticas são essenciais para definir a aplicação dos filmes, uma vez que o aspecto pode prejudicar a sua qualidade (PEREDA et al., 2014). Neste trabalho, foi observado que a adição de óleo de mamona reduziu a opacidade dos filmes de nanocompósitos reforçados com NCC.

O BPEAD puro é translúcido como a maioria dos filmes poliméricos de baixa espessura (JUNIOR DE MENEZES et al., 2009). Ao adicionar 3, 6 e $9 \%$ de nanocristais de curauá, o filme apresentou pontos brancos. Esta heterogeneidade revela a dispersão não homogênea dos NCCs no interior da matriz polimérica, atribuída à natureza altamente hidrofóbica da matriz e o caráter altamente hidrofílico das nanopartículas de celulose. Os filmes dos nanocompósitos BPEAD/3\%CO/3\%NCC, BPEAD/6\%CO/6\%NCC e BPEAD/9\%CO/9\%NCC apresentaram-se muito mais homogêneos se comparados ao filme BPEAD/3\%NCC, BPEAD/6\%NCC e BPEAD/9\%NCC indicando a ação de CO como compatibilizante. Este resultado é relevante, pois muito se tem investigado sobre modificações que possam levar a melhor dispersão de NCC em matrizes hidrofóbicas, geralmente através de modificações químicas da superfície dos NCCs (MORANDI; HEATH; THIELEMANS, 2009; GOFFIN et al., 2011; LEE; PARK; KIM, 2014). No presente trabalho, uma melhora significativa na dispersão foi obtida, sem a 
ocorrência de reações químicas, mas usando CO, um agente oriundo de fonte renovável.

\subsubsection{Análise Morfológica}

A Figura 75 apresenta a Microscopia Eletrônica de Varredura (MEV) dos filmes dos nanocompósitos e do BPEAD puro. A superfície fraturada do filme de BPEAD puro é mostrada na Figura 75a.

Figura 75. Imagens de MEV da superfície fraturada dos nanocompósitos e do BPEAD puro: (a) BPEAD puro (X 15000), (b) BPEAD/3\%NCC (X 5000) e (c) BPEAD/3\%CO/3\%NCC (X 5000).

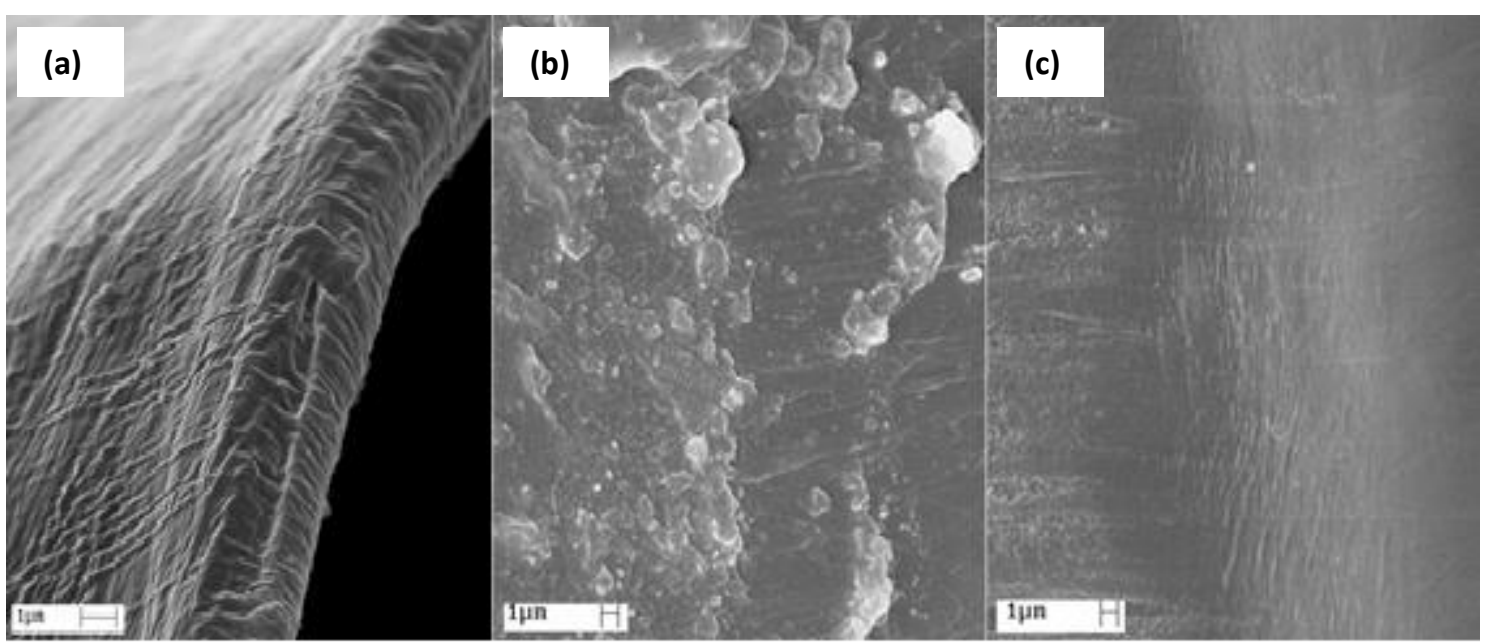

Para os nanocompósitos com 3\% de NCC (Figura 75b), observa-se a presença de aglomerados de nanocristais. Esta aglomeração não foi observada para os filmes de nanocompósitos compatibilizados com CO (Figura 75c), confirmando a ação de CO como um agente de compatibilização que aumentou de forma significativa a dispersão de nanocristais em BPEAD. A Figura 76 mostra as imagens (MEV) dos filmes dos nanocompósitos com 6 e $9 \%$ de NCC.

A Figura 76 apresenta a Microscopia Eletrônica de Varredura (MEV) dos filmes dos nanocompósitos com 6 e $9 \%$ de NCC. 
Figura 76. Imagens de MEV da superfície fraturada dos nanocompósitos e do BPEAD puro: (a) BPEAD/6\%NCC (X 5000), (b) BPEAD/6\%CO/6\%NCC (X 5000) e (c) BPEAD/9\%NCC (X 5000) e (d) BPEAD/9\%CO/9\%NCC (X 5000).
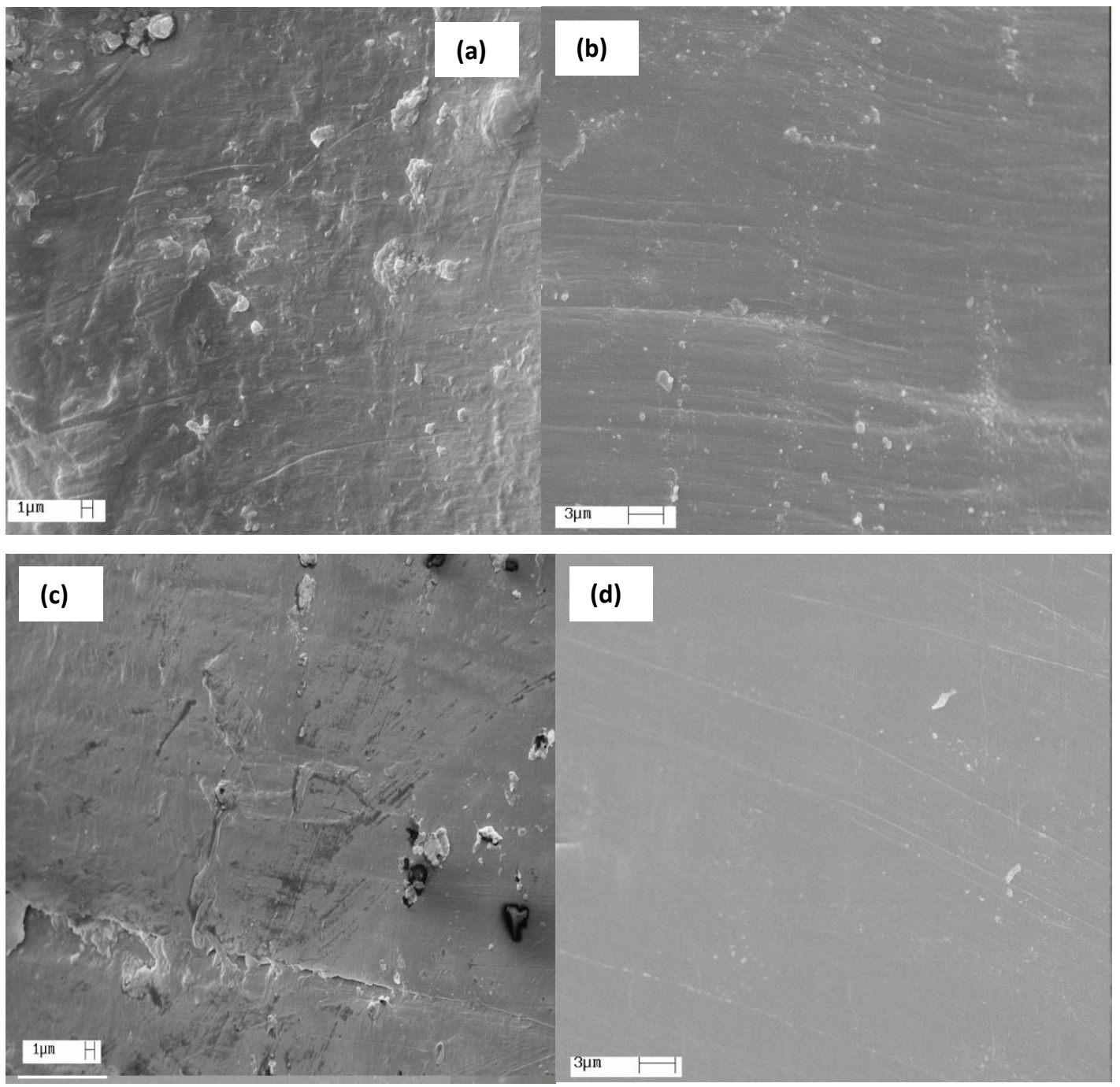

Para todas as composições, a presença de óleo de mamona levou a filmes mais uniformes quando comparados aos nanocompósitos BPEAD/NCC, no entanto, pelas imagens de MEV, observou-se que o filme mais homogêneo e sem a presença de aglomerados foi o BPEAD/3\%NCC/3\%NCC. Essa mais uniforme dispersão de NCC na matriz, na presença de $\mathrm{CO}$, desempenhou um papel importante em algumas propriedades dos nanocompósitos, conforme será descrito a seguir. 


\subsubsection{Análise Dinâmico-Mecânica}

A Figura 77 apresenta o módulo de armazenamento em função da temperatura para os nanocompósitos de BPEAD reforçados com nanocristais de curauá. Os nanocompósitos BPEAD/3, 6 e 9\%NCC e misturas BPEAD/3, 6 e 9\% CO apresentaram comportamento similar, sendo as figuras não apresentadas.

Figura 77. Módulo de Armazenamento em função da temperatura para nanocompósitos de BPEAD reforçados com nanocristais de curauá extrudados.

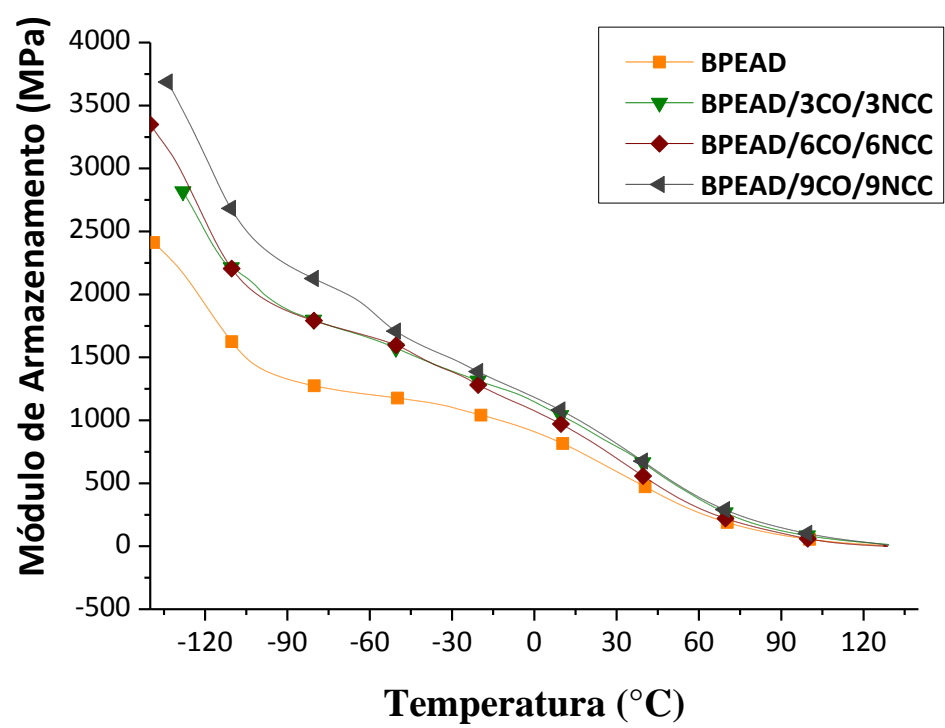

Os resultados na Figura 77 mostram que a adição de nanocristais de curauá aos nanocompósitos aumentou ligeiramente o módulo de armazenamento. Este pequeno aumento, entretanto significativo, foi atribuído ao efeito de reforço que a adição de NCC fornece ao nanocompósito e/ou para o aumento do grau de cristalinidade relatado a partir das análises de DSC, provavelmente a área superficial dos NCC, têm a capacidade de afetar a mobilidade das cadeias poliméricas da matriz (PETERSSON; MATHEW; OKSMAN, 2009; LIPPONEN et al., 2012).

O módulo de armazenamento aumentou à medida que os NCCs foram adicionados ao BPEAD. O nanocompósito BPEAD/3\%CO/3\%NCC apresentou $\mathrm{E}^{\prime}$ a $30{ }^{\circ} \mathrm{C}$ $=806 \mathrm{MPa}$ e a matriz $\mathrm{E}^{\prime}$ a $30{ }^{\circ} \mathrm{C}=583 \mathrm{MPa}$, ou seja, um aumento de $28 \%$. 
Como mostrado anteriormente, tipicamente o polietileno de alta densidade, apresentou duas relaxações, uma relaxação em torno de $-120^{\circ} \mathrm{C}$, relacionada à região não cristalina e associada à transição vítrea $\left(\operatorname{Tg}, \alpha_{a}\right)$. A outra relaxação ocorreu entre 50 e $120^{\circ} \mathrm{C}$, acima da $\mathrm{Tg}$ e abaixo de $\mathrm{Tm}$ (temperatura de fusão, em torno de $135^{\circ} \mathrm{C}$ ) pode ser considerado decorrente de uma transição do tipo $\alpha^{\prime}$.

Um pico entre -40 e $-65^{\circ} \mathrm{C}$ foi observado, e é característico do CO. Geralmente, as temperaturas de fusão dos óleos vegetais apresentam comportamento complexo, o pico observado na Figura 78 (pico 2) foi relacionado com a fusão dos vários ácidos graxos presentes nos CO (TAN; CHE MAN, 2002).

Figura 78. Tan $\delta$ em função da temperatura para nanocompósitos de BPEAD reforçados com nanocristais de curauá extrudados: (a) e (c) -130 a $130{ }^{\circ} \mathrm{C}$; (b) e (d) -130 a $0{ }^{\circ} \mathrm{C}$.

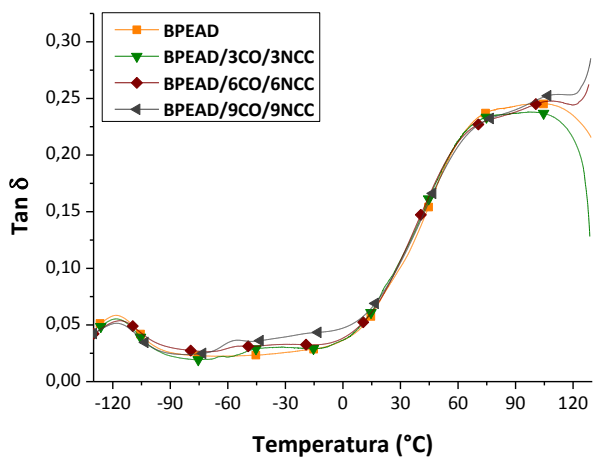

(a)

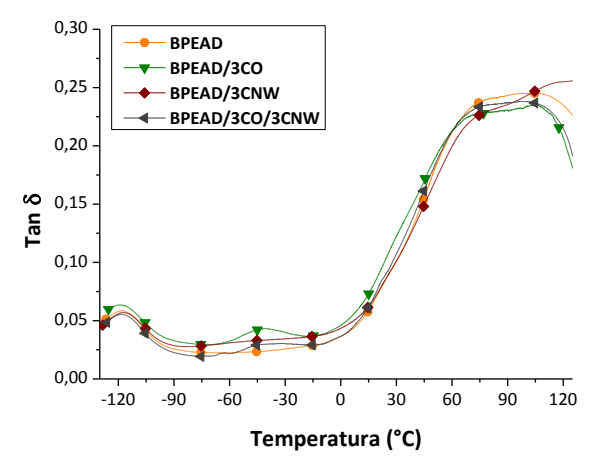

(c)

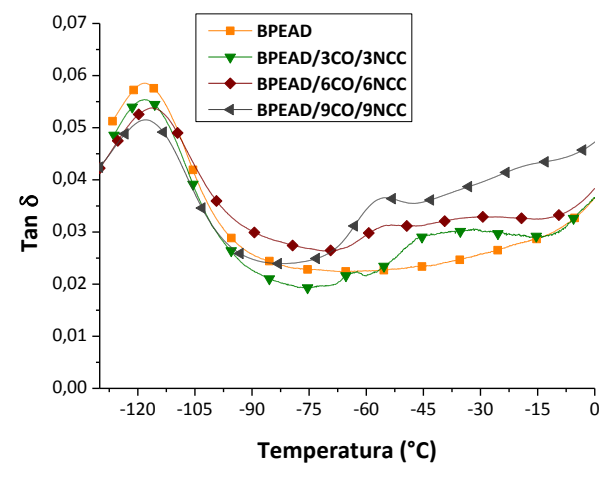

(b)

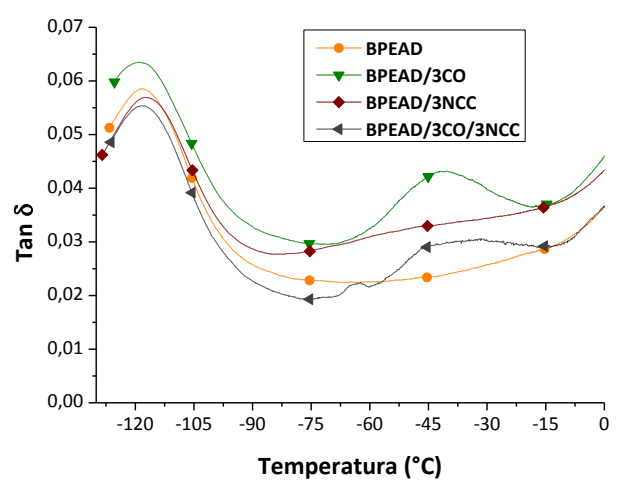

(d) 
Através da $\tan \delta$ foi possível se obter informações sobre a interface nanocristais/BPEAD. Novamente destaca-se que a observação ou não de um deslocamento em $\mathrm{Tg}$ devido à ação de compatibilizantes depende da proporção de segmentos de cadeias da matriz próximos à interface, e da cristalinidade do polímero, ou seja, proporção de domínios não cristalinos presentes. Neste estudo, à semelhança com o ocorrido com os compósitos, através da análise de DMA não se pôde observar alteração na relaxação $\mathrm{Tg}$ quando NCC e CO foram adicionados ao BPEAD na preparação de filmes (Figura 78b).

Tabela 13. Picos do BPEAD puro e nanocompósitos (Desvio entre $0,3-0,7^{\circ} \mathrm{C}$ ).

\begin{tabular}{cccc}
\hline Compósito & Pico $\mathbf{1}\left({ }^{\circ} \mathbf{C}\right)$ & Pico 2 $\left({ }^{\circ} \mathbf{C}\right)$ & Pico 3 $\left({ }^{\circ} \mathbf{C}\right)$ \\
\hline BPEAD & -118 & - & 94 \\
BPEAD/3\%CO & -118 & -42 & 90 \\
BPEAD/6\%CO & -117 & -45 & 91 \\
BPEAD/9\%CO & -118 & -40 & 94 \\
BPEAD/3\%NCC & -117 & - & 94 \\
BPEAD/6\%NCC & -116 & - & 94 \\
BPEAD/9\%NCC & -116 & - & 92 \\
BPEAD/3\%CO/3\%NCC & -118 & -63 & 95 \\
BPEAD/6\%CO/6\%NCC & -115 & -58 & 98 \\
BPEAD/9\%CO/9\%NCC & -116 & -57 & 98 \\
\hline
\end{tabular}

O valor de $\tan \delta$ nos nanocompósitos BPEAD/3\%CO/3\%NCC $(0,053)$ BPEAD/6\%CO/6\%NCC $(0,054)$ e BPEAD/9\%CO/9\%NCC $(0,051)$ mostraram uma diminuição em comparação aos nanocompósitos $\operatorname{BPEAD/3\% NCC~}(0,056)$, $\operatorname{BPEAD} / 6 \% \operatorname{NCC}(0,056)$ e $\operatorname{BPEAD} / 9 \% \mathrm{NCC}(0,057)$, a dissipação de energia ocorreu na matriz polimérica, já que a interface apresentou adesão $\mathrm{NCC} /$ matriz e menor dissipação de energia. Assim, um material com uma fraca interação interfacial entre a matriz e NCC tenderá a dissipar mais energia, mostrando elevados valores de $\tan \delta$, em comparação a um material com uma interface fortemente ligada (MOHANTY; VERMA; NAYAK, 2006). O valor de $\tan \delta$ para as misturas BPEAD/3\%CO $(0,06)$, BPEAD/6\%CO $(0,06)$ e BPEAD/9\%CO $(0,07)$ apresentaram um aumento na altura do pico de $\tan \delta$ em relação ao $\operatorname{BPEAD}(0,058)$, indicando que os óleos aumentaram a mobilidade dos segmentos das cadeias de polímero. 


\subsubsection{Resistência à Tração}

Os ensaios de resistência à tração foram realizados à temperatura ambiente. A partir das curvas de tensão versus deformação, foi determinada a resistência à tração, a deformação na ruptura e o módulo de Young para os nanocompósitos reforçados com nanocristais de curauá. A Tabela 14 mostra a evolução destes parâmetros.

Os nanocompósitos de matriz termoplástica reforçados com NCC apresentaram uma queda nas propriedades mecânicas, comparativamente a BPEAD, provavelmente devido à aglomeração de NCCs, que pode criar regiões de concentração de tensões que requerem menos energia para dar início ou propagar uma trinca (JARUKUMJORN; SUPPAKARN, 2009).

Tabela 14. Módulo de Young, Resistência à Tração e Deformação na Ruptura.

\begin{tabular}{cccc}
\hline Nanocompósitos & Módulo de Young (MPa) & $\begin{array}{c}\text { Resistência à Tração } \\
\text { (MPa) }\end{array}$ & $\begin{array}{c}\text { Deformação na } \\
\text { Ruptura (\%) }\end{array}$ \\
\hline BPEAD & $330 \pm 27$ & $16 \pm 1,8$ & $198 \pm 12$ \\
BPEAD/3\%NCC & $139 \pm 7$ & $5 \pm 0,3$ & $77 \pm 6$ \\
BPEAD/6\%NCC & $230 \pm 6$ & $9 \pm 0,8$ & $79 \pm 5$ \\
BPEAD/9\%NCC & $203 \pm 6$ & $5 \pm 0,5$ & $63 \pm 5$ \\
BPEAD/3\%CO & $142 \pm 2$ & $11 \pm 0,9$ & $164 \pm 8$ \\
BPEAD/6\%CO & $139 \pm 1$ & $10 \pm 0,1$ & $117 \pm 11$ \\
BPEAD/9\%CO & $111 \pm 3$ & $6 \pm 0,8$ & $97 \pm 7$ \\
BPEAD/3\%CO/3\%NCC & $211 \pm 22$ & $14 \pm 0,2$ & $131 \pm 11$ \\
BPEAD/6\%CO/6\%NCC & $242 \pm 23$ & $13.5 \pm 1,3$ & $160 \pm 9$ \\
BPEAD/9\%CO/9\%NCC & $209 \pm 11$ & $10 \pm 0,7$ & $108 \pm 10$ \\
\hline
\end{tabular}

A mistura BPEAD/CO apresentou diminuição do módulo de Young, da resistência à tração e da deformação na ruptura, provavelmente o óleo de mamona agiu como plastificante. O plastificante pode diminuir a coesão entre as cadeias de BPEAD, no caso de BPEAD, o que pode levar a diminuição das propriedades mecânicas dos nanocompósitos e das misturas (MADALENO et al., 2009).

Para os nanocompósitos com óleo de mamona, o incremento no teor de NCCs causou um aumento na resistência à tração em comparação aos nanocompósitos BPEAD/NCC, até atingir um patamar em $6 \%$, a partir do qual, a resistência do nanocompósito sob a aplicação de uma determinada amplitude de tensão, apresentou 
uma tendência de decaimento. $\mathrm{O}$ aumento na resistência à tração dos nanocompósitos foi atribuído ao efeito de reforço que os NCCs proporcionaram, o qual permitiu a distribuição uniforme da tensão aplicada, da matriz polimérica contínua para a fase dispersa, que são as NCCs. Já a pequena diminuição na resistência mecânica com a adição de teores de NCCs maiores do que $6 \%$ ocorreu provavelmente devido à aglomeração das fibras na matriz durante a extrusão o que levou à formação de pontos de fragilização nos filmes.

O módulo de Young, também conhecido como módulo de elasticidade, é um parâmetro que está diretamente relacionado com a rigidez do polímero. O módulo de elasticidade foi obtido através da inclinação da curva a baixas deformações, ou seja, até $0,2 \%$ de deformação. O módulo de elasticidade, segundo a lei das misturas, é uma propriedade aditiva, ou seja, com o aumento da quantidade de NCCs, há um aumento linear no valor do módulo (JUNIOR DE MENEZES et al., 2009). Na Tabela 14, observouse que a adição de NCC, com ou sem presença de $\mathrm{CO}$, levou a um aumento do módulo elástico dos nanocompósitos, apesar da presença de agregados nos nanocompósitos BPEAD/NCC, como observado nas análises de microscopia (Figuras 75 e 76), ou seja, a presença de NCC levou a uma maior rigidez. Os valores de módulo dos nanocompósitos BPEAD/CO/NCC foram ligeiramente maiores do que os módulos encontrados para os nanocompósitos BPEAD/NCC, isso foi provavelmente consequência da maior cristalinidade observada para os nanocompósitos BPEAD/CO/NCC (Tabela 11), maiores cristalinidades levam à maior rigidez do material (MATHEW; THIELEMANS; DUFRESNE, 2008).

A deformação na ruptura diminuiu com a adição de NCC em relação ao BPEAD. Observando os resultados da Tabela 14, notou-se que a incorporação das partículas rígidas de NCC tornou o material menos deformável, uma vez que a deformação na ruptura de todos os nanocompósitos BPEAD/NCC foi inferior a 100\%. Para os nanocompósitos BPEAD/CO/NCC e para as misturas BPEAD/CO um aumento na deformação na ruptura destes materiais foi observado, indicando que a adição de CO pode ter levado a uma plastificação da matriz de BPEAD. 
6.8 Filmes Nanocompósitos Preparados por Extrusão/Termoprensagem:

Comparação de Propriedades de Filmes Extrudados e

Extrudados/Termoprensados

No estudo supramencionado, foi estabelecida uma porcentagem fixa de nanocristais de celulose (3\%) e de óleo vegetal (3\%). Esta escolha foi baseada nos resultados descritos previamente, que mostraram que uma menor porcentagem de NCC, no geral leva a filmes com propriedades melhores que aqueles em que 6 e $9 \%$ de NCC foram adicionadas ao BPEAD. Com o objetivo de melhorar a compatibilidade entre os nanocristais, os quais têm caráter hidrofílico, e o BPEAD, que tem caráter hidrofóbico, óleo de soja epoxidado e óleo de linhaça epoxidado foram adicionados, afim de que atuassem na interface nanocristais/matriz, além de $\mathrm{CO}$, já considerado no estudo previamente descrito. A extrusão foi o método usado para preparar nanocompósitos, e os resultados foram comparados com aqueles obtidos com a adição de óleo de mamona. Visando melhorar as propriedades mecânicas dos nanocompósitos parâmetros de processamento também foram modificados, utilizando a termoprensa para a obtenção de filmes.

\subsubsection{Análise Térmica}

A caracterização térmica dos filmes de BPEAD reforçados com NCC foi realizada utilizando DSC e TG. As análises de TG foram realizadas para o NCC liofilizado, para as misturas 1:1 CO/NCC, OSE/NCC, OLE/NCC, para a polpa de curauá e para os nanocompósitos. Os resultados são apresentados na Figura 79. Alguns resultados já descritos neste texto serão aqui repetidos, visando facilitar o acompanhamento desta parte. 
Figura 79. Curvas TG do NCC liofilizado, polpa de curauá e misturas 1:1 CO/NCC, OSE/NCC e OLE/NCC. (a) curvas TG, (b) curvas dTG, atmosfera de $\mathrm{N}_{2}$, fluxo de $20 \mathrm{~mL} \mathrm{~min}^{-1}$ e razão de aquecimento de $10^{\circ} \mathrm{C}$ $\min ^{-1}$.

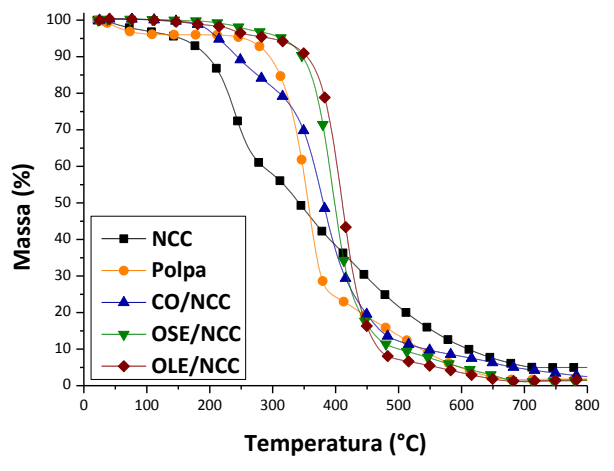

(a)

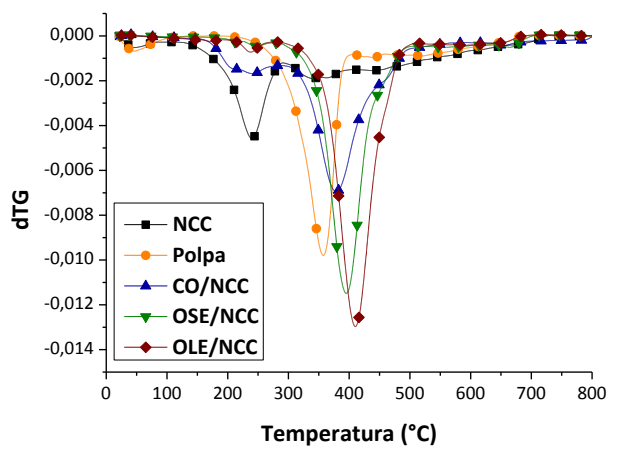

(b)

A partir da Figura 79a, observou-se que para o NCC liofilizado, houve uma perda de massa em torno de $100^{\circ} \mathrm{C}$, que foi atribuída à perda de água aderida aos NCCs. O processo de hidrólise com ácido sulfúrico da fibra de curauá, para obtenção dos NCCs, levou à diminuição da temperatura de início de degradação térmica da polpa de curauá de $246^{\circ} \mathrm{C}$ (Figura 29b) para $148^{\circ} \mathrm{C}$ (NCC) devido à presença de grupos sulfato na superfície dos NCC. Roman et al. (2004) avaliaram o influência dos grupos sulfatos no processo de decomposição da nanocelulose bacteriana. Observaram que o processo de decomposição a mais baixa temperatura pode estar relacionado com os grupos sulfatos presentes nas regiões não cristalinas, já a decomposição a temperaturas mais elevadas pode corresponder a cadeias menos acessíveis, presentes em regiões cristalinas.

A decomposição térmica dos nanocristais de curauá iniciou-se a $148^{\circ} \mathrm{C}$, já para a mistura 1:1 OSE/NCC, a decomposição térmica iniciou a $308^{\circ} \mathrm{C}$ e para a mistura $1: 1$ OLE/NCC, a decomposição térmica iniciou a $313^{\circ} \mathrm{C}$. Assim, as misturas 1:1 OSE/NCC e OLE/NCC apresentaram temperaturas superiores se comparados ao NCC, possivelmente a acessibilidade dos grupos presentes na superfície dos NCCs é diminuída com a adição dos óleos vegetais, já que estes protegem os grupos sulfatos da superfície dos nanocristais. 
Figura 80. Curvas TG do BPEAD puro e nanocompósitos reforçados com NCC, atmosfera de $\mathrm{N}_{2}$, fluxo de $20 \mathrm{~mL} \mathrm{~min}^{-1}$ e razão de aquecimento de $10^{\circ} \mathrm{C} \mathrm{min}^{-1}$.

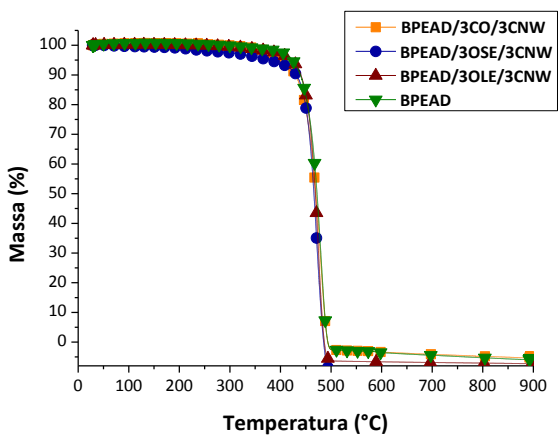

(a)

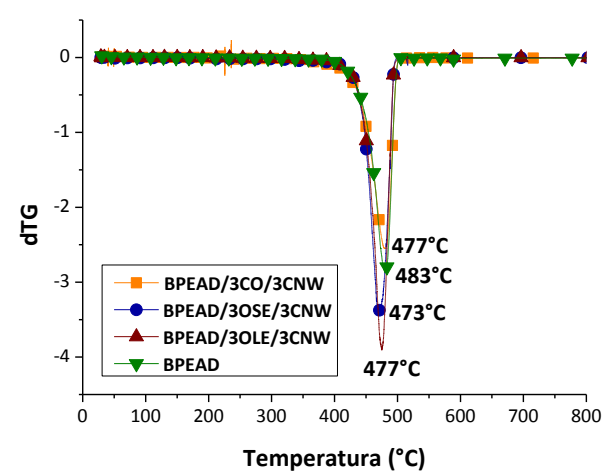

(b)

A perda de massa máxima ocorreu em temperaturas menores para os nanocompósitos comparativamente ao BPEAD (Tpico $=483^{\circ} \mathrm{C}$ ) (Figura $\left.80 \mathrm{~b}\right)$. A temperatura de perda máxima permanece praticamente constante, independentemente do óleo vegetal presente nos nanocompósitos, BPEAD $/ 3 \% C O / 3 \%$ NCC Tpico $=477^{\circ} \mathrm{C}$, BPEAD $/ 3 \% O S E / 3 \% N C C$ Tpico $=473^{\circ} \mathrm{C}$ e BPEAD $/ 3 \% O L E / 3 \%$ NCC Tpico $=477^{\circ} \mathrm{C}$. Os NCCs estavam presentes em pequena proporção, e foram protegidos por CO e BPEAD, o que levou a pequeno deslocamento de início de decomposição, comparativamente a BPEAD.

As análises de TG e dTG foram realizadas para os nanocompósitos extrudados, e para os nanocompósitos extrudados e termoprensados (Figuras não mostradas), no entanto, não foram observadas diferenças significativas entre os materiais processados diferentemente.

A partir da análise de DSC pode-se determinar a temperatura de fusão $\left(T_{m}\right)$, a entalpia de fusão $\left(\Delta \mathrm{H}_{m}\right)$ e o índice de cristalinidade $\left(\mathrm{X}_{\mathrm{c}}\right)$ para os nanocompósitos. Os resultados são apresentados na Tabela 15.

Os nanocompósitos BPEAD/3 \%NCC e misturas BPEAD/3\% CO, OSE ou OLE apresentaram comportamento similar, sendo as figuras não apresentadas. 
Figura 81. Curvas DSC para o BPEAD e nanocompósitos reforçados com NCC, atmosfera de $\mathrm{N}_{2}$, fluxo de $20 \mathrm{~mL} \mathrm{~min}^{-1}$ e razão de aquecimento de $10^{\circ} \mathrm{C} \mathrm{min}^{-1}$.

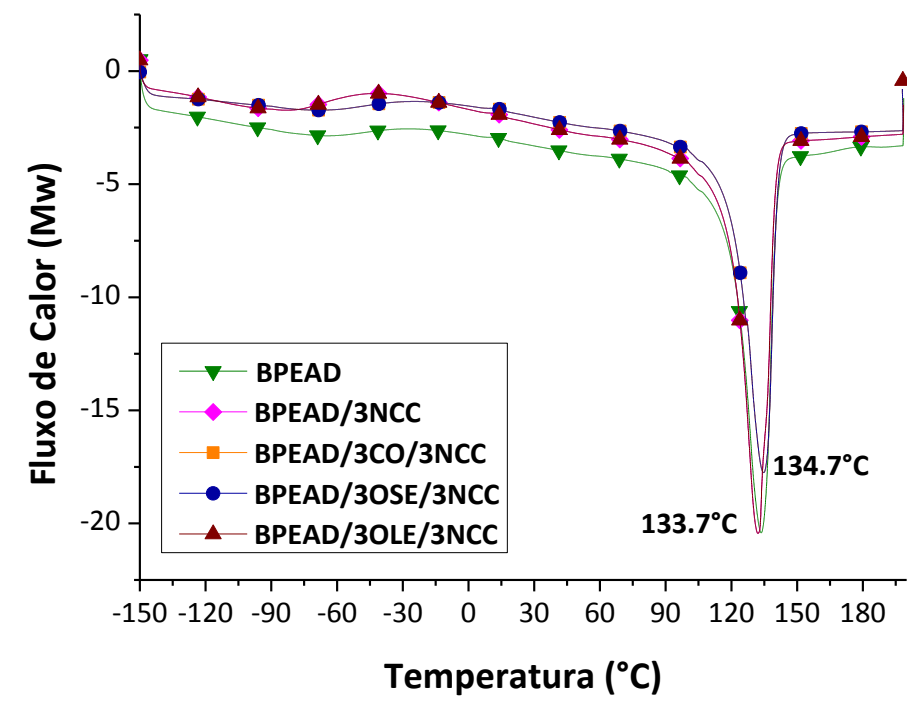

O índice de cristalinidade (Tabela 15) foi calculado, considerando que o BPEAD é o único polímero cristalino nos nanocompósitos, de acordo com a norma ASTM D 3417, utilizando $293 \mathrm{~J} \mathrm{~g}^{-1}$ para a entalpia de fusão, que é o valor do PEAD $100 \%$.

O Xc para o nanocompósito BPEAD/3\%CO/3\%Fibra é maior se comparado a BPEAD e BPEAD/3\%Fibra, fica claro a partir da Tabela 15 que o acréscimo de NCC ao BPEAD resulta em um aumento na Xc devido a capacidade de nucleação dos NCCs, devido à presença de agente compatibilizante (CO), este efeito é intensificado na presença do óleo.

Os resultados da Tabela 15 mostram que o óleo de mamona levou ao efeito mais intenso sobre a cristalinidade de BPEAD, comparativamente aos outros óleos, indicando que $\mathrm{CO}$ atuou mais intensamente como compatibilizante. Este resultado sugere que a estrutura do ácido ricinoléico (Tabela 3), componente majoritário de CO, é muito adequada para interagir tanto com NCC como com BPEAD. Os filmes preparados a partir dos outros óleos apresentaram cristalinidade próxima ao do respectivo BPEAD/3\%NCC (filmes extrudados) ou inferiores (filmes extrudados/termoprensados).

A temperatura de fusão permanece entre 131 e $135^{\circ} \mathrm{C}$ para os diferentes nanocompósitos estudados. 
Tabela 15. Temperatura de fusão $\left(T_{m}\right)$, entalpia de fusão $\left(\Delta H_{m}\right)$ e Índice de Cristalinidade (Xc), de filmes baseados em BPEAD e BPEAD/óleo/NCC.

Extrudado - Extrudado/Termoprensado

\begin{tabular}{ccccc}
\hline Filme & $\mathbf{T}_{\mathbf{m}}\left({ }^{\circ} \mathrm{C}\right)$ & $\Delta \mathbf{H}_{\mathbf{m}}\left(\mathrm{J} \mathrm{g}^{-1}\right)$ & $\Delta \mathrm{H}_{\mu} / \varphi_{\mu}$ & $\mathbf{X}_{\mathrm{c}}$ \\
\hline BPEAD & $134-132$ & $208-207$ & $208-207$ & $71-70$ \\
\hline BPEAD/3\%CO/3\%NCC & $135-135$ & $218-216$ & $232-230$ & $79-78$ \\
BPEAD/3\%OSE/3\%NCC & $135-133$ & $204-211$ & $217-224$ & $74-77$ \\
BPEAD/3\%OLE/3\%NCC & $134-133$ & $203-210$ & $216-224$ & $74-76$ \\
BPEAD/3\%NCC & $132-132$ & $214-213$ & $228-227$ & $78-77$ \\
\hline
\end{tabular}

Não foram observadas diferenças significativas entre as curvas de DSC dos nanocompósitos processados por extrusão e dos nanocompósitos extrudados e termoprensados (Figura não mostrada).

\subsubsection{Reologia}

O comportamento reológico em regime permanente a baixas taxas de cisalhamento dos nanocompósitos é apresentado na Figura 82. Os nanocompósitos BPEAD/3 \%NCC e misturas BPEAD/3\% CO, OSE ou OLE apresentaram comportamento similar, sendo as figuras não apresentadas.

Figura 82. Viscosidade versus Taxa de Cisalhamento para nanocompósitos de BPEAD reforçados com nanocristais de curauá: (a) Extrudados e (b) Extrudados/Termoprensados.

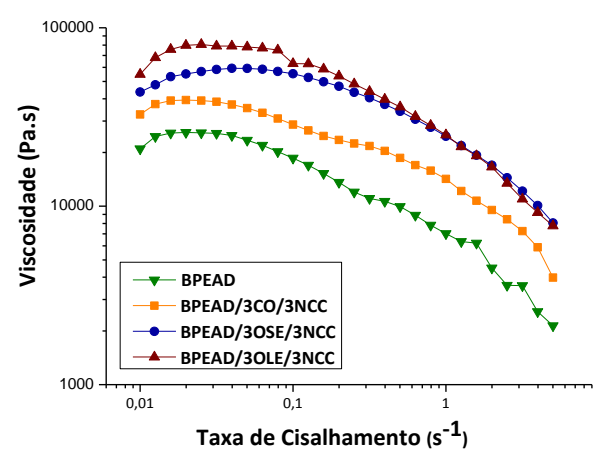

(a)

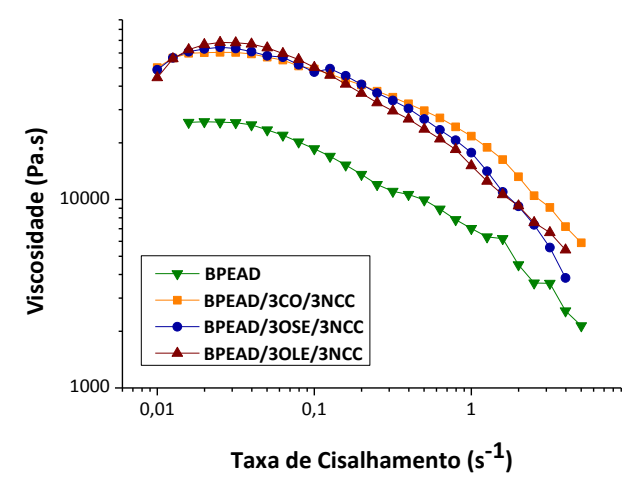

(b)

A adição do NCC e dos óleos vegetais aumentou a viscosidade quando comparados ao BPEAD, alterando o comportamento Newtoniano para um 
comportamento pseudoplástico mais acentuado. Esta mudança pode ser atribuída à presença de interações entre os grupos polares e apolares dos óleos com NCC e o com $B P E A D$, respectivamente. O comportamento reológico em regime permanente a baixas taxas de cisalhamento da mistura $\mathrm{BPEAD} / 3 \% \mathrm{CO}$ e para os nanocompósitos BPEAD/3\%NCC extrudados e extrudados/termoprensados (Figuras não mostradas), apresentaram comportamento similar aos nanocompósitos BPEAD/3\%CO, OLE ou OSE/3\%CNW. O comportamento reológico em regime permanente a baixas taxas de cisalhamento da mistura BPEAD/3\%CO e para os nanocompósitos BPEAD/3\%NCC extrudados e extrudados/termoprensados (Figuras não mostradas), apresentaram comportamento semelhante aos nanocompósitos BPEAD/3\%CO, OLE ou OSE/3\%CNW.

Para as misturas BPEAD/3\%CO, OSE ou OLE/3\%NCC a viscosidade à taxa de cisalhamento zero foi praticamente constante para as misturas extrudadas e extrudadas/termoprensadas, indicando o efeito plastificante dos óleos vegetais na matriz.

Tabela 16. Valores de no para os nanocompósitos e para o BPEAD puro a $175^{\circ} \mathrm{C}$.

\begin{tabular}{cc}
\hline Filmes & $\begin{array}{c}\text { Viscosidade à taxa de cisalhamento zero } \\
\left(\eta_{0}\right) \text { Pa.s }\end{array}$ \\
& Extrudado - Extrudado/Termoprensado \\
\hline BPEAD & $20958-25775$ \\
BPEAD/3\%CO & $26500-23441$ \\
BPEAD/3\%OSE & $23200-26000$ \\
BPEAD/3\%OLE & $22500-25400$ \\
BPEAD/3\%NCC & $40640-102000$ \\
BPEAD/3\%CO/3\%NCC & $39353-60454$ \\
BPEAD/3\%OSE/3\%NCC & $58537-63000$ \\
BPEAD/3\%OLE/3\%NCC & $75000-68000$ \\
\hline
\end{tabular}

A viscosidade à taxa de cisalhamento zero do nanocompósito BPEAD/3\%NCC (102 000 Pa.s) termoprensado foi maior se comparada aos nanocompósitos com OLE (68 000 Pa.s), OSE (63000 Pa.s) e CO(60454 Pa.s). A elevada viscosidade dos nanocompósitos BPEAD/3\%NCC mostrou que a presença de nanocristais restringiu os movimentos das cadeias poliméricas, como resultado da formação de uma rede BPEAD/NCC. A presença de óleos vegetais dificultou a aglomeração e melhorou a dispersão dos NCCs. Pereda et al. (2013) observaram o mesmo efeito em nanocristais de celulose (CNC) modificados com uma solução aquosa de polioxietileno (PEO) 
disperso na matriz de polietileno de baixa densidade, no qual o tratamento da superfície dos CNCs com PEO melhorou as interações entre os nanocristais e a matriz e reduziu a viscosidade dos nanocompósitos.

A viscosidade à taxa de cisalhamento zero $\left(\eta_{0}\right)$ do BPEAD, do nanocompósitos BPEAD/3\%NCC, BPEAD/3\%CO/3\%NCC e BPEAD/3\%OSE/3\%NCC dos filmes extrudados/termoprensados foi ligeiramente maior se comparada às amostras dos filmes extrudados, indicados na Tabela 16, esta ligeira redução pode ser causada pela degradação parcial das amostras na extrusora (30 min), já que o tempo para obtenção dos filmes foi maior se comparado aos filmes termoprensados (13 $\mathrm{min}$ ).

Para os nanocompósitos extrudados não se observaram diferenças significativas da $\left(\eta_{0}\right)$ entre os nanocompósitos BPEAD/3\%NCC e os nanocompósitos BPEAD/3\%CO, OSE ou OLE/3\%NCC, provavelmente o tempo de processamento interferiram no comportamento reológico dos materiais.

A Figura 83 mostra a evolução dos módulos $G^{\prime}$ e G" obtidos no regime linear, em função da frequência angular para a BPEAD puro e para os nanocompósitos.

Para o BPEAD puro (Figura 83), a componente elástica é muito acentuada, apresentando valor um pouco superior ao da componente viscosa em grande parte da faixa de frequência analisada (BESBES; MAGNIN; BOUFI, 2011).

Figura 83. G' (preenchido) e G" (aberto) versus frequência angular a $175^{\circ} \mathrm{C}$ para os nanocompósitos: (a), (c), (e), (i) Filmes extrudados e (b), (d), (f), (j) Filmes extrudados/termoprensados.

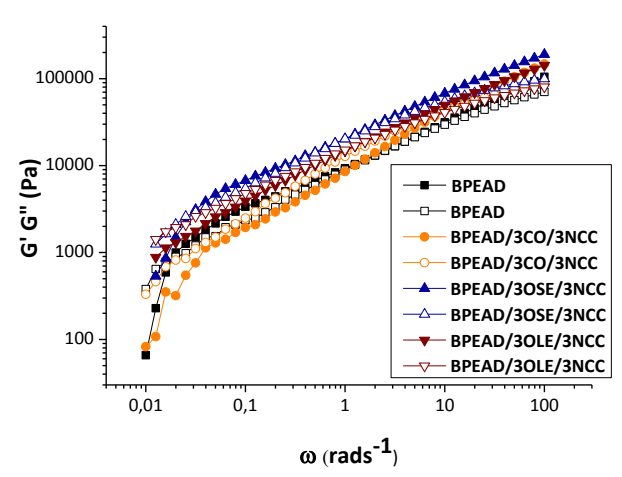

(a)

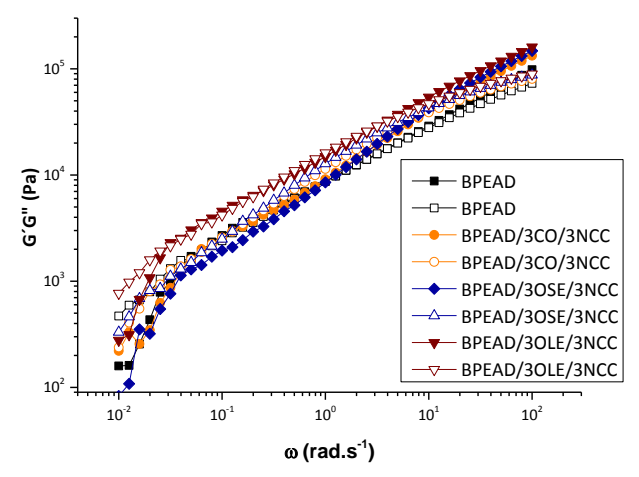

(b) 


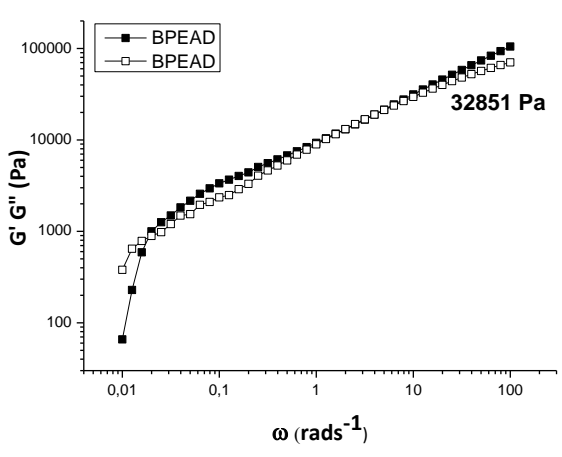

(c)

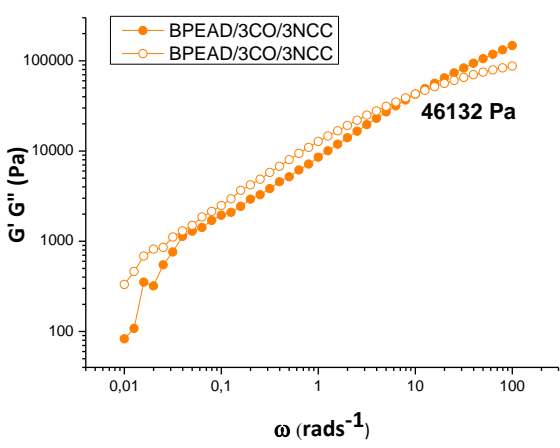

(e)

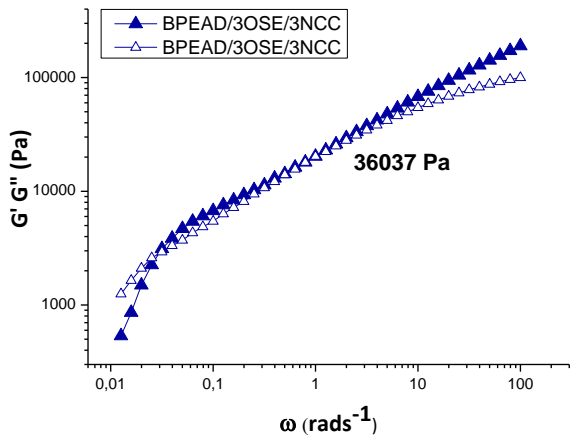

(g)

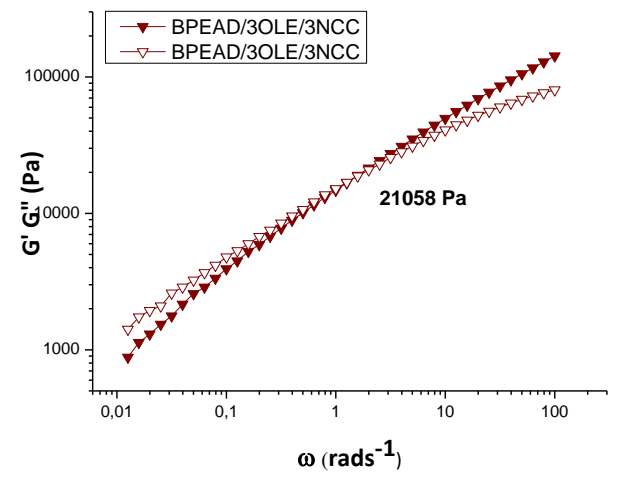

(i)

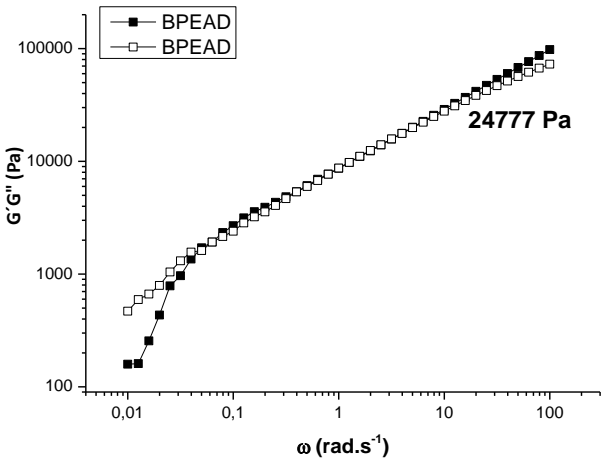

(d)

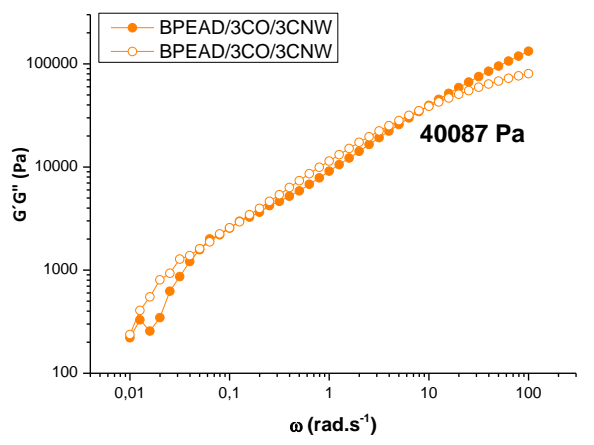

(f)

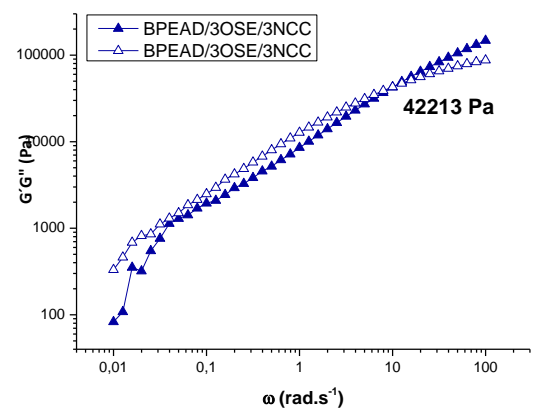

(h)

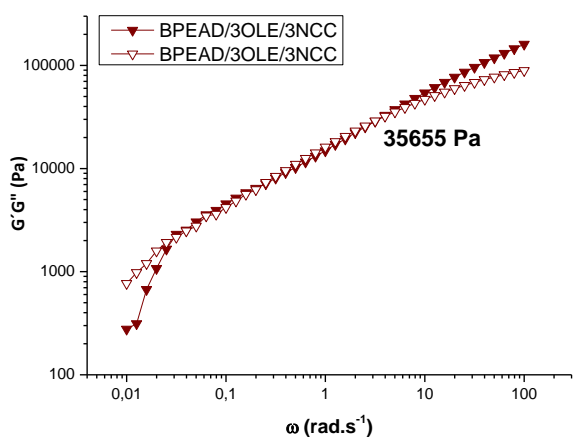

(j) 
Os filmes (Figura 83) exibiram um comportamento viscoelástico semelhante para as diferentes composições.

Considerando a resposta viscoelástica dos nanocompósitos BPEAD/CO, OLE ou OSE/NCC a observação mais importante está relacionada com a evolução da frequência correspondente ao ponto de cruzamento do G'- G", que aumentou com a adição de NCC e óleos vegetais, para os nanocompósitos extrudados e extrudados/termoprensandos, indicando que a dinâmica molecular foi afetada com a presença dos óleos e do NCC. Os nanocompósitos extrudados apresentaram ponto de cruzamento entre $G^{\prime}-G^{\prime \prime}$ menores se comparados aos nanocompósitos extrudados/termoprensados. Essa diferença pode estar relacionada com o tempo de permanência na extrusora, extrusão (aproximadamente $30 \mathrm{~min}$ ) e extrusão/termoprensagem (aproximadamente 10 min de permanência na extrusora).

Idealmente, a formação de uma rede percolada entre reforços de uma matriz ocorre quando as conexões existentes entre esses reforços deixam de ser locais, passando para um estado de conexão infinita. Ou seja, as cargas deixam de atuar simplesmente como partículas individuais e passam a fazer parte de uma estrutura rígida de sustentação, conectada em forma de rede.

Zhaoa et al. (2005) criaram um modelo representativo da mudança de $G^{\prime}(\omega)$ e $G^{\prime \prime}(\omega)$ a baixas frequências em função da quantidade de nanoargilas adicionadas a uma matriz polimérica, considerando a manutenção de uma boa dispersão e a existência de uma boa interação entre reforço e matriz. O aumento da adição de partículas bem dispersas aumenta a rigidez do compósito, resultando em G' e G" maiores e em uma menor inclinação da curva de $G^{\prime \prime}(\omega)$. Conforme o teor de partícula adicionado aproxima-se do teor mínimo para formação de uma rede percolada, um comportamento de transição é observado. Em teores acima de rede percolada a movimentação das cadeias poliméricas se torna bastante limitada devido ao ancoramento imposto em sua estrutura pela rede de percolação formada, de modo que o comportamento elástico $\left(G^{\prime}\right)$ supera a resposta viscosa $\left(G^{\prime \prime}\right)$. A região do platô elastomérico é então antecipada devido ao aumento de rigidez estrutural do polímero fundido ocasionado pela rede de conexão entre os reforços no compósito. Esse tipo de análise foi empregado para verificação da formação de uma rede percolada nos nanocompósitos com nanocristais de celulose, e por isso foi aqui contextualizado. No 
entanto, não se observou indícios da formação de uma rede percolada através da análise das curvas de $G^{\prime}(\omega)$ e G" $(\omega)$ (Figura 83), já que não se observou G' >> G".

Para uma análise mais aprofundada das curvas de $G^{\prime}(\omega)$ e $G^{\prime \prime}(\omega)$, parâmetros de processamento, porcentagem de NCC e de óleos vegetais deveriam ser variados.

\subsubsection{Propriedades Óticas}

A Figura 84 mostra as fotografias dos filmes de BPEAD e dos filmes baseados em nanocompósitos reforçados com nanocristais de curauá, extrudados e extrudados/termoprensados.

Figura 84. Fotos de: BPEAD/3\%NCC (Extrudado), BPEAD/3\%NCC (Extrudado/Termoprensado), BPEAD/3\%CO/3\%NCC (Extrudado), BPEAD/3\%OSE/3\%NCC (Extrudado), BPEAD/3\%OLE/3\%NCC

(Extrudado), BPEAD/3\%CO/3\%NCC (Extrudado/Termoprensado), BPEAD/3\%OSE/3\%NCC

(Extrudado/Termoprensado), BPEAD/3\%OLE/3\%NCC (Extrudado/Termoprensado).
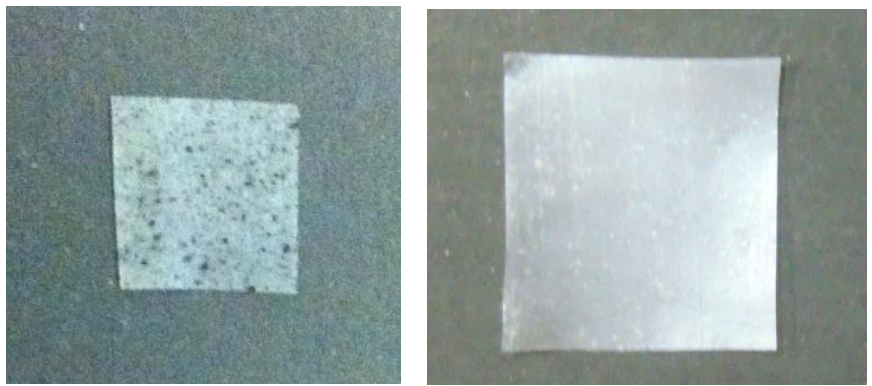

BPEAD/3\%NCC (Extrudado)- Opaco

BPEAD/3\%NCC (Extrudado /Termoprensado)- Opaco

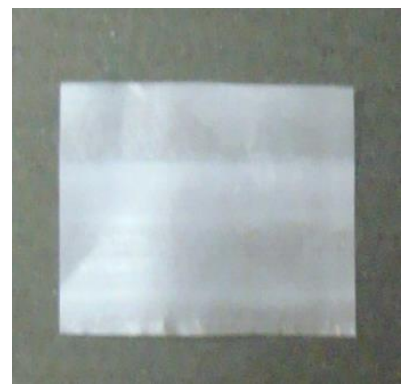

BPEAD/3\%CO/3\%NCC (Extrudado)

Translúcido

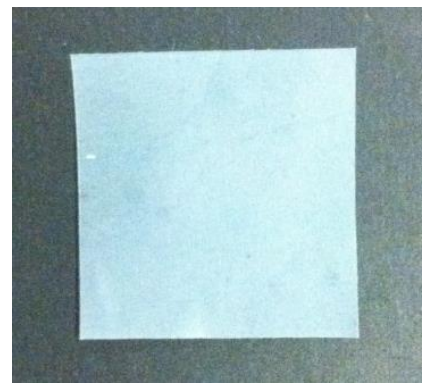

BPEAD/3\%OSE3\%NCC (Extrudado)

Opaco

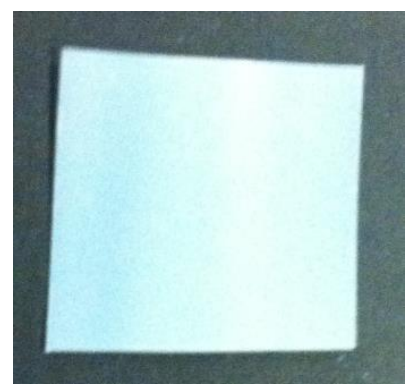

BPEAD/3\%OLE3\%NCC (Extrudado)

Opaco 


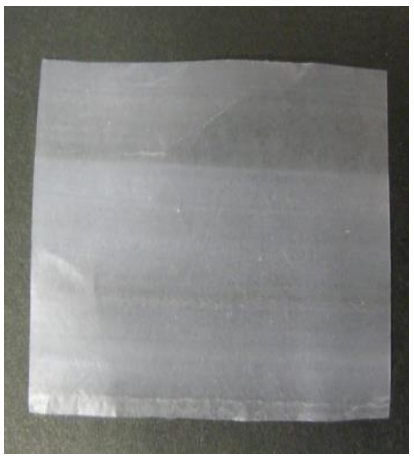

BPEAD/3\%CO/3\%NCC

(Extrudado /Termoprensado)

Translúcido

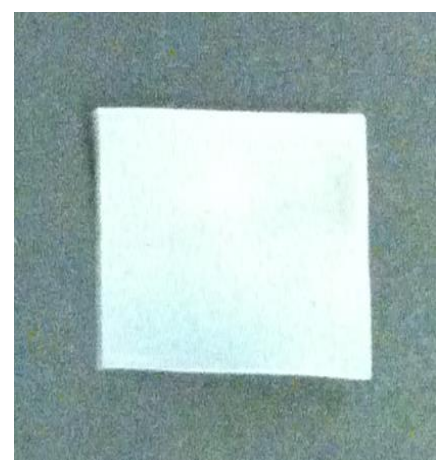

BPEAD/3\%OSE3\%NCC

(Extrudado/Termoprensado)

Translúcido

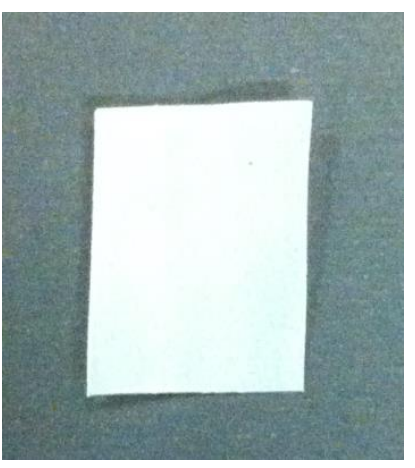

BPEAD/3\%OLE3\%NCC

(Extrudado/ Termoprensado)

Translúcido

Neste trabalho, foi observado que os nanocompósitos com óleo de mamona apresentaram menor opacidade quando comparados aos nanocompósitos com óleo de soja e de linhaça epoxidados. A opacidade pode limitar a aplicação dos filmes poliméricos e prejudicar a sua qualidade.

O filme BPEAD/3\%NCC (Figura 84) apresentou pontos brancos e pretos, esta heterogeneidade revelou a dispersão não homogênea dos NCCs no interior da matriz polimérica, além de decomposição parcial durante o processamento.

\subsubsection{Análise Dinâmico-Mecânica}

A Figura 85 apresenta as curvas de módulo de armazenamento ( $\left.E^{\prime}\right)$ versus a temperatura para os nanocompósitos reforçados com NCC na presença de CO, OSE e OLE. 
Figura 85. Módulo de armazenamento em função da temperatura para os nanocompósitos reforçados com NCC: (a) Filmes extrudados e (b) Filmes extrudados e temoprensados.

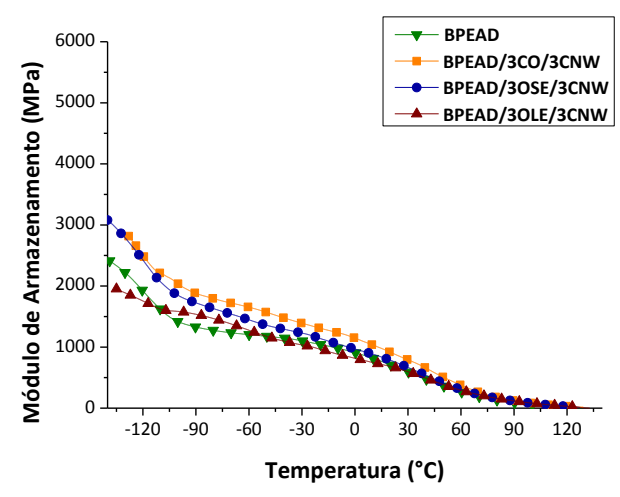

(a)

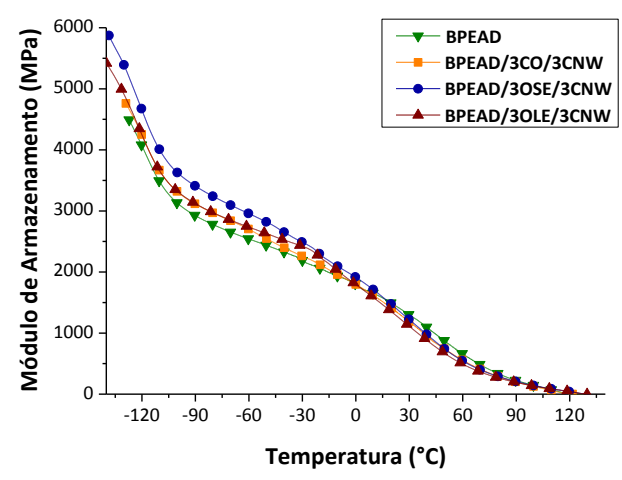

(b)

Os valores do módulo de armazenamento, para os nanocompósitos extrudados, apresentaram um ligeiro aumento com a adição de óleos vegetais aos nanocompósitos quando comparados ao BPEAD. O nanocompósito BPEAD/3\%CO/3\%NCC extrudados apresentou o melhor desempenho, quando comparado aos nanocompósitos BPEAD/3\%OSE/3\%NCC e BPEAD/3\%OLE/3\%NCC, indicando que o CO intensificou as interações na interface, diminuindo a mobilidade dos segmentos de BPEAD presentes nesta região.

O módulo de armazenamento dos filmes extrudados foi inferior em comparação com os filmes extrudados e termoprensados, uma vez que o tempo de processamento dos nanocompósitos extrudados foi superior em comparação com os nanocompósitos extrudados/termoprensados.

Tabela 17. Comparação do módulo de armazenamento $\left(a 30^{\circ} \mathrm{C}\right.$ ) dos nanocompósitos processados por extrusão e dos nanocompósitos processados por extrusão e termoprensados.

\begin{tabular}{cc}
\hline Filmes & $\begin{array}{c}\text { Módulo de Armazenamento (MPa) } \\
\text { Extrudado - Extrudado/Termoprensado }\end{array}$ \\
\hline BPEAD & $582-1329$ \\
BPEAD/3\%CO/3\%NCC & $783-1246$ \\
BPEAD/3\%OSE/3\%NCC & $669-1243$ \\
BPEAD/3\%OLE/3\%NCC & $584-1132$ \\
BPEAD/3\%NCC & $760-1138$ \\
BPEAD/3\%CO & $535-722$ \\
BPEAD/3\%OSE & $465-785$ \\
BPEAD/3\%OLE & $512-712$ \\
\hline
\end{tabular}


Os resultados na Tabela 17 mostram, para os nanocompósitos extrudados, ao adicionar 3 \% de nanocristais de curauá ao BPEAD (760 MPa) (Figura não mostrada), o módulo de armazenamento aumentou ligeiramente se comparado a matriz (582 MPa). Este pequeno aumento, foi atribuído a um efeito de reforço dos nanocristais e/ou ao aumento do grau de cristalinidade relatado a partir das análises de DSC (Tabela 15).

Para as misturas extrudadas, o BPEAD/3\%CO (535 MPa), BPEAD/3\%OSE (465 MPa) e BPEAD/3\%OLE (512 MPa) apresentaram uma diminuição no módulo de armazenamento (Figura não mostrada), em relação ao BPEAD, provavelmente devido à ação plastificante dos óleos vegetais. O mesmo foi observado para as misturas extrudadas e termoprensadas.

Para os nanocompósitos BPEAD/3\%NCC, BPEAD/3\%CO/3\%NCC, BPEAD/3\%OSE/3\%NCC e BPEAD/3\%OLE/3\%NCC extrudados e termoprensados não se observou mudanças significativas nas curvas de módulo de armazenamento em função da temperatura.

Um dos principais objetivos das análises térmicas dinâmico-mecânica é relacionar as propriedades macroscópicas às relaxações moleculares e deformações microscópicas. Dessa forma, a análise térmica dinâmico-mecânica pode refletir as interações intra e/ou intermoleculares das cadeias poliméricas (MATTHEWS; WARD; CAPACCIO, 1999).

O maior valor do módulo de armazenamento do nanocompósito $\mathrm{BPEAD} / 3 \% \mathrm{CO} / 3 \% \mathrm{NCC}$ preparado por extrusão em comparação com o BPEAD, em toda a faixa de temperatura estudada, indica a presença de fortes interações intermoleculares entre a matriz e os NCCs. Estas interações fazem com que os segmentos de BPEAD tenham menor mobilidade, enrijecendo o material (MATTHEWS; WARD; CAPACCIO, 1999). A Figura 86 apresenta a variação de $\tan \delta$ (isto é, relação entre $E^{\prime \prime} / E^{\prime}$ ) em função da temperatura para o BPEAD e para os nanocompósitos extrudados e calandrados.

O comportamento de relaxação dos polietilenos é fortemente influenciado por variáveis que descrevem a estrutura do material, como cristalinidade, espessura lamelar e espessura da camada não cristalina (PASSADOR; RUVOLO-FILHO; PESSAN, 2012). 
Figura 86. Tan $\delta$ em função da temperatura para os nanocompósitos extrudados.

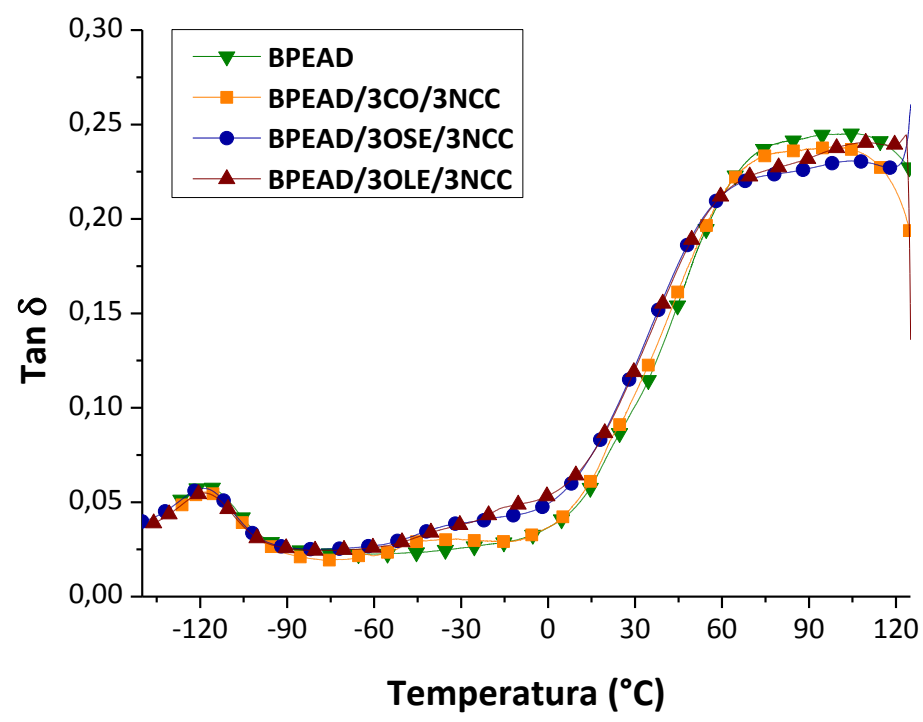

A partir da análise térmica dinâmico-mecânica foi possível determinar a temperatura de transição vítrea do BPEAD nos filmes preparados (Tabela 18).

Tabela 18. Relaxações para o BPEAD puro e para os nanocompósitos (Desvio entre 0,2 e $0,7^{\circ} \mathrm{C}$ ).

Calandrados / Termoprensados

\begin{tabular}{ccc}
\hline Filmes & Pico 1 $\left({ }^{\circ} \mathrm{C}\right)$ & Pico 2 $\left({ }^{\circ} \mathbf{C}\right)$ \\
\hline BPEAD & $-118 /-117$ & $94 / 82$ \\
BPEAD/3\%NCC & $-117 /-116$ & $95 / 97$ \\
BPEAD/3\%CO/3\%NCC & $-116 /-116$ & $95 / 89$ \\
BPEAD/3\%OSE/3\%NCC & $-118 /-118$ & $97 / 96$ \\
BPEAD/3\%OLE/3\%NCC & $-118 /-118$ & $98 / 96$ \\
BPEAD/3\%CO & $-117 /-117$ & $90 / 94$ \\
BPEAD/3\%OSE & $-118 /-117$ & $92 / 92$ \\
BPEAD/3\%OLE & $-119 /-118$ & $93 / 91$ \\
\hline
\end{tabular}

Nos nanocompósitos a incorporação de NCC e óleo de mamona praticamente não alteraram o valor da Tg.

Comparando os resultados obtidos para os nanocompósitos processados por extrusão com os nanocompósitos processados por extrusão e termoprensados, observou-se uma pequena diferença entre os módulos de armazenamento e entre as temperaturas de relaxação $\alpha$ e $\alpha_{c}$, indicando uma dependência dos diferentes métodos de processamento dos filmes aplicados no presente estudo (MOHANTY, A. K. et al., 2004). 


\subsubsection{Resistência à Tração}

A resistência à tração dos nanocompósitos foi avaliada na Figura 87.

Figura 87. (1) BPEAD, (2) BPEAD/3\%NCC, (3) BPEAD/3\%CO/3\%NCC, (4) BPEAD/3\%OSE/3\%NCC, (5) BPEAD/3\%CO/3\%NCC, (6) BPEAD/3\%CO, (7) BPEAD/3\%OSE e (8) BPEAD/3\%OLE: (a) Módulo de Young, (b) Resistência à Tração e (c) Deformação na Ruptura.

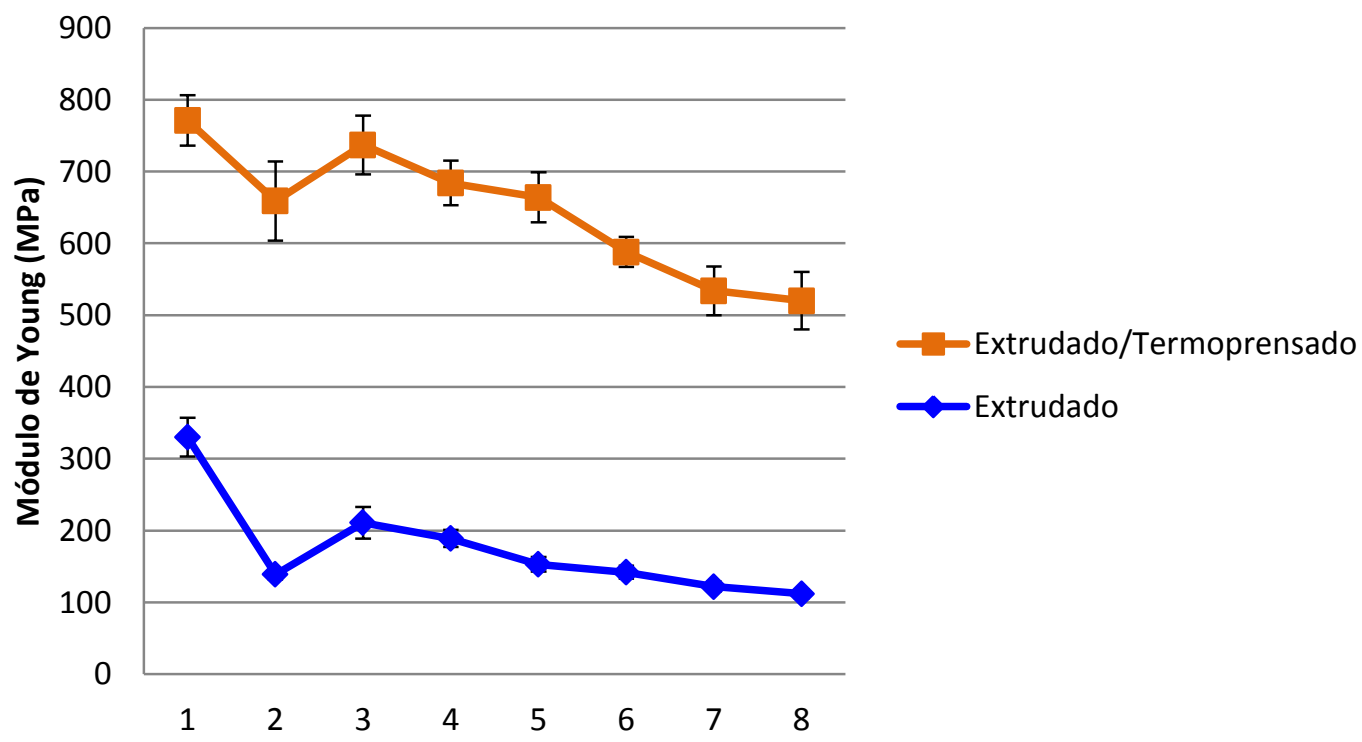

(a)

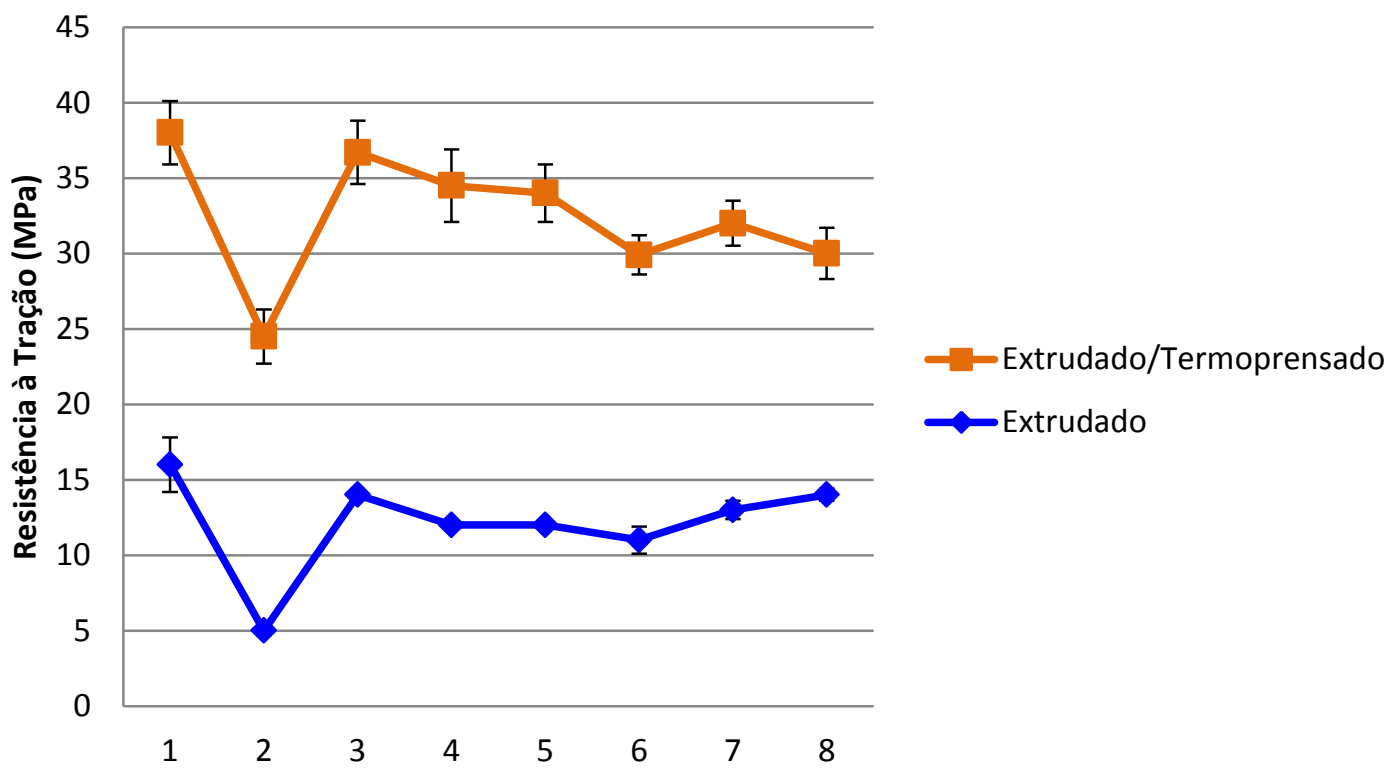

(b) 


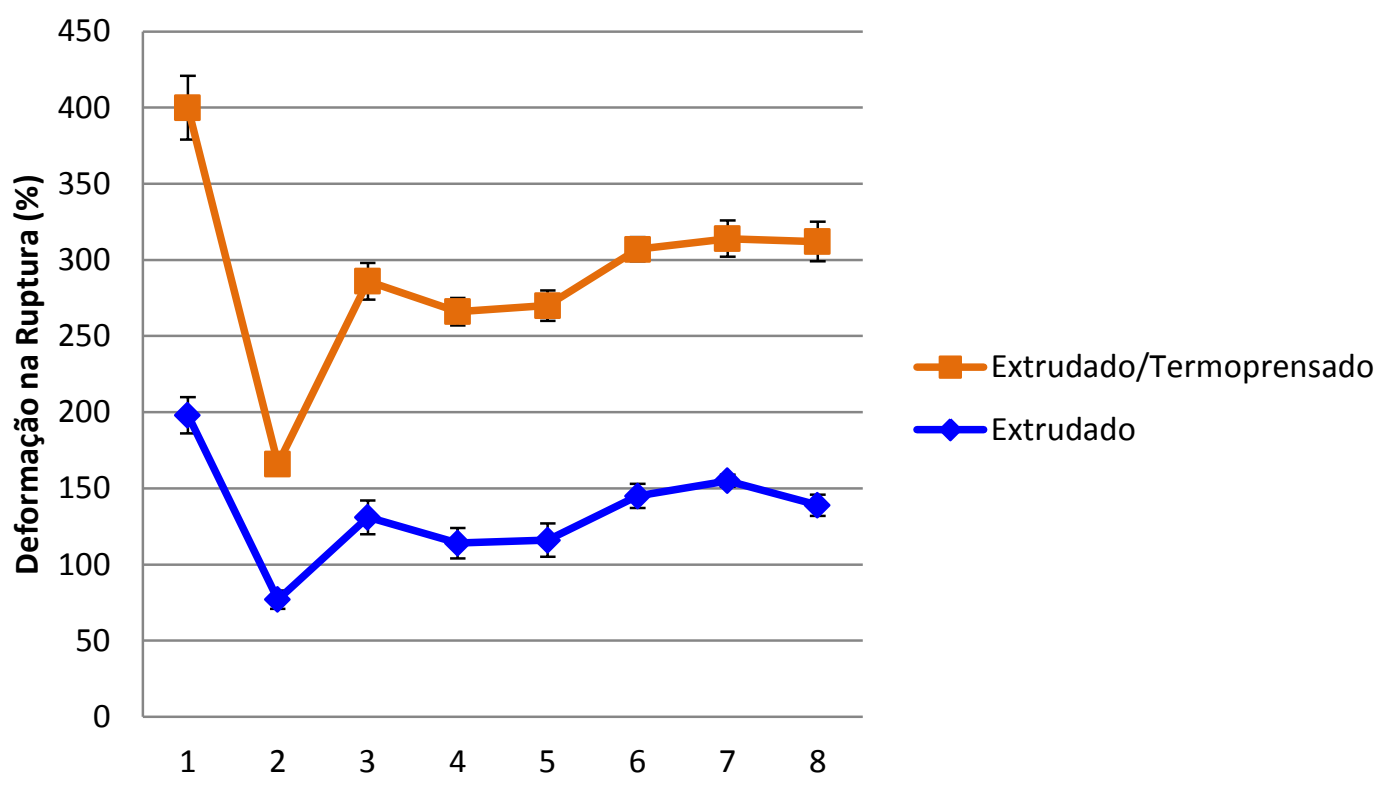

(c)

Como já era esperado, dada à natureza hidrofílica dos nanocristais e o caráter hidrofóbico do BPEAD, os nanocompósitos obtidos com NCC sem a adição de óleos vegetais, exibiram redução em todas as propriedades mecânicas avaliadas, o que é um indício da fraca adesão dos NCCs à matriz. Estes nanocompósitos obtidos sem adição de óleos vegetais, não apenas apresentaram cargas sem adesão ao BPEAD, como também apresentam aglomerados de cargas em razão das interações de hidrogênio existentes entre as cadeias de celulose, comprometendo as propriedades mecânicas dos nanocompósitos (PEI; ZHOU; BERGLUND, 2010).

Para os nanocompósitos processados na presença de óleos vegetais, os módulos elásticos apresentaram uma tendência de aumento, como resultado da melhor interação da carga com a matriz, devido ao efeito de compatibilização entre elas.

As misturas BPEAD/CO, BPEAD/OSE e BPEAD/OLE apresentaram diminuição do módulo de Young, da resistência à tração e um aumento da deformação na ruptura (Figura 87) quando comparados aos nanocompósitos BPEAD/3\% OSE, CO ou OLE/3\% NCC, provavelmente o CO, o OSE e OLE atuaram como plastificante.

As propriedades mecânicas dos filmes extrudados foi inferior em comparação com os filmes extrudados e termoprensados, uma vez que o tempo de processamento 
dos nanocompósitos extrudados foi superior em comparação com os nanocompósitos extrudados/termoprensados, assim como foi observado no ensaio de DMA.

Importante ressaltar que houve certa dificuldade em se fazer comparações entre as propriedades dos nanocompósitos obtidos neste trabalho com as propriedades dos nanocompósitos reportados na literatura, visto que os métodos de modificação de superfície são bastante específicos. Também, ainda que o número de trabalhos relacionados ao desenvolvimento de nanocompósitos com nanocristais de celulose seja grande, poucos utilizaram a técnica de processamento por extrusão, sendo a maioria dos nanocompósitos obtidos por meio de solvent-casting o que sugere a necessidade de mais pesquisas e novas abordagens a respeito da ação como reforço de NCC sobre filmes de matrizes poliméricas.

Ainda que não se observasse melhoras significavas nas propriedades mecânicas dos nanocompósitos no presente estudo, destaca-se que todos os óleos considerados, de origem vegetal, levaram a uma melhor dispersão de NCC em uma matriz apolar como BPEAD, com destaque para $\mathrm{CO}$, o que representa um ganho frente a muitas alternativas em que modificações via reações químicas são aplicadas, visando melhor dispersar NCC em matrizes hidrofóbicas. 


\section{Conclusão}

No estudo desenvolvido foram preparados compósitos e filmes do tipo nanocompósitos baseados em BPEAD e diferentes porcentagens de fibras e de nanocristais de curauá (obtidos através de hidrólise ácida), assim como usando diferentes óleos vegetais, visando ação dos mesmos como compatibilizante entre BPEAD (hidrofóbico, com afinidade pela cadeia hidrocarbônica dos óleos) e fibras ou nanocristais (hidrofílicos, com afinidade pelos grupos polares presentes nos óleos). $\mathrm{Na}$ preparação de compósitos e de nanocompósitos, dois processos diferentes foram usados, visando avaliar a influência do processamento nas propriedades dos materiais obtidos: misturador interno (Haake)/termoprensagem e extrusão/injeção, na obtenção de compósitos, extrusão e extrusão/termoprensagem no caso de filmes do tipo nanocompósitos.

No que se referem aos compósitos reforçados com fibra de curauá, os melhores resultados foram obtidos para os materiais obtidos via extrusão/injeção. Pelo menos em parte, estes resultados devem ser consequência de as fibras terem sofrido desfibramento, formando microfibrilas, durante o processamento na extrusora (dupla rosca).

A presença das fibras de curauá diminuiu a resistência ao impacto do BPEAD. No entanto, no geral, para ambos os processamentos, a adição de CO, CA, OSE e OLE, levou uma melhor adesão na interface, assim como a uma distribuição mais homogênea das fibras de curauá na matriz termoplástica, evidenciando a ação dos óleos, com destaque para $\mathrm{CO}$, como compatibilizantes na interface fibra/matriz. A melhora ocorrida na interface pela ação dos óleos foi acompanhada por melhoras nas propriedades mecânicas destes compósitos, particularmente na resistência ao impacto.

A análise de DMA dos compósitos mostrou que a presença de fibras leva a um material mais rígido, comparativamente ao BPEAD puro, isto indica que estes compósitos podem ser usados em aplicações em que mais alto módulo de armazenamento seja necessário. 
Na preparação de nanocristais, na etapa de purificação prévia à hidrólise, o tratamento com solução de $\mathrm{NaOH}$ se mostrou satisfatório para a remoção de lignina, como mostraram as caracterizações químicas da polpa de celulose extraída a partir da fibra de curauá. Para promover a melhor dispersão dos NCCs na matriz de BPEAD, uma troca de solventes foi utilizada. Inicialmente promoveu-se a troca da suspensão de nanocristais em água por etanol e após quatro ciclos, promoveu-se uma nova troca de solvente, desta vez etanol por óleo de mamona (CO), o mesmo procedimento foi realizado com óleo de linhaça e de soja epoxidados (OLE e OSE). Os nanocristais preparados apresentaram formato de agulhas e suas dimensões foram de $10 \mathrm{~nm}$ de espessura e $187 \mathrm{~nm}$ de comprimento. O uso de óleos vegetais na preparação de filmes, levou a uma distribuição mais homogênea dos NCCs na matriz de BPEAD e a uma melhor adesão na interface, evidenciando o efeito compatibilizante dos óleos, com destaque para $\mathrm{CO}$. A presença dos óleos levou a filmes menos opacos e com melhores resultados nos ensaios de tração, para ambos os tipos de processamentos usados.

Com relação aos diferentes processamentos usados na preparação dos filmes baseados em BPEAD, óleos e nanocristais, o melhor conjunto de resultados, com destaque para aqueles obtidos no ensaio de tração, foram resultantes do processamento via extrusão/termoprensagem, indicando que este processamento deve favorecer a dispersão de NCCs na matriz de BPEAD. Os resultados obtidos no presente estudo poderão ser usados como base para avançar o processo investigativo, buscando condições em que filmes com superiores propriedades mecânicas sejam obtidos.

Materiais foram preparados a partir de matéria prima oriunda de fontes renováveis, ou seja, BPEAD, óleos vegetais, fibras de curauá ou nanocristais de celulose. Parte do polímero foi substituída parcialmente por óleos, fibras ou nanocristais de curauá, o que leva a materiais com menor densidade, e normalmente menor custo. $\mathrm{O}$ conjunto de resultados vem de encontro às expectativas referentes à obtenção de materiais a partir de componentes não fósseis, com boas propriedades. 


\section{Referências}

ABDELMOULEH, M.; BOUFI, S.; BELGACEM, M.; DUFRESNE, A. Short natural-fibre reinforced polyethylene and natural rubber composites: Effect of silane coupling agents and fibres loading. Composites Science and Technology, v. 67, n. 7-8, p. 16271639, 2007.

ALAM, A. K. M. M.; SHUBHRA, Q. T. H.; AL-IMRAN, G.; BARAI, S.; ISLAM, M. R.; RAHMAN, M. M. Preparation and characterization of natural silk fiber-reinforced polypropylene and synthetic e-glass fiber-reinforced polypropylene composites: A comparative study. Journal of Composite Materials, v. 45, n. 22, p. 2301-2308, 2011.

ALLOIN, F.; D'APREA, A.; DUFRESNE, A.; KISSI, N. E.; BOSSARD, F. Poly(oxyethylene) and ramie whiskers based nanocomposites: Influence of processing: Extrusion and casting/evaporation. Cellulose, v. 18, n. 4, p. 957-973, 2011.

ANDRESEN, M.; STENIUS, P. Water-in-oil emulsions stabilized by hydrophobized microfibrillated cellulose. Journal of Dispersion Science and Technology, v. 28, n. 6, p. 837-844, 2007.

ANGLES, M. N.; DUFRESNE, A. Plasticized starch/tunicin whiskers nanocomposites. 1. Structural analysis. Macromolecules, v. 33, n. 22, p. 8344-8353, 2000.

ANUAR, H.; AHMAD, S. H.; RASID, R.; AHMAD, A.; BUSU, W. N. W. Mechanical properties and dynamic mechanical analysis of thermoplastic-natural-rubberreinforced short carbon fiber and kenaf fiber hybrid composites. Journal of Applied Polymer Science, v. 107, n. 6, p. 4043-4052, 2008.

ARAUJO, J. R.; MANO, B.; TEIXEIRA, G. M.; SPINACÉ, M. A. S.; DE PAOLI, M.-A. Biomicrofibrilar composites of high density polyethylene reinforced with curauá fibers: Mechanical, interfacial and morphological properties. Composites Science and Technology, v. 70, n. 11, p. 1637-1644, 2010.

BATTISTA, O. A.; SMITH, P. A. Microcrystalline cellulose - oldest polymer finds new industrial uses. Industrial and Engineering Chemistry, v. 54, n. 9, p. 20-28, 1962.

BECK-CANDANEDO, S.; ROMAN, M.; GRAY, D. G. Effect of reaction conditions on the properties and behavior of wood cellulose nanocrystal suspensions.

Biomacromolecules, v. 6, n. 2, p. 1048-1054, 2005.

BEN AZOUZ, K.; RAMIRES, E. C.; VAN DEN FONTEYNE, W.; EL KISSI, N.; DUFRESNE, A. Simple method for the melt extrusion of a cellulose nanocrystal reinforced hydrophobic polymer. ACS Macro Letters, v. 1, n. 1, p. 236-240, 2012. 
BEN MABROUK, A.; KADDAMI, H.; MAGNIN, A.; BELGACEM, M. N.; DUFRESNE, A.; BOUFI, S. Preparation of nanocomposite dispersions based on cellulose whiskers and acrylic copolymer by miniemulsion polymerization: Effect of the silane content.

Polymer Engineering \& Science, v. 51, n. 1, p. 62-70, 2011.

BENGTSSON, M.; LE BAILLIF, M.; OKSMAN, K. Extrusion and mechanical properties of highly filled cellulose fibre-polypropylene composites. Composites Part a-Applied Science and Manufacturing, v. 38, n. 8, p. 1922-1931, 2007.

BESBES, I.; MAGNIN, A.; BOUFI, S. Rheological behavior of nanofibrillated cellulose/acrylic polymer nanocomposites: Effect of melt extrusion. Polymer Composites, v. 32, n. 12, p. 2070-2075, 2011.

BLEDZKI, A. K.; GASSAN, J. Composites reinforced with cellulose based fibres. Progress in Polymer Science, v. 24, n. 2, p. 221-274, 1999.

BONDESON, D.; MATHEW, A.; OKSMAN, K. Optimization of the isolation of nanocrystals from microcrystalline cellulose by acid hydrolysis. Cellulose, v. 13, n. 2, p. 171-180, 2006.

BONDESON, D.; OKSMAN, K. Polylactic acid/cellulose whisker nanocomposites modified by polyvinyl alcohol. Composites Part a-Applied Science and Manufacturing, v. 38, n. 12, p. 2486-2492, 2007.

BRAUN, B.; DORGAN, J. R.; CHANDLER, J. P. Cellulosic nanowhiskers. Theory and application of light scattering from polydisperse spheroids in the rayleigh-gans-debye regime. Biomacromolecules, v. 9, n. 4, p. 1255-1263, 2008.

BRIGIDA, A. I. S.; CALADO, V. M. A.; GONCALVES, L. R. B.; COELHO, M. A. Z. Effect of chemical treatments on properties of green coconut fiber. Carbohydrate Polymers, $v$. 79, n. 4, p. 832-838, 2010.

BRITO, B. S. L.; PEREIRA, F. V.; PUTAUX, J.-L.; JEAN, B. Preparation, morphology and structure of cellulose nanocrystals from bamboo fibers. Cellulose, v. 19, n. 5, p. 15271536, 2012.

BUSCHLE-DILLER, G.; ZERONIAN, S. H. Enhancing the reactivity and strength of cotton fibers. Journal of Applied Polymer Science, v. 42, p. 967-979, 1992.

CALLISTER, W. D. Ciência e engenharia de materiais: Uma introdução. Rio de Janeiro: LTC, 2002. 132-167 p.

CAMARERO ESPINOSA, S.; KUHNT, T.; FOSTER, E. J.; WEDER, C. Isolation of thermally stable cellulose nanocrystals by phosphoric acid hydrolysis. Biomacromolecules, v. 14, n. 4, p. 1223-30, 2013. 
CAMPOS, A.; TEODORO, K. B. R.; TEIXEIRA, E. M.; CORREA, A. C.; MARCONCINI, J. M.; WOOD, D. F.; WILLIAMS, T. G.; MATTOSO, L. H. C. Properties of thermoplastic starch and $\mathrm{tps} /$ polycaprolactone blend reinforced with sisal whiskers using extrusion

processing. Polymer Engineering and Science, v. 53, n. 4, p. 800-808, 2013.

CANEVAROLO JUNIOR, S. V. Técnicas de caracterização de polímeros. São Paulo: Artliber, 2004. 263-277 p.

CASTRO COIMBRA CORDEIRO, I. M.; DE SANTANA, A. C.; LAMEIRA, O. A.; SILVA, I. M. Economical analysis of cultivation systems with schizolobium parahyba var. Amazonicum (huber ex ducke) barneby (parica) and ananas comosus var. Erectifolius (I. B. Smith) coppus \& leal (curaua) crop at aurora do para, brazil. Revista De La Facultad De Agronomia De La Universidad Del Zulia, v. 26, n. 2, p. 243-265, 2009.

CASTRO, D. O.; FROLLINI, E.; MARINI, J.; RUVOLO-FILHO, A. Preparação e caracterização de biocompósitos baseados em fibra de curauá, biopolietileno de alta densidade (bpead) e polibutadieno líquido hidroxilado (pbhl). Polímeros, n. 1, p. 65-73, 2013.

CASTRO, D. O.; RUVOLO-FILHO, A.; FROLLINI, E. Materials prepared from biopolyethylene and curaua fibers: Composites from biomass. Polymer Testing, v. 31, n. 7, p. 880-888, 2012.

CHAWLA, K. K. Composites materials. New York: Springer, 1998. p.304

CHUNG, T. C. M. Functional polyolefins for energy applications. Macromolecules, v. 46, n. 17, p. 6671-6698, 2013.

CONCEIÇÃO, M. M.; FERNANDES JR, V. J.; ARAÚJO, A. S.; FARIAS, M. F.; SANTOS, I. M. G.; SOUZA, A. G. Thermal and oxidative degradation of castor oil biodiesel. Energy and Fuels, v. 21, n. 3, p. 1522-1527, 2007.

CORRÊA, A. C.; DE TEIXEIRA, E. M.; PESSAN, L. A.; MATTOSO, L. H. C. Cellulose nanofibers from curaua fibers. Cellulose, v. 17, n. 6, p. 1183-1192, 2010.

COSTA, H. M.; RAMOS, V. D.; ABRANTES, T. A. S.; CASTRO, D. F.; VISCONTE, L. L. Y.; NUNES, R. C. R.; FURTADO, C. R. G. Effects from the castor oil on silica-filled natural rubber compounds. Polímeros, v. 14, n. 1, p. 46-50, 2004.

COUTINHO, F. M. B.; MELLO, I. L.; SANTA MARIA, L. C. D. Polietileno: Principais tipos, propriedades e aplicações. Polímeros: Ciência e Tecnologia, v. 13, n. 1, p. 01-13, 2003.

DE CAMPOS, A.; CORREA, A. C.; CANNELLA, D.; TEIXEIRA, E. D. M.; MARCONCINI, J. M.; DUFRESNE, A.; MATTOSO, L. H. C.; CASSLAND, P.; SANADI, A. R. Obtaining nanofibers from curaua and sugarcane bagasse fibers using enzymatic hydrolysis followed by sonication. Cellulose, v. 20, n. 3, p. 1491-1500, 2013. 
DE OLIVEIRA SANTOS, R. P.; CASTRO, D. O.; RUVOLO-FILHO, A. C.; FROLLINI, E. Processing and thermal properties of composites based on recycled pet, sisal fibers, and renewable plasticizers. Journal of Applied Polymer Science, v. 131, n. 12, p., 2014.

DE PAOLI, M. A. Degradação e estabilização de polímeros. São Paulo: Artliber Editora, 2008. p. $11-41$

DEVI, L. U.; BHAGAWAN, S. S.; THOMAS, S. Dynamic mechanical properties of pineapple leaf fiber polyester composites. Polymer Composites, v. 32, n. 11, p. 17411750, 2011.

DONG, X. M.; REVOL, J. F.; GRAY, D. G. Effect of microcrystallite preparation conditions on the formation of colloid crystals of cellulose. Cellulose, v. 5, n. 1, p. 19-32, 1998.

DUFRESNE, A. Polysaccharide nano crystal reinforced nanocomposites. Canadian Journal of Chemistry, v. 86, n. 6, p. 484-494, 2008.

DUFRESNE, A. Processing of polymer nanocomposites reinforced with polysaccharide nanocrystals. Molecules, v. 15, n. 6, p. 4111-28, 2010.

DUFRESNE, A.; DUPEYRE, D.; PAILLET, M. Lignocellulosic flour-reinforced poly(hydroxybutyrate-co-valerate) composites. Journal of Applied Polymer Science, v. 87, n. 8, p. 1302-1315, 2003.

DURAN, N.; LEMES, A. P.; SEABRA, A. B. Review of cellulose nanocrystals patents: Preparation, composites and general applications. Recent Patents on Nanotechnology, v. 6, n. 1, p. 16-28, 2012.

EL-SABBAGH, A. Effect of coupling agent on natural fibre in natural fibre/polypropylene composites on mechanical and thermal behaviour. Composites Part B-Engineering, $v$. 57, p. 126-135, 2014.

FARIAS, M.; MARTINELLI, M.; ROLIM, G. K. Immobilized molybdenum acetylacetonate complex on montmorillonite k-10 as catalyst for epoxidation of vegetable oils. Applied Catalysis a-General, v. 403, n. 1-2, p. 119-127, 2011.

FARUK, O.; BLEDZKI, A. K.; FINK, H.-P.; SAIN, M. Progress report on natural fiber reinforced composites. Macromolecular Materials and Engineering, v. 299, n. 1, p. 926, 2014.

FAVIER, V.; CHANZY, H.; CAVAILLE, J. Y. Polymer nanocomposites reinforced by cellulose whiskers. Macromolecules, v. 28, n. 18, p. 6365-6367, 1995.

FENGEL, D.; WEGENER, G. Wood e chemistry, ultrastructure, reactions. Berlin: Walter de Gruyter, 1984. p. 613 
FENGEL, D.; WEGENER, G. Wood e chemistry, ultrastructure, reactions. Berlin: Walter de Gruyter, 1989. p. 1-130

FILSON, P. B.; DAWSON-ANDOH, B. E.; SCHWEGLER-BERRY, D. Enzymatic-mediated production of cellulose nanocrystals from recycled pulp. Green Chemistry, v. 11, n. 11, p. 1808-1814, 2009.

FISCH, A. G.; CARDOZO, N. S. M.; SECCHI, A. R.; DOS SANTOS, J. H. Z. Supported metallocene catalysts for polyolefin production: Review of the immobilization strategies. Quimica Nova, v. 34, n. 4, p. 646-657, 2011.

FOGASSY, G.; KE, P.; FIGUERAS, F.; CASSAGNAU, P.; ROUZEAU, S.; COURAULT, V.; GELBARD, G.; PINEL, C. Catalyzed ring opening of epoxides: Application to bioplasticizers synthesis. Applied Catalysis a-General, v. 393, n. 1-2, p. 1-8, 2011.

FROLLINI, E.; BARTOLUCCI, N.; SISTI, L.; CELLI, A. Poly(butylene succinate) reinforced with different lignocellulosic fibers. Industrial Crops and Products, v. 45, p. 160-169, 2013.

FRONE, A. N.; BERLIOZ, S.; CHAILAN, J. F.; PANAITESCU, D. M. Morphology and thermal properties of pla-cellulose nanofibers composites. Carbohydr Polym, v. 91, n. 1, p. 37784, 2013.

GAMAGE, P. K.; FARID, A. S.; KARUNANAYAKE, L. Kinetics of degradation of pvccontaining novel neem oil as stabilizer. Journal of Applied Polymer Science, v. 112, n. 4, p. 2151-2165, 2009.

GEORGE, J.; BHAGAWAN, S. S.; THOMAS, S. Effects of environment on the properties of low-density polyethylene composites reinforced with pineapple-leaf fibre. Composites Science and Technology, v. 58, n. 9, p. 1471-1485, 1998.

GHAZANI, S. M.; MARANGONI, A. G. Minor components in canola oil and effects of refining on these constituents: A review. Journal of the American Oil Chemists Society, v. 90, n. 7, p. 923-932, 2013.

GODWIN, A. D. Plasticizer. In: C. CRAVER, C. C. (Ed.). Applied polymer science: 21st century. United States of America: Elsevier, 2000. p. 157

GODWIN, A. D. Plasticizer. In: KUTZ, M. (Ed.). Applied plastics engineering handbook: Processing and materials. United States of America: Elsevier, 2011. p. 574

GOFFIN, A.-L.; RAQUEZ, J.-M.; DUQUESNE, E.; SIQUEIRA, G.; HABIBI, Y.; DUFRESNE, A.; DUBOIS, P. From interfacial ring-opening polymerization to melt processing of cellulose nanowhisker-filled polylactide-based nanocomposites. Biomacromolecules, v. 12, n. 7 , p. 2456-2465, 2011. 
GOMES, A.; MATSUO, T.; GODA, K.; OHGI, J. Development and effect of alkali treatment on tensile properties of curaua fiber green composites. Composites Part aApplied Science and Manufacturing, v. 38, n. 8, p. 1811-1820, 2007a.

GOMES, A.; MATSUO, T.; GODA, K.; OHGI, J. Development and effect of alkali treatment on tensile properties of curaua fiber green composites. Composites Part A: Applied Science and Manufacturing, v. 38, n. 8, p. 1811-1820, 2007b.

GONZÁLEZ-SÁNCHEZ, C.; FONSECA-VALERO, C.; OCHOA-MENDOZA, A.; GARRIGAMECO, A.; RODRÍGUEZ-HURTADO, E. Rheological behavior of original and recycled cellulose-polyolefin composite materials. Composites Part A: Applied Science and Manufacturing, v. 42, n. 9, p. 1075-1083, 2011.

GOULART, S. A. S.; OLIVEIRA, T. A.; TEIXEIRA, A.; MILÉO, P. C.; MULINARI, D. R. Mechanical behaviour of polypropylene reinforced palm fibers composites. Procedia Engineering, v. 10, p. 2034-2039, 2011.

GROSSMAN, R. F. Lubricants. In: JR., J. T. L.; GROSSMAN, R. F.; DEKKER, M. (Ed.). Polymer modifiers and additives. United States of America: Marcel Dekker, 2001. p. 363

GRUNERT, M.; WINTER, W. T. Nanocomposites of cellulose acetate butyrate reinforced with cellulose nanocrystals. Journal of Polymers and the Environment, v. 10, n. 1-2, p. 27-30, 2002.

GUNNING, M. A.; GEEVER, L. M.; KILLION, J. A.; LYONS, J. G.; HIGGINBOTHAM, C. L. Mechanical and biodegradation performance of short natural fibre polyhydroxybutyrate composites. Polymer Testing, v. 32, n. 8, p. 1603-1611, 2013.

HARNNECKER, F.; DOS SANTOS ROSA, D.; LENZ, D. M. Biodegradable polyester-based blend reinforced with curauá fiber: Thermal, mechanical and biodegradation behaviour. Journal of Polymers and the Environment, v. 20, n. 1, p. 237-244, 2011.

HASANI, M.; CRANSTON, E. D.; WESTMAN, G.; GRAY, D. G. Cationic surface functionalization of cellulose nanocrystals. Soft Matter, v. 4, n. 11, p. 2238-2244, 2008.

HERAKOVICH, C. T. Mechanics of fibrous composites. New York: Willey, 1998. p. 1-7

HERRERA FRANCO, P.; VALADEZ GONZALEZ, A.; CERVANTESUC, M. Development and characterization of a hdpe-sand natural fiber composite. Composites Part BEngineering, v. 28, n. 3, p. 331-343, 1997.

HILL, C. A. S.; ABDUL KHALIL, H. P. S. Effect of fiber treatments on mechanical properties of coir or oil palm fiber reinforced polyester composites. Journal of Applied Polymer Science, v. 78, p. 1685-1697, 2000. 
HUDA, M. S.; DRZAL, L. T.; MOHANTY, A. K.; MISRA, M. The effect of silane treated-and untreated-talc on the mechanical and physico-mechanical properties of poly(lactic acid)/newspaper fibers/talc hybrid composites. Composites Part B-Engineering, v. 38, n. 3, p. 367-379, 2007.

HUNT, B. J.; BLACKIE, M. I. J. Polymer characterisation. Edited by. Glasgow: Chapman \& Hall, 1993. p. 264-276

IAN M. WARD, J. S. Mechanical properties of solid polymers. London: Wiley, 2004. p. 19-26

IANNACE, S.; ALI, R.; NICOLAIS, L. Effect of processing conditions on dimensions of sisal fibers in thermoplstic biodegradable composites. Journal of Applied Polymer Science, v. 79, p. 1084-1091, 2001.

ISLAM, M. R.; BEG, M. D. H.; GUPTA, A. Characterization of laccase-treated kenaf fibre reinforced recycled polypropylene composites. BioResources, v. 8, n. 3, p. 3753-3770, 2013.

JARUKUMJORN, K.; SUPPAKARN, N. Effect of glass fiber hybridization on properties of sisal fiber-polypropylene composites. Composites Part B: Engineering, v. 40, n. 7, p. 623-627, 2009.

JOHN, M.; THOMAS, S. Biofibres and biocomposites. Carbohydrate Polymers, v. 71, n. 3, p. 343-364, 2008.

JOSEPH, P. V.; OOMMEN, Z.; JOSEPH, K.; THOMAS, S. Melt rheological behaviour of short sisal fibre reinforced polypropylene composites. Journal of Thermoplastic Composite Materials, v. 15, n. 2, p. 89-114, 2002.

JUNIOR DE MENEZES, A.; SIQUEIRA, G.; CURVELO, A. A. S.; DUFRESNE, A. Extrusion and characterization of functionalized cellulose whiskers reinforced polyethylene nanocomposites. Polymer, v. 50, n. 19, p. 4552-4563, 2009.

KAJIYAMA, T.; OKADA, T.; SAKODA, A.; TAKAYANA.M. Analysis of alpha-relaxation process of bulk crystallized polyethylene based on that of single-crystal mat. Journal of Macromolecular Science-Physics, v. B 7, n. 3, p. 583-608, 1973.

KALAPRASAD, G.; MATHEW, G.; PAVITHRAN, C.; THOMAS, S. Melt rheological behavior of intimately mixed short sisal-glass hybrid fiber-reinforced low-density polyethylene composites. I. Untreated fibers. Journal of Applied Polymer Science, v. 89, n. 2, p. 432442, 2003.

KALIA, S.; VASHISTHA, S. Surface modification of sisal fibers (agave sisalana) using bacterial cellulase and methyl methacrylate. Journal of Polymers and the Environment, v. 20, n. 1, p. 142-151, 2011. 
KARNANI, R.; KRISHNAN, M.; NARAYAN, R. Biofiber-reinforced polypropylene composites. Polymer Engineering and Science, v. 37, n. 2, p. 476-483, 1997.

KHOSHKAVA, V.; KAMAL, M. R. Effect of surface energy on dispersion and mechanical properties of polymer/nanocrystalline cellulose nanocomposites. Biomacromolecules, v. 14, n. 9, p. 3155-3163, 2013.

KIM, D. Y.; NISHIYAMA, Y.; KUGA, S. Surface acetylation of bacterial cellulose. Cellulose, v. 9, n. 3-4, p. 361-367, 2002.

KU, H.; WANG, H.; PATTARACHAIYAKOOP, N.; TRADA, M. A review on the tensile properties of natural fiber reinforced polymer composites. Composites Part BEngineering, v. 42, n. 4, p. 856-873, 2011.

KYU, T.; YASUDA, N.; SUEHIRO, S.; NOMURA, S.; KAWAI, H. Dynamic birefringence behavior of semicrystalline polymers .2. Crystalline relaxation mechanisms of lowdensity and medium-density polyethylenes. Polymer Journal, v. 8, n. 6, p. 565-584, 1976.

LACEY, A. A.; NIKOLOPOULOS, C.; READING, M. A mathematical model for modulated differential scanning calorimetry. Journal of Thermal Analysis, v. 50, n. 1-2, p. 279-333, 1997.

LEÃO, A. L.; CARASCHI, J. C. Curaua fiber - a tropical natural fibers from amazon potential and applications in composites. In: FROLLINI, E. L., A. L.; MATTOSO, L. H. C. (Ed.). Natural polymer and agrofibers based composites. São Carlos: USP/Embrapa/UNESP, 2000. p. 257-271.

LEE, J. H.; PARK, S. H.; KIM, S. H. Preparation of cellulose nanowhiskers and their reinforcing effect in polylactide. Macromolecular Research, v. 21, n. 11, p. 1218-1225, 2013.

LEE, J. H.; PARK, S. H.; KIM, S. H. Surface modification of cellulose nanowhiskers and their reinforcing effect in polylactide. Macromolecular Research, v. 22, n. 4, p. 424430, 2014.

LEI, Y.; WU, Q.; YAO, F.; XU, Y. Preparation and properties of recycled hdpe/natural fiber composites. Composites Part A: Applied Science and Manufacturing, v. 38, n. 7, p. 1664-1674, 2007.

LI, Y.; MAI, Y. W.; YE, L. Effects of fibre surface treatment on fracture-mechanical properties of sisal-fibre composites. Composite Interfaces, v. 12, n. 1-2, p. 141-163, 2005.

LIN, N.; CHEN, G.; HUANG, J.; DUFRESNE, A.; CHANG, P. R. Effects of polymer-grafted natural nanocrystals on the structure and mechanical properties of poly(lactic acid): $A$ 
case of cellulose whisker-graft-polycaprolactone. Journal of Applied Polymer Science, v. 113, n. 5, p. 3417-3425, 2009.

LIN, N.; HUANG, J.; DUFRESNE, A. Preparation, properties and applications of polysaccharide nanocrystals in advanced functional nanomaterials: A review. Nanoscale, v. 4, n. 11, p. 3274-3294, 2012.

LIPPONEN, S.; SAARIKOSKI, E.; RISSANEN, M.; SEPPÄLÄ, J. Preparation and properties of cellulose/pe-co-aa blends. European Polymer Journal, v. 48, n. 8, p. 1439-1445, 2012.

LUCAS, E. F.; SOARES, B. G.; MONTEIRO, E. E. C. Caracterização de polímeros:

Determinação de peso molecular e análise térmica. Rio de Janeiro: E-papers, 2001. $613 \mathrm{p}$.

MACHADO, M. L. C.; PEREIRA, N. C.; MIRANDA, L. F.; TERENCE, M. C.; PRADELLA, J. G. C. Estudo das propriedades mecânicas e térmicas do polímero poli-3-hidroxibutirato (phb) e de compósitosn phb/pó de madeira. Polímeros, v. 20, n. 1, p. 65-71, 2010.

MADALENO, E.; ROSA, D. D. S.; ZAWADZKI, S. F.; PEDROZO, T. H.; RAMOS, L. P. Study of the use of plasticizer from renewable sources in pvc compositions. Polimeros-Ciencia $\mathbf{E}$ Tecnologia, v. 19, n. 4, p. 263-270, 2009.

MALAININE, M. E.; MAHROUZ, M.; DUFRESNE, A. Lignocellulosic flour from cladodes of opuntia ficus-indica reinforced poly(propylene) composites. Macromolecular Materials and Engineering, v. 289, n. 10, p. 855-863, 2004.

MANO, B.; ARAÚJO, J. R.; SPINACÉ, M. A. S.; DE PAOLI, M. A. Polyolefin composites with curaua fibres: Effect of the processing conditions on mechanical properties, morphology and fibres dimensions. Composites Science and Technology, v. 70, n. 1, p. 29-35, 2010.

MARINI, J.; SUMAN BRETAS, R. E. Influence of shape and surface modification of nanoparticle on the rheological and dynamic-mechanical properties of polyamide 6 nanocomposites. Polymer Engineering and Science, v. 53, n. 7, p. 1512-1528, 2013.

MATHEW, A. P.; GONG, G.; BJORNGRIM, N.; WIXE, D.; OKSMAN, K. Moisture absorption behavior and its impact on the mechanical properties of cellulose whiskersbased polyvinylacetate nanocomposites. Polymer Engineering and Science, v. 51, n. 11, p. 2136-2142, 2011.

MATHEW, A. P.; THIELEMANS, W.; DUFRESNE, A. Mechanical properties of nanocomposites from sorbitol plasticized starch and tunicin whiskers. Journal of Applied Polymer Science, v. 109, n. 6, p. 4065-4074, 2008.

MATTHEWS, R. G.; WARD, I. M.; CAPACCIO, G. The relationship between the dynamic mechanical relaxations and the tensile deformation behaviour of polyethylene. Journal of Materials Science, v. 34, n. 12, p. 2781-2787, 1999. 
MAZUR, R. L.; BOTELHO, E. C.; COSTA, M. L.; REZENDE, M. C. Thermal and rheological evaluation of pekk thermoplastic matrix for aeronautical application. Avaliações térmica e reológica da matriz termoplástica PEKK utilizada em compósitos aeronáuticos, v. 18, n. 3, p. 237-243, 2008.

MEGIATTO, J. D.; SILVA, C. G.; RAMIRES, E. C.; FROLLINI, E. Thermoset matrix reinforced with sisal fibers: Effect of the cure cycle on the properties of the biobased composite. Polymer Testing, v. 28, n. 8, p. 793-800, 2009.

MEGIATTO, J. D.; SILVA, C. G.; ROSA, D. S.; FROLLINI, E. Sisal chemically modified with lignins: Correlation between fibers and phenolic composites properties. Polymer Degradation and Stability, v. 93, n. 6, p. 1109-1121, 2008.

MERLINI, C.; SOLDI, V.; BARRA, G. M. O. Influence of fiber surface treatment and length on physico-chemical properties of short random banana fiber-reinforced castor oil polyurethane composites. Polymer Testing, v. 30, n. 8, p. 833-840, 2011.

MILINSK, M. C. Análise comparativa entre oito métodos de esterificação na determinação quantitativa de ácidos graxos em óleo vegetal. 2007. 92f. Tese (Doutorado) - Departamento de Química, Universidade Estadual de Maringá, 2007.

MISSOUM, K.; BELGACEM, M.; BRAS, J. Nanofibrillated cellulose surface modification: A review. Materials, v. 6, n. 5, p. 1745-1766, 2013.

MOHANTY, A. K.; MISRA, M.; HINRICHSEN, G. Biofibres, biodegradable polymers and biocomposites: An overview. Macromolecular Materials and Engineering, v. 276, n. 34, p. 1-24, 2000.

MOHANTY, A. K.; WIBOWO, A.; MISRA, A.; DRZAL, L. T. Effect of process engineering on the performance of natural fiber reinforced cellulose acetate biocomposites.

Composites Part a-Applied Science and Manufacturing, v. 35, n. 3, p. 363-370, 2004.

MOHANTY, S.; NAYAK, S. K.; VERMA, S. K.; TRIPATHY, S. S. Effect of mapp as a coupling agent on the performance of jute-pp composites. Journal of Reinforced Plastics and Composites, v. 23, n. 6, p. 625-637, 2004.

MOHANTY, S.; VERMA, S.; NAYAK, S. Dynamic mechanical and thermal properties of mape treated jute/hdpe composites. Composites Science and Technology, v. 66, n. 34, p. 538-547, 2006.

MONTEIRO, S. N.; LOPES, F. P. D.; FERREIRA, A. S.; NASCIMENTO, D. C. O. Natural-fiber polymer-matrix composites: Cheaper, tougher, and environmentally friendly. Jom, $v$. 61, n. 1, p. 17-22, 2009. 
MOORE, R. S.; MATSUOKA, S. Morphological + rheological studies of polyethylene by light scattering. Journal of Polymer Science Part C-Polymer Symposium, n. 5PC, p. 163-\&, 1964.

MORANDI, G.; HEATH, L.; THIELEMANS, W. Cellulose nanocrystals grafted with polystyrene chains through surface-initiated atom transfer radical polymerization (siatrp). Langmuir, v. 25, n. 14, p. 8280-8286, 2009.

MORTON-JONES, D. H. Polymer processing. London: Chapman and Hall, 1989. p. 112125

MOSIER, N.; WYMAN, C.; DALE, B.; ELANDER, R.; LEE, Y. Y.; HOLTZAPPLE, M.; LADISCH, $M$. Features of promising technologies for pretreatment of lignocellulosic biomass.

Bioresource Technology, v. 96, n. 6, p. 673-686, 2005.

MOTHE, C. G.; DE ARAUJO, C. R.; WANG, S. H. Thermal and mechanical characteristics of polyurethane/curaua fiber composites. Journal of Thermal Analysis and Calorimetry, v. 95, n. 1, p. 181-185, 2009.

MUELLER, C. M. O.; YAMASHITA, F.; LAURINDO, J. B. Evaluation of the effects of glycerol and sorbitol concentration and water activity on the water barrier properties of cassava starch films through a solubility approach. Carbohydrate Polymers, v. 72, n. 1, p. 82-87, 2008.

MUKHERJEE, T.; SANI, M.; KAO, N.; GUPTA, R. K.; QUAZI, N.; BHATTACHARYA, S. Improved dispersion of cellulose microcrystals in polylactic acid (pla) based composites applying surface acetylation. Chemical Engineering Science, v. 101, p. 655-662, 2013.

NOR AZOWA, I.; YUNUS, W. M. Z. W.; OTHMAN, M.; ABDAN, K. Effect of chemical surface treatment on the mechanical properties of reinforced plasticized poly(lactic acid) biodegradable composites. Journal of Reinforced Plastics and Composites, v. 30, n. 5, p. 381-388, 2011.

OKSMAN, K.; MATHEW, A. P.; BONDESON, D.; KVIEN, I. Manufacturing process of cellulose whiskers/polylactic acid nanocomposites. Composites Science and Technology, v. 66, n. 15, p. 2776-2784, 2006.

OKSMAN, K.; SKRIFVARS, M.; SELIN, J. F. Natural fibres as reinforcement in polylactic acid (pla) composites. Composites Science and Technology, v. 63, n. 9, p. 1317-1324, 2003.

PAIVA, J. M. F.; FROLLINI, E. Unmodified and modified surface sisal fibers as reinforcement of phenolic and lignophenolic matrices composites: Thermal analyses of fibers and composites. Macromolecular Materials and Engineering, v. 291, n. 4, p. 405-417, 2006. 
PASSADOR, F. R.; RUVOLO-FILHO, A.; PESSAN, L. A. Effect of blending protocol on the rheological properties and morphology of hdpe/lldpe blend-based nanocomposites. International Polymer Processing, v. 27, n. 3, p. 378-385, 2012.

PEACOCK, A. J. Handbook of polyethylene: Structures, properties and applications. New York: Basel, 2000. p. 43-67

PEARSON, J. R. A. Mechanics of polymer processing. New York: Elsevier, 1985. 5 p. 13533

PEI, A.; ZHOU, Q.; BERGLUND, L. A. Functionalized cellulose nanocrystals as biobased nucleation agents in poly(l-lactide) (plla) - crystallization and mechanical property effects. Composites Science and Technology, v. 70, n. 5, p. 815-821, 2010.

PEREDA, M.; DUfRESNE, A.; ARANGUREN, M. I.; MARCOVICH, N. E. Polyelectrolyte films based on chitosan/olive oil and reinforced with cellulose nanocrystals. Carbohydrate Polymers, v. 101, p. 1018-1026, 2014.

PEREDA, M.; KISSI, N. E.; DUFRESNE, A. Melt extrusion of cnc based polymer nanocomposites. In: (Ed.). Production and applications of cellulose nanomaterials. Atlanta: TAPPI Press, 2013. p. 103-107

PEREZ, I. S. B.; MANRICH, S.; MANRICH, S. The effect of different block copolymers on post consumer hdpe/hips blends: Phase morphology and thermal properties.

Polímeros, v. 18, n. 3, p. 207-214, 2008.

PETERSSON, L.; MATHEW, A. P.; OKSMAN, K. Dispersion and properties of cellulose nanowhiskers and layered silicates in cellulose acetate butyrate nanocomposites. Journal of Applied Polymer Science, v. 112, n. 4, p. 2001-2009, 2009.

PETERSSON, L.; OKSMAN, K. Biopolymer based nanocomposites: Comparing layered silicates and microcrystalline cellulose as nanoreinforcement. Composites Science and Technology, v. 66, n. 13, p. 2187-2196, 2006.

PUTAUX, J. L.; MOLINA-BOISSEAU, S.; MOMAUR, T.; DUFRESNE, A. Platelet nanocrystals resulting from the disruption of waxy maize starch granules by acid hydrolysis. Biomacromolecules, v. 4, n. 5, p. 1198-1202, 2003.

RAMIAH, M. V. Thermogravimetric and differential thermal analysis of cellulose, hemicellulose, and lignin. Journal of Applied Polymer Science, v. 14, n. 5, p. 1323-\&, 1970.

RAMIRES, E. C.; DE OLIVEIRA, F.; FROLLINI, E. Composites based on renewable materials: Polyurethane-type matrices from forest byproduct/vegetable oil and reinforced with lignocellulosic fibers. Journal of Applied Polymer Science, v. 129, n. 4, p. 2224-2233, 2013. 
RAMIRES, E. C.; MEGIATTO, J. D., JR.; GARDRAT, C.; CASTELLAN, A.; FROLLINI, E. Biobased composites from glyoxal-phenolic resins and sisal fibers. Bioresour Technol, v. 101, n. 6, p. 1998-2006, 2010.

RANBY, B. Fibrious macromolecular systems. Cellulose ans muscle, the colloidal properties of cellulose micelles. Faraday Discuss, v. 11, p. 158-164, 1951.

REN, X.; LI, K. Investigation of vegetable-oil-based coupling agents for kenaf-fiberreinforced unsaturated polyester composites. Journal of Applied Polymer Science, v. 128, n. 2, p. 1101-1109, 2013.

ROMAN, M.; WINTER, W. T. Effect of sulfate groups from sulfuric acid hydrolysis on the thermal degradation behavior of bacterial cellulose. Biomacromolecules, v. 5, n. 5, p. 1671-1677, 2004.

RUEDA, L.; SARALEGUI, A.; FERNANDEZ D'ARLAS, B.; ZHOU, Q.; BERGLUND, L. A.; CORCUERA, M. A.; MONDRAGON, I.; ECEIZA, A. Cellulose nanocrystals/polyurethane nanocomposites. Study from the viewpoint of microphase separated structure.

Carbohydrate Polymers, v. 92, n. 1, p. 751-757, 2013.

RULLAND, W. International tables of $\mathbf{x}$ ray crystallography. Birmingham: : Kinoch Press, 1974. p. 85

SAHEB, D. N.; JOG, J. P. Natural fiber polymer composites: A review. Advances in Polymer Technology, v. 18, n. 4, p. 351-363, 1999.

SAMIR, M.; ALLOIN, F.; DUFRESNE, A. Review of recent research into cellulosic whiskers, their properties and their application in nanocomposite field.

Biomacromolecules, v. 6, n. 2, p. 612-626, 2005.

SAMYN, P.; SCHOUKENS, G.; VONCK, L.; STANSSENS, D.; ABBEELE, H. Quality of brazilian vegetable oils evaluated by (modulated) differential scanning calorimetry. Journal of Thermal Analysis and Calorimetry, v. 110, n. 3, p. 1353-1365, 2011.

SANTOS, E. F.; MORESCO, M.; ROSA, S. M. L.; NACHTIGALL, S. M. B. Extrusion of pp composites with short coir fibers: Effect of temperature and coupling agents. Extrusão de compósitos de PP com fibras curtas de coco: Efeito da temperatura e agentes de acoplamento, v. 20, n. 3, p. 215-220, 2010.

SANTOS, P. A.; SPINACÉ, M. A. S.; FERMOSELLI, K. K. G.; DE PAOLI, M.-A. Polyamide$6 /$ vegetal fiber composite prepared by extrusion and injection molding. Composites Part A: Applied Science and Manufacturing, v. 38, n. 12, p. 2404-2411, 2007.

SATYANARAYANA, K. G.; GUILMARAES, J. L.; WYPYCH, F. Studies on lignocellulosic fibers of brazil. Part i: Source, production, morphology, properties and applications. Composites Part a-Applied Science and Manufacturing, v. 38, n. 7, p. 1694-1709, 2007. 
SCHAWE, J. E. K. A description of the glass transition measured by temperature modulated differential scanning calorimetry. Colloid and Polymer Science, v. 276, n. 7, p. 565-569, 1998.

SCHLEMMER, D.; ARAUJO SALES, M. J. Thermoplastic starch films with vegetable oils of brazilian cerrado thermal characterization. Journal of Thermal Analysis and Calorimetry, v. 99, n. 2, p. 675-679, 2010.

SCHRAMM, G. Reologia e reometria - fundamentos teóricos e práticos. Rio de Janeiro: Artliber, 2006. 21-96 p.

SDROBIŞ, A.; DARIE, R. N.; TOTOLIN, M.; CAZACU, G.; VASILE, C. Low density polyethylene composites containing cellulose pulp fibers. Composites Part B: Engineering, v. 43, n. 4, p. 1873-1880, 2012.

SHARMA, V.; KUNDU, P. P. Addition polymers from natural oils-a review. Progress in Polymer Science, v. 31, n. 11, p. 983-1008, 2006.

SHI, Q. F.; MOU, H. Y.; LI, Q. Y.; WANG, J. K.; GUO, W. H. Influence of heat treatment on the heat distortion temperature of poly(lactic acid)/bamboo fiber/talc hybrid biocomposites. Journal of Applied Polymer Science, v. 123, n. 5, p. 2828-2836, 2012.

SHIBULAL, G. S.; NASKAR, K. Exploring a novel multifunctional agent to improve the dispersion of short aramid fiber in polymer matrix. Express Polymer Letters, v. 6, n. 4, p. 329-344, 2012.

SILVA, R.; HARAGUCHI, S. K.; MUNIZ, E. C.; RUBIRA, A. F. Applications of lignocellulosic fibers in polymer chemistry and in composites. Aplicações de fibras lignocelulosicas na quimica de polimeros e em compositos, v. 32, n. 3, p. 661-671, 2009.

SILVA, R. V.; AQUINO, E. M. F. Curaua fiber: A new alternative to polymeric composites. Journal of Reinforced Plastics and Composites, v. 27, n. 1, p. 103-112, 2008.

SIQUEIRA, G.; BRAS, J.; DUFRESNE, A. Cellulosic bionanocomposites: A review of preparation, properties and applications. Polymers, v. 2, n. 4, p. 728-765, 2010a.

SIQUEIRA, G.; BRAS, J.; DUFRESNE, A. New process of chemical grafting of cellulose nanoparticles with a long chain isocyanate. Langmuir, v. 26, n. 1, p. 402-411, 2010b.

SIQUEIRA, G.; FRASCHINI, C.; BRAS, J.; DUFRESNE, A.; PRUD'HOMME, R.; LABORIE, M.$P$. Impact of the nature and shape of cellulosic nanoparticles on the isothermal crystallization kinetics of poly( $\varepsilon$-caprolactone). European Polymer Journal, v. 47, n. 12, p. 2216-2227, 2011. 
SOYKEABKAEW, N.; ARIMOTO, N.; NISHINO, T.; PEIJS, T. All-cellulose composites by surface selective dissolution of aligned ligno-cellulosic fibres. Composites Science and Technology, v. 68, n. 10-11, p. 2201-2207, 2008.

SPINACÉ, M. A. S.; LAMBERT, C. S.; FERMOSELLI, K. K. G.; DE PAOLI, M.-A. Characterization of lignocellulosic curaua fibres. Carbohydrate Polymers, v. 77, n. 1, p. 47-53, 2009.

SUEHIRO, S.; YAMADA, T.; INAGAKI, H.; KYU, T.; NOMURA, S.; KAWAI, H. Rheo-optical studies on the deformation mechanism of semi-crystalline polymers .4. Nature of alpha mechanical dispersion of low-density polyethylene in relation to the mechanism of spherulite deformation. Journal of Polymer Science Part B-Polymer Physics, v. 17, n. 5, p. 763-790, 1979.

TAIPINA, M. D.; FERRAREZI, M. M. F.; GONCALVES, M. D. Morphological evolution of curaua fibers under acid hydrolysis. Cellulose, v. 19, n. 4, p. 1199-1207, 2012.

TAN, C. P.; CHE MAN, Y. B. Comparative differential scanning calorimetric analysis of vegetable oils: I. Effects of heating rate variation. Phytochemical Analysis, v. 13, n. 3, p. 129-141, 2002.

TAN, S. G.; AHMAD, Z.; CHOW, W. S. Interpenetrating polymer network structured thermosets prepared from epoxidized soybean oil/diglycidyl ether of bisphenol a. Polymer International, v. 63, n. 2, p. 273-279, 2014.

TEN, E.; JIANG, L.; WOLCOTT, M. P. Crystallization kinetics of poly(3-hydroxybutyrateco-3-hydroxyvalerate)/cellulose nanowhiskers composites. Carbohydrate Polymers, v. 90, n. 1, p. 541-550, 2012.

THIELEMANS, W.; BELGACEM, M. N.; DUFRESNE, A. Starch nanocrystals with large chain surface modifications. Langmuir, v. 22, n. 10, p. 4804-4810, 2006.

TOMCZAK, F.; SATYANARAYANA, K. G.; SYDENSTRICKER, T. H. D. Studies on lignocellulosic fibers of brazil: Part iii - morphology and properties of brazilian curauá fibers. Composites Part A: Applied Science and Manufacturing, v. 38, n. 10, p. 22272236, 2007.

TRINDADE, W. G.; DE PAIVA, J. M. F.; LEÃO, A. L.; FROLLINI, E. lonized-air-treated curaua fibers as reinforcement for phenolic matrices. Macromolecular Materials and Engineering, v. 293, n. 6, p. 521-528, 2008.

TRINDADE, W. G.; HOAREAU, W.; MEGIATTO, J. D., JR.; RAZERA, I. A. T.; CASTELLAN, A.; FROLLINI, E. Thermoset phenolic matrices reinforced with unmodified and surfacegrafted furfuryl alcohol sugar cane bagasse and curaua fibers: Properties of fibers and composites. Biomacromolecules, v. 6, p. 2485-2496, 2005. 
TRINDADE, W. G.; HOAREAU, W.; RAZERA, I. A. T.; RUGGIERO, R.; FROLLINI, E.; CASTELLAN, A. Phenolic thermoset matrix reinforced with sugar cane bagasse fibers: Attempt to develop a new fiber surface chemical modification involving formation of quinones followed by reaction with furfuryl alcohol. Macromolecular Materials and Engineering, v. 289, n. 8, p. 728-736, 2004.

TSERKI, V.; ZAFEIROPOULOS, N. E.; SIMON, F.; PANAYIOTOU, C. A study of the effect of acetylation and propionylation surface treatments on natural fibres. Composites Part a-Applied Science and Manufacturing, v. 36, n. 8, p. 1110-1118, 2005.

TURAN, D.; SIRIN, H.; OZKOC, G. Effects of poss particles on the mechanical, thermal, and morphological properties of pla and plasticised pla. Journal of Applied Polymer Science, v. 121, n. 2, p. 1067-1075, 2011.

UEKI, M. M.; ZANIN, M. Influência de aditivos na rigidez dielétrica do polietileno de alta densidade. Polímeros: Ciência e Tecnologia, v. 7, n. 4, p. 42-50, 1997.

WAGBERG, L.; DECHER, G.; NORGREN, M.; LINDSTROEM, T.; ANKERFORS, M.; AXNAES, $K$. The build-up of polyelectrolyte multilayers of microfibrillated cellulose and cationic polyelectrolytes. Langmuir, v. 24, n. 3, p. 784-795, 2008.

WAMBUA, P.; IVENS, J.; VERPOEST, I. Natural fibres: Can they replace glass in fibre reinforced plastics? Composites Science and Technology, v. 63, n. 9, p. 1259-1264, 2003.

WANG, N.; DING, E.; CHENG, R. Preparation and 'liquid crystalline properties of spherical cellulose nanocrystals. Langmuir, v. 24, n. 1, p. 5-8, 2008.

WONG, S.; SHANKS, R. A.; HODZIC, A. Poly(I4actic acid) composites with flax fibers modified by plasticizer absorption. Polymer Engineering \& Science, v. 43, n. 9, p. 1566-1575, 2003.

WU, S. P.; QIU, J. F.; RONG, M. Z.; ZHANG, M. Q.; ZHANG, L. Y. Plant oil-based biofoam composites with balanced performance. Polymer International, v. 58, n. 4, p. 403-411, 2009.

ZAH, R.; HISCHIER, R.; LEÃO, A. L.; BRAUN, I. Curauá fibers in the automobile industry a sustainability assessment. Journal of Cleaner Production, v. 15, n. 11-12, p. 10321040, 2007.

ZHANG, H.; TONG, M. Influence of hemicelluloses on the structure and properties of lyocell fibers. Polymer Engineering and Science, v. 47, n. 5, p. 702-706, 2007. 
ZHANG, W.; HE, X.; LI, C.; ZHANG, X.; LU, C.; ZHANG, X.; DENG, Y. High performance poly (vinyl alcohol)/cellulose nanocrystals nanocomposites manufactured by injection molding. Cellulose, v. 21, n. 1, p. 485-494, 2014.

ZHAOA, J.; MORGANB, A. B.; HARRISC, J. D. Rheological characterization of polystyrene-clay nanocomposites to

compare the degree of exfoliation and dispersion. Polymer, v. 46, p. 8641-8660, 2005.

ZHU, J.; WEI, S.; YADAV, A.; GUO, Z. Rheological behaviors and electrical conductivity of epoxy resin nanocomposites suspended with in-situ stabilized carbon nanofibers.

Polymer, v. 51, n. 12, p. 2643-2651, 2010. 